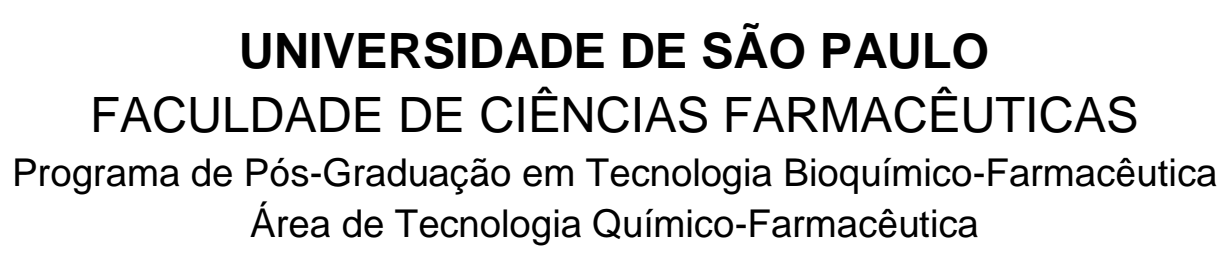

\title{
Planejamento, síntese e avaliação da atividade antimicrobiana de derivados furfurilidênicos frente a micro- organismos causadores de infecções hospitalares
}

Rodrigo Rocha Zorzi

Dissertação para obtenção do grau de MESTRE

Orientador

Prof. Assoc. Leoberto Costa Tavares

SÃO PAULO

2013 



\author{
UNIVERSIDADE DE SÃO PAULO \\ FACULDADE DE CIÊNCIAS FARMACÊUTICAS \\ Programa de Pós-Graduação em Tecnologia Bioquímico-Farmacêutica \\ Área de Tecnologia Químico-Farmacêutica
}

\title{
Planejamento, síntese e avaliação da atividade antimicrobiana de derivados furfurilidênicos frente a micro- organismos causadores de infecções hospitalares
}

Versão corrigida da Dissertação conforme Resolução CoPGr 5890.

O original encontra-se disponível no Serviço de Pós-Graduação da FCF/USP.

\section{Rodrigo Rocha Zorzi}

Dissertação para obtenção do grau de MESTRE

Orientador

Prof. Assoc. Leoberto Costa

Tavares

SÃO PAULO

2013 
Ficha Catalográfica

Elaborada pela Divisão de Biblioteca e

Documentação do Conjumto das Qú́micas da USP.

\footnotetext{
Zorzi, Rodrigo Rocha

Z88p Planejamento, sintese e avaliação da atividade antimicrobiana de derivados furfurilidênicos frente a micro-organismos causadores de infecções hospitalares / Rodrigo Rocha Zorzi. -- São Paulo, 2013. $199 \mathrm{p}$.

Dissertação (mestrado) - Faculdade de Ciências Farmacêuticas da Universidade de São Paulo. Departamento de Tecnologia Bioquímico-Farmacêutica.

Orientador: Tavares, Leoberto Costa

1. Fármaco : Planejamento : Química farmacêutica 2. Qimiometria 3. Ensaios biológicos : Farmacologia I. T. II. Tavares, Leoberto Costa, orientador.
} 


\section{Rodrigo Rocha Zorzi}

\section{Planejamento, síntese e avaliação da atividade antimicrobiana de derivados furfurilidênicos frente a micro-organismos causadores de infecções hospitalares}

Comissão Julgadora

da

Dissertação para obtenção do grau de Mestre

Prof. Assoc. Leoberto Costa Tavares orientador/presidente

1을 Examinador

2ํㅡㄹ Examinador

São Paulo, de de 2014 

Aos meus pais, Rubens e Cleide, que me apoiaram e ensinaram a nunca desistir. 

"A dúvida é o princípio da sabedoria"

Aristóteles (384 - 322 a.C.) 



\section{AGRADECIMENTOS}

A Deus pelas ótimas oportunidades oferecidas nesta jornada.

Aos meus pais Rubens e Cleide, minhas avós Semiramis e Olga (in memorian), meu avô Sante (in memorian), minha tia-avó Maria Madalena (in memorian), minha namorada Cecília, meu cunhado Renato e meus sogros Ana Cristina e Luís pelo apoio e conselhos durante esta etapa da minha vida.

Ao Prof. Assoc. Leoberto Costa Tavares pela amizade, orientação, paciência, oportunidades oferecidas no laboratório e confiança, todas de grande importância para a conclusão deste mestrado.

À Me. Fanny Palace-Berl pela amizade, apoio, atenção, inúmeros ensinamentos, conselhos e conversas que foram fundamentais para finalizar esta etapa de minha formação para a conclusão deste mestrado.

Ao Dr. Salomão Dória Jorge pela amizade, conversas construtivas, ensinamentos práticos e teóricos, atenção e risadas durante estes anos de convívio.

Ao Me. Leandro de Sá Bortolozzo e ao técnico João Sussumu Murayama pela amizade, conversas e risadas durantes estes anos de convívio.

Às Prof ${ }^{a}$. Dra. Marina Ishii, Prof ${ }^{a}$. Dra. Kerly Fernanda Mesquista Pasqualoto e ao Prof. Dr. Roberto Parise Filho pelos ensinamentos, conselhos e orientações ao longo destes anos.

Aos colegas do Laboratório de Planejamento e Desenvolvimento de Fármacos André Murilo, Laís, Adelson, Ana Carolina, Alex e Michael, pelas inúmeras conversas e discussões para aprimoramento deste trabalho.

À Miriam e Elza, da Secretária do Departamento de Tecnologia BioquímicoFarmacêutica-FCF/USP e ao Jorge da Secretaria de Pós-Graduação da FCF/USP pela atenção e paciência.

À Silvia Regina dos Santos e Cristiane Mika do Laboratório de Microbiologia do Hospital Universitário-USP pela disponibilização dos micro-organismos utilizados neste estudo. 
Aos amigos André, Bruno "Guima", Daniel, Diego, Flávio, Gustavo, Gabriel, Pedro, Piero e Thiago pelas conversas, momentos de lazer e risadas durante todos estes anos.

À Faculdade de Ciências Farmacêuticas da USP e ao Departamento de Tecnologia Bioquímico-Farmacêutica pela oportunidade de realização deste trabalho.

À FAPESP, CAPES e CNPq pelo auxílio financeiro e bolsa de estudos concedida.

A todos aqueles que de alguma forma, direta ou indiretamente, contribuíram para a realização deste trabalho. 
ZORZI, R. R., Planejamento, síntese e avaliação da atividade antimicrobiana de derivados furfurilidênicos frente a micro-organismos causadores de infeç̧ões hospitalares. São Paulo, 2013. 199 p. (Dissertação de Mestrado - Faculdade de Ciências Farmacêuticas, Universidade de São Paulo).

\section{Resumo}

Infecções hospitalares, causadas por fungos e bactérias, são responsáveis por milhares de mortes anuais e disseminam-se cada vez mais rápido em ambiente hospitalar. Estas infecções afetam principalmente pacientes que são submetidos a procedimentos invasivos ou que apresentam baixa imunidade. Este quadro tende a agravar-se devido ao surgimento de micro-organismos resistentes aos tratamentos atualmente disponíveis, decorrentes, principalmente, de excessivas prescrições, automedicação, pela utilização errônea de antibióticos bem como pela aplicação de métodos de profilaxia inadequados determinando, desta forma, a necessidade de pesquisar e de identificar novos medicamentos para esta finalidade. Neste contexto, ressalta-se que os nitrocompostos que vêm demonstrando bons resultados como agentes antimicrobianos e, sendo assim, este trabalho se propõe a planejar, sintetizar e avaliar duas séries de compostos análogos à nifuroxazida frente a bactérias Gram-positivas, Gram-negativas e fungos de importância em infecções hospitalares com caráter de multirresistência. O planejamento de modificações moleculares na estrutura da série de análogos à nifuroxazida foi auxiliado pelo diagrama de Craig, que se aplica à seleção dos grupos substituintes. A identificação dos compostos obtidos foi realizada por análise espectrofotométrica RMN ${ }^{1} \mathrm{H}$ e RMN ${ }^{13} \mathrm{C}$ e, como critério de pureza, foi realizado análise elementar de $\mathrm{CHN}$. A melhor atividade dos análogos foi frente à $S$. aureus, onde 16 dos 23 compostos planejados apresentaram atividade superior aos fármacos de referência, estas quais, e composto protótipo. Vale salientar também que os compostos mais ativos foram os análogos 4-butil-N'-[(5-nitrofuran-2-il) metileno] benzidrazida e 3-acetil-2-[5-nitrofuran-2-il]-5-[4-ciano-fenil]-2,3-diidro-1,3,4-oxadiazolínico com IC $90=1,8 \pm 0,04 \mu \mathrm{M} \mathrm{e}$ $3,89 \pm 0,07 \mu \mathrm{M}$, respectivamente. Nos estudos de relações estrutura-atividade, a propriedade eletrônica se mostrou com importância fundamental para a atividade dos compostos frente aos micro-organismos considerados. Os resultados encontrados são bastantes promissores e sinalizam para a possibilidade de identificação de um novo candidato para fármaco antimicrobiano frente à infecções hospitalares com caráter de multirresistência. 
ZORZI, R. R., Design, synthesis and evaluation of antimicrobial activity of novel furfuryliden derivatives against nosocomial infections. São Paulo, 2013. 199 p. (Master's degree dissertation Faculdade de Ciências Farmacêuticas, Universidade de São Paulo).

\section{Abstract}

Nosocomial infections are caused by bacteria and fungi and are the main reason for thousands of deaths every year in the hospital environment. The most susceptible individuals to these type of infection are the immunocompromised, highlighting oldaged and immunodeficiency people, as also patients who passed by invasive procedures. Not only do this situation is very serious, but also a huge number of multidrug-resistant microorganisms are reported worldwide, basically due to excess of prescription and wrong use of antibiotics. If this situation doesn't be maintained today, there will not be a bright sight in the future. In this context, there is the necessity for research and development of new antimicrobial agents, and the nitrocompounds, highlighting nifuroxazide's analogs, are showing excellent activity against several pathogens related to multidrug resistant nosocomial infections. Therefore, this work aims to design, to synthesize and to evaluate two series of nifuroxazide's analogs against strains of gram-positive and gram-negative bacteria, also fungi strains. The sets of analogs were designed based on the replacement of hydroxyl group of nifuroxazide by different substituent groups according to Craig's diagram, also a modification in the structure core; identification of these compounds was carried out through ${ }^{1} \mathrm{H}$ and ${ }^{13} \mathrm{C}$ NMR. Melting point and elementary analysis were analyzed for purity criteria. Until the moment, about 23 compounds were evaluated and the best observed activity was against $S$. aureus strains, which 16 analogs showed better activity than the lead compound and several other compounds, used as referential drug. It is noteworthy that the best activity were analogs 4-butyl-N'-((5-nitrofuran-2-yl) methylene) benzohydrazide and 3-acetyl-2-[5nitro-furan-2-yl]-5-[4-cyano-phenil]-2,3-dihydro-1,3,4 oxadiazole with $\mathrm{IC}_{90}=1,8 \pm 0,04$ $\mu \mathrm{M}$ and 3,89 $\pm 0,07 \mu \mathrm{M}$, respectively. The chemometrics studies suggest that electronic properties are most related to the biological activity on these microorganisms. All the available results shows the potential of nitrofurans to be a new candidate for an antimicrobial drug against multidrug resistant nosocomial infections. 


\section{Lista de Figuras}

Figura 1. Etapas para descoberta, desenvolvimento e introdução de um novo fármaco no mercado.

Figura 2. Modificação molecular do sildenafila, gerando o vardenafila .38

Figura 3. Fases de um fármaco no organismo. .40

Figura 4. Possíveis interações fármaco-receptor. .43

Figura 5. Influência na ionização causada pelo substituinte. 48

Figura 6. Molécula da nitrofurazona (A) e nifuroxazida (B). 49

Figura 7. Exemplos de derivados com estruturas oxadiazolínicas. .50

Figura 8. Mecanismo de ação de compostos nitrofurânicos. Passagem por difusão passiva e redução aos primeiros radicais livres.

Figura 9. Provável grupo farmacofórico dos nitrocompostos

Figura 10. Nifuroxazida (A), série I azometínica (B) e série Il oxadiazolínica (C).

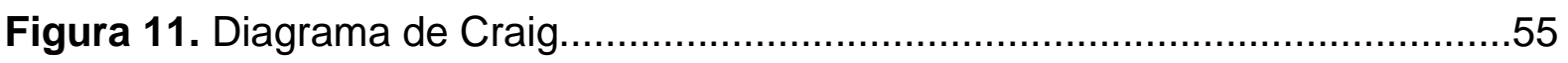

Figura 12. Rota sintética para obtenção da série I e série II....................................59

Figura 13. Formação de bases de Schiff, série I, a partir de benzidrazidas substituídas.

Figura 14. Formação de oxadiazolínas, série II, a partir de bases de Schiff.. 60

Figura 15. Esquema de diluição dos compostos utilizados no ensaio de atividade antimicrobiana.

Figura 16. llustração da microplaca utilizada para os ensaios de atividade antimicrobiana.

Figura 17. Esquema de preparo de soluções na fase II para um composto fictício 
Figura 18. Ilustração da microplaca utilizada para os ensaios na Fase II. 69

Figura 19. Mecanismo de reação para obtenção das bases de Schiff .74

Figura 20. Subestrutura central dos análogos à nifuroxazida .79

Figura 21. Subestrutura furânica das bases de Schiff .79

Figura 22. Subestrutura benzênica das bases de Schiff. Rx é referente ao grupo substituinte 80

Figura 23. Mecanismo de reação para obtenção de compostos oxadiazolínicos.....81

Figura 24. Subestrutura oxadiazolínica, com anel heterocíclico e grupo acetila.......87

Figura 25. Curva de crescimento microbiano nas concentrações testadas do composto I-G $\left(\mathrm{R}=\mathrm{C}_{4} \mathrm{H}_{9}\right)$ frente a $S$. Aureus, cepa ATCC 29213.

Figura 26. Mapas de potencial eletrostático (MPEs) dos compostos I-G, II-E, NF, I-K e o composto protótipo, gerados no programa Gaussian 03W e visualizados no GaussView. .105

Figura 27. Vetores de dipolo dos compostos I-G, II-E, NF, I-K e o composto protótipo, gerados pelo método de HF/3-21G* com cálculo de cargas CHELPG, no programa Gaussian 03W e visualizados no programa GaussView.... .106

Figura 28. Mapas de potencial lipofílico (MPLs) dos compostos I-G, II-E, I-K e NF, o composto protótipo, gerados no programa Sybyl 8.0 pelo método de Ghose 108

Figura 29. Dispersão da atividade biológica dos compostos de série I e Il frente à $S$. aureus com os descritores x14 (ASA-) e x35 (Chelpg_NO $\mathrm{N}_{2}$ ) e coeficiente de correlação de Pearson, $\mathbf{R}$

Figura 30. Análise de PCA dos compostos de série I e II frente à $S$. aureus: Seleção de componentes principais $(A)$ e pesos de descritores $(B)$; Dispersão de escores entre PC1 e PC2, separando o conjunto de dados em A e B (B' e B') (C). .114 
Figura 31. Dendrograma dos compostos estudados das séries I e II frente à $S$. aureus. Conjunto de dados separado em clusters A e B. Letras R, M, B foram utilizados na classificação da atividade biológica em ruim, moderado e bom, respectivamente

Figura 32. Dendrograma de variáveis - Correlação entre a atividade antimicrobiana e descritores físico-químicos obtidos para o conjunto de análise frente à $S$. aureus.

Figura 33. Resíduo versus distância de Mahalanobis para compostos analisados frente à $S$. aureus.

Figura 34. Análise de PCA dos compostos de série I e II frente à E. coli: Seleção de componentes principais $(A)$ e pesos de descritores $(B)$; Dispersão de escores entre PC1 e PC2, separando o conjunto de dados em A, B, C (C).

Figura 35. Dendrograma dos compostos estudados das séries I e II frente à E. coli. Conjunto de dados foi separado em quatro clusters distintos: $A, B, C$. Letras $R, M, B$ foram utilizados na classificação da atividade biológica em ruim, moderado e bom, respectivamente.

Figura 36. Dendrograma de variáveis - Correlação entre a atividade antimicrobiana e descritores físico-químicos obtidos para os compostos anaisados frente à E. coli..120

Figura 37. Resíduo versus distância de Mahalanobis para compostos analisados frente à E. coli.

Figura 38. Análise de PCA dos compostos de série I e II frente à E. faecalis: Seleção de componentes principais $(A)$ e pesos de descritores $(B)$; Dispersão de escores entre PC1 e PC2, separando o conjunto de dados em A, B e C (C). 122

Figura 39. Dendrograma dos compostos estudados das séries I e II frente à $E$. faecalis. Conjunto de dados foi separado em quatro clusters distintos: A, B, C. Letras $\mathrm{R}, \mathrm{M}, \mathrm{B}$ foram utilizados na classificação da atividade biológica em ruim, moderado e bom, respectivamente. 
Figura 40. Dendrograma de variáveis - Correlação entre a atividade antimicrobiana e descritores físico-químicos obtidos para o conjunto de análise frente à $E$. faecalis...

Figura 41. Resíduo versus distância de Mahalanobis para compostos analisados frente à E. faecalis. 124 


\section{Lista de Tabelas}

Tabela 1. Descritores calculados e obtidos na literatura para os compostos das séries I e II. .72

Tabela 2. Rendimento e faixa de fusão dos compostos 4-substituído-[(5-nitrofuran-2il) metileno] benzidrazida - Série I. .75

Tabela 3. Análise elementar de $\mathrm{CHN}$ dos compostos 4-substituído-[(5-nitrofuran-2-il) metileno] benzidrazida - Série I. .76

Tabela 4. Principais sinais de RMN ${ }^{1} \mathrm{H}$ (ppm) dos compostos 4-substituído-[(5nitrofuran-2-il) metileno] benzidrazida - Série I

Tabela 5. Principais sinais de RMN ${ }^{13} \mathrm{C}$ dos compostos 4-substituído-[(5-nitrofuran-2il) metileno] benzidrazida - Série I.

Tabela 6. Rendimento e faixa de fusão dos compostos 3-acetil-2-[5-nitro-furan-2-il]5-[4-substituído-fenil]-2,3-diidro-1,3,4-oxadiazolínico - Série II. .83

Tabela 7. Análise elementar de $\mathrm{CHN}$ dos compostos 3-acetil-2-[5-nitro-furan-2-il]-5[4-substituído-fenil]-2,3-diidro-1,3,4-oxadiazolínico - Série II 84

Tabela 8. Principais sinais de RMN ${ }^{1} \mathrm{H}$ (ppm) dos compostos 3-acetil-2-[5-nitro-furan2-il]-5-[4-substituído-fenil]-2,3-diidro-1,3,4-oxadiazolínico - Série II. .85

Tabela 9. Principais sinais de RMN ${ }^{13} \mathrm{C}$ dos compostos 3-acetil-2-[5-nitro-furan-2-il]5-[4-substituído-fenil]-2,3-diidro-1,3,4-oxadiazolínico - Série II. .86

Tabela 10. Atividade antimicrobiana dos compostos 4-substituído [(5nitrofuran-2il)metileno] benzidrazida - Série I, frente à S. aureus, cepa ATCC 29213.

Tabela 11. Atividade antimicrobiana dos compostos 3-acetil-2-[5-nitro-furan-2-il]-5-[4substituído-fenil]-2,3-diidro-1,3,4-oxadiazolínico - Série II, frente à $S$. aureus, cepa ATCC 29213.

Tabela 12. Inibição de crescimento de S. Aureus, cepa ATCC 29213, nas concentrações testadas do composto I-G

Tabela 13. Correlação de Pearson entre resultados obtidos na fase II e IC 90 .92 
Tabela 14. Atividade antimicrobiana dos compostos 4-substituído-[(5-nitrofuran-2-il) metileno] benzidrazida - Série I, frente à E. coli, cepa ATCC 25922.

Tabela 15. Atividade antimicrobiana dos compostos 3-acetil-2-[5-nitro-furan-2-il]-5-[4substituído-fenil]-2,3-diidro-1,3,4-oxadiazolínico - Série II, frente à E. coli, cepa ATCC 25922

Tabela 16. Atividade antimicrobiana dos compostos 4-substituído-[(5-nitrofuran-2-il) metileno] benzidrazida - Série I, frente à E. faecalis, cepa ATCC 29212. .96

Tabela 17. Atividade antimicrobiana dos compostos 3-acetil-2-[5-nitro-furan-2-il]-5-[4substituído-fenil]-2,3-diidro-1,3,4-oxadiazolínico - Série II, frente à E. faecalis, cepa ATCC 29212.

Tabela 18. Atividade antimicrobiana dos compostos 4-substituído-[(5-nitrofuran-2-il) metileno] benzidrazida - Série I, frente à C. albicans, cepa ATCC537Y..... . .99

Tabela 19. Atividade antimicrobiana dos compostos 3-acetil-2-[5-nitro-furan-2-il]-5-[4substituído-fenil]-2,3-diidro-1,3,4-oxadiazolínico - Série II, frente à $C$. albicans, cepa ATCC537Y...

0

Tabela 20. Valores de IC 90 da série I com a série II frente à S. aureus, cepa ATCC 29213.

Tabela 21. Valores de $\mathrm{IC}_{90}$ da série I com a série II frente à E. coli, cepa ATCC 25922

Tabela 22. Valores de $\mathrm{IC}_{90}$ da série I com a série II frente à $E$. faecalis, cepa ATCC 29212

Tabela 23. Valores de $\mathrm{IC}_{90}$ da série I com a série II frente à $C$. albicans, ATCC $537 Y$.

Tabela 24. Atividade antimicrobiana frente a $S$. aureus multirresistente, cepa VISA3, dos compostos de série I e II que apresentaram melhor atividade frente à cepa ATCC 29213 de S. aureus. 
Tabela 25. Comparação de IC 90 entre as cepas ATCC 29213 e VISA3 multirresistente de $S$. aureus.

Tabela 26. Atividade antimicrobiana, representado por $\mathrm{IC}_{90}$, dos compostos de série I e II. 109 


\section{Abreviaturas e Símbolos}

ADME: Absorção, distribuição, metabolismo e excreção

ANVISA: Agência Nacional de Vigilância Sanitária

ASA: Superfície acessível à solvente

ASA-: Superfície acessível à solvente de todos os átomos com carga parcial negativa

ASA_H: Superfície acessível à solvente de todos átomos hidrofóbicos

ASA_P: Superfície acessível à solvente de todos os átomos hidrofílicos

ASA+: Superfície acessível à solvente de todos os átomos com carga parcial positiva

ATCC: American Type Culture Collection (Coleção de Tipos de Cultura Americano)

CHELPG: Charges from electrostatic potentials using a drug based method (Cargas de potencial eletrostático baseadas pelo método de grid)

CHN: Análise elementar de carbono, hidrogênio e nitrogênio.

CIM: Concentração Inibitória Mínima

CLSI: Clinical and Laboratory Standards Institute (Instituto de Padrões Clínicos e Laboratoriais)

CP: Controle positivo

CS: Controle de Solvente

DMF: N,N-dimetilformamida

DMSO: Dimetilsulfóxido

DMSO-d 6 : Dimetilsulfóxido deuterado

DP: Desvio Padrão

Eномо: Energia do orbital de fronteira HOMO

ELUMO: Energia do orbital de fronteira LUMO 
ESBL: Extended-spectrum beta-lactamase

F: Constante de efeito indutivo de Swain e Lupton

FDA: Food and Drug Administration Agency (Administração Federal de Alimentos e Medicamentos)

FR: Interação Fármaco-Receptor

HCA: Hierarchical Cluster Analysis (Análise Hierárquica de Cluster)

HF: Método ab initio Hartree-Fock

IC 90 : Concentração Inibitória de 90\% das células

IS: Índice de Seletividade

J: Constante de acoplamento

$\mathrm{K}_{\mathrm{a}}$ : Constante de ionização ácida

KPC: Klebisella pneumoniae Carbapenemase

ClogP: Coeficiente de partição

$\mathrm{MH}:$ Mueller Hinton

MM: Massa Molar

MM+: Campo de força derivado do MM2

MPE: Mapa de potencial elestrostático

MPL: Mapa de potencial lipofílico

MR: Refratividade molar

MRSA: Meticilin-resistant Staphylococcus aureus

NCE: New Chemical Entity (Nova Entidade Química)

NF: Nifuroxazida

NME: New Molecular Entity (Nova Entidade Molecular) 
P: Coeficiente de partição

PC: Componente principal

PCA: Principal Component Analysis (Análise de Componentes Principais)

pH: Potencial hidrogeniônico

PSA: Área de superfície polar

QSAR: Quantitative Structure-Activity Relationships

R: Constante de efeito de ressonância de Swain e Lupton

R: Coeficiente de correlação de Pearson

$r^{2}$ : Coeficiente de determinação

RMN ${ }^{13} \mathrm{C}$ : Ressonância Magnética Nuclear de Carbono

RMN ${ }^{1} \mathrm{H}$ : Ressonância Magnética Nuclear de Hidrogênio

RPMI-1640: Roswell Park Memorial Institute 1640

SAR: Structure-Activity Relationships

SOD: Superóxido Desmutase

TMS: Tetrametilsilano

UFC: Unidades formadoras de colônias

UV/VIS: Ultravioleta/Visível

VISA: Vancomycin-intermediate Staphylococcus aureus

VRE: Vancomycin-resistant enterococcus

$\mathrm{V}_{\mathrm{va}} \mathrm{W}$ : Volume de van der Waals

WHO: World Health Organization

$\lambda$ : Comprimento de onda

$\mu$ : Momento dipolo 
т: Constante de grupo de Hansch

$\sigma:$ Constante de grupo de Hammett 


\section{Sumário}

1. INTRODUÇÃO

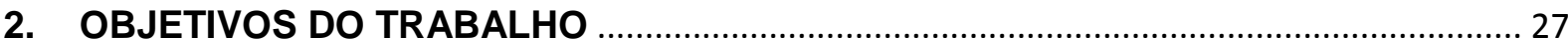

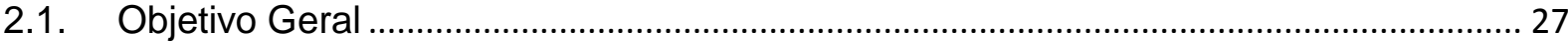

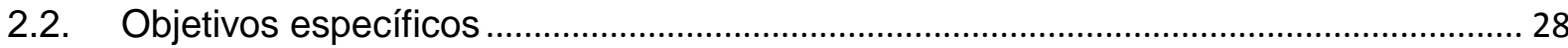

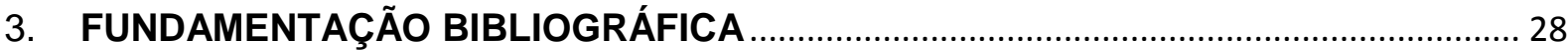

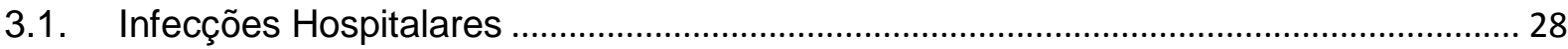

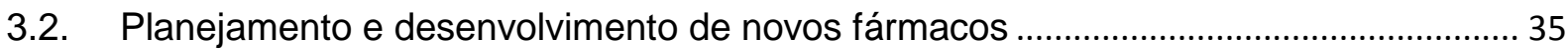

3.2.1. Abordagens no planejamento de fármacos ................................................................. 37

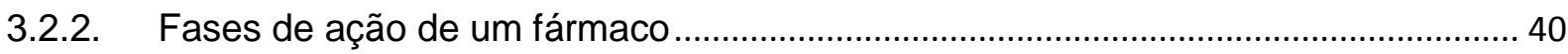

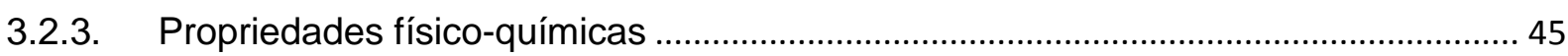

3.3. Nitrocompostos e composto protótipo - nifuroxazida.................................................... 48

4. PLANO DE TRABALHO

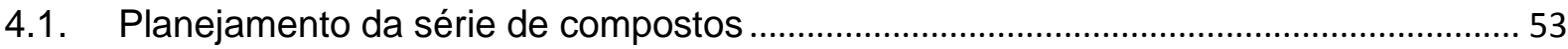

4.1.1. Planejamento da série de compostos - seleção dos grupos substituintes ............... 54

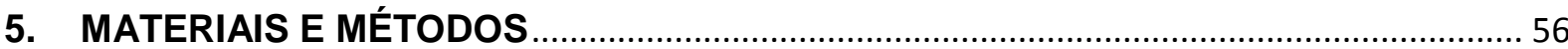

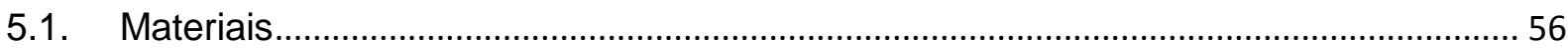

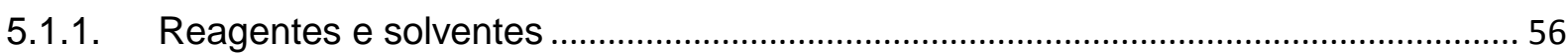

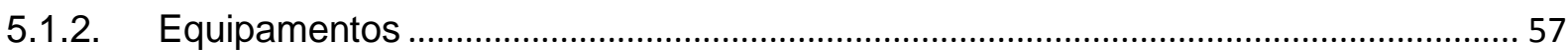

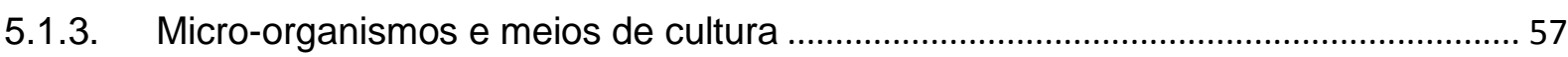

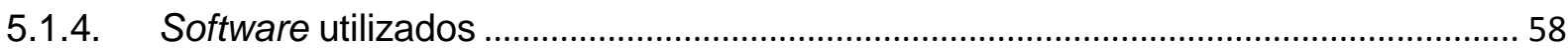

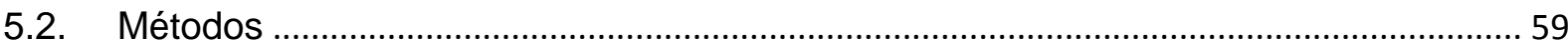

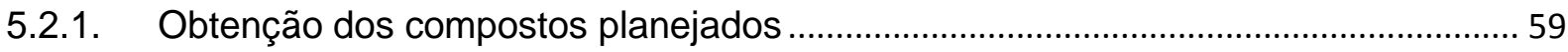

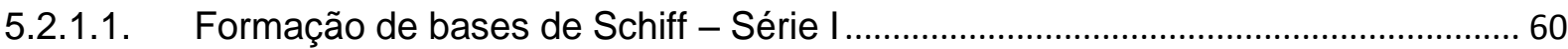

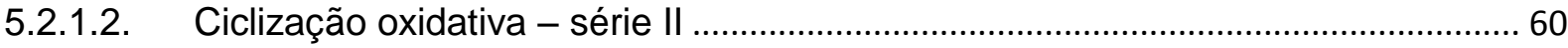

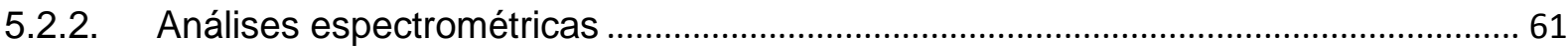

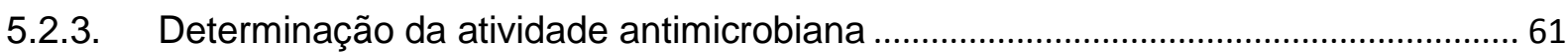

5.2.3.1. Diluição dos compostos e fármacos de referência .................................................. 62

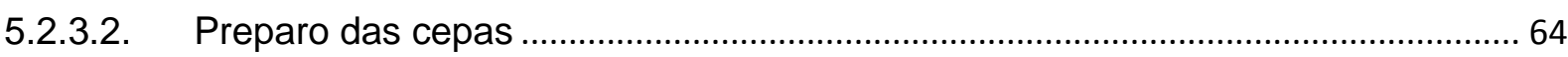

5.2.3.3. Ensaio de Concentração Inibitória Mínima (CIM) de fase I ..................................... 65

5.2.3.4. Ensaio de Concentração Inibitória Mínima (CIM) de fase II ...................................... 67

5.2.3.5. Contagem do número de unidades formadores de colônia (UFC) .......................... 69

5.2.4. Métodos de modelagem molecular e quimiométricos para estudos de relações estrutura-atividade. 
5.2.4.1. Construção e otimização de modelos moleculares tridimensionais (3D) .............. 70

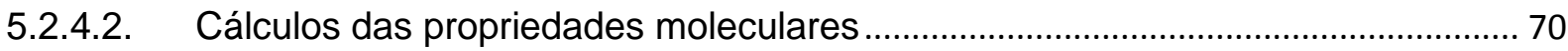

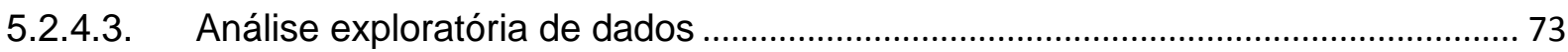

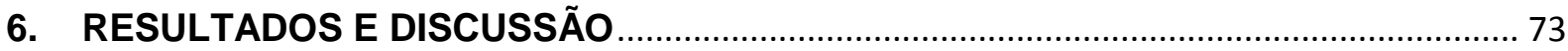

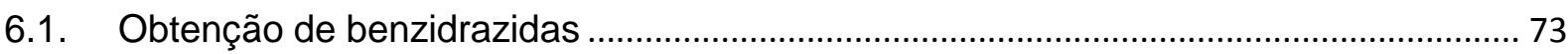

6.2. Obtenção de derivados furfurilidênicos, Série I ................................................................. 74

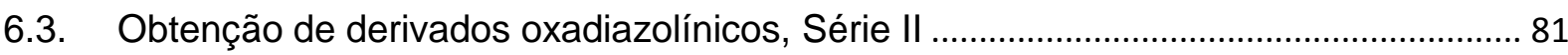

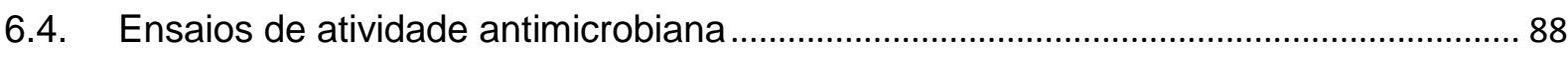

6.5. Relações entre estrutura química e atividade biológica utilizados na análises

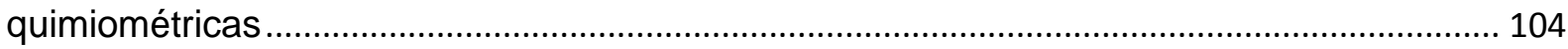

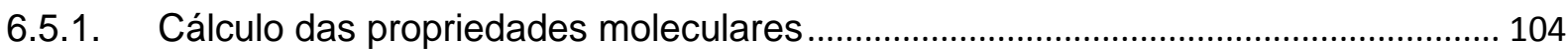

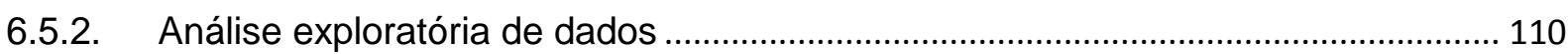

6.5.2.1. Análise Exploratória frente à Staphylococcus aureus .......................................... 113

6.5.2.2. Análise Exploratória para atividade frente à Escherichia coli................................ 117

6.5.2.3. Análise Exploratória para os dados obtidos com Enterococcus faecalis ............ 121

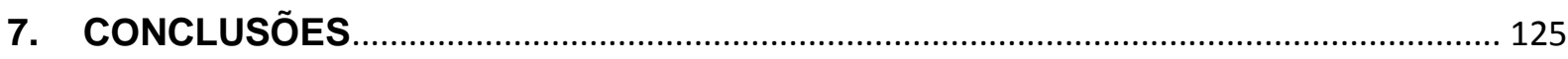

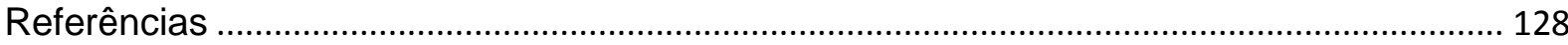





\section{INTRODUÇÃO}

Infecções hospitalares multirresistentes são, atualmente, uma das principais preocupações da Organização Mundial de Saúde. Cerca de 9\% dos pacientes hospitalizados apresentam algum tipo de infecção hospitalar, resultando em cerca de 140 mil mortes por ano no mundo (WHO, 2011a). O tratamento destas infecções torna-se cada vez mais difícil, principalmente, pelo uso inadequado de agentes antimicrobianos, gerando grande número de cepas bacterianas e fúngicas resistentes.

A nifuroxazida, atualmente, tem se mostrado com grande potencial nos estudos de modificação molecular, demonstrando análogos com atividade promissora contra diversos micro-organismos patogênicos e de importância em Saúde Pública, tais como: Trypanosoma cruzi, Candida albicans, Mycobacterium tuberculosis e cepas multirresistentes de Staphylococcus aureus (TAVARES, 1993; RODRIGUEZ, 2000; REZENDE, 2002; RANDO et al., 2002; MASUNARI, 2005; SONEHARA, 2009; JORGE et al., 2009; PAULA, SERRANO, TAVARES, 2009; PAULA et al., 2009; JORGE, 2011; PALACE-BERL et al., 2013).

Neste contexto, este trabalho tem como foco o planejamento e desenvolvimento de análogos furfurilidênicos da nifuroxazida com estruturas azometínicas e oxadiazolínicas, e subsequente testes in vitro frente a diferentes cepas de micro-organismos comumente associadas a infecções hospitalares, como bactérias Gram-positivas, Gram-negativas e fungos. Por fim, estudos quimiométricos qualitativos das relações estrutura-atividade foram realizados para melhor entendimento das propriedades físico-químicas que mais influenciam nesta atividade.

\section{OBJETIVOS DO TRABALHO}

\subsection{Objetivo Geral}

O presente trabalho tem como objetivo pesquisar e desenvolver análogos à nifuroxazida com potencial para serem biologicamente ativos frente a micro- 
organismos causadores de infecções hospitalares. Este trabalho também tem como objetivo analisar as propriedades físico-químicas que mais influenciaram nesta atividade, a fim de auxiliar na busca de novos compostos nitrofurânicos com perfil antimicrobiano otimizado.

\subsection{Objetivos específicos}

- Planejar e selecionar grupos substituintes para a modificação molecular;

- Sintetizar duas séries de compostos furfurilidênicos, Série I azometínica e Série II oxadiazolínica;

- Realizar análises físico-químicas para comparação estrutural dos compostos sintetizados;

- Verificar atividade antimicrobiana frente a cepas ATCC de Staphylococcus aureus, Escherichia coli, Serratia marcescens, Enterobacter clocae, Klebsiella pneumoniae, Enterococcus faecalis e Candida albicans;

- Verificar atividade antimicrobiana frente a cepa multiresistente de Staphylococcus aureus, VISA3;

- Aplicar metodologias quimiométricas focadas em estudos de relações estrutura-atividade para identificação de propriedades físico-químicas que estão diretamente relacionadas com estabelecimento da atividade biológica.

\section{FUNDAMENTAÇÃO BIBLIOGRÁFICA}

\subsection{Infecções Hospitalares}

Infecção hospitalar, em termos gerais, significa "infecção que ocorre no paciente em ambiente hospitalar ou locais de saúde" e não apresentam qualquer evidência que possa estar presente no período anterior à admissão em um hospital (WHO, 2011a; TORTORA, 2005). Estudos realizados em diversas partes do mundo 
mostram que infecções desta natureza são de alta prevalência, por exemplo, nos Estados Unidos estimou-se que em 2002, 1,7 milhões de internações foram decorrentes somente pela incidência deste tipo de infecção. Estas também são responsáveis por alta taxa de mortalidade, próxima à 100 mil mortes todos os anos (KLEVENS et al., 2007; CDC, 2012). Na Europa, as estimativas são de 4 milhões de pessoas internadas, resultando pelo menos em 37 mil mortes anuais (ECDC, 2012). Entre outros dados alarmantes relacionados à infecções hospitalares, cita-se também o aumento de 2,5 vezes no tempo de internação, além do custo adicional por pacientes para o hospital, variando de US\$1.006,00 até US\$25.546,00 nos Estados Unidos e $£ 3.000,00$ na Inglaterra (INWEREGBU, DAVE, PITTARD, 2005; REED, KEMMERLY, 2009). No Brasil, infelizmente, estudos em âmbito nacional desta natureza ainda são limitados, porém já há incentivos para início dos mesmos, conforme citado no edital 40/2010 do Ministério da Ciência e Tecnologia e o Ministério da Saúde, que tem como objetivo desenvolver estudos epidemiológicos acerca de incidência de infecções hospitalares no Brasil.

As infecções hospitalares são resultado de uma tríade de fatores, a saber: a presença do patógeno no ambiente hospitalar, o paciente que apresenta baixa defesa imunológica e, por fim, as formas de infecção dos micro-organismos ao paciente. Separadamente, tais fatores não são de grande importância clínica, pois não conseguem causar infecção no ser humano (TORTORA, 2005). Porém, em ambiente hospitalar, a possibilidade deste conjunto de fatores ocorrer é bastante elevada.

Com relação aos micro-organismos que possam estar presentes no ambiente hospitalar, os principais patógenos causadores de infecções são bactérias comensais, que não costumam causar malefícios em indivíduos saudáveis (TORTORA, 2005). Entre elas destacam-se os gêneros Staphylococcus spp., Enterococcus spp., e as famílias Enterobacteriaceae spp. e Pseudomonadaceae spp.. Além destes, destacam-se também fungos como Candida albicans e alguns protozoários responsáveis por infecções parasitárias, sendo a mais comum Giardia lamblia (JONES, 2001; DE OLIVEIRA, MAFFEI, MARTINEZ, 2001; TORTORA, 2005; WHO, 2011a). 
Como já citado, estas infecções se manifestam, principalmente, em pacientes com sistema imune debilitado e que frequentemente são internados em hospitais, em especial nos extremos de idade, sendo idosos e crianças recém-natos os mais suscetíveis. A infecção cruzada é a principal forma de disseminação no meio hospitalar, resultante do contato entre pacientes e de seus funcionários. Outra forma de disseminação é resultante de infecções endógenas decorrentes da exposição do paciente à microbiota natural do corpo, por exemplo, cirurgias ou técnicas invasivas (KOLLEF, 2000; WHO, 2011a). Cerca de 9 a 15\% dos pacientes internados apresentam algum tipo de infecção hospitalar. As mais frequentes são no sistema urinário, pós-operatórios e no trato respiratório inferior. Além destas, citam-se outras de menor importância, como infecções de pele, gastroenterites, sinusites e conjuntivites (TORTORA, 2005; WHO, 2011a).

Este quadro está se agravando devido, principalmente, ao aumento no número de casos de resistência dos micro-organismos aos tratamentos existentes. Estimativas apontam que cerca de 50 a $60 \%$ das infecções hospitalares são causadas por micro-organismos resistentes (KOLLEF, 2000; JONES, 2001; WHO, 2011a; WHO, 2011b). As causas atribuídas a este fato são o número excessivo de prescrições de antibióticos, indicação e utilização errônea destes medicamentos no que se refere à dose e/ou duração do tratamento (WHO, 2011a).

As principais bactérias Gram positivas com caráter da multirresistência são pertencentes ao gênero Staphylococcus e ao gênero Enterococcus (JONES, 2001; WHO, 2011a). O primeiro caso de cepas resistentes de $S$. aureus foi reportado em 1942, quando foram isolados cepas resistentes à penicilina, fármaco recém descoberto e mais utilizado na época para tratamento de infecções (RAMMELKAMP, 1942; BRYSKIER, 2005). A partir desta data, inúmeras alternativas como cefalosporinas, quinolonas e até mesmo novas gerações de penicilinas foram sintetizadas e testadas, a fim de se buscar possíveis alternativas terapêutica (ANDERSSON, MACGOWAN, 2003; MUÑIZ et al., 2007). Os principais resultados obtidos foram alguns novos antibióticos, em especial análogos à penicilina, como a meticilina e oxacilina (BRYSKIER, 2005). Porém, devido a facilidade de disseminação no ambiente hospitalar, em parte por sua rápida adaptação ao meioambiente, novas cepas isoladas mostraram-se resistentes a estas penicilinas semi- 
sintéticas, como também a outros antibióticos $\beta$-lactâmicos, como as cefalosporinas, até mesmo às de quarta geração (OKAMOTO et al., 1994). Tais micro-organismos foram denominados Staphylococcus aureus resistentes a meticilina (MRSA, methicilin resistant $S$. aureus) (DANCER, 2001; PATRICK, 2009). Há também relatos de resistência de cepas MRSA a quinolonas de primeira a quarta geração (WITTE, GRIMM, 1992; GOLDSTEIN, ACAR, 1995; FEIZ, REDLINE, 2007; ELSAHN et al., 2010); tetraciclinas (SCHMITZ et al., 2001); e também resistência a novos tratamentos como daptomicina e linezolina (HAYDEN et al., 2005; MANGILI et al., 2005; MURTHY et al., 2008; MORALES et al., 2010). Estas bactérias resistentes afetam, principalmente, pacientes debilitados que estão internados em unidades de tratamento intensivo (UTI), queimados, cardiopatas e imunodeprimidos (WHO, 2011a). Estima-se que 20 a 50\% das cepas de S. aureus identificadas na Europa e América Latina são MRSA, sendo que a taxa de mortalidade entre os pacientes infectados com esta bactéria variam de 15 a 60\% dependendo da região (JONES, 2001; TIEMERSMA et al., 2004; BRYSKIER, 2005; WHO, 2011b).

O tratamento indicado para cepas MRSA envolve a utilização de antibióticos glicopeptídicos, entre as quais a vancomicina é a mais prescrita. Este fármaco age similarmente aos antibióticos $\beta$-lactâmicos, inibindo a biossíntese da parede celular bacteriana, porém com mecanismo de ação totalmente diferente. Enquanto compostos que contém anel $\beta$-lactâmico inibem a enzima transpeptidase, responsável pela formação da ligação cruzada entre peptideoglicanos, a vancomicina se liga a porção C-terminal D-Alanil-D-Alanila das mesmas, impedindo que ocorra ligação entre estes polímeros, resultando na não formação da parede bacteriana (HOWDEN et al., 2010). Entretanto, já existem cepas MRSA que apresentam resistência intermediária à vancomicina, denominada VISA (vancomycin intermediate Staphylococcus aureus), a qual foi identificada pela primeira vez na década de 90 no Japão (HIRAMATSU et al., 1997). A cepa bacteriana multirresistente apresenta parede bacteriana mais espessa, o que dificulta a passagem do agente antibacteriano (HOWDEN et al., 2010). Outra cepa com grande resistência à vancomicina é a VRSA (vancomycin resistant Staphylococcus aureus), descoberta pela primeira vez em 2002 nos Estados Unidos (HOWDEN et al., 2010). Esta cepa, considerada rara por Howden e colaboradores, apresenta resistência total à vancomicina por aquisição do gene vanA, adquirido de enterococci 
multiresistentes (CDC, 2002; HOWDEN et al., 2010; CDC, 2011). Vale salientar que o número de infecções hospitalares causadas por $S$. aureus multirresistente caiu em 18\% nos Estados Unidos de 2009 para 2010 devido a avanços em questões de higiene, sendo esta, a melhor forma para o controle de infecções desta natureza (FRANCE PRESSE, 2011; TORTORA, 2005). Além disso, há indícios na literatura que novos fármacos, como cefalosporinas de quinta geração, derivados da vancomicina (chamados de lipoglicopeptideos, com único exemplar o telavancina) e o fármaco tigeciclina, da nova classe das glicilciclinas, apresentam atividade contra estes tipos de cepas resistentes (STEIN, CRAIG, 2006; COREY et al., 2009; LAUDANO, 2011).

Os enterococcus resistentes à vancomicina (VRE, vancomycin resistant enterococcus), em especial os Enteroccus faecium, Enterococcus faecalis e Enterococcus raffinosus apresentam, respectivamente, $3 \%, 47 \%$ e $72 \%$ de resistência à vancomicina (JONES, 2001; NORMARK, NORMARK, 2002). Porém, o E. raffinosus é raramente diagnosticado (JONES, PFALLER, 1998). Com a decorrência de patologias causadas por cepas VRE, citam-se o aumento em $30 \%$ do risco de morte, duplicação dos custos hospitalares dispendidos e o tempo de internação que pode prolongar-se por até 27 dias (REED, KEMMERLY, 2009). No entanto, a grande ameaça destas cepas é sua capacidade de transmitirem seus genes, em especial o de resistência vanA, para outros micro-organismos, como já citado anteriormente. Isso garante que outras bactérias adquiram resistência total a vancomicina, como é o caso das cepas VRSA (JONES, 2001; CDC, 2002; CHANG et al., 2003; LONGZHU et al., 2006). Para o tratamento de infecções causadas por VRE, preconiza-se o uso de cloranfenicol, dalfopristina, linezolida e tigeciclina, que ainda apresentam boa atividade in vitro e in vivo (TUON, FILHO, 2009). Outra possibilidade de tratamento é a utilização do antibiótico lipopeptídeo daptomicina, porém relatos sugerem que algumas cepas já apresentam diminuição na susceptibilidade a este fármaco (POUND, REEL, 2013).

No início da última década ocorreu reemergência de contaminações hospitalares por bactérias Gram negativas, chegando a ser a segunda principal causa de infecções no ano de 2003 (ALBRECHT et al., 2006; TORTORA, 2005). Atualmente, os principais causadores de infecções desta natureza são da família 
Enterobacteriaceae e de gêneros como Pseudomonas spp. e Acinetobacter spp., responsáveis por $30 \%$ dos casos gerais de infecções hospitalares, e $50 \%$ dos casos de pneumonia e infecções urinárias adquiridas no ambiente hospitalar nos Estados Unidos (PELEG, HOOPER, 2010).

Este grupo de bactérias se caracteriza, principalmente, por cepas com amplo espectro de resistência a antibióticos beta-lactâmicos (ESBL, Extended-Spectrum Beta-lactamase). Tais micro-organismos se encontram disseminados em âmbito mundial, especialmente Oriente Médio, Africa, Ásia e América Latina, sendo que nesta última região, cerca de $30 \%$ a $50 \%$ das cepas isoladas apresentam esta característica de resistência (SADER et al., 1998; JONES, 2001; RODRIGUEZBAÑO et al., 2006; DIENSTMANN et al., 2010; KANJ, KANAFANI, 2011). O principal tratamento para estas infecções são os antibióticos carbapenêmicos, como imipenem e meropenem. Porém, cepas de diversos micro-organismos como Klebsiella pneumoniae, Escherichia coli, Serratia marcescens, Pseudomonas aeruginosa, Acinobacter baumanni e Enterobacter clocae já produzem a enzima Klebsiella pneumoniae carbapenemase (KPC), garantindo resistência a esta classe de antibióticos (DESHPANDE et al., 2006; VILLEGAS et al., 2007; CAl et al., 2008; NORDMANN, CUZON, NAAS, 2009; BENNETT et al., 2009; DIENSTMANN et al., 2010; PELEG, HOOPER, 2010; ROBLEDO, AQUINO, VÁZQUEZ, 2011; KIM et al., 2012). Vale salientar que tais cepas já se encontram disseminadas em âmbito mundial, incluído Brasil e America Latina, e já são consideradas endêmicas em países como a Grécia, onde a resistência já atingiu $85 \%$ dos casos de septicemias de pacientes em UTI. (VILLEGAS et al., 2006; SOULI, GALANI, GIAMARELLOU, 2008; NORDMANN, CUZON, NAAS, 2009; PINHO, 2010; VARGAS, 2011; VEIGA, 2011; ROBLEDO, AQUINO, VÁZQUEZ, 2011; PELOSO, BARROS, SANTOS, 2012). Para tais cepas resistentes a carbapenêmicos, os tratamentos disponíveis são polimixinas (colistina e polimixina B), descobertas na década de 40 e reintroduzidas na terapêutica recentemente, e a tigeciclina (PELEG, HOOPER, 2010). Entretanto, há indícios na literatura de alguns casos de cepas Gram-negativas que já estão com características de resistência a estes antibióticos (ANTONIADOU et al., 2007; NAVON-VENEZIA, LEAVITT, CARMELI, 2007; SUH et al., 2010; HORIYAMA et al., 2011) 
Similar ao descritor para as bactérias, o número de infecções hospitalares causadas por fungos do gênero Candida spp. tem aumentado nas últimas décadas, em especial às espécies não-albicans (DE OLIVEIRA, MAFFEI, MARTINEZ, 2001; CARVALHO et al., 2001; MARTIN et al., 2003; WISPLINGHOFF et al., 2004). Este gênero, entre outros locais, hospeda-se no trato urinário de pacientes que fizeram utilização prolongada de antibióticos e imunossupressores, além da utilização de sondas vesicais, como também pacientes portadores de neuropatias, diabetes melitus e portadores do vírus da imunodeficiência humana (HIV) (JARVIS, 1995; DE OLIVEIRA, MAFFEI, MARTINEZ, 2001; CARVALHO et al., 2001). Atualmente, os tratamentos recomendados para infecções fúngicas são fármacos pertencente ao grupo dos azóis, como fluconazol e cetoconazol, assim como antibióticos poliênicos como a anfotericina $B$ e as recentes equinocandinas (CHEN, SLAVIN, SORREL, 2011). Tais antifúngicos apresentam mecanismos de ações distintos, das quais os azóis agem preferencialmente na enzima CYP51, inibindo a síntese de ergosterol (SONEHARA, 2009; LUPETTI et al., 2002; COWEN, 2008); a anfotericina B age neste mesmo ergosterol presente na membrana do fungo com a criação de canais de fluxo iônico, resultando na lise do micro-organismo (FILLIPPIN, SOUZA, 2006); as equinocandinas agem na síntese da membrana celular fúngica por inibição da enzima 1,3- $\beta$-D-glicana sintase, apresentando um grande potencial para 0 tratamento de patógenos resistentes aos tratamentos convencionais (TURNER, DREW, PERFECT, 2006; CHEN, SLAVIN, SORREL, 2011). Porém, similarmente aos tratamentos para os outros diferentes micro-organismos, algumas cepas já apresentam resistência a tais fármacos (BARAN JUNIOR, et al., 2000; FILLIPPIN, SOUZA, 2006; PERLIN, 2007; COWEN, 2008; COWEN, 2008; WALKER, GOW, MUNRO, 2010).

Diante deste quadro, mesmo com tecnologias inovadoras para descoberta de fármacos e um mercado que movimenta US\$25 bilhões ao ano (COATES et al., 2002; KRESSE, BELSEY, ROVINI, 2007), os investimentos para a pesquisa de novos agentes antimicrobianos estão decaindo por uma série de fatores, dentre os quais citam-se: a) tempo reduzido de tratamento, cerca de 7 a 10 dias; b) restrições de uso, principalmente pelo fato de que os antimicrobianos de última geração são destinados ao uso hospitalar; c) descoberta de sítios-alvos para novos fármacos desta classe terapêutica ainda é uma tarefa complexa, necessitando de muito tempo 
e investimento para tal e d) Tempo de vida útil relativamente curto, devido ao rápido aparecimento de resistência (KRESSE, BELSEY, ROVINI, 2007; WHO, 2011c). Este quadro de pouco desenvolvimento é refletido no período de 37 anos, entre $1962 \mathrm{com}$ o ácido nalidíxico e 2000 com a linezolidona, sem uma nova classe de fármacos antimicrobianos realmente inovadora no mercado (COATES et al., 2002).

Para melhora do panorama referente às infecções hospitalares, deve haver incentivo na descoberta de novas moléculas com capacidade antimicrobiana, baixa toxicidade e, ainda, de serem capazes de dificultar e/ou retardar o desenvolvimento de mecanismos de resistência por parte dos micro-organismos.

\subsection{Planejamento e desenvolvimento de novos fármacos}

As etapas necessárias para inclusão de um novo fármaco no mercado são separadas nas fases pré-clínica, que varia de três a quatro anos e clínica, que dura em torno de cinco a oito anos, figura 1. Todo o processo de desenvolvimento de um novo fármaco pode chegar a 15 anos (PhRMA, 2012).

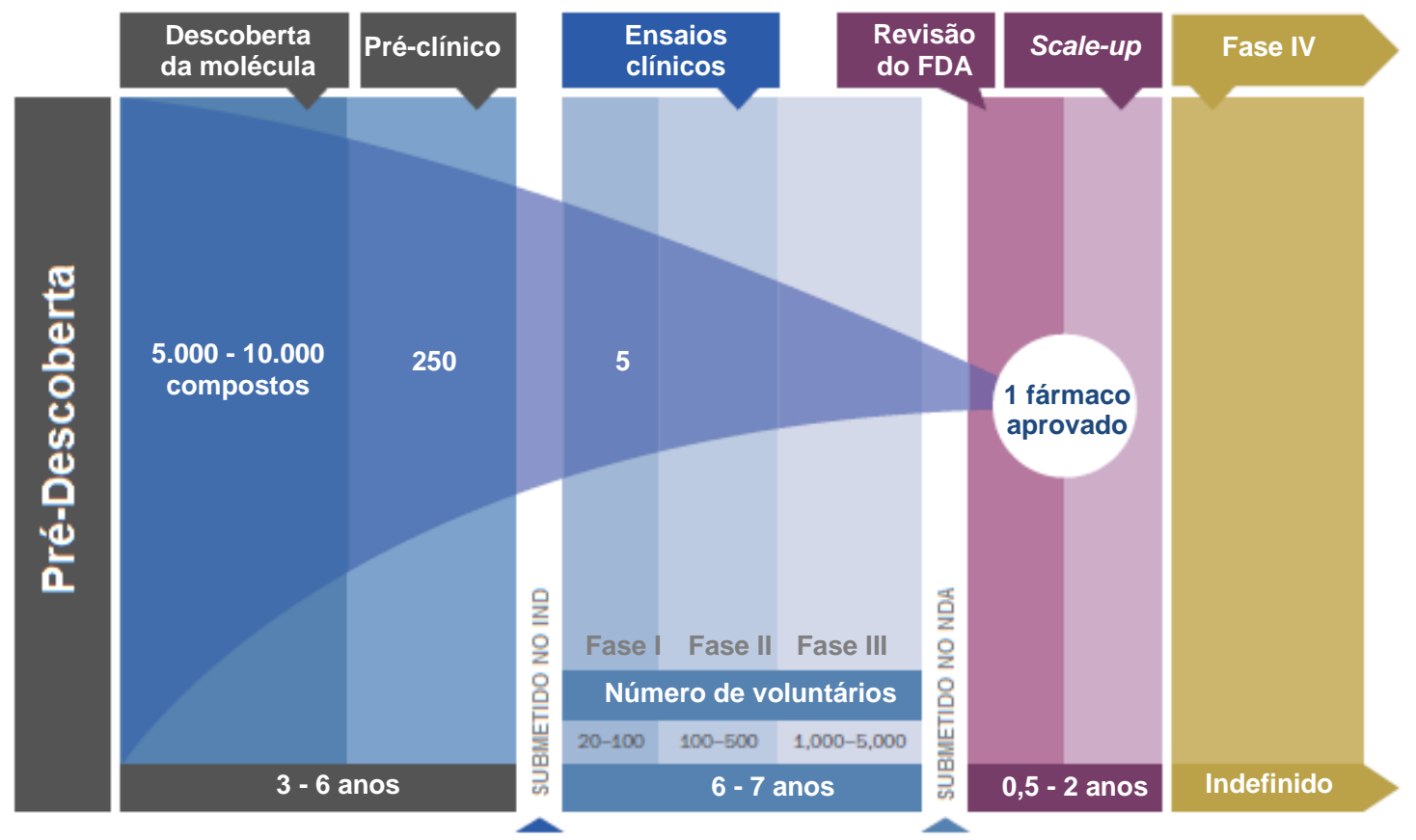

Figura 1. Etapas para descoberta, desenvolvimento e introdução de um novo fármaco no mercado.

Adaptado de Pharmaceutical Industry Profile 2012. Washington, DC: PhRMA - Report 2012,

Copyright (2012). 
A etapa pré-clínica abrange o planejamento e síntese de novas moléculas, feitos predominantemente por empresas farmacêuticas, meios acadêmicos e também por órgãos governamentais (GAO, 2006). Após este processo, são avaliados estudos de atividade in vitro e in vivo para predizer se esta molécula é segura 0 bastante para estudos em humanos (WERMUTH, 2003; GAO, 2006; PATRICK, 2009). Apenas de 5 a 10 a cada 10.000 moléculas inicialmente testadas conseguem aprovação para a etapa clínica (GAO, 2006; WERMUTH, 2003). Além disso, os custos desta fase podem chegar a cerca de 600 milhões de dólares (BCG, 2011; RAWLINS, 2004).

Após ter sido comprovada a eficácia contra determinada patologia, entra-se com pedido de patente e início do IND (Investigation Exemption to a New Drug Investigação para Isenção de uma Nova Droga) a órgãos governamentais competentes, como no Brasil a ANVISA (Agência Nacional de Vigilância Sanitária), nos Estados Unidos a FDA (Food and Drug Adminstration) e na Europa a EMEA (European Medicines Agency) (WERMUTH, 2003; PATRICK, 2009). Somente após este pedido, pode-se dar continuidade nos ensaios clínicos. Tal pedido pode ser feito para novas entidades moleculares (New Molecular Entity - NME ou New Chemical Entity - NCE), nova rota sintética ou até mesmo para novo uso terapêutico (GAO, 2006).

Depois de terminada a parte regulatória, segue-se para a etapa clínica deste potencial grupo de moléculas, subdividido em fases I, II, III e IV (LESKO, et al., 2000; WERMUTH, 2003). Na fase I o estudo costuma consumir um ano e envolve dezenas a centenas de voluntários saudáveis (PATRICK, 2009; GAO, 2006). São estudados diversos parâmetros, como farmacocinético, para elucidar as formas de absorção, metabolismo e excreção; padronização de uma dose segura para uso e também identificação de possível toxicidade aguda da molécula.

Os estudos de fase II começam logo após os estudos de fase I e costumam ter 2 anos de duração, com média de 100 pacientes (PATRICK, 2009). Estes testes ocorrem em pacientes com a doença a ser tratada, tendo como principal finalidade verificar se as moléculas contém atividade contra a patologia. Além disso, é 
esperada a identificação da dose necessária e eficácia terapêutica, como também verificar possíveis efeitos colaterais a curto prazo (PATRICK, 2009).

Os estudos de fase III duram em torno de 3 anos e fazem a utilização de grandes populações. É testado, principalmente, a efetividade do novo fármaco quando comparado a outros já disponíveis no mercado e também a variações em relação a sexo, idade e etnia (PATRICK, 2009).

Após fase III, é feito a aprovação e regulamentação da molécula para determinado alvo terapêutico, realizado por agências governamentais responsáveis, podendo finalmente ser comercializado como fármaco (LESKO, et al., 2000; PATRICK, 2009; ANVISA, 2011). Este novo fármaco agora entra na Fase IV ou farmacovigilância, onde são observados efeitos adversos raros ou de longo prazo (PATRICK, 2009).

Os custos totais da etapa clínica podem chegar a 500 milhões de dólares, totalizando em torno de um bilhão de dólares para o desenvolvimento de um novo fármaco (DIMASI, HANSEN, GRABOWSKI, 2003; RAWLINS, 2004; BCG, 2011). Estes custos extremamente altos, aliado ao longo tempo gasto, faz com que qualquer falha possa se tornar um prejuízo de enormes proporções. Assim, para minimização dos riscos durante o processo, é de grande importância que este candidato tenha um planejamento bem elaborado na etapa pré-clínica. Para isto, o planejamento e desenvolvimento racional de novos fármacos, uma abordagem que utiliza os conhecimentos teóricos multidisciplinares para direcionamento dos estudos, é uma alternativa viável, pois auxilia na diminuição de custos e aumenta as possibilidades de sucesso na identificação de um composto mais seletivo, menos tóxico e mais ativo (WERMUTH, 2003).

\subsubsection{Abordagens no planejamento de fármacos}

O planejamento racional de fármacos, que teve início na década de $70 \mathrm{com}$ o descobrimento da cimetidina (MOLINDER, 1994; BARREIRO, 2002), pode ser feito a partir de um composto protótipo, este considerado a primeira molécula de uma série congênere com pureza, boa atividade relacionada à patologia, porém com 
necessidade de modificação estrutural (FRAGA, LIMA, BARREIRO, 2011). A descoberta deste tipo de molécula pode ser realizada por quatro vertentes: a) varredura sistemática, identificando aleatoriamente compostos com algum efeito biológico; b) observação e exploração de tratamentos medicinais populares ou efeitos adversos aproveitáveis, a fim de identificar novas possibilidades de tratamento; c) planejamento de fármacos provenientes da descoberta de novo sítios alvos em enzimas, canais de sódio, proteínas, entre outros, para o planejamento de moléculas seletivas para estes alvos, também chamadas de planejamento baseado no alvo macromolecular; d) otimização de fármacos já existentes no mercado, utilizando-o como modelo para melhorar aspectos farmacocinéticos, farmacodinâmicos e toxicológicos (WERMUTH, 2003).

Entre as possíveis formas de planejamento de novos fármacos, a modificação molecular é vista como a mais eficaz para identificação de novos compostos potencialmente aproveitáveis, devido à possibilidade de utilizar moléculas protótipo com comprovada eficácia terapêutica para base do estudo (WERMUTH, 2003). Um exemplo clássico disto, figura 2, é a sildenafila, que com a devida modificação gerou a molécula da vardenafila, um fármaco "me too" utilizado com a mesma finalidade, porém com melhor seletividade na biomacromolécula alvo, a enzima fosfodiesterase-5 (WERMUTH, 2003; DOGGRELL, 2005).

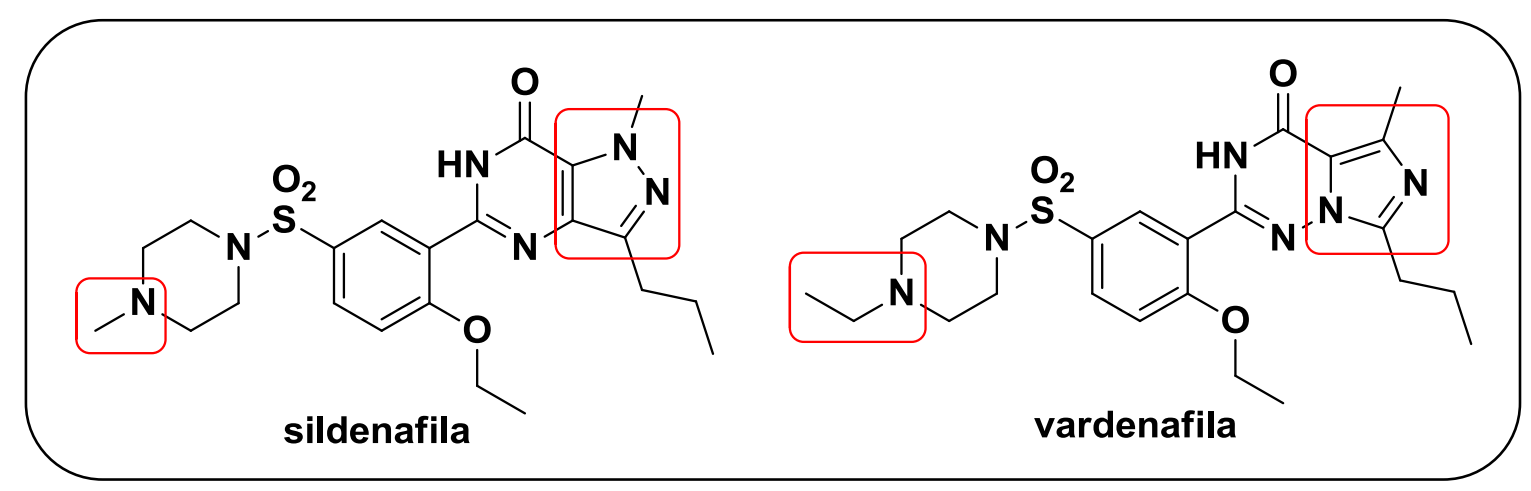

Figura 2. Modificação molecular do sildenafila, gerando o vardenafila.

Para otimização de um composto protótipo, entre diversos tipos de modificações moleculares pode-se fazer a alteração de grupos substituinte em sua molécula, a fim de identificar e quantificar quais propriedades físico-químicas (hidrofobicidade, efeito eletrônico ou volume molecular) influenciam na atividade 
biológica (THOMAS, 2003; WERMUTH, 2003). O estudo da influência destas propriedades na bioatividade é chamado de Relações Estrutura-atividade (SAR Structure Activity Relationships), que podem ser tanto qualitativos quanto quantitativos (QSAR - Quantitative Structure Activity Relationships) (THOMAS, 2003; WERMUTH, 2003).

$\mathrm{Na}$ forma qualitativa, o foco do estudo é identificar quais são os principais grupos moleculares do composto protótipo que influenciam a bioatividade. Tal identificação deve ser realizada por meio de síntese de análogos estruturais a este, porém sem quantificar a variação resultante de propriedade físico-química que foi modificada. As modificações que originam estes análogos podem ser resultantes de: grupos substituintes em diferentes posições; do aumento ou diminuição do tamanho de cadeias alquílicas; da abertura ou fechamento de anéis e da variação de bioisósteros, entre outros (PATRICK, 2009).

$\mathrm{Na}$ forma quantitativa (QSAR), o principal foco do estudo é identificar e quantificar, a partir de modelos matemáticos preditivos, quais são as principais propriedades físico-químicas responsáveis por desencadear uma determinada atividade biológica (TAVARES, 2004; PATRICK, 2009). A partir desta abordagem, a síntese de análogos tende a diminuir, pois já há um direcionamento para os grupos que devem ou não ser adicionados à molécula (PATRICK, 2009).

Para auxiliar neste tipo de planejamento, a seleção de grupos substituintes pode ser feita por uma ferramenta bastante utilizada, o diagrama de Craig (CRAIG, 1971). Este diagrama consiste em um sistema cartesiano bidimensional que pode correlacionar algumas variáveis estruturais, como por exemplo, hidrofobicidade com o efeito eletrônico. Além destes, o formato molecular pode também ser relacionado no sistema, devido a sua afinidade com as outras duas propriedades citadas (TAVARES, 2004). Estas alterações podem trazer diversas mudanças nas propriedades físico-químicas, como na hidrofobicidade, alterações na distribuição eletrônica da molécula, além de modificações farmacocinéticas e farmacodinâmicas resultantes destas alterações (WERMUTH, 2003). A partir disso, existe a possibilidade de verificar a inter-relação entre estas, possibilitando maior 
aprofundamento no conhecimento de determinada propriedade e direcionando a síntese de novos análogos, com potencial melhoramento do perfil farmacológico.

\subsubsection{Fases de ação de um fármaco}

A busca por fármacos mais seletivos e mais ativos considera conceitos envolvidos nas fases farmacêutica, farmacocinética e farmacodinâmica durante seu planejamento e desenvolvimento. As fases de ação de um fármaco no organismo, que envolve as etapas farmacêutica, farmacocinética e farmacodinâmica, estão ilustratadas na figura 3.

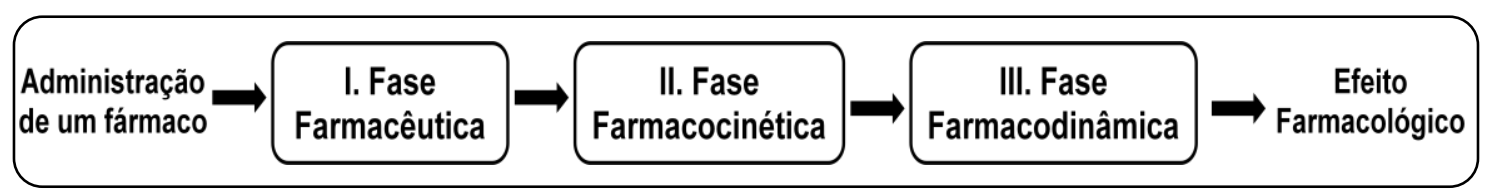

Figura 3. Fases de um fármaco no organismo. Adaptado de WERMUTH, 2003; PATRICK, 2009.

A fase I, denominada fase farmacêutica, corresponde à administração de fármacos por diferentes vias, sendo as mais comuns a via oral, a via injetável e o uso tópico; outras menos comuns são por inalação, retal, entre outros (PATRICK, 2009; WERMUTH, 2003). A mais preconizada é a utilização via oral, por ser mais adaptável e confortável para o paciente.

No caso de fármaco administrado por via oral, o mesmo tem que passar pelos processos de liberação, que equivale à desintegração da forma farmacêutica e aumento da disponibilidade do fármaco e pela a dissolução deste nos fluídos biológicos para assim, poder entrar em contato com barreiras orgânicas (WERMUTH, 2003b).

Depois da dissolução do fármaco nos fluídos biológicos, o mesmo precisa, sobretudo, chegar a seu sítio de ligação. Para que isto ocorra, uma série de fatores relacionados à fase II, denominada fase farmacocinética (figura 3 ) deve ser levada em consideração. Nesta etapa, são importantes as características de absorção, distribuição, metabolismo e excreção (ADME) de um fármaco (PATRICK, 2009). 
Para a absorção de fármacos administrados por via oral considera-se o modelo mais aceito de membrana celular o de mosaico fluído (SINGER, NICOLSON, 1972). Neste esquema, a mesma é composta tanto de porções hidrofílicas (mais externas) quanto de porções lipofílicas (mais internas) (PATRICK, 2009). A principal propriedade físico-química que está relacionada à passagem de moléculas através destas membranas, principalmente no sistema gastrintestinal - TGI, é o equilíbrio hidro-lipofílico (PATRICK, 2009). Porém, a eletronegatividade apresenta também grande influência, devido a características de bases e ácidos fracos dos fármacos, resultando em variações nas formas ionizadas (baixa absorção) e não ionizadas (alta absorção), em função do $\mathrm{pH}$ do sistema biológico. A estereoquímica da molécula também influencia na transposição pela membrana passivamente, principalmente em relação a compostos com alto número de ligações rotáveis, que acabam dificultando essa passagem (VEBER et al., 2002; PATRICK, 2009).

Após a absorção, ocorre a distribuição do fármaco no sistema sanguíneo e por fim distribuição para os tecidos e órgãos. Durante este processo, os fármacos se ligam a proteínas plasmáticas, fato este intimamente relacionado suas propriedades eletrônicas e que interferem diretamente no seu potencial de ionização. Esta ligação é um dos principais fatores que rege a concentração e disponibilidade de fármaco na corrente sanguínea (PATRICK, 2009).

Uma vez que o fármaco encontra-se na corrente sanguínea, este passa a ser extremamente suscetível a diversas reações enzimáticas, sendo a maioria dos casos por enzimas hepáticas. Esta biotransformação tem como principal finalidade a diminuição da toxicidade e auxílio para posterior eliminação. Sendo assim, tais ações enzimáticas tem papel importante na tempo de ação de um fármaco, evitando tempos de meia-vida excessivamente altos (PEREIRA, 2007), sendo, portanto, de grande importância para compostos com grau de toxicidade elevado. Em contrapartida, alguns tipos de fármacos podem sofrer biotransformações rápidas, sendo inutilizados antes de desempenharem sua atividade biológica (PATRICK, 2009). Similarmente as outras etapas farmacocinéticas, o metabolismo está ligado também à características físico-químicas, como por exemplo, equilíbrio hidrolipofílico e fatores estereoquímicos (TAVARES, 2004; PEREIRA, 2007; PATRICK, 2009). 
Por fim, a última etapa envolvida na farmacocinética é a eliminação ou excreção. Tal processo pode ocorrer tanto por via renal como também pelo TGI, sendo este último, para fármacos que não apresentam absorção desejável, substâncias que procuram atingir alvos contidos neste sistema ou para fármacos que são excretados por via biliar (PATRICK, 2009; TMM, 2012). Na eliminação por via renal, os metabólitos devem apresentar mais hidrofilicidade e capacidade de ionização, sendo muitas vezes o resultado da biotransformação de fase II (TMM, 2012).

Dos medicamentos disponíveis hoje na terapêutica, grande parte tem como mecanismo de ação a interação entre parte estrutural da molécula responsável pela resposta fisiológica (grupo farmacofórico) e a biomacromoléculas alvo (receptor). Tal interação é denominada de Fase III ou fase farmacodinâmica, figura 4 (ROSS, 1996; FRAGA, LIMA, BARREIRO, 2011). Estes alvos biológicos são comumente proteínas, enzimas, canais iônicos, DNA, lipídeos ou carboidratos (THOMAS, 2003; WERMUTH, 2003; PATRICK, 2009).

Para que ocorra a interação fármaco-receptor (FR), deve haver forças intermoleculares, em geral não formais, mas fortes o suficiente para manter as ligações entre ambos, influenciadas principalmente pela eletronegatividade. $\mathrm{Na}$ figura 4, representa-se uma molécula com suas possíveis interações em um receptor hipotético. 


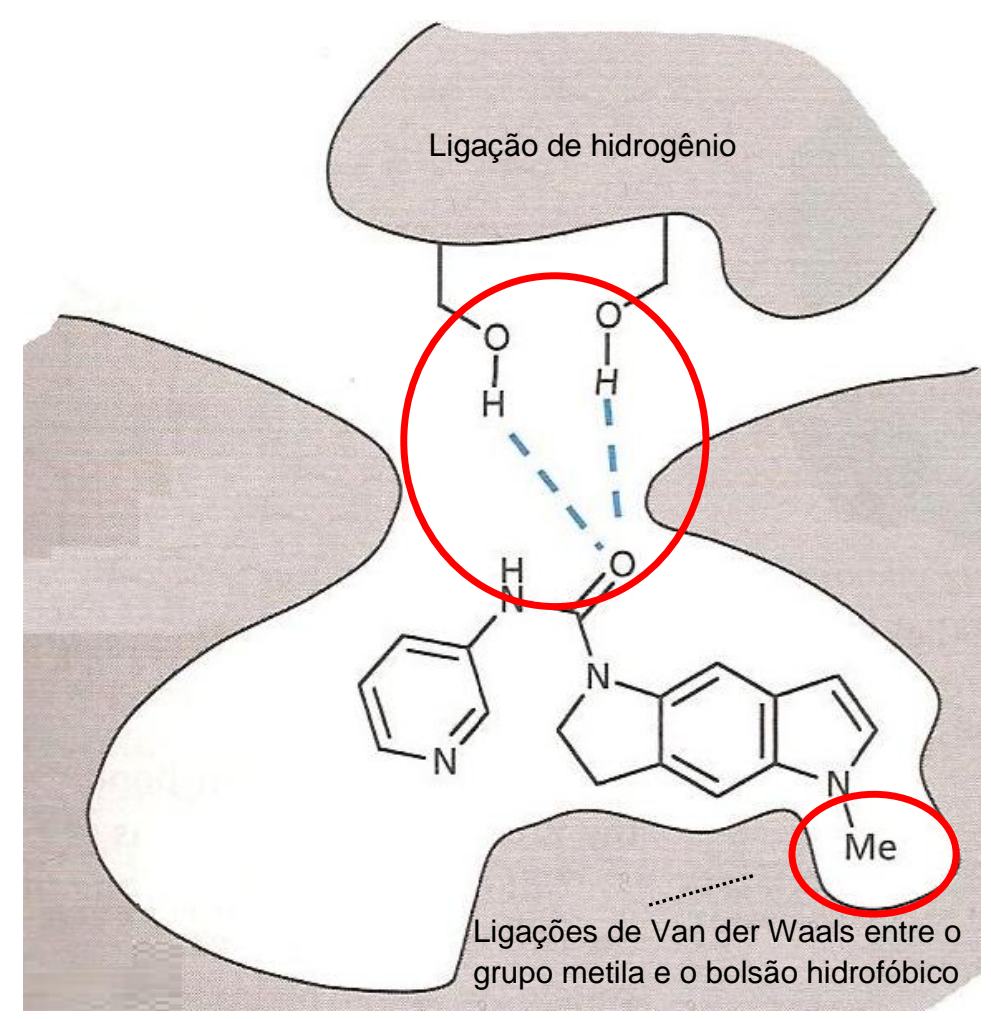

Figura 4. Possíveis interações fármaco-receptor. As principais interações estão marcadas com um círculo vermelho (Adaptado de PATRICK, 2009).

De modo geral, as principais forças que agem na fase farmacodinâmica são descritas a seguir.

-Ligações covalentes: ligações extremamente fortes entre o ligante e o sítio de ligação do receptor. Um exemplo clássico disso são as reações de alquilação que podem ocorrem entre halogênios presentes na molécula e resíduos de aminoácidos do sítio de ligação, como por exemplo, serina e cisteína. Não costuma ser a melhor alternativa para fármacos, devido a inutilização do receptor devido a força da ligação. Porém, há casos em que seu uso pode ser favorável, como em alguns agentes anti-neoplásicos (PATRICK, 2009).

-Ligações iônicas: ocorrem entre dois íons de cargas diferentes, como íons carboxilatos e amoníacos, presentes tanto na molécula quanto no receptor. (PATRICK, 2009). 
-Ligações de hidrogênio: ocorrem entre um átomo com um par de elétrons disponível, comumente um nitrogênio ou um oxigênio, com um átomo de hidrogênio (PATRICK, 2009). Sua importância está na estabilização e seletividade da molécula, gerando ligações relativamente estáveis e também por ser uma das ligações mais comuns (GIES, LANDRY, 2003).

-Ligações de van der Waals: denominadas também como forças de London, estas ligações são interações entre regiões hidrofóbicas da molécula e do receptor (PATRICK, 2009; GALDINO, PITTA, 2011). A energia para liberar esta ligação é baixa, próxima a 2 - $4 \mathrm{~kJ} \mathrm{~mol}^{-1}$, porém são de extrema importância para reconhecimento da molécula e modulação do receptor (PATRICK, 2009; GALDINO, PITTA, 2011).

-Ligações dipolo-dipolo: alguns substituintes podem gerar um dipolo entre si, isto é, ocorre uma variação de eletronegatividade interna entre átomos. Também se observa esta variação com determinados resíduos de aminoácidos presentes nos receptores. Tal situação gera a possibilidade de ocorrer a interação entre estes dois pontos eletronegativamente distintos, formando a ligação (PATRICK, 2009; GALDINO, PITTA, 2011).

-Ligação íon-dipolo: ocorrem de maneira similar as ligações dipolo-dipolo, sendo que estas interações utilizam um resíduo de aminoácido em forma de íon para interagir com o dipolo da outra molécula. São mais fortes que ligações dipolodipolo e demoram mais tempo para serem dissociadas (PATRICK, 2009).

$\mathrm{Na}$ fase farmacodinâmica, as características eletrônicas são as mais importantes para condicionar a ligação com 0 alvo biológico, mas outras propriedades podem influenciar nesta interação, como lipofilicidade (ligações hidrofóbicas) e estereoquímica, principalmente, por haver necessidade de complementaridade entre os formatos da molécula e do receptor, para assim ocorrer a interações entre ambas (WERMUTH, 2003; THOMAS, 2003; PATRICK, 2009). Vale salientar que todas estas propriedades são cruciais tanto para o farmacóforo quanto também em grupos auxiliares, importantes para o reconhecimento da molécula (THOMAS, 2003; PATRICK, 2009). 
Outra característica importante de fármacos é a toxicidade e/ou efeitos adversos, que podem variar de imperceptíveis à extremamente severos, que podem até causar o óbito do paciente (WERMUTH, 2003; PATRICK, 2009). A toxicidade está intimamente relacionada à dose administrada e pode causar a retirada imediata de um fármaco do mercado. Um exemplo clássico é a talidomida, utilizada na década de 50 como um fármaco antiemético e considerado seguro, porém causou efeito teratogênico e má-formação fetal, afetando cerca de 8000 a 12000 pessoas (PATRICK, 2009).

\subsubsection{Propriedades físico-químicas}

Todas as etapas de ação de um fármaco no sistema biológico, como também o planejamento de novos fármacos, estão intimamente ligadas com propriedades físico-químicas. O equilíbrio hidro-lipofílico, distruibuição eletrônica e estereoquímica são de extrema importância para se entender ou até mesmo se prever como uma determinada molécula irá interagir com o sistema biológico. Estas propriedades podem ser expressas de uma forma qualitativa, em estudos de SAR, ou da forma quantitativa, com o uso de descritores estruturais, em estudos de QSAR (TAVARES, 2004; PATRICK, 2009).

As principais interações envolvidos no equilíbrio hidro-lipofílico, relacionadas com a passagem através de membranas celulares e também na interação fármacoreceptor. Esta propriedade é definida como solubilidade de uma molécula em um sistema contendo uma fase aquosa e uma fase não aquosa, comumente presente no sistema biológico (PATRICK, 2009). Para se quantificar esta propriedade é comum a utilização de descritores como coeficiente de partição $(P)$, que analisa a molécula como um todo, e a constante de hidrofobicidade de Hansch ( $\pi$ ), que quantifica a contribuição de grupos substituintes para o equilíbrio hidro-lipofílico de moléculas como um todo (THOMAS, 2003; TAVARES, 2004; PATRICK, 2009).

O coeficiente de partição $(P)$, equação 1 , é definido como sendo a partição de um composto em um meio contendo uma fase aquosa e outra não aquosa (KUBINYI, 1993; PATRICK, 2009). Moléculas hidrofóbicas tem preferência em 
dissolver-se na fase não aquosa, enquanto moléculas hidrofílicas a tendência é oposta (THOMAS, 2003; PATRICK, 2009).

$$
P=\frac{X}{Y}
$$

Em que:

$P=$ Coeficiente de partição;

$X=$ Concentração da molécula na fase não aquosa;

$Y=$ Concentração da molécula na fase aquosa;

A constante de hidrofobicidade de Hansch ( $\pi$ ) define a relação entre 0 coeficiente de partição de um composto substituído (LogPx) e o coeficiente de partição de seu análogo não substituído (LogPh), equação 2 (TAVARES, 2004; PATRICK, 2009).

$$
\pi=\log P_{X}-\log P_{H}
$$

Equação 2

Em que:

$\pi=$ Constante de hidrofobicidade de Hansch, parâmetro que mensura a variação do equilíbrio hidro-lipofílico do grupo substituinte de uma molécula em relação a mesma não substituída. Valores positivos de $\pi$ são para grupos com caráter lipofílico, enquanto que valores negativos são para compostos hidrofílicos;

$\log P_{x}=$ Valor logarítmico do coeficiente de partição de uma molécula substituída;

$\log P_{H}=$ Valor logarítmico do coeficiente de partição de uma molécula não substituída.

Se os valores do $\pi$ de Hansch encontrados forem positivos, o substituinte em questão tem caráter mais lipofílico, enquanto que valores negativos são característicos de substituintes hidrofílicos (TAVARES, 2004).

O efeito eletrônico, ou a distribuição de elétrons pelas diferentes regiões de uma molécula, tem um grande efeito na ionização e na polaridade da mesma, ambos importantes para a farmacocinética e a farmacodinâmica (THOMAS, 2003; TAVARES, 2004; PATRICK, 2009). Para quantificar esta propriedade é comumente utilizado a constante de ionização ácida $\left(\mathrm{K}_{\mathrm{a}}\right)$ que relaciona espécies ionizadas com não ionizadas, equação 3 (TAVARES, 2004; PATRICK, 2009). 


$$
K a=\frac{\left[H^{+}\right] x\left[A^{-}\right]}{[H A]}
$$

Equação 3

Em que:

$K_{a}=$ Constante de ionização ácida;

$\left[A^{-}\right]=$Ácido fraco na forma ionizada;

$\left[\mathrm{H}^{+}\right]=\mathrm{H}^{+}$;

$[H A]=$ Ácido fraca na forma não ionizada.

A relação logarítimica entre constantes de ionização de ácidos benzóicos substituídos ( $\log \mathrm{Kx}$ ) e de ácidos benzóicos não substituídos ( $\log \mathrm{Kh}$ ) pode ser definido pela equação da constante de Hammett ( $\sigma$ ), equação 4 (TAVARES, 2004; PATRICK, 2009). A partir desta pode-se estimar a influência na ionização de grupos substituintes retiradores ou doadores de elétrons na eletronegatividade total de uma molécula, figura 5 (TAVARES, 2004; PATRICK, 2009).

$$
\sigma=\log K_{x}-\log K_{H}
$$

Equação 4

Em que:

$\sigma=$ Constante de Hammett. Parâmetro que mensura a variação da influência eletrônica de grupos substituintes em relação à molécula não substituída;

$\log K_{x}=$ Valor logarítmico da constante de ionização de uma molécula substituída;

$\log K_{H}=$ Valor logarítmico da constante de ionização de uma molécula não substituída. 


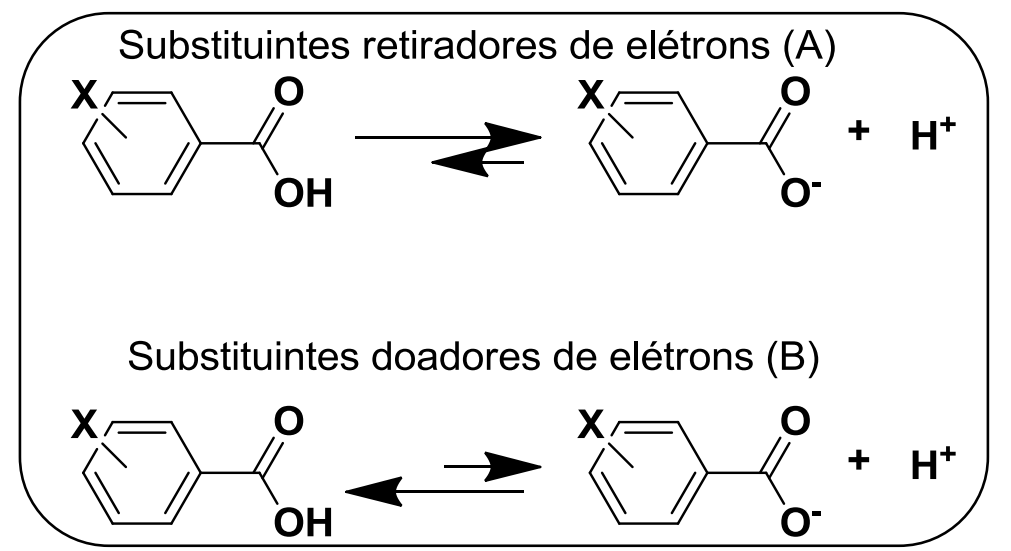

Figura 5. Influência na ionização causada pela substituinte. A Substituintes retiradores de elétrons deslocam o equilíbrio da reação para o lado ionizado da mesma. B - Substituintes doadores de elétrons deslocam o equilíbrio para o lado não ionizado (PATRICK, 2009).

Similar ao encontrado no $\pi$ de Hansch, $0 \sigma$ de Hammett pode ser observado de duas maneiras. Quando positivo, o substituinte é retirador de elétrons, enquanto que com um valor negativo o substituinte apresenta característica doadora de elétrons (TAVARES, 2004).

Por fim, a última propriedade considerada aqui é o fator estereoquímico, que relaciona aspectos estéricos entre fármaco e receptor (TAVARES, 2004). Distância interatômica, conformação e o volume geral são de grande importância para farmacocinética e farmacodinâmica, pois irão ditar como uma molécula poderá interagir com o receptor e também quais são os grupos auxofóricos que podem auxiliar, ou não, na atividade (PATRICK, 2009). Alguns descritores estruturais que podem explicar esta propriedade são refratividade molar (MR), que quantifica o volume ocupado por um átomo ou um grupo de átomos; o volume de de Van der Waals $\left(V_{W}\right)$, relacionado com o relevo de uma determinada estrutura molecular; e também os parâmetros estéricos de Verloop, que calcula concomitantemente as angulações, raio de van der Waals, distância de ligação e possíveis conformações da estrutura no programa Sterimol ${ }^{\circledR}$ (TAVARES, 2004; PATRICK, 2009).

3.3. Nitrocompostos e composto protótipo - nifuroxazida 
Nitrocompostos são uma classe de compostos químicos abrangentes com diversas finalidades, dentre elas cita-se o uso clínico, onde são utilizados como fármacos anti-hipertensivos, sedativos, hipnóticos, anti-histamínicos, antibacterianos, antichagásicos e antifúngicos (TAVARES, 1993; CERECETTO et al., 1998; BLUMENSTIEL et al., 1999; OTERO et al., 2006; PAULA, SERRANO, TAVARES, 2009; SONEHARA, 2009; PATRICK, 2009).

O primeiro nitrocomposto com atividade antibacteriana utilizado foi a nitrofurazona, figura 6A, utilizada desde a década de 40 (DODD, STILLMAN, 1944). Dentre os nitrocompostos cita-se nifuroxazida, figura $6 \mathrm{~B}$, fármaco pertencente à classe dos nitrofuranos com atividade antimicrobiana de amplo espectro e muito utilizado na década de 70 e 80 , tanto para uso humano quanto veterinário (CAGLIERO, 1978). No entanto, este fármaco teve seu uso restrito devido ao desenvolvimento de novos compostos mais ativos e mais seguros (AVRIL et al., 1980; CARRON, 1962). Estudos demonstram que este nitrofurano e análogos apresentam também atividade antiparasitária e antifúngica (BLUMENSTIEL et al., 1999; OTERO et al., 2006; CERECETTO et al., 1998; SONEHARA, 2009), assim como grande potencial em relação à modificação molecular, por ser facilmente sintetizada e pela possibilidade de alteração de diversas subestruturas de sua molécula. Isto pode gerar uma vasta gama de análogos, o que possibilita a busca por substâncias com melhores perfis farmacológicos (TAVARES, PENNA, AMARAL, 1997; TAVARES et al., 1999; RODRIGUEZ, 2000; ROLLAS, GULERMAN, ERDENIZ, 2002; REZENDE, 2002; MASUNARI, TAVARES, 2006; JORGE et al., 2009; PAULA, SERRANO, TAVARES, 2009; PAULA et al., 2009; SONEHARA, 2009; ISHII et al., 2011; JORGE et al., 2011; PALACE-BERL et al., 2013).

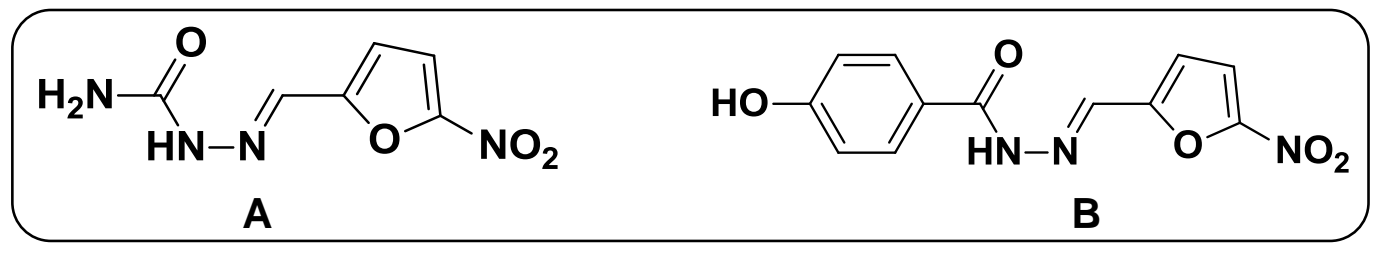

Figura 6. Molécula da nitrofurazona (A) e nifuroxazida (B).

Uma das modificações estruturais mais descritas na literatura para compostos azometínico é a sintese de derivados heterocíclicos com anel 3-acetil-1,3,4oxadiazol, formando compostos oxadiazolinicos, figura 7. Há estudos destes 
compostos em diferentes vertentes, entre eles inibidores da MAO (Monoamina Oxidase) (MACCIONI et al., 2011), anticonvulsivos (DOĞAN, ROLLAS, ERDENIZ, 1998), anti-inflamatórios (KOÇYIĞIT-KAYMAKÇIOĞLU et al., 2011), antibacterianos (ISHII et al., 2011; OSÓRIO et al., 2012) e também com atividade frente a Trypanosoma cruzi (ISHII et al., 2011; PALACE-BERL et al., 2013). Uma ampla revisão de compostos desta natureza foi feita por Rollas e Karakuş em 2012.

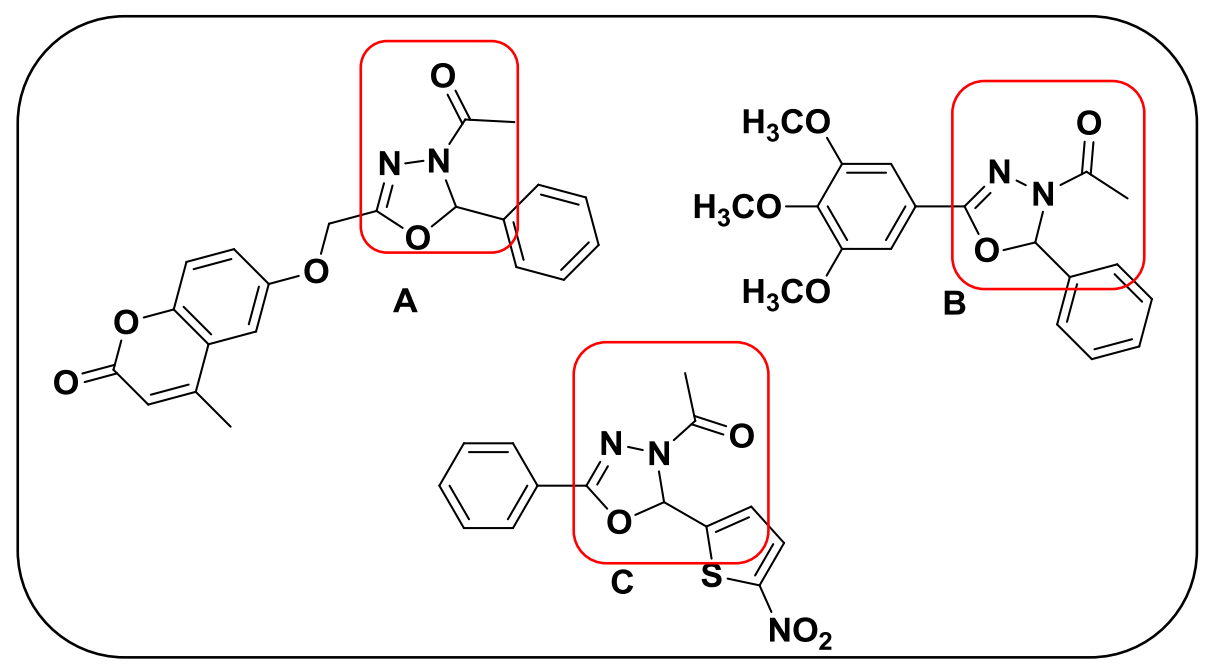

Figura 7. Exemplos de derivados com estruturas oxadiazolínicas. A. 7-[[4-acetil-5-fenil-4,5-diidro-oxadiazol-2-il]metóxi-]-4-metil-2-cromen2-ona; B. 3-acetil-2-fenil-5-[3,4,5-trimetóxifenil]-2,3-diidro-1,3,4oxadiazolínico; C. 3-acetil-2-[5-nitro-tiofen-2-il]-5-fenil-2,3-diidro-1,3,4oxadiazolínico (ROLLAS, KARAKUŞ, 2012; ISHII et al., 2011). Anel oxadiazolínico marcado em vermelho.

Outro ponto interessante dos compostos oxadiazolínicos é sua baixa toxicidade quando comparados com compostos não cíclicos. Em estudos de citotoxicidade frente a células macrofágicas murinas de linhagem $\mathbf{J 7 7 4}$ realizados por Palace-Berl em 2013, é sugerido que análogos da nifuroxazida com estrutura azometínica são mais tóxicos que compostos com estrutura oxadiazolinica, demonstrando o potencial destas moléculas (PALACE-BERL et al., 2013).

O mecanismo de ação destas classes de nitrocompostos é resultante, provavelmente, da biorredução do grupo nitro, Figura 8, gerando radicais livres deletérios aos micro-organismos decorrentes da desestabilização de suas membranas (DOCAMPO, 1990; SQUELLA et al., 1996; BLUMENSTIEL et al., 1999; 
VIODÉ et al., 1999; PAULA, SERRANO, TAVARES, 2009; PAULA et al., 2009). À medida que estes compostos entram na célula do micro-organismo desestabilizam cada vez mais suas membranas, facilitando assim a entrada de mais compostos (PAULA, SERRANO, TAVARES, 2009).

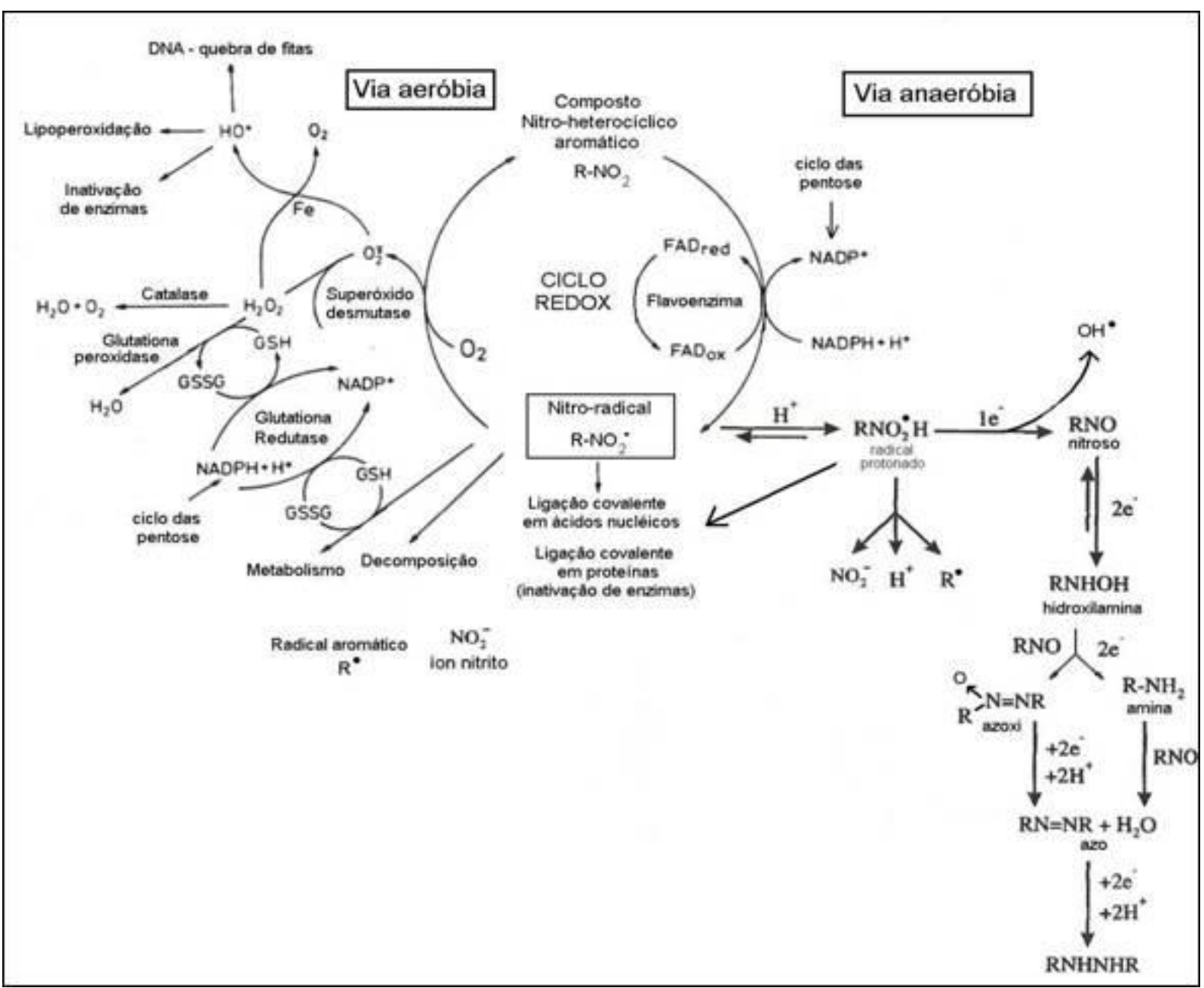

Figura 8. Mecanismo de ação de compostos nitrofurânicos. Passagem por difusão passiva e redução aos primeiros radicais livres (Adaptado de VIODÉ et al., 1999).

Esta via da biorredução, proposta por Viodé e colaboradores (1999), ocorre em seis etapas elétron-redutivas, começando pela formação do par $\mathrm{Ar}-\mathrm{NO}_{2} / \mathrm{Ar}-\mathrm{NO}_{2}$, tendo atividade sobre o DNA (PAULA, SERRANO, TAVARES, 2009). As etapas subsequentes podem ocorrer de duas maneiras distintas, tanto em meio aeróbio como anaeróbio. $\mathrm{Na}$ via anaeróbia ocorre a redução do intermediário $\mathrm{Ar}-\mathrm{NO}_{2} \cdot \mathrm{a}$ radical amina $\left(\mathrm{Ar}-\mathrm{NH}_{2}\right.$ ), passando pelo derivado nitroso (Ar-NO), um receptor de grupos tióis de enzimas detoxificantes, podendo assim inativá-las, e o radical 
hidroxilamina ( $\mathrm{Ar}-\mathrm{NHOH})$, agindo no DNA do micro-organismo. Na via aeróbia, o radical $\mathrm{Ar}-\mathrm{NO}_{2}$ ' formado interage com o oxigênio livre do meio, denominado ciclo fútil, formado o radical $\mathrm{O}_{2}$. Este oxigênio irá sofrer ação da enzima superóxido dismutase (S.O.D.), formando assim peróxido de hidrogênio $\left(\mathrm{H}_{2} \mathrm{O}_{2}\right)$, responsável pela desestruturação das membranas biológicas. Além disso, o $\mathrm{O}_{2} \cdot \mathrm{H}_{2} \mathrm{O}_{2}$, podem interagir com enzimas ferrodoxinas, possibilitando a formação de $\mathrm{OH}$; provocando efeitos celulares tóxicos (SQUELLA, et al., 1996; VIODÉ, et al., 1999; MAYA et al., 2003; PAULA, 2007; PAULA, SERRANO, TAVARES, 2009).

Observando o mecanismo de ação de compostos nitro-heterocíclicos, percebese a real necessidade do substituinte nitro $\left(-\mathrm{NO}_{2}\right)$ ligado ao carbono $\underline{5}$ para a atividade biológica, figura 9. Diversos nitrocompostos disponíveis na terapêutica, como nitrofurazona, nitrofurantoína e nifurtimox também apresentam um grupo azometínico ligado ao carbono $\underline{2}$ desta estrutura farmacofórica. Isso levanta a hipótese que este grupo azometínico tenha uma atividade antimicrobiana indireta, auxiliando sinergicamente na atividade biológica do grupo nitrofurano (LEMKE, WILLIAMS, 2008).

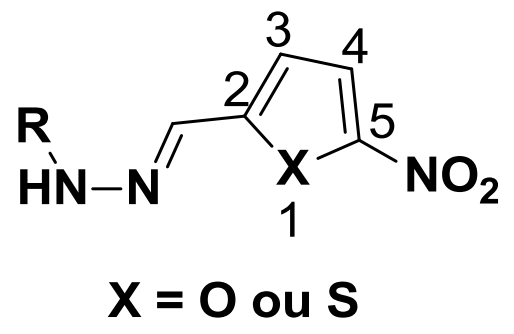

Figura 9. Provável grupo farmacofórico dos nitrocompostos.

Estudos de modificação molecular desta classe de compostos, desenvolvido no Laboratório de Planejamento e Desenvolvimento de Fármacos - LPDF da FCF/USP se mostraram promissores, resultando na identificação de análogos à nifuroxazida efetivos como agentes antimicrobianos contra $S$. aureus multirresistentes, $T$. cruzi e C. albicans (TAVARES, 1993; RODRIGUEZ, 2000; REZENDE, 2002; MASUNARI, 2005; SONEHARA, 2009; PAULA, SERRANO, TAVARES, 2009; PAULA et al., 2009; JORGE et al., 2009; JORGE et al., 2011; PALACE-BERL et al., 2013). Portanto, os nitrocompostos, em especial a nifuroxazida, demonstram facilidade para modificação estrutural e apresentam grande espectro de ação, podendo ser 
considerados como potenciais compostos protótipos para a síntese de análogos mais ativos, mais seletivos e menos tóxicos.

\section{PLANO DE TRABALHO}

O presente trabalho está dividido em quatro etapas, a saber:

a) Planejamento de duas séries de compostos, selecionando diferentes substituintes;

b) Síntese e identificação estrutural dos compostos;

c) Determinação da atividade antimicrobiana dos compostos obtidos;

d) Estudos de relações estrutura-atividade.

\subsection{Planejamento da série de compostos}

A partir das possibilidades atuais de modificação da nifuroxazida, figura $10 \mathrm{~A}$, foi planejada e sintetizada duas séries de compostos furfurilidênicos, uma com estrutura azometínica, série I e outra com estrutura oxadiazolínica, série II.

Na série I a modificação ocorre na hidroxila fenólica da nifuroxazida, figura 10B, substituindo-o por grupos com características físico-químicas diferentes; a partir disso planejou-se estudar as relações estrutura-atividade destes análogos frente à bactérias e fungos, com importância em infecções hospitalares com caráter de multirresistência.

Na série II, foi planejada a modificação molecular da estrutura azometínica com uma ciclização e adição de um grupo acetila, aumentando a lipofilicidade e impedimento estérico da molécula (figura 10C). O equilíbrio hidro-lipofílico é de grande importância para passagem através de membranas (PATRICK, 2009), sendo assim, esta modificação tem como finalidade verificar se a lipofilicidade causará melhora na atividade antimicrobiana avaliada in vitro. 


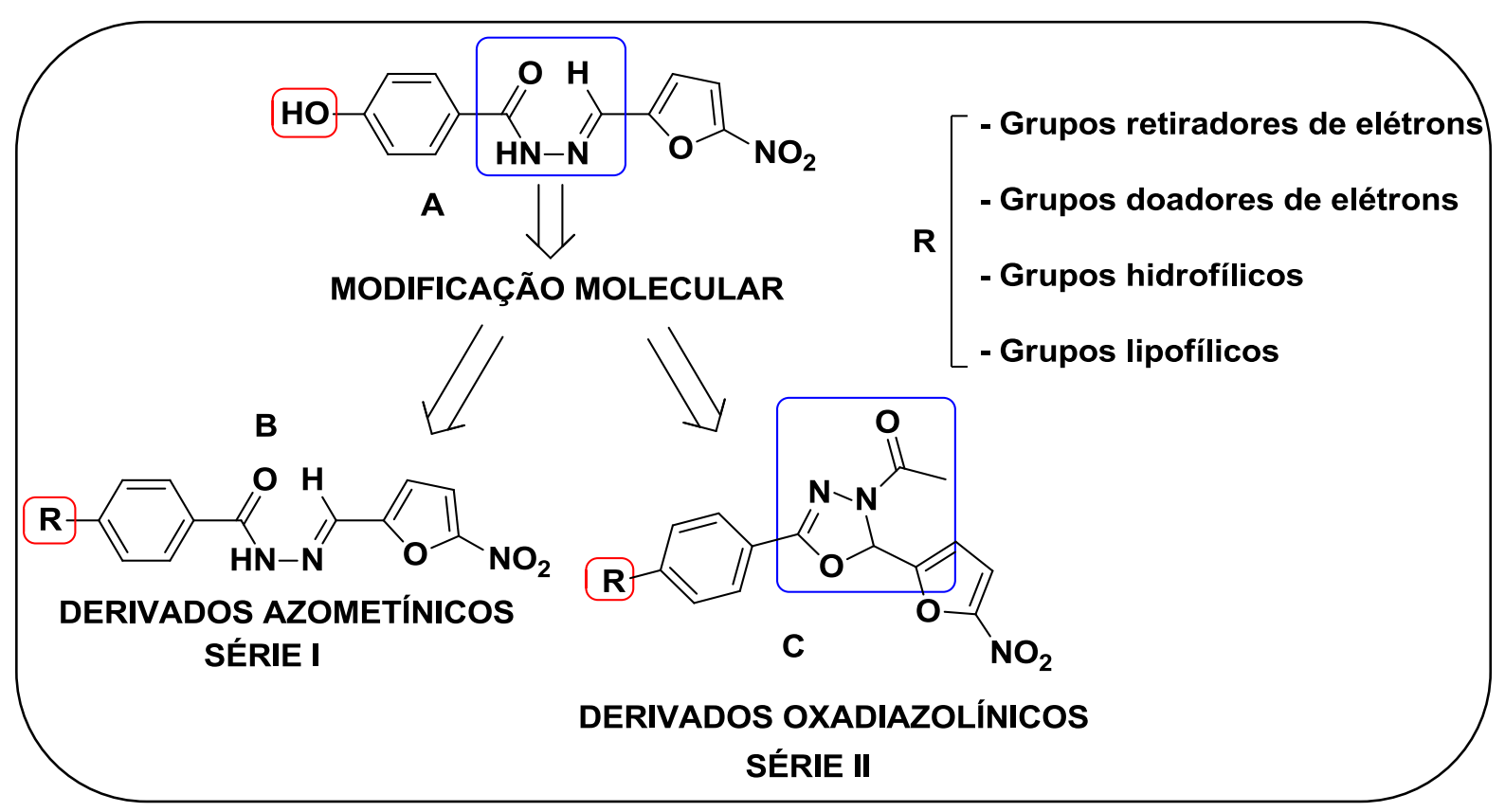

Figura 10. Nifuroxazida (A), série I azometínica (B) e série Il oxadiazolínica (C).

4.1.1. Planejamento da série de compostos - seleção dos grupos substituintes

O processo de desenvolvimento de novas moléculas baseado em uma estrutura líder, no caso a nifuroxazida, requer seleção criteriosa e ampla de grupos substituintes com maior afinidade e/ou seletividade para interação fármaco-receptor. Deste modo, a escolha de grupos substituintes baseada no Diagrama de Craig é etapa fundamental para o planejamento de novos análogos (CRAIG, 1971; HANSCH, FUJITA, 1964). Em seus estudos, Craig identificou a relação entre diversos descritores estruturais, destacando a correlação da hidrofobicidade expressa pelo parâmetro $\pi$ de Hansch e o efeito eletrônico descrito pelo parâmetro $\sigma$ de Hammett, que são independentes entre si (HAMMETT, 1937; HANSCH, FUJITA, 1964; CRAIG, 1970; TAVARES, 2004). Sendo assim, Craig construiu uma dispersão cartesiana, correlacionando tais propriedades, que foi utilizado, neste trabalho, para a escolha dos grupos substituintes do anel benzênico, Figura 11. 


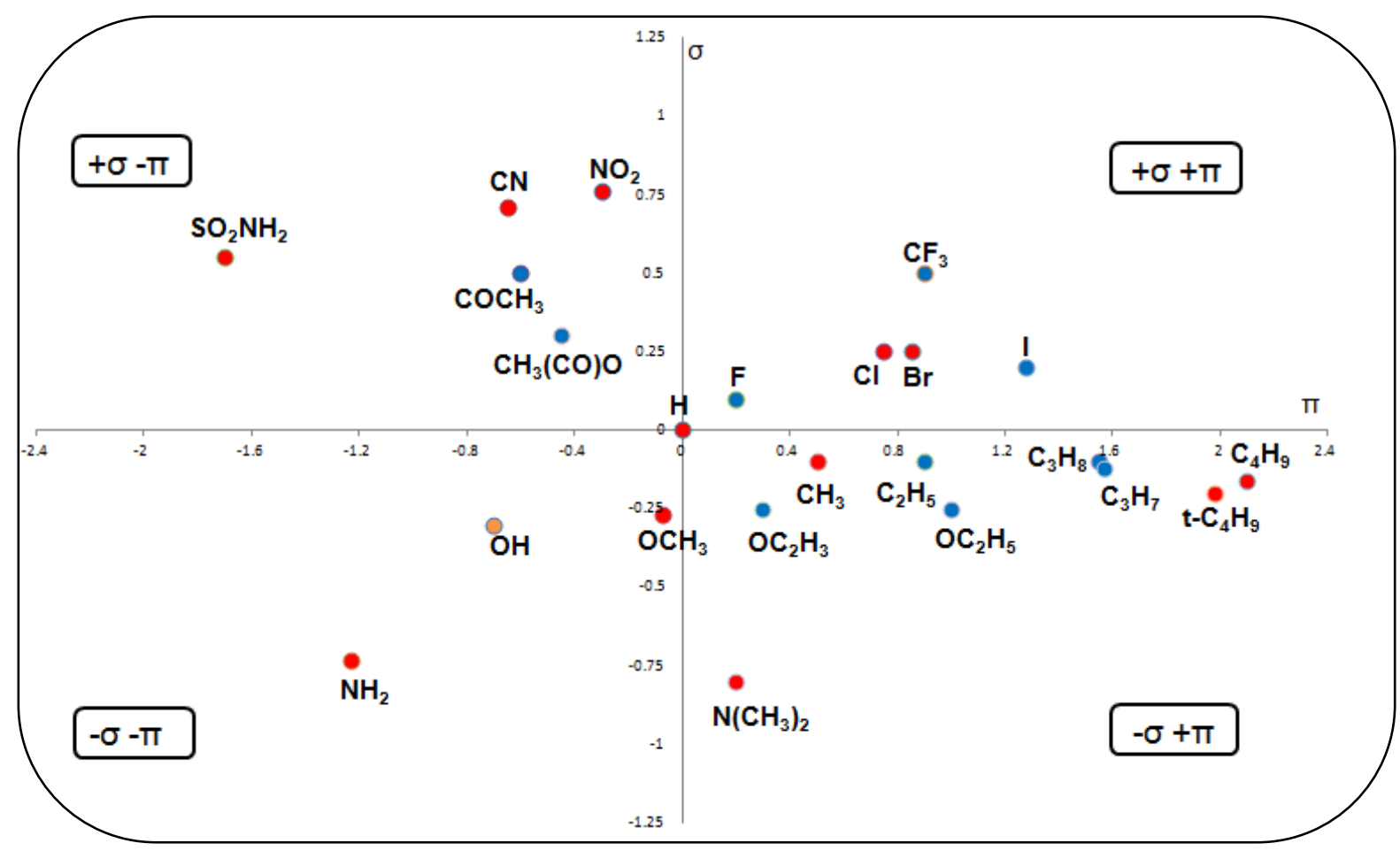

Figura 11. Diagrama de Craig. Em vermelho, grupos substituintes planejados para a série de compostos; em laranja, substituinte da nifuroxazida. Adaptado de CRAIG, 1971; HANSCH, LEO, HOEKMAN, 1995.

Durante a escolha dos grupos substituintes, deve-se levar em consideração a maior dispersão possível no diagrama, para assim, selecionar de forma coerente os valores, evitando resultados pouco relevantes e tendenciosos (TAVARES, 2004). Uma dispersão recomendada na literatura é a utilização dos substituintes $-\mathrm{NH}_{2}$, grupo doador de elétrons com características polares; - $\mathrm{H}$, considerado marco zero dos análogos; - $\mathrm{Br}$ e - $\mathrm{Cl}$, retiradores de elétrons com características lipofílicas; $-\mathrm{CH}_{3}$, doador de elétrons com característica lipofílica; $-\mathrm{NO}_{2}$, retirador de elétrons com característica hidrofílica, garantindo assim a dispersão por todos os quadrantes do diagrama (CRAIG, 1974; TAVARES, 2004). Além destes, foram também incluídos neste trabalho:

- Grupo butila $\left(-\mathrm{C}_{4} \mathrm{H}_{9}\right)$, substituinte doador de elétrons e com característica apolar;

- Grupo ciano (-CN), substituinte retirador de elétrons com característica hidrofílica; 
- Grupo metoxila $\left(-\mathrm{OCH}_{3}\right)$, substituinte doador de elétrons com características polares;

- Grupo terc-butila (-t- $\left.\mathrm{C}_{4} \mathrm{H}_{9}\right)$, substituinte doador de elétrons com característica apolar e alto impedimento estereoquímico;

- Grupo sulfonamida $\left(-\mathrm{SO}_{2} \mathrm{NH}_{2}\right)$, substituinte retirador de elétrons com características polares;

- Grupo dimetilamino $\left(-\mathrm{N}\left(\mathrm{CH}_{3}\right)_{2}\right)$, substituinte doador de elétrons com característica lipofílica;

- Grupo iodeto (-I), substituinte retirador de elétrons com característica lipofílica.

\section{MATERIAIS E MÉTODOS}

\subsection{Materiais}

\subsubsection{Reagentes e solventes}

- 5-nitro-2-furaldeído- Aldrich Chemical Company, Inc;

- Benzidrazidas substituídas disponíveis no laboratório de pesquisa;

- Anidrido acético - Aldrich Chemical Company, Inc;

- Álcool metílico - Labsynth Produtos Químicos para laboratórios;

- Ácido sulfúrico - Labsynth Produtos Químicos para laboratórios;

- Dimetilsufóxido- Labsynth Produtos Químicos para laboratórios;

- N,N-Dimetilformamida (DMF) - Labsynth Produtos Químicos para laboratórios;

- Pentóxido de fósforo - Vetec Produtos Químicos para laboratórios;

- vancomicina $C P^{\circledR}$, cloridrato de vancomicina - $A B L$ Antibiótico do Brasil, LTDA;

- nitrofurantoína - Sigma Chemical Co.;

- levofloxacino - Sigma Chemical Co.;

- cloranfenicol - Sigma Chemical Co.;

- ampicilina - Sigma Chemical Co.;

- sulfametoxazol - Sigma Chemical Co.;

- fluconazol - Sigma Chemical Co.; 
- itraconazol - Sigma Chemical Co.;

- cetoconazol - Sigma Chemical Co.;

- Dimetisulfóxido- $d_{6}$ - Cambridge isotope Laboratories, Inc.;

- Púrpura de bromocresol 0,01\% em solução a 1\% de manitol; pH 5,2 6,8 - Labsynth Produtos Químicos para Laboratório.

\subsubsection{Equipamentos}

- Aparelho de ponto de fusão MICRO-QUÍMICA modelo MQAPF - 301;

- Balança analítica Digital OHAUS;

- Espectrofotômetro de ressonância magnética nuclear BRUKER modelo Advanced DPX $300-300 \mathrm{MHz}$;

- Rota-evaporador FISATOM modelo 802;

- Bomba a vácuo QUIMIS Aparelhos Científicos Ltda;

- Cabine de segurança com fluxo laminar VECO;

- Pipeta multicanal GILSON;

- Microplaca;

- Micropipetas;

- Vórtex MAX MIX;

- Autoclave;

- Espectrofotômetro UV/VIS modelo T80+ PG Instruments LTD;

- Leitora de microplaca EZ Read 400 - Biochrom.

5.1.3. Micro-organismos e meios de cultura

- Staphylococcus aureus, cepa padrão ATCC 29213;

- Serratia marcescens, cepa padrão ATCC 14576;

- Escherichia coli, cepa padrão ATCC 25922;

- Candida albicans, cepa padrão ATCC 537Y;

- Enterococcus faecalis, cepa padrão ATCC 29212;

- Klebsiella pneumoniae, cepa padrão ATCC 700603;

- Enterobacter clocae, cepa padrão ATCC 23355;

- Staphylococcus aureus, cepa multiresistente VISA3; 
- Caldo nutritivo Mueller Hinton II BBL ${ }^{\mathrm{TM}}$ Becton, Dickinson and Company, com composição ( $\mathrm{g} / \mathrm{L})$ : Caseína enzimática hidrolisada, 17,5; extrato de carne, 3,0; amido, 1,5;

- Caldo nutritivo RPMI-1640, Sigma-Aldrich Co., com L-glutamina, sem bicarbonato de sódio;

- Agar Difco ${ }^{\mathrm{TM}}$ Saboraud-Dextrose, Becton, Dickinson and Company, com composição ( $\mathrm{g} / \mathrm{L}$ ): Enzima digestive casein, 10,0; Dextrose, 40,0; Agar, 15,0;

- Meio PCA (Plate Count Agar) FLUKA AND RIEDEL-DE HAEN COMPANY., com composição (g/L): Peptona de caseína, 5,0; Extrato de levedura, 2,50; Dextrose, 1,00;

- Solução fisiológica $0,9 \%(\mathrm{~m} / \mathrm{v})$ de $\mathrm{NaCl}$.

5.1.4. Software utilizados

- OriginPro 8, versão 8.0724 SR0 - OriginLab Corporation: One Roundhouse Plaza, Northampton, MA, USA, 1997-2007 - licença institucional;

- GAUSSVIEW, Gaussian Inc.: Pittsburgh, PA, USA, 2000-2003 - licença institucional;

- GAUSSIAN 03W-revisão B.02 para Windows, versão 6.0; Gaussian Inc.: Pittsburgh, PA, EUA, 1995-2003 - licença institucional;

- Sybyl para Linux, versão 8.0; Tripos, Inc.: South Hanley Rd., St. Louis, MO 63144-2917, EUA, 2007 - licença institucional;

- Marvin Beans, versão 5.0.4.1; ChemAxon Ldt.: Budapeste, Hungria 1998-2010.

- Pirouette, versão 3.11; Infometrix Inc.: Woodinville, WA, USA, 19902003.

- Mestre-C, versão 5.0; MestreLab Research, Trial, Inc.: Santiago de Compostela, Espanha, 2006. 


\subsection{Métodos}

\subsubsection{Obtenção dos compostos planejados}

A rota de síntese, figura 12, é constituída de três etapas, a saber: amonólise a partir de ácidos benzóicos (representado como rota otimizada na figura 11); reação de condensação utilizando as benzidrazidas previamente sintetizadas para obtenção de (5-nitrofuran-2-il)metileno)benzidrazida / bases de Schiff substituídas (Série I) e ciclização oxidativa dos compostos azometínicos, série I, gerando os compostos oxadiazolínicos (Série II). Todas estas etapas seguem metodologias provenientes de trabalhos anteriores desenvolvidos em nosso grupo de pesquisa, em especial os compostos de série I (TAVARES, 1993; TAVARES, PENNA, AMARAL, 1997; ROLLAS, GULERMAN, ERDENIZ, 2002; MASUNARI, 2005; VIANA, 2009; LI, MA, CAO, 2009; OLIVEIRA, 2011; JORGE et al., 2011; PALACE-BERL et al., 2013).

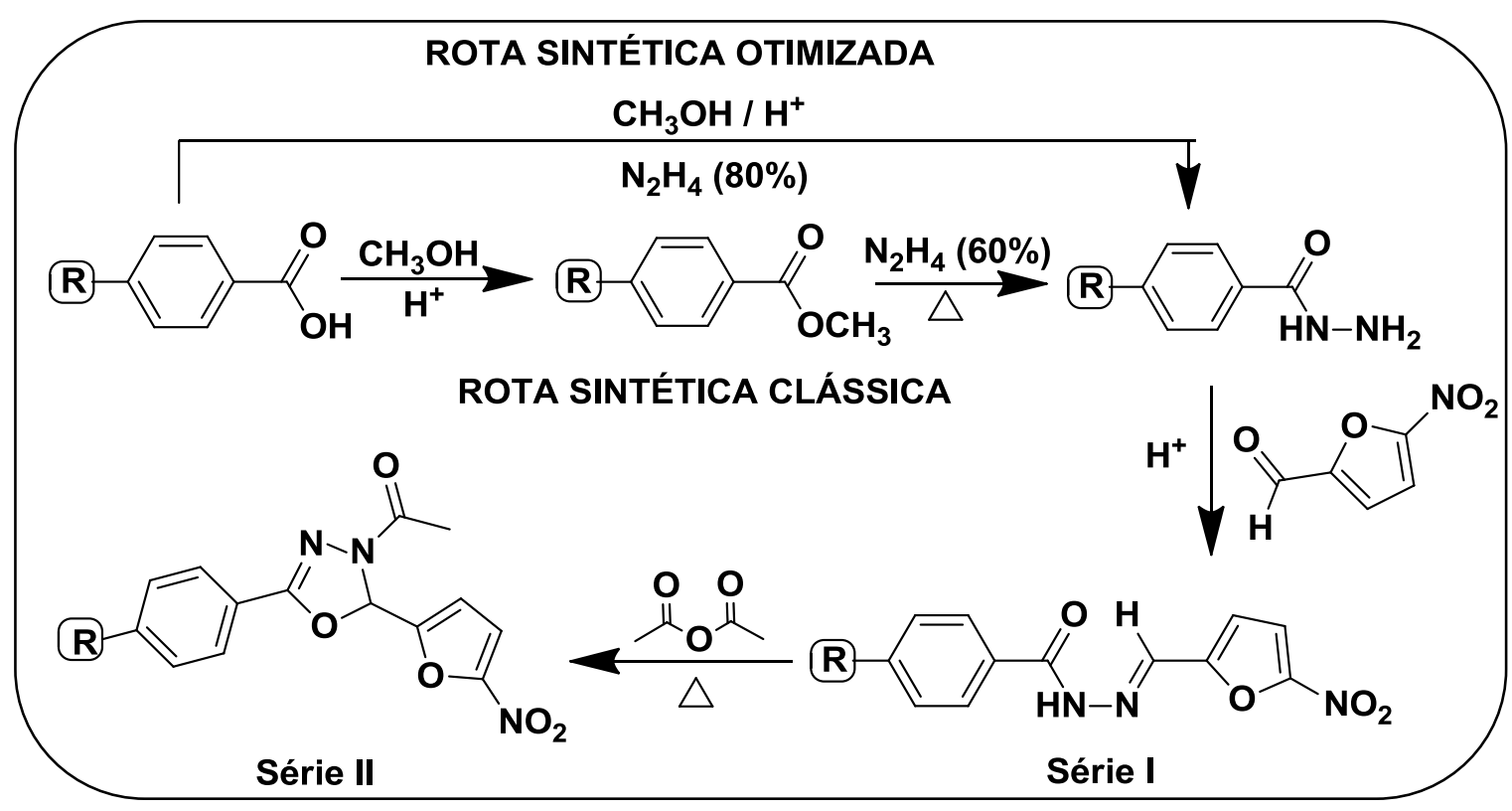

Figura 12. Rota sintéticas para obtenção da série I e série II.

Vale salientar que neste trabalho todas as benzidrazidas utilizadas estavam disponíveis no LPDF, não havendo necessidade de sintetizá-las novamente, portanto sua metodologia sintética não será considerada no decorrer deste trabalho, mas somente referenciada (ZORZI, 2011; JORGE et al., 2011; PALACE-BERL et al., 2013). 


\subsubsection{Formação de bases de Schiff - Série I}

Para obtenção das (5-nitrofuran-2-il)metileno)benzidrazidas (IV) substituídas, bases de Schiff, foi feita reação de condensação figura 13, partindo-se de $7,0 \mathrm{mmol}$ de benzidrazida (II), e 5,0 mmol de 5-nitro-2-furaldeído (III), em meio reacional composto por água, ácido sulfúrico, ácido acético glacial, metanol na proporção 8:7:8:20 (v/v) e em sistema de refluxo por 1 hora (MORRISON, BOYD, 1981; TAVARES, 1993, CAREY, 2008). Os compostos foram recristalizados em acetonitrila, lavados com água gelada e secos em presença de pentóxido de fósforo.

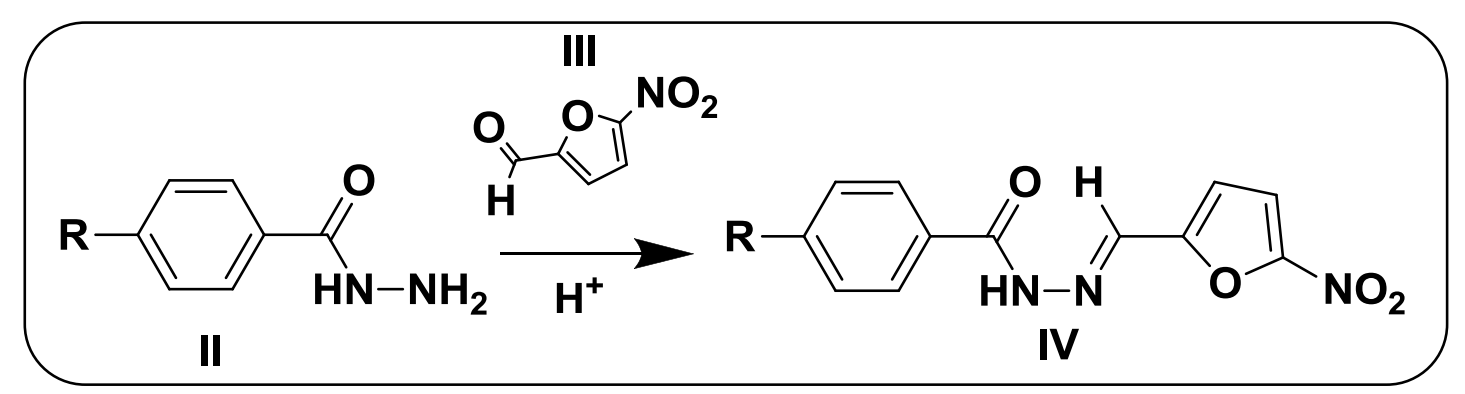

Figura 13. Formação de bases de Schiff, série I, a partir de benzidrazidas substituídas.

\subsubsection{Ciclização oxidativa - série II}

$\mathrm{Na}$ última etapa sintética, figura 14 , procedeu-se à ciclização oxidativa de 1,5 mmol de base de Schiff (IV), Figura 10, em presença de 100,0 mmols de anidrido acético, formando os derivados 3-acetil-2-[5-nitro-furan-2-il]-5-fenil-2,3-diidro-1,3,4oxadiazolínicos (V), série II (SHERMAN, 1960; HEARN, CHANYAPUTHIPONG, 1995; ROLLAS, GULERMAN, ERDENIZ, 2002; RAJAK, KHARYA, MISHRA, 2007; VIANA, 2009; LI, MA, CAO, 2009; OLIVEIRA, 2011; BAQUERO et al., 2011; PALACE-BERL et al., 2013). Esta reação ocorre em atmosfera inerte de nitrogênio, em temperatura de $110 \stackrel{\circ}{\circ}$ a $120 \stackrel{\circ}{\circ}$ por 12 horas.

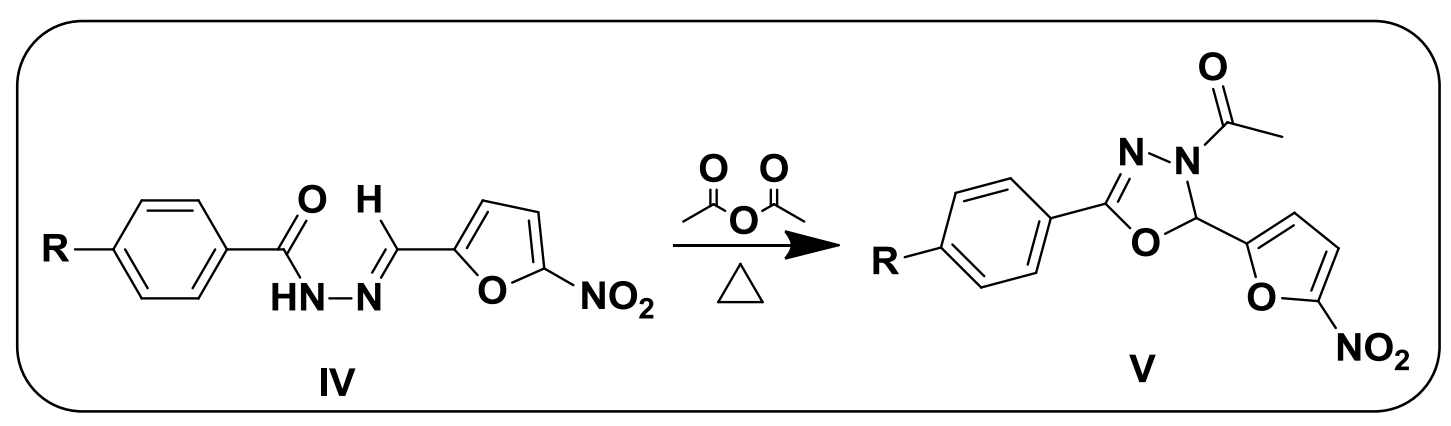

Figura 14. Formação de oxadiazolínas, série II, a partir de bases de Schiff. 
Ocorrido o tempo de reação, interrompeu-se o refluxo e adicionou-se água em quantidades equimolares ao conteúdo de anidrido acético em temperatura ambiente, causando a hidrólise do anidrido remanescente e precipitação subsequente dos compostos formados (LI, MAO, CAO, 2009). Por fim, foram recristalizados em acetona, lavados com água gelada e secos em presença de pentóxido de fósforo.

\subsubsection{Análises espectrométricas}

Para confirmação estrutural dos compostos de interesse foi utilizada espectrometria de ressonância magnética nuclear de hidrogênio $\left(R M N{ }^{1} H\right)$ e de carbono $\left(\mathrm{RMN}{ }^{13} \mathrm{C}\right)$, sendo estas realizadas pelo Laboratório de Análise Instrumental da Faculdade de Ciências Farmacêuticas da USP, utilizando como solvente dimetilsulfóxido deuterado $\left(\mathrm{DMSO}-d_{6}\right)$ e como padrão interno o tetrametilsilano (TMS).

A identificação preliminar e pureza dos compostos intermediários e de interesse foram feitas a partir da análise de faixa de fusão, e posteriormente, para confirmação dos resultados, foi feita análise elementar de $\mathrm{CHN}$, realizada na Central Analítica-IQ/USP.

\subsubsection{Determinação da atividade antimicrobiana}

Todo material utilizado neste ensaio foi previamente esterilizado em autoclave a $121 \stackrel{\circ}{\mathrm{C}}$ por 30 minutos. A avaliação de atividade antimicrobiana foi realizada frente às cepas ATCC 29213 de Staphylococcus aureus; ATCC 14576 de Serratia marcensis; ATCC 25922 de Escherichia coli, ATCC 29212 de Enterococcus faecalis, ATCC 23355 de Enterobacter clocae, ATCC 700603 de Kblesiella pneumoniae e ATCC537Y de Candida albicans. Para as bactérias, o caldo nutritivo utilizado foi o Mueller Hinton (MH) com ajuste catiônico de magnésio e cálcio (CLSI, 2003). Já nos testes frente ao fungo o caldo utilizado foi RPMI-1640 tamponado com MOPS. Para ajuste do caldo em pH 7,0 utilizou-se hidróxido de sódio 1M (CLSI, 2002; SONEHARA, 2009). Ambos os caldos são preconizados pela CLSI e são amplamente utilizados na literatura para crescimento de diversos tipos de microorganismos (KOETH et. al, 2000; PFALLER et al., 2000), especialmente o caldo MH, 
utilizado para bactérias aeróbias e anaeróbias facultativas não fastidiosas, como as deste estudo (CLSI, 2003). Por fim, os meios de cultura ágar PCA e Sabouraud Dextrose foram utilizados respectivamente para cultivo das cepas bacterianas e fúngica em tubo de ensaio inclinado (incubado a $35^{\circ} \mathrm{C}$ por 24 horas para bactérias e 48 horas fungos).

Os ensaios foram feitos por determinação de concentração inibitória mínima (CIM) em microplaca e foram divididos em três etapas: i) Método clássico de microdiluição seriada em caldo, onde se preconiza encontrar a menor concentração de fármaco capaz de causar inibição de crescimento, chamada de Fase I (CLSI, 2003). As concentrações inibitórias nesta etapa foram determinadas de duas formas diferentes, uma por leitura visual, com intuito de verificar o poço que não apresenta crescimento bacteriano visível quando comparado com um controle positivo (CLSI, 2002; CLSI, 2003); e uma segunda leitura realizada em espectrofotômetro, que foi considerado como CIM a faixa que inibe $90 \%$ ou mais da população de microorganismo contida no poço (ARTHINGTON-SKAGGS et al., 2002; DIEDEREN et al., 2006). ii) A partir dos resultados de fase I foi definido o endpoint biológico por regressões estatísticas para determinar a inibição de crescimento $90 \%$ (IC $\left.\mathrm{C}_{90}\right)$, que consiste na concentração necessária para inibir $90 \%$ da população bacteriana quando comparado com o controle positivo. iii) Chamada de Fase II, esta etapa foi feita para validação dos resultados obtidos no $\mathrm{IC}_{90}$, verificando assim se os valores teóricos estão de acordo com os experimentais. A fase II consiste em uma adaptação do CIM clássico, criado por Tavares e colaboradores e adaptada para microescala por Jorge e colaboradores, com a intenção de estreitar esta faixa de inibição da Fase I e aumentar a sensibilidade do ensaio (TAVARES, 1993; TAVARES, PENNA, AMARAL, 1997; TAVARES et al., 1999; JORGE et al., 2009).

\subsubsection{Diluição dos compostos e fármacos de referência}

Os compostos sintetizados, composto protótipo (nifuroxazida) e fármacos de referência (vancomicina, nitrofurantoína, cloranfenicol, ampicilina, sulfametoxazol, levofloxacino) foram testados a partir da concentração de 128,0 $\mu \mathrm{M}$ para $S$. aureus, E. coli e S. marcesens, K. pneumoniae, E. faecalis e E. clocae. Para C. albicans os compostos e seus devidos fármacos de referência (itraconazol, fluconazol e 
cetoconazol) foram testados a partir de $64,0 \mu \mathrm{M}$, devido à baixa solubilidade no caldo nutritivo. Na figura 15 é ilustrado o preparo destas soluções para bactérias. Partiu-se de 64.000,0 $\mu \mathrm{M}$ de cada composto diluído em $10 \mathrm{~mL}$ de DMSO, utilizado como solvente para facilitar a diluição dos compostos, gerando solução com 6.400,0 $\mu \mathrm{M}$. A partir desta solução foi transferido $1,0 \mathrm{~mL}$ para frasco contendo $4,0 \mathrm{~mL}$ de DMSO originando solução com 1280,0 $\mu \mathrm{M}$. Em seguida, foi transferido $1 \mathrm{~mL}$ desta última em um frasco com $4 \mathrm{~mL}$ de meio $\mathrm{MH}$ de forma a obter uma solução com 256,0 $\mu \mathrm{M}$. Por fim, 1,0 mL de cada solução foram transferidas para um reservatório com divisórias. Foram utilizadas 11 divisórias no total, nove para os compostos, uma para fármaco de referência e uma última para controle de solvente DMSO.

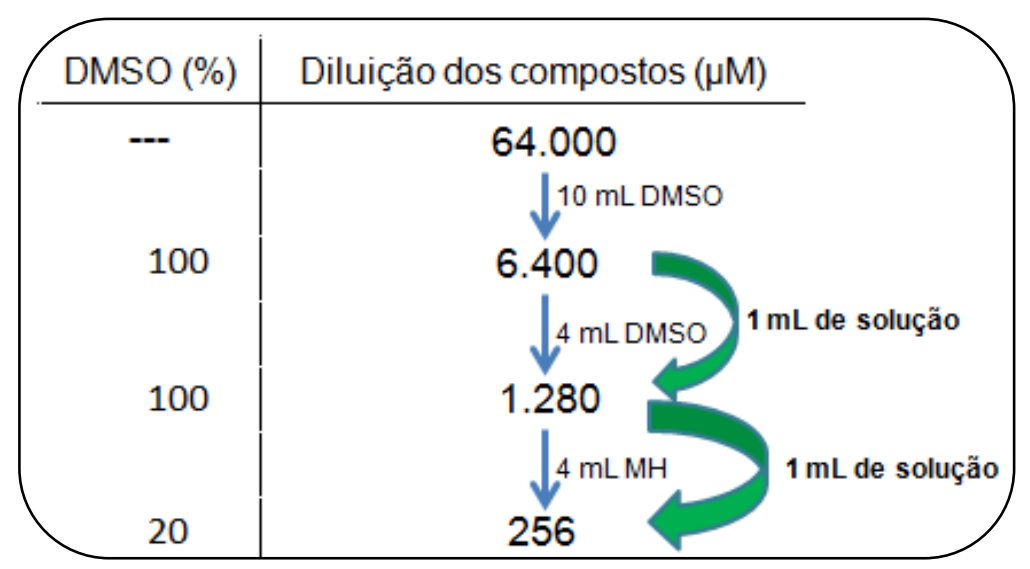

Figura 15. Esquema de diluição dos compostos utilizados no ensaio de atividade antimicrobiana.

Neste estudo foi utilizado inicialmente o controle de solvente (CS) à $20 \% \mathrm{v} / \mathrm{v}$. Vale salientar que a concentração inicial de DMSO dos compostos diluídos não ultrapassou valor superior a $10 \%$ ou $5 \% \mathrm{v} / \mathrm{v}$ no momento do ensaio. Tais concentrações foram estabelecidas a partir da literatura, onde se verificou que valores similares ou abaixo de $12 \%, 15 \%$ e $5 \%$ não interferem no crescimento de $S$. aureus (cepa padrão e multiresistente) e E. faecalis, E. coli e C. albicans, respectivamente (ANSEL, NORRED, ROTH, 1969; TAVARES, PENNA, AMARAL, 1997; SONEHARA, 2009). No caso da S. marcescens, K. pneumoniae e E. clocae a concentração de solvente utilizada foi de $5 \%$, valor abaixo do limite de tolerância observado nos testes de susceptibilidade da bactéria frente ao solvente. 


\subsubsection{Preparo das cepas}

Primeiramente, vale salientar que todas as cepas utilizadas neste estudo não ultrapassaram cinco repiques em relação à cepa original, preconizados na literatura (MOSER, MEYER, 2011). As cepas bacterianas foram cultivadas em tubo de ensaio inclinado contendo ágar $\mathrm{MH}$ e incubadas a $35{ }^{\circ} \mathrm{C}$ por 24 horas, similar ao descrito em metodologia internacional (CLSI, 2003). Após repique, transferiu-se parte do material contido nos tubos de ensaio para solução fisiológica 0,9\% e ajustou-se em espectrofotômetro UV/VIS, com comprimento de onda de $625 \mathrm{~nm}$, para concentração que contenha absorbância de 0,08 - 0,1, similar a concentração encontrada na solução de 0,5 da escala McFarland e equivalente a uma suspensão bacteriana de 1 a $2 \times 10^{8} \mathrm{UFC} / \mathrm{mL}$. Em seguida, transferiu-se $1 \mathrm{~mL}$ deste inóculo para um frasco contendo $99 \mathrm{~mL}$ de solução fisiológica, pérolas de vidro e barra magnética, que foram agitados brandamente por 15 minutos, o que gerou suspensão bacteriana de $10^{-2} \mathrm{UFC} / \mathrm{mL}$ em relação à original. Decorrido este período, transferiu-se 1,0 mL desta solução fisiológica para frasco contendo $99,0 \mathrm{~mL}$ de caldo nutritivo $\mathrm{MH}$ e agitou-se por mais 15 minutos, o que gerou suspensão de 1,0 x 10-4 $\mathrm{UFC} / \mathrm{mL}$ em relação à original, que foi utilizada no ensaio.

Para preparo das cepas de $C$. albicans, o procedimento foi similar ao citado para bactérias (SONEHARA, 2009). Cultivadas em ágar Saboraud-Dextrose por 48 horas, transferiu-se parte do material para solução fisiológica 0,9\% e ajustou-se em espectrofotômetro UV/VIS para concentração que contenha absorbância de 0,08 0,1 (0,5 McFarland), que apresenta suspensão fúngica de $10^{6} \mathrm{UFC} / \mathrm{mL}$ (CLSI, 2002). $\mathrm{O}$ comprimento de onda utilizado nesta etapa foi de $630 \mathrm{~nm}$. Após, foi realizada uma diluição 1:50 em solução fisiológica $0,9 \%$, seguida por agitação branda. Por fim, a suspensão de leveduras sofreu uma diluição 1:20 em caldo nutritivo RPMI-1640, esta com concentração de $10^{3} \mathrm{UFC} / \mathrm{mL}$ e utilizada no ensaio.

O preparo da cepa multirresistente de S.aureus VISA3 foi similar ao preparo das cepas ATCC. A cepa estocada e congelada em glicerol foi diluída em caldo $\mathrm{MH}$ na proporção 1:200 (v/v) e incubadas a $35{ }^{\circ} \mathrm{C}$ por 24 horas (CLSI, 2003). Após o repique, o material incumbado foi transferido para solução fisiológica $0,9 \%$ e ajustado em espectrofotômetro UV/VIS $(\lambda=625 \mathrm{~nm})$ para concentração que 
apresente absorbância de 0,08 - 0,1 (similar à 0,5 McFarland). Após ajuste da concentração, o procedimento é similar as cepas ATCC, com posterior transferência de $1 \mathrm{~mL}$ para $99 \mathrm{~mL}$ de solução fisiológica e outra para $99 \mathrm{~mL}$ de caldo nutritivo $\mathrm{MH}$, na qual foi utilizada para o ensaio.

\subsubsection{Ensaio de Concentração Inibitória Mínima (CIM) de fase I}

Após preparo das soluções iniciais de $256 \mu \mathrm{M}$, foram adicionados $100 \mu \mathrm{L}$ das soluções dos compostos, fármaco de referência e controle de solvente nas cavidades das colunas 1 , 2 e 11, figura $16(\underline{\boldsymbol{A}})$, distribuindo em seguida $100 \mu \mathrm{L}$ de determinado caldo nutritivo nas colunas 2 até $12(\underline{B})$. Após este procedimento, foram retirados $100 \mu \mathrm{L}$ da coluna 2 e esta solução foi transferida para coluna 3 , realizando uma diluição de 1:2. Este procedimento foi feito até a coluna 10, onde os $100 \mu \mathrm{L}$ residuais foram descartados $(\underline{\boldsymbol{C}})$. Por fim, foi adicionando $100 \mu \mathrm{L}$ de inóculo em todas as colunas, com exceção da coluna 11, considerado o controle negativo interno do teste. A coluna 12 foi considerada controle positivo $(\underline{\mathcal{C}})$. Ao final do ensaio de fase I o intervalo utilizado foi de 128,0 $\mu \mathrm{M}-2,0 \mu \mathrm{M}$. Após este procedimento, a placa foi vedada e incubada a $35 \stackrel{\circ}{\circ}$. Vale salientar que o ensaio foi feito, no mínimo, em triplicata. Ademais, foi preparada uma placa com os compostos diluídos da mesma maneira que a triplicata, porém sem adição do inóculo. Esta placa foi considerada como branco do ensaio.

Como já citado, a leitura visual foi feita considerando o poço que não apresentou crescimento em comparação com o controle positivo. Para bactérias (cepas padrão), a leitura deve ser realizada com 18 e 24 horas, porém o momento mais indicado é o de 18 horas sendo a análise de 24 horas somente para observar o controle negativo. Para cepas de C. albicans é preconizado realizar a leitura em 48 horas (CLSI, 2002). Para a cepa VISA3 o indicado é a leitura em 24 horas (CLSI, 2003), porém para efeitos comparativos com a cepa padrão, a leitura foi realizada também em 18 horas. Vale a salientar que somente os compostos mais promissores frente a cepa padrão de $S$. aureus foram testados na cepa multirresistente VISA3. Esta abordagem foi escolhida para diminuir o tempo de manuseio da cepa como também para avaliar se existe alguma resistência a estes compostos mais promissores. 


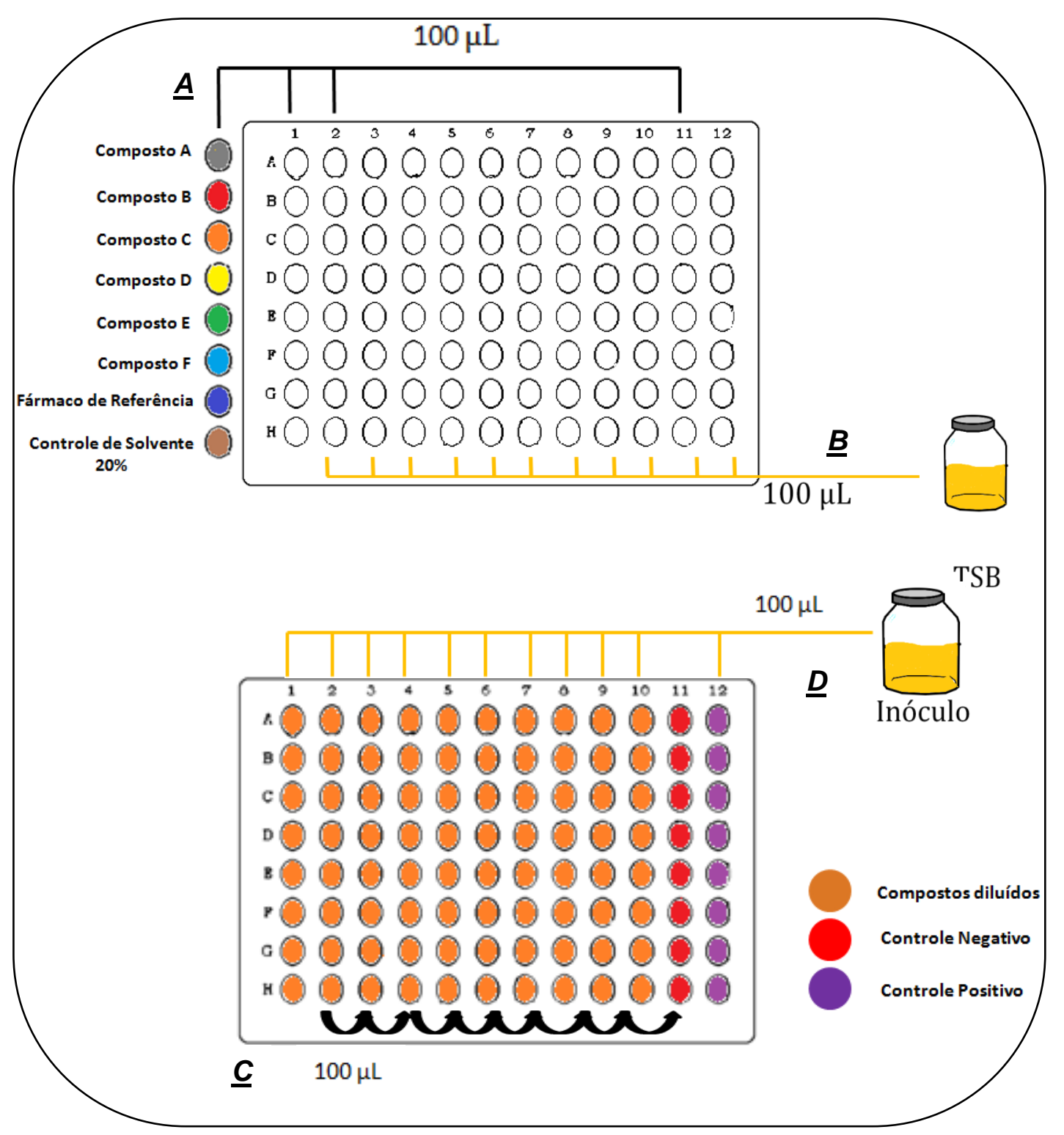

Figura 16. Ilustração da microplaca utilizada para os ensaios de atividade antimicrobiana.

A leitura espectrofotométrica foi feita nos mesmos horários das leituras visuais, porém realizadas em leitora de microplacas. Foi utilizado um comprimento de onda de $625 \mathrm{~nm}$ para as cepas bacterianas e $630 \mathrm{~nm}$ para C.albicans. Os CIMs deste tipo de leitura foram calculados a partir da diferença entre absorbância nos poços com compostos e a absorbância do controle positivo, utilizando a equação 5 . A microplaca utilizada como branco foi também analisada para eliminar as possíveis interferências causadas por precipitações dos compostos. 


$$
\% I C=\left[\frac{(A c-A b)}{A c}\right] \times 100
$$

Equação 5

Em que:

$\% I C$ = porcentagem de inibição de crescimento;

$\boldsymbol{A C}=$ Absorbância do controle positivo;

$\boldsymbol{A} \boldsymbol{b}=$ Absorbância de um determinado poço contendo composto.

Depois de obtidas as \%IC, foram realizados tratamentos estatísticos no programa OriginPro 8 , para obtenção do endpoint biológico de interesse (IC $\left.\mathrm{C}_{90}\right)$, coeficiente de determinação, $r^{2}$, e os desvios padrões dos resultados.

\subsubsection{Ensaio de Concentração Inibitória Mínima (CIM) de fase II}

Para o plaqueamento da fase II e consequente confirmação do valor de $\mathrm{IC}_{90}$, foi utilizada metodologia descrita por Jorge e colaboradores (2009), que é similar ao procedimento operacional dos ensaios de Fase I. Suas principais diferenças são que as soluções dos compostos são preparadas a partir dos resultados obtidos na Fase I, com ajuste tanto na pesagem quanto na diluição. A concentração inicial na microplaca deve ficar próxima ao valor máximo de inibição encontrado na fase I e a concentração final deve ficar próxima a primeira concentração onde foi observado turvação devido o crescimento microbiano. Para facilitar entendimento, figura 17, um composto fictício que apresentou faixa de inibição entre 32,0 $\mu \mathrm{M}-16,0 \mu \mathrm{M}$ em um determinado micro-organismo na Fase I deve ser preparada, inicialmente, pesando $64.000,0 \mu \mathrm{M}$ e com diluições posteriores deve obter-se solução que apresente o dobro da concentração obtida na Fase I, no caso 64,0 $\mu \mathrm{M}$. Por fim, 1,0 mL de cada solução são armazenadas em reservatórios com divisórias. 


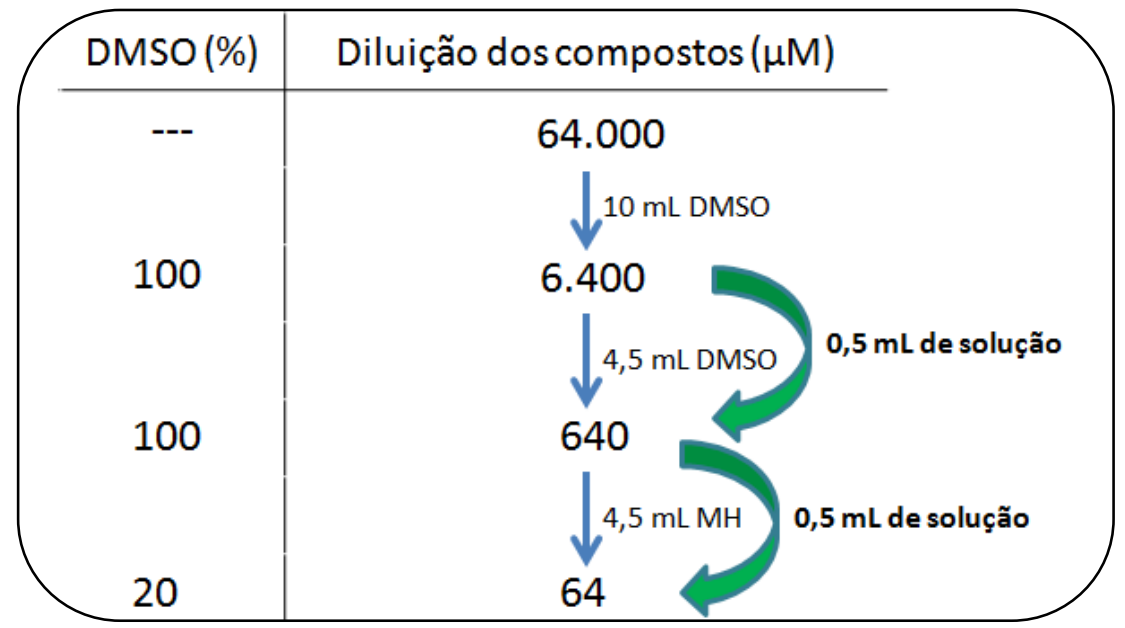

Figura 17. Ilustração de preparo de soluções na fase II para um composto fictício. $64,0 \mu \mathrm{M}$ é o dobro da concentração inibitória mínima inicial.

Após armazenamento (figura 18), 100,0 $\mu \mathrm{L}$ das soluções de compostos, fármaco de referência e controle de solvente são adicionados na coluna 1 (E). Em seguida, são adicionados $100 \mu \mathrm{L}$ de meio $\mathrm{MH}$ a este reservatório $(\underline{\boldsymbol{F}})$ que gera solução com concentração 10\% inferior a solução inicial. A mesma é adicionada na coluna $2(\underline{G})$. Isso é repetido em todos os micropoços até o poço 11 . Por fim, são adicionados $100 \mu \mathrm{L}$ de inóculo em todos os poços, com exceção no número 11 , considerado controle negativo. O poço 12 será considerado como controle positivo do teste. A microplaca utilizada nos ensaio é acondicionada a $35^{\circ} \mathrm{C}$ por 18 horas para bactérias ou 48 horas para $C$. albicans. Vale salientar que todos os ensaios de fase II foram lidos por meio de espectrofotômetro e que, novamente, o ensaio foi feito em triplicata e com a preparação de um branco. 


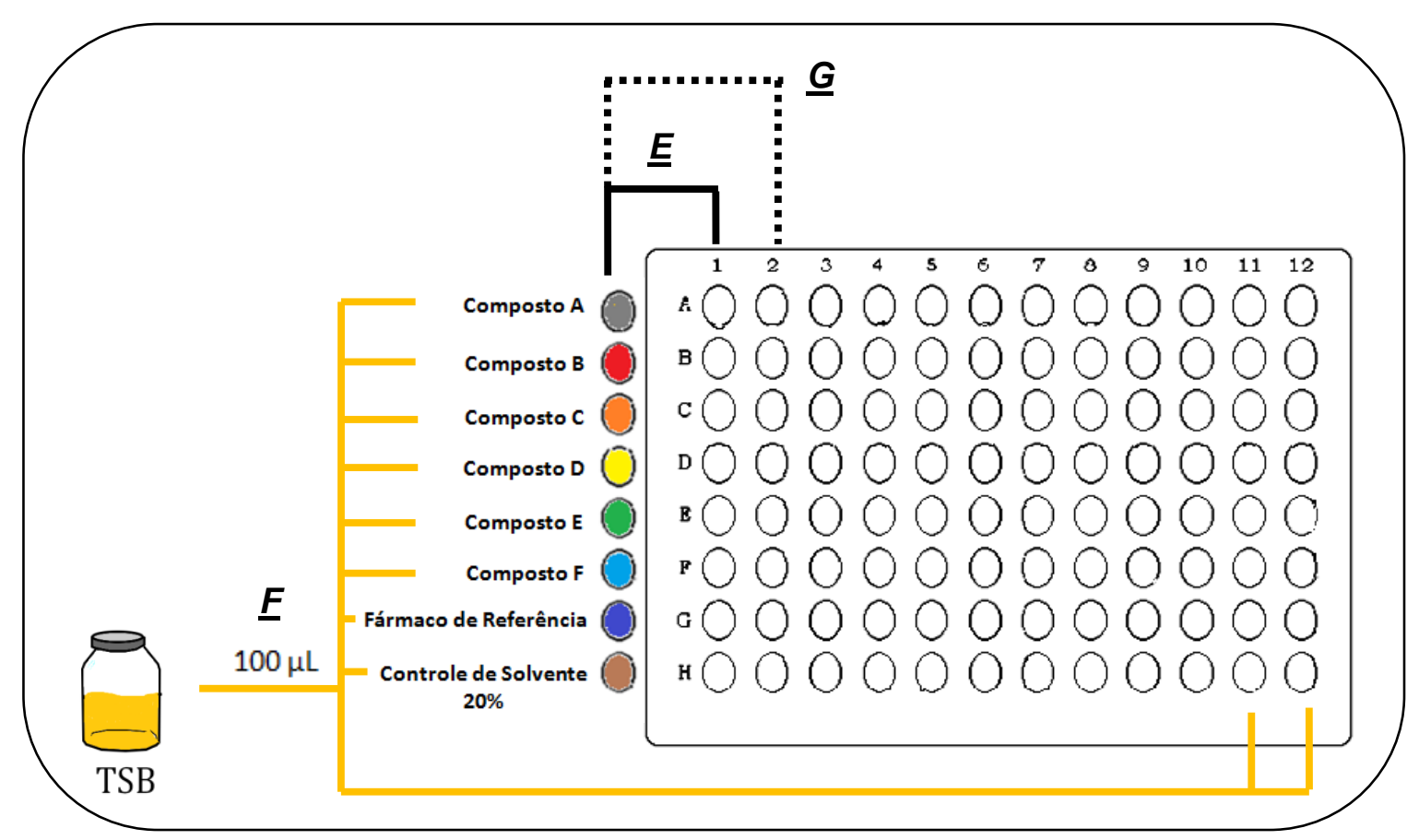

Figura 18. Ilustração da microplaca utilizada para os ensaios na Fase II.

\subsubsection{Contagem do número de unidades formadores de colônia (UFC)}

Para validação do teste quantificou-se a concentração microbiana utilizada durante o ensaio. Para isso, foram esterilizados cinco tubos de ensaios com 9,0 mL de solução fisiológica. No primeiro tubo foi transferido $1,0 \mathrm{~mL}$ da suspensão de inóculo utilizada, transferindo sucessivamente entre todos os tubos de ensaio. Transferiu-se 1,0 $\mathrm{mL}$ de cada tubo de ensaio para placas de Petri. Nestas placas foi vertido meio PCA, homogeneizado e incubado a $35^{\circ} \mathrm{C}$ durante 24 horas. Foram considerados ensaios válidos os que apresentaram uma média de crescimento próxima a $10^{4} \mathrm{UFC} / \mathrm{mL}$. Salienta-se que só foi realizada as leituras nas placas contendo no máximo 250 colônias e no mínimo 25 colônias (TORTORA, 2003). Para fungos, a quantificação foi realizado somente pelo ajuste na escala Mcfarland.

5.2.4. Métodos de modelagem molecular e quimiométricos para estudos de relações estrutura-atividade

A relação entre atividade biológica e propriedades físico-químicas dos compostos testados nos micro-organismos foi realizada em etapas distintas, sendo elas: construção dos modelos moleculares tridimensionais, cálculo dos descritores físico-químicos e por fim análise exploratória dos dados. Nesta etapa computacional 
foi utilizado um computador sistema operacional Windows $7^{\circledR}$ com configuração Intel ${ }^{\circledR}$ Core i7-2600 3,40 GHz, RAM DDR3 8,00 GB, NVIDIA ${ }^{\circledR}$ GeForce $^{\circledR}$ GTX 580 2GB.

5.2.4.1. Construção e otimização de modelos moleculares tridimensionais (3D)

Os modelos moleculares do composto protótipo e do 3-acetil-2-[5-nitro-furan-2il]-5-[4-tercbutil-fenil]-2,3-diidro-1,3,4-oxadiazolínico já estavam descritos na literatura (PALACE-BERL et al., 2013). A autora gentilmente cedeu tais dados para este estudo, portanto não foi realizada a minimização de energia destes modelos nesta etapa inicial.

Estas duas moléculas foram utilizadas como modelo para construção dos demais análogos da Série I e II, realizados no programa Hyperchem 8.0. Nesta etapa foi utilizado campo de força MM+ para otimização da geometria, realizada pelo método de Polak-Ribiere de gradiente conjugado, com critério de convergência de 0,1 kcal/(Å mol) ou 180 ciclos máximos (POLAK, RIBIERE, 1969; ALLINGER, 1977). Além disso, foi utilizado método de mecânica quântica semi-empíricos Hamiltoniano AM1 (AustinModel) para cálculos das cargas atômicas parciais de ponto único destas moléculas (DEWAR et al., 1985).

\subsubsection{Cálculos das propriedades moleculares}

Os descritores eletrônicos foram calculados no programa Gaussian 03W. Foram calculados neste programa o momento de dipolo total, as energias dos orbitais moleculares de fronteira ( $E_{\text {Homo }}$ e $E_{\text {Lumo }}$ ) e as cargas atômicas ajustadas pelo potencial eletrostático (CHELPG, Charges from Electrostatis Potentials using a Grid based method) (BRENEMAN, WIBERG, 1990) foram calculados pelo método ab initio Hartree-Fock com conjunto de base de dados 3-21G* (MORGON, COUTINHO, 2007). A representação dos mapas de potencial eletrostático e os cálculos dos vetores de momento de dipolo também foram realizados a partir desta metodologia.

Os dados referentes aos coeficiente de partição das moléculas foram obtidos no programa Sybyl 8.0. Foram calculados os coeficientes de partição em superfície 
molecular de Connolly, obtida com sonda de raio 1,4 $\AA$ utilizando métodos de Clog $_{\text {sg-sin }}$ (GHOSE, VISWANADHAN, WENDOLOSKY, 1998) e Clog $\mathrm{P}_{\mathrm{sv}}$ (VISWANADHAN et al., 1989). Ademais, nesta etapa também foram calculados os mapas de potencial lipofílico (MPL) dos compostos estudados.

O programa Marvin Beans foi utilizado para cálculo das propriedades geométricas, estereoquímicas e topológicas das moléculas. Além disso, foi obtido também o $C \log \mathrm{P}_{\mathrm{MB}}$, este último calculado pelo método de pesos do programa, atribuindo pesos iguais para os métodos de Viswanadhan e colaboradores (1989), Klopman e colaboradores (1994), e PHYSPROP ${ }^{\odot}$.

Depois de terminada a etapa de propriedades geradas computacionalmente, descritores referentes aos diferentes $p$-substituintes utilizados nos análogos foram extraídos da literatura (HANSCH, LEO, HOEKMAN, 1995).

As propriedades moleculares calculadas foram adicionadas a uma tabela com 38 colunas e 24 linhas. As colunas são referentes aos 37 descritores calculados, mais a atividade biológica linearizada $(\log 1 / \mathrm{C})$ dos compostos. Vale salientar que para cada micro-organismo foi constituída uma tabela com sua devida atividade biológica. As 24 linhas na matriz são referentes ao número total de compostos analisados, 14 da Série I (incluindo nifuroxazida) e 10 da Série II. Além disso, para cada micro-organismo analisado os compostos foram classificados quanto a sua atividade biológica ( $B=$ mais ativo, $M=$ média atividade e $R=$ menos ativos). Os valores selecionados estão descritos na seção 7.5 deste trabalho.

A tabela de dados original passou por dois critérios de seleção para selecionar os descritores mais representativos, sendo estas: (i) Gráfico de dispersão entre atividade biológica e cada descritor (Scatter plot); (ii) Coeficiente de correlação linear de Pearson (R) entre atividade biológica e cada descritor calculado (FERREIRA, KIRALJ, 2011). Esta tabela tratada por ambos critérios de seleção foi utilizada para os estudos de HCA (Hierarchical Cluster Analysis - Análise de Agrupamento por método Hierárquico) e PCA (Principal Component Analysis - Análise de Componentes Principais) (FERREIRA, KIRALJ, 2011). O compilado de todas as 
propriedades eletrônicas, hidrofóbicas, topológicas/geométricas, estéricas e referentes aos grupos substituintes dos análogos estão listadas na tabela 1.

Tabela 1. Descritores calculados e obtidos na literatura para os compostos das séries I e II.

\begin{tabular}{|c|c|c|c|c|}
\hline & Descritor & Propriedade & Descrição & Programa \\
\hline $\mathbf{X} 1$ & $C \log P_{M B}$ & Hidrofóbico & $\begin{array}{c}\text { Coeficiente de partição calculado pelo método de pesos iguais } \\
\text { para VISWANADHAN et al., 1989; KLOPMAN et al., } 1994 \mathrm{e} \\
\text { PHYSPROP }{ }^{\circ} \text { database. }\end{array}$ & \multirow{15}{*}{$\begin{array}{l}\text { MARVIN } \\
\text { BEANS }\end{array}$} \\
\hline $\mathbf{X} 2$ & Índice de Platt & Topológico & Soma dos graus de contorno da superfície molecular. & \\
\hline X3 & Índice de Randic & Topológico & Soma das médias geométricas dos graus dos vértices. & \\
\hline $\mathbf{X} 4$ & Índice de Balaban & Topológico & Média da somatória da distância de conectividade molecular. & \\
\hline $\mathbf{X} 5$ & Índice de Harary & Topológico & Metade da somatória da distância de conectividade molecular. & \\
\hline X6 & $\begin{array}{l}\text { Indice de Hiper } \\
\text { Weiner }\end{array}$ & Topológico & Variação do índice de Weiner. & \\
\hline $\mathbf{X 7}$ & Índice de Szeged & Topológico & $\begin{array}{l}\text { Aprofunda índice de Weiner para gráficos cíclicos pelo contagem } \\
\text { do número de átomos em ambos os lados de cada ligação } \\
\text { (considerado os átomos próximos de um lado da ligação do que } \\
\text { do outro). }\end{array}$ & \\
\hline $\mathbf{X 8}$ & Índice de Weiner & Topológico & Distância topológica média. & \\
\hline $\mathbf{X 9}$ & Dreiding & Topológico & Energia relacionada com a estabilidade conformacional molecular. & \\
\hline $\mathrm{X} 10$ & PSA & Topológico & Área de superfície polar. & \\
\hline X11 & $\mathbf{V}_{\mathrm{vd}} \mathbf{W}$ & Topológico & Superfície de van der Waals calculada. & \\
\hline $\mathrm{X} 12$ & ASA & Topológico & $\begin{array}{l}\text { Superfície acessível de solvente, utilizando o raio do solvente }(1,4 \\
\text { Å para a molécula de água). }\end{array}$ & \\
\hline $\mathbf{X 1 3}$ & ASA+ & Topológico & $\begin{array}{l}\text { Superfície acessível de solvente para átomos com carga parcial } \\
\text { positiva. }\end{array}$ & \\
\hline $\mathrm{X} 14$ & ASA- & Topológico & $\begin{array}{c}\text { Superfície acessível de solvente para átomos com carga parcial } \\
\text { negativa. }\end{array}$ & \\
\hline $\begin{array}{l}X 15 \\
X 16\end{array}$ & $\begin{array}{l}\text { ASA_H } \\
\text { ASA_P }\end{array}$ & $\begin{array}{l}\text { Topológico } \\
\text { Topológico }\end{array}$ & $\begin{array}{l}\text { Superfície acessível de solvente para átomos hidrofóbicos. } \\
\text { Superfície acessível de solvente para átomos hidrofílicos. }\end{array}$ & \\
\hline $\mathbf{X 1 7}$ & $\pi$ & Hidrofóbico & Constante de hidrofobicidade de Hansch-Fujita. & \multirow{8}{*}{$\begin{array}{l}\text { HANSCH, } \\
\text { LEO, } \\
\text { HOEKMAN, } \\
1995 .\end{array}$} \\
\hline $\mathrm{X} 18$ & $\boldsymbol{\sigma}$ & Eletrônico & Constante de Hammett. & \\
\hline $\mathrm{X} 19$ & $\mathbf{F}$ & Eletrônico & Constante de efeito indutivo de Swain-Lupton. & \\
\hline $\mathbf{X} 20$ & $\mathbf{R}$ & Eletrônico & Constante de efeito de ressonância de Swain-Lupton. & \\
\hline $\mathbf{X} 21$ & $\mathbf{L}$ & Topológico & & \\
\hline $\mathbf{X} 22$ & B1 & Topológico & Parâmetros de STERIMOL (VERLOOP, 1987). & \\
\hline $\mathbf{X} 23$ & B5 & Topológico & & \\
\hline X24 & RM & $\begin{array}{l}\text { Topológico / } \\
\text { Hidrofóbico }\end{array}$ & Refratividade molar. & \\
\hline X25 & CLogP $P_{\text {SG-SLN }}$ & Hidrofóbico & $\begin{array}{l}\text { Coeficiente de partição calculado pelo método de GHOSE, } \\
\text { VISWANADHAN, WENDOLOSKY, 1998-SLN. }\end{array}$ & \multirow{2}{*}{ SYBYL 8.0} \\
\hline X26 & $C \log P_{s v}$ & Hidrofóbico & $\begin{array}{l}\text { Coeficiente de partição calculado pelo método de VISWANADHAN } \\
\text { et al., } 1989 .\end{array}$ & \\
\hline $\mathbf{X} 27$ & $\mu$ & Eletrônico & Momento dipolo total calculado pelo método HF/3-21G*. & \multirow{11}{*}{$\begin{array}{l}\text { GAUSSIAN } \\
\text { 03W }\end{array}$} \\
\hline $\mathrm{X} 28$ & $\mathbf{E}_{\text {homo }}$ & Eletrônico & $\begin{array}{l}\text { Energia do maior orbital molecular ocupado, calculado pelo } \\
\text { método HF/3-21G*. }\end{array}$ & \\
\hline X29 & $\mathrm{E}_{\text {lumo }}$ & Eletrônico & $\begin{array}{l}\text { Energia do menor orbital molecular ocupado, calculado pelo } \\
\text { método HF/3-21G*. }\end{array}$ & \\
\hline X30 & GAP & Eletrônico & Diferença entre Homo e Lumo. & \\
\hline X31 & Chelpg_01 & Eletrônico & $\begin{array}{c}\text { Carga do potencial eletrostárico do átomo de oxigênio carbonílico } \\
\text { para série I e do oxigênio do anel oxadiazolínico para série II, } \\
\text { calculados por ChelpG. }\end{array}$ & \\
\hline X32 & Chelpg_O2 & Eletrônico & $\begin{array}{l}\text { Carga do potencial eletrostárico do átomo de oxigênio do anel } \\
\text { furânico para as série I e II, calculados por ChelpG. }\end{array}$ & \\
\hline X33 & Chelpg_N=C & Eletrônico & $\begin{array}{c}\text { Carga do potencial eletrostárico do átomo de nitrogênio da ligação } \\
\mathrm{N}=\mathrm{C} \text {, tanto da porção azometínica quando para série I quanto anel } \\
\text { oxadiazolínico na série II. Calculados por ChelpG. }\end{array}$ & \\
\hline X34 & Chelpg_N-H & Eletrônico & $\begin{array}{l}\text { Carga do potencial eletrostárico do átomo de nitrogênio da ligação } \\
\mathrm{N}-\mathrm{C} \text {, tanto da porção azometínica quando para série I quanto anel } \\
\text { oxadiazolínico na série II. Calculados por ChelpG }\end{array}$ & \\
\hline X35 & Chelpg_NO2 & Eletrônico & $\begin{array}{c}\text { Carga do potencial eletrostárico do grupo nitro para série I e II, } \\
\text { calculado por Chelpg. }\end{array}$ & \\
\hline X36 & Chelpg_C & Eletrônico & $\begin{array}{l}\text { Carga do potencial eletrostárico do átomo de carbono do anel } \\
\text { benzênico ligado ao } p \text {-substituinte modificado para série I e II, } \\
\text { calculado por Chelpg. }\end{array}$ & \\
\hline X37 & Chelpg_CF & Eletrônico & $\begin{array}{c}\text { Carga do potencial eletrostárico do átomo de carbono do anel } \\
\text { furânico ligado ao grupo nitro para série I e II, calculado por } \\
\text { Chelpg. }\end{array}$ & \\
\hline
\end{tabular}




\subsubsection{Análise exploratória de dados}

A análise exploratória dos dados compreende em PCA e HCA. $\mathrm{Na}$ análise de PCA os dados são decompostos em 2 matrizes $T$ e $L$, de acordo com a expressão $X$ $=\mathrm{TL}^{\top}$. $\mathrm{T}$ é referente a matriz de escores (scores), que relaciona as amostras, e $\mathrm{L}$ é referente a matriz de pesos (loadings), que mostram os pesos entre as variáveis estudadas (FERREIRA, KIRALJ, 2011). As componentes principais ou fatores (PC) explicam as informações do conjunto de dados e, nas análises realizadas, foram atribuídas 7 PCs. Vale salientar que as tabelas de dados foram pré-processadas por auto-escalamento devido as diferentes ordens de grandeza das variáveis independentes.

O método de HCA, calculado por distância euclidiana, é utilizado para agrupar dados que apresentam características semelhantes entre si (FERREIRA, KIRALJ, 2011). Esta metodologia também tem como característica a representação de dados multidimensionais em gráficos bidimensionais (2D), expressos por uma árvore hierárquica, mais conhecida como dendograma (FERREIRA, KIRALJ, 2011). A semelhança entre os compostos foi analisada pelos índices de similaridade, que variam entre 0 e 1 , onde o valor de 1 é equivalente a uma alta semelhança. Neste estudo, foram realizados dois tipos de análises de HCA: i) atividade biológica considerada como variável dependente, com intuito de agrupar os compostos; ii) atividade biológica considerada variável independente para se obter uma correlação desta com os descritores (FERREIRA, KIRALJ, 2011; TURRA, PASQUALOTO, BARROS, 2012).

\section{RESULTADOS E DISCUSSÃO}

\subsection{Obtenção de benzidrazidas}

Todos os compostos de série I foram obtidos a partir de benzidrazidas disponíveis no LPDF, não havendo a necessidade de sintetizá-las (ZORZI, 2011; PALACE-BERL et al., 2013). 


\subsection{Obtenção de derivados furfurilidênicos, Série I}

Para obtenção dos compostos da série I, o método utilizado para síntese envolveu a reação de adição nucleofílica entre compostos nucleofílicos, no caso as benzidrazidas substituídas e compostos eletrofílicos, no caso o aldeído 5nitrofurano-2-carbaldeído (MORRISON, BOYD, 1981). O princípio do mecanismo desta reação baseia-se no ataque nucleofílico da amina primária da benzidrazida substituída (1) na carbonila deficiente de elétrons do aldeído (2). Logo após, ocorre liberação de uma molécula de água do sistema (3) e formação da ligação azometínica (4), característica de compostos imínicos, comumente chamados de bases de Schiff, figura 19 (CAREY, 2008; MORRISON, BOYD, 1981).

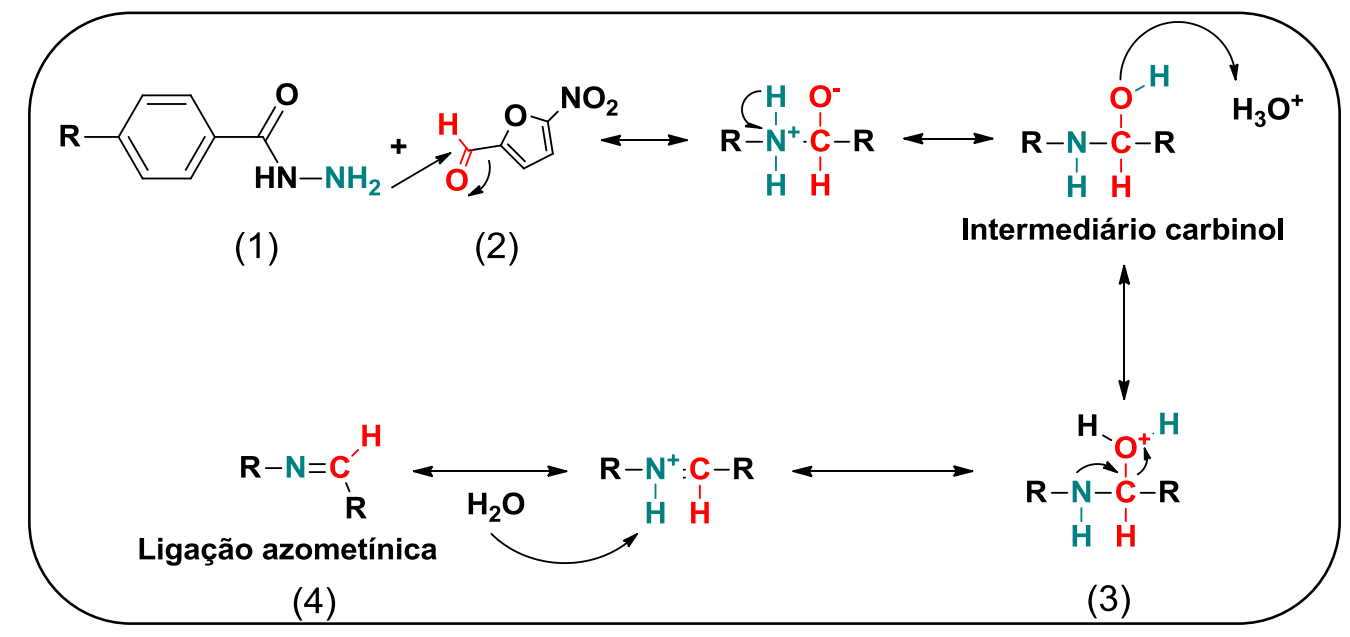

Figura 19. Mecanismo de reação para obtenção das bases de Schiff

Para que estas etapas reacionais ocorram é de imprescindível que o meio reacional esteja ácido o suficiente para protonar a carbonila do aldeído e acelerar o processo reacional. Porém, meios ácidos em demasia podem protonar, além da carbonila, a amina da benzidrazida, retirando o poder nucleofílico desta (TAVARES, PENNA, AMARAL, 1997).

Os compostos I-E $(R=C N)$ e I-M $(R=I)$ já estavam disponíveis no laboratório de pesquisa e foram gentilmente cedidos pela autora (PALACE-BERL et al., 2013), portanto não foram sintetizados nem avaliados nas análises espectrométricas de RMN, faixa de fusão e análise elementar de CHN. 
O rendimento médio desta etapa sintética demonstrou-se satisfatório, próximo a 90\%. Quando comparados com a literatura, os que apresentaram aumento de rendimento foram os compostos I-A (8\%), I-H (47\%), I-J (36\%) e I-K (19\%) (TAVARES, PENNA, AMARAL, 1997; RANDO et al., 2008; PALACE-BERL et al., 2013). Outro ponto para se salientar é que o rendimento na série I variou de $98 \%$ (IA) a $74 \%$ (I-G), onde a baixa solubilidade do intermediário benzidrazida no meio reacional pode ser o principal motivo pelo baixo rendimento do último (23\% menor quando comparado com a literatura) (PALACE-BERL et al., 2013). Ajustes nas condições reacionais como temperatura, tempo e/ou esteoqueometria podem ser fatores a serem explorados para obter este composto com melhores rendimento. Os dados experimentais referentes a etapa sintética estão descritos na tabela 1.

Tabela 2. Rendimento e faixa de fusão dos compostos 4-substituído-[(5nitrofuran-2-il) metileno] benzidrazida - Série I

\begin{tabular}{|c|c|c|c|c|c|c|}
\hline & \multicolumn{3}{|c|}{ Rendimento (\%) } & \multicolumn{3}{|c|}{ Faixa de fusão $\left({ }^{\circ} \mathrm{C}\right)$} \\
\hline & $\mathbf{R}$ & Exp. & Lit. & Exp. & Lit. & $\Delta^{*}$ \\
\hline $\mathrm{I}-\mathrm{A}$ & $\mathrm{H}$ & 98 & $91^{\mathrm{a}}$ & $219,8-221,8$ & $211-212^{a}$ & 9,3 \\
\hline I-B & $\mathrm{CH}_{3}$ & 97 & $88^{b}$ & $228,4-231$ & $233-235^{b}$ & 4,3 \\
\hline I-C & $\mathrm{OCH}_{3}$ & 93 & $81^{\mathrm{b}}$ & $241,2-243,9$ & $237-239^{b}$ & 4,55 \\
\hline I-D & $\mathrm{Br}$ & 85 & $97^{\mathrm{a}}$ & $232,4-233,7$ & $242-243^{a}$ & 9,45 \\
\hline $\mathrm{I}-\mathrm{F}$ & $\mathrm{NO}_{2}$ & 87 & $81^{\mathrm{b}}$ & $229-233$ & $236-238^{a}$ & 6 \\
\hline$I-G$ & $n-\mathrm{C}_{4} \mathrm{H}_{9}$ & 74 & $97^{\mathrm{a}}$ & $203,1-203,9$ & $192-194^{a}$ & 10,5 \\
\hline $\mathrm{I}-\mathrm{H}$ & $\mathrm{SO}_{2} \mathrm{NH}_{2}$ & 88 & $41^{\mathrm{c}}$ & $277,3-280,0$ & $270-272^{c}$ & 7,65 \\
\hline$I-I$ & $\mathrm{Cl}$ & 97 & $90^{\mathrm{b}}$ & $223-225,2$ & $225-227^{b}$ & 1,9 \\
\hline I-J & $\mathrm{N}\left(\mathrm{CH}_{3}\right)_{2}$ & 80 & $44^{b}$ & $254,2-255,1$ & $257-259^{b}$ & 3,35 \\
\hline $\mathrm{I}-\mathrm{K}$ & $\mathrm{NH}_{2}$ & 89 & $70^{b}$ & $278,5-281,2$ & $280-283^{b}$ & 1,65 \\
\hline I-L & $t-\mathrm{C}_{4} \mathrm{H}_{9}$ & 92 & ---- & $305,8-308,6$ & ---- & --- \\
\hline
\end{tabular}

Também na tabela 1 estão descritos os valores de faixa de fusão dos compostos. Estas apresentaram-se similares às descritas na literatura e com intervalo estreito, indicando bom grau de pureza.

Na confirmação da pureza total dos compostos realizada por análise elementar de $\mathrm{CHN}$, que tem como finalidade determinar a porcentagem centesimal dos átomos mais usuais da molécula, como carbono, hidrogênio, nitrogênio e compará-los a 
valores apresentados calculados, os valores obtidos se mostraram muito próximo aos calculados, sendo portanto considerados satisfatórios. Os resultados obtidos estão na tabela 2.

Tabela 3. Análise elementar de CHN dos compostos 4-substituído-[(5-nitrofuran-2-il) metileno] benzidrazida - Série I

\begin{tabular}{|c|c|c|c|c|c|c|c|c|c|c|c|c|}
\hline & \multirow{2}{*}{$\mathbf{R}$} & \multirow{2}{*}{$\begin{array}{c}\text { Fórmula } \\
\text { molecular }\end{array}$} & \multirow{2}{*}{$\begin{array}{c}\text { Massa } \\
\text { molar }(g)\end{array}$} & \multicolumn{3}{|c|}{ CHN experimental } & \multicolumn{3}{|c|}{ CHN calculado } & \multicolumn{3}{|c|}{$\Delta^{*}$} \\
\hline & & & & $\% \mathrm{C}$ & $\% \mathrm{H}$ & $\% N$ & $\% \mathrm{C}$ & $\% \mathrm{H}$ & $\% N$ & $\% \mathrm{C}$ & $\% \mathrm{H}$ & $\% \mathbf{N}$ \\
\hline I-A & $\mathrm{H}$ & $\mathrm{C}_{12} \mathrm{H}_{9} \mathrm{~N}_{3} \mathrm{O}_{4}$ & 259,2 & 55,6 & 3,5 & 16,2 & 55,1 & 3,7 & 16,2 & 0,5 & 0,2 & 0 \\
\hline I-B & $\mathrm{CH}_{3}$ & $\mathrm{C}_{13} \mathrm{H}_{11} \mathrm{~N}_{3} \mathrm{O}_{4}$ & 273,2 & 56,7 & 3,9 & 15,2 & 57,1 & 4,0 & 15,3 & 0,4 & 0,1 & 0,1 \\
\hline I-C & $\mathrm{OCH}_{3}$ & $\mathrm{C}_{13} \mathrm{H}_{11} \mathrm{~N}_{3} \mathrm{O}_{5}$ & 289,2 & 53,9 & 3,8 & 14,5 & 53,8 & 3,8 & 14,5 & 0,1 & 0 & 0 \\
\hline I-D & $\mathrm{Br}$ & $\mathrm{C}_{12} \mathrm{H}_{8} \mathrm{~N}_{3} \mathrm{O}_{4} \mathrm{Br}$ & 336,9 & 42,1 & 2,4 & 12,2 & 42,6 & 2,3 & 12,4 & 0,5 & 0,1 & 0,2 \\
\hline I-F & $\mathrm{NO}_{2}$ & $\mathrm{C}_{12} \mathrm{H}_{8} \mathrm{~N}_{4} \mathrm{O}_{6}$ & 304,2 & 47,3 & 2,5 & 18,3 & 47,3 & 2,6 & 18,4 & 0 & 0,1 & 0,1 \\
\hline I-G & $\mathrm{C}_{4} \mathrm{H}_{9}$ & $\mathrm{C}_{16} \mathrm{H}_{17} \mathrm{~N}_{3} \mathrm{O}_{4}$ & 315,3 & 61,3 & 5,2 & 13,8 & 60,9 & 5,4 & 13,3 & 0,4 & 0,2 & 0,5 \\
\hline $\mathrm{I}-\mathrm{H}$ & $\mathrm{SO}_{2} \mathrm{NH}_{2}$ & $\mathrm{C}_{12} \mathrm{H}_{10} \mathrm{~N}_{4} \mathrm{O}_{6} \mathrm{~S}$ & 338,3 & 42,3 & 2,9 & 16,4 & 42,6 & 2,9 & 16,5 & 0,3 & 0 & 0,1 \\
\hline$I-I$ & $\mathrm{Cl}$ & $\mathrm{C}_{12} \mathrm{H}_{8} \mathrm{~N}_{3} \mathrm{O}_{4} \mathrm{Cl}$ & 293.6 & 46,2 & 3,2 & 13,4 & 46,3 & 3,1 & 13,5 & 0,1 & 0,1 & 0,1 \\
\hline I-J & $\mathrm{N}\left(\mathrm{CH}_{3}\right)_{2}$ & $\mathrm{C}_{14} \mathrm{H}_{14} \mathrm{~N}_{4} \mathrm{O}_{4}$ & 302,2 & 55,6 & 4,6 & 18,5 & 54,1 & 5,0 & 18,0 & 1,5 & 0,4 & 0,5 \\
\hline $\mathrm{I}-\mathrm{K}$ & $\mathrm{NH}_{2}$ & $\mathrm{C}_{12} \mathrm{H}_{10} \mathrm{~N}_{4} \mathrm{O}_{4}$ & 274,2 & 51,9 & 3,5 & 20,1 & 52,5 & 3,6 & 20,4 & 0,6 & 0,1 & 0,3 \\
\hline I-L & $\mathrm{t}-\mathrm{C}_{4} \mathrm{H}_{9}$ & $\mathrm{C}_{16} \mathrm{H}_{17} \mathrm{~N}_{3} \mathrm{O}_{4}$ & 315,1 & 60,5 & 5,7 & 13,3 & 60,9 & 5,4 & 13,3 & 0,4 & 0,3 & 0 \\
\hline
\end{tabular}

Os espectros de RMN ${ }^{1} \mathrm{H}$ e RMN ${ }^{13} \mathrm{C}$ dos compostos foram comparados com dados da literatura e apresentaram deslocamentos químicos correspondentes as suas estruturas químicas, descritos nas tabelas 3 e 4, respectivamente (TAVARES, 1993; RODRIGUES, 2000; ZORZI, 2011; PALACE-BERL et al., 2013). Os espectros de série I obtidos foram tratados no programa Mestre- $C$ e estão disponíveis no Anexo 1 deste trabalho. 
Tabela 4. Principais sinais de $\mathrm{RMN}{ }^{1} \mathrm{H}$ (ppm) dos compostos 4-substituído-[(5-nitrofuran-2-il) metileno] benzidrazida - Série I

\begin{tabular}{|c|c|c|c|c|c|c|c|c|c|c|c|}
\hline & \multirow[b]{3}{*}{$\mathbf{R}$} & \multirow{3}{*}{$\begin{array}{c}\text { NH } \\
(s, H 8)\end{array}$} & \multirow{3}{*}{$\begin{array}{l}\mathrm{N}=\mathrm{CH} \\
(\mathrm{s}, \mathrm{H} 6)\end{array}$} & \multirow{2}{*}{\multicolumn{4}{|c|}{$\left.\underbrace{12}_{14}\right|_{15} ^{11}$}} & & & & \\
\hline & & & & & & & & \multicolumn{4}{|c|}{ Ar - benzeno } \\
\hline & & & & (d, H3) & $J(H z)$ & $(d, H 4)$ & $J(H z)$ & $\begin{array}{c}\text { (d,H11; } \\
\text { H15) }\end{array}$ & $\begin{array}{c}J \\
(\mathrm{~Hz})\end{array}$ & $\begin{array}{c}\text { (d, H12; } \\
\text { H14) }\end{array}$ & $\begin{array}{c}J \\
(\mathrm{~Hz})\end{array}$ \\
\hline $\mathrm{I}-\mathrm{A}$ & $\mathrm{H}$ & 12,23 & 8,43 & 7,27 & 3,7 & 7,78 & 3,9 & 7,93 & 7,5 & $7,66-7,53(\mathrm{t})$ & --- \\
\hline I-B & $\mathrm{CH}_{3}$ & 12,15 & 8,42 & 7,25 & 3,7 & 7,78 & 3,9 & 7,84 & 8 & 7,35 & 7,9 \\
\hline $\mathrm{I}-\mathrm{C}$ & $\mathrm{OCH}_{3}$ & 12,11 & 8,41 & 7,24 & 3,9 & 7,78 & 3,9 & 7,92 & 8,8 & 7,07 & 8,8 \\
\hline I-D & $\mathrm{Br}$ & 12,29 & 8,41 & 7,27 & 3,3 & 7,79 & 3,9 & 7,88 & 8,1 & 7,77 & 8,4 \\
\hline I-F & $\mathrm{NO}_{2}$ & 12,48 & 8,43 & 7,31 & 3,0 & 7,79 & 3,6 & 8,16 & 8,4 & 8,39 & 8,4 \\
\hline$I-G$ & $n-\mathrm{C}_{4} \mathrm{H}_{9}$ & 12,15 & 8,42 & 7,25 & 3,8 & 7,78 & 3,9 & 7,86 & 8,1 & 7,36 & 8,1 \\
\hline $\mathrm{I}-\mathrm{H}$ & $\mathrm{SO}_{2} \mathrm{NH}_{2}$ & 12,36 & 8,42 & 7,30 & 2,7 & 7,79 & 3,8 & 7,9 & 8,1 & 8,08 & 7,7 \\
\hline I-I & $\mathrm{Cl}$ & 12,93 & 8,41 & 7,29 & 3,4 & 7,79 & 3,9 & 7,96 & 8,1 & 7,64 & 8,4 \\
\hline I-J & $\mathrm{N}\left(\mathrm{CH}_{3}\right)_{2}$ & 11,93 & 8,40 & 7,20 & 3,9 & 7,78 & 3,9 & 7,83 & 8,7 & 6,76 & 9 \\
\hline $\mathrm{I}-\mathrm{K}$ & $\mathrm{NH}_{2}$ & 11,86 & 8,38 & 7,19 & 3,9 & 7,78 & 3,9 & 7,70 & 8,4 & 6,63 & 8,4 \\
\hline$I-L$ & $t-\mathrm{C}_{4} \mathrm{H}_{9}$ & 12,16 & 8,42 & 7,26 & 3,8 & 7,79 & 3,8 & 7,86 & 8,3 & 7,56 & 8,3 \\
\hline
\end{tabular}


Tabela 5. Principais sinais de $\mathrm{RMN}{ }^{13} \mathrm{C}$ dos compostos 4-substituído-[(5-nitrofuran-2-il) metileno] benzidrazida - Série I

\begin{tabular}{|c|c|c|c|c|c|c|c|c|c|c|c|}
\hline & & & & 13 & $\underset{\mathrm{HN}-}{\mathrm{HN}}$ & 6 & $\mathrm{NC}$ & & & & \\
\hline & $\mathbf{R}$ & C2 & C3 & C4 & C5 & C6 & C9 & C10 & C11/15 & C12/14 & C13 \\
\hline $\mathrm{I}-\mathrm{A}$ & $\mathrm{H}$ & 151,8 & 113,9 & 114,5 & 151,7 & 135,4 & 163,4 & 132,7 & 127,7 & 128,5 & 132,1 \\
\hline I-B & $\mathrm{CH}_{3}$ & 151,8 & 115 & 114,6 & 150,1 & 135,2 & 163,2 & 129,8 & 127,8 & 129 & 142,3 \\
\hline I-C & $\mathrm{OCH}_{3}$ & 151,9 & 114,8 & 114,6 & 151,7 & 134,7 & 162,3 & 124,7 & 129,8 & 113,7 & 162,9 \\
\hline I-D & $\mathrm{Br}$ & 151,6 & 114,5 & 115,3 & 151,8 & 135,8 & 162,4 & 131,8 & 129,8 & 131,6 & 126 \\
\hline I-F & $\mathrm{NO}_{2}$ & 151,9 & 114,4 & 115,8 & 151,3 & 136,5 & 161,8 & 138,3 & 129,2 & 123,6 & 149,4 \\
\hline I-G & $n-\mathrm{C}_{4} \mathrm{H}_{9}$ & 151,3 & 114,6 & 115 & 151,8 & 130,1 & 163,3 & 135,1 & 128,3 & 127,8 & 147 \\
\hline $\mathrm{I}-\mathrm{H}$ & $\mathrm{SO}_{2} \mathrm{NH}_{2}$ & 151,9 & 114,5 & 115,5 & 151,5 & 135,6 & 162,4 & 136,1 & 128,4 & 125,8 & 147 \\
\hline$I-I$ & $\mathrm{Cl}$ & 151,8 & 114,5 & 115,4 & 151,6 & 135,7 & 162,3 & 131,4 & 128,6 & 129,6 & 137 \\
\hline I-J & $\mathrm{N}\left(\mathrm{CH}_{3}\right)_{2}$ & 152,7 & 114,7 & 114,3 & 152,3 & 133,6 & 163,2 & 118,5 & 129,4 & 110,8 & 151,3 \\
\hline I-K & $\mathrm{NH}_{2}$ & 152,6 & 114,7 & 114,2 & 152,3 & 133,4 & 163,3 & 118,7 & 129,6 & 112,6 & 151,6 \\
\hline I-L & $\mathrm{t}-\mathrm{C}_{4} \mathrm{H}_{9}$ & 151,9 & 114,6 & 115 & 151,8 & 135,1 & 163,3 & 130 & 125,3 & 127,7 & 155,1 \\
\hline
\end{tabular}


Os sinais 12,93 - 11,86 ppm (8) e 8,43-8,38 ppm (6) no espectro de RMN ${ }^{1} \mathrm{H}$; 163,4 - 161,8 ppm (9) e 136,5 - 130,1 ppm (6) no espectro de RMN ${ }^{13} \mathrm{C}$ são característicos dos grupos azometínicos, figura 20. Desta forma a formação da subestrutura característica desta classe química ficou comprovada (CREWS, RODRIGUEZ, JASPARS, 1998; ROLLAS, GULERMAN, ERDENIZ, 2002; PAVIA et al., 2010).

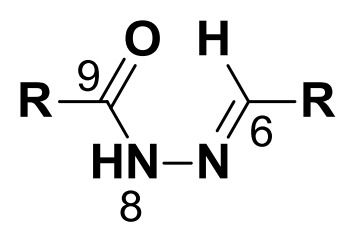

Figura 20. Subestrutura central dos

análogos à nifuroxazida

Os sinais característicos da subestrutura nitrofurânica no $\mathrm{RMN}{ }^{1} \mathrm{H}$ são de 7,31 7,19 ppm (3) e 7,79 - 7,43 ppm (4), enquanto que no RMN ${ }^{13} \mathrm{C}$ são 152,7 - 151,3 (2), 115,1 - 113,9 (3), 115,8 - 114 (4) e 152,3 - 150,1 (5), figura 21 (KATRITZKY, POZHARSKII, 2000; EICHER, HAUPTMANN, 2003). O grupo nitro deste anel é altamente retirador de elétrons e, consequentemente, tem grande influência no deslocamento dos sinais de sua vizinhança, em especial no RMN ${ }^{1} \mathrm{H}$ (sinal $4 \mathrm{com}$ maior deslocamento) (CREWS, RODRIGUES, JASPARS, 1998).

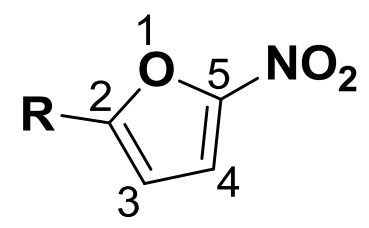

Figura 21. Subestrutura furânica das bases de Schiff.

$\mathrm{Na}$ análise de RMN ${ }^{1} \mathrm{H}$ para aneis benzênicos há duas faixas consideradas importantes, de 8,16 - 7,69 ppm (11/15) e 8,39 - 6,63 ppm (12/14), figura 22. Na análise de $\mathrm{RMN}{ }^{13} \mathrm{C}$ as principais faixas de sinais são 130 - 125,3 ppm (11/15), 137,9 - 110,8 ppm (12/14), 138,3 - 118,5 ppm (10) e 162,9 - 110,5 ppm (13) (CREWS, RODRIGUEZ, JASPARS, 1998). Como se pode notar, os sinais são muito próximos entre um grupo $e$ outro porque diversos substituintes influenciam na eletronegatividade de sua vizinhança. De uma maneira geral, substituintes 
retiradores de elétrons tendem apresentar os sinais em campo mais desprotegido, enquanto que doadores de elétrons tendem a apresentar os sinais em campos mais protegido.

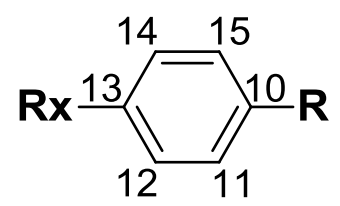

Figura 22. Subestrutura benzênica

das bases de Schiff. Rx é referente ao

grupo substituinte.

Por fim, há também os sinais específicos de cada análogo, provenientes do substituinte modificado. Estes apresentam:

RMN ${ }^{1} \mathrm{H}(\mathrm{ppm})$

- I-A: $7,63(\mathrm{~m}, 1 \mathrm{H}, \mathrm{H})$;

- I-B: $2,38\left(\mathrm{~s}, 3 \mathrm{H}, \mathrm{CH}_{3}\right)$;

- I-C: $3,83\left(\mathrm{~s}, 3 \mathrm{H}, \mathrm{CH}_{3}\right)$;

- I-G: 2,66 (t, 2H, $\left.\mathrm{CH}_{2}\right) ; 1,59\left(\mathrm{~m}, 2 \mathrm{H}, \mathrm{CH}_{2}\right) ; 1,33\left(\mathrm{~m}, 2 \mathrm{H}, \mathrm{CH}_{2}\right) ; 0,90\left(\mathrm{t}, 3 \mathrm{H}, \mathrm{CH}_{3}\right)$;

- I-H: 7,53 (s, 2H, $\left.\mathrm{NH}_{2}\right)$;

- I-J: $3,01\left(\mathrm{~s}, 6 \mathrm{H},\left(\mathrm{CH}_{3}\right)_{2}\right)$;

- I-K: $5,88\left(\mathrm{~s}, 2 \mathrm{H}, \mathrm{NH}_{2}\right)$;

- I-L: $1,32\left(\mathrm{~s}, 9 \mathrm{H},\left(\mathrm{CH}_{3}\right)_{3}\right)$.

RMN ${ }^{13} \mathrm{C}(\mathrm{ppm})$

- I-B: $21,02\left(\mathrm{CH}_{3}\right)$;

- I-C: $55,43\left(\mathrm{CH}_{3}\right)$;

- I-G: $34,6\left(\mathrm{CH}_{2}\right) ; 32,7\left(\mathrm{CH}_{2}\right) ; 21,6\left(\mathrm{CH}_{2}\right) ; 13,6\left(\mathrm{CH}_{3}\right)$;

- I-J: $\left.40,29\left(\mathrm{CH}_{3}\right)_{2}\right)$;

- I-L: $34,72(\mathrm{C}) ; 30,85\left(\left(\mathrm{CH}_{3}\right)_{3}\right)$. 
6.3. Obtenção de derivados oxadiazolínicos, Série II

Para obtenção da série II, figura 23 , foi empregada reação de ciclização oxidativa que forma o sistema heterocíclico 3-acetil-2,3,-diidro-1,3,4-oxadiazolínico (JOULE, MILLS, 2007; LI, MA, CAO, 2009; OLIVEIRA, 2011; PALACE-BERL et al., 2013).

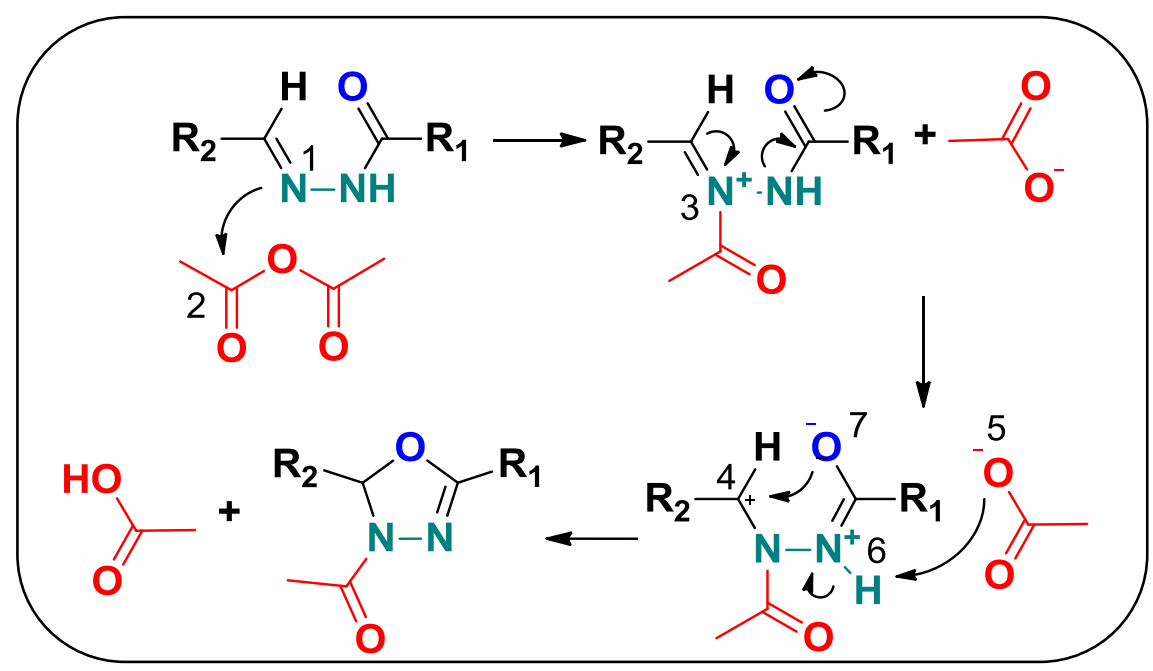

Figura 23. Mecanismo de reação para obtenção de compostos oxadiazolínicos.

Nesta reação foram utilizadas as bases de Schiff previamente sintetizadas e anidrido acético em excesso. O mecanismo de reação envolve o ataque nucleofílico da amina terciária (1) na carbonila do anidrido acético (2) com consequente clivação do grupo acetila, que se liga na amina e forma uma carga parcial positiva (3). O par eletrônico deste nitrogênio procura se estabilizar, gerando um carbocátion transitório no processo (4). O íon acetato (5) formado ataca o próton amínico (6), formando ácido acético no final do ciclo. Por fim, o oxigênio com carga parcial negativa (7) ataca o carbocátion transitório (4), ciclizando o anel (PALACE-BERL et al., 2013; OLIVEIRA, 2011; LI, MA, CAO, 2009; JOULE, MILLS, 2007).

Para evitar as dificuldades citadas na literatura, como difícil síntese e separação do meio reacional, padronizou-se a utilização de temperaturas entre 110 a $120{ }^{\circ} \mathrm{C}$ e de atmosfera inerte, com o objetivo de impedir interferência de água e evitar a degradação do anidrido acético, o que diminuiria a reatividade do sistema (PALACE-BERL et al., 2013; OLIVEIRA, 2011). As reações químicas, em condições de refluxo, variaram de 12 a 24 horas, devido a interferência de alguns substituintes 
nas características eletrônicas das moléculas e consequente diminuição na reatividade (PALACE-BERL et al., 2013; OLIVEIRA, 2011).

O composto II-M $(R=$ I) já estava disponível no laboratório de pesquisa e foram gentilmente cedidos pelos autores (PALACE-BERL et al., 2013). Portanto, novamente, o mesmo não foi sintetizado nem avaliado quanto a sua estrutura química e pureza. Salienta-se também que os análogos oxadiazolínicos dos compostos II-H $\left(R=\mathrm{SO}_{2} \mathrm{NH}_{2}\right)$, II-J $\left(\mathrm{R}=\mathrm{N}\left(\mathrm{CH}_{3}\right)_{2}\right)$ e II-K $\left(\mathrm{R}=\mathrm{NH}_{2}\right)$ não foram sintetizados com sucesso. Durante o processo sintético tais substituintes reagem com o anidrido acético e formam compostos diferentes do desejado. Ainda há necessidade de estudos adicionais para possíveis alternativas.

O rendimento médio da etapa sintética ficou em torno de $65,5 \%$, similar ao descrito na literatura (65\%) (PALACE-BERL et al., 2013). Em especial, o composto II-G apresentou um rendimento melhor do que o documentado, cerca de $23 \%$ superior. Em contrapartida, os compostos II-E (41\%) e II-A (61\%) não apresentaram rendimentos satisfatórios, cerca de $15 \%$ a menos do que é descrito para ambos (PALACE-BERL et al., 2013). O baixo rendimento obtido pode ter sido decorrente de dificuldades na extração destes análogos do meio reacional ou de perdas durante o processo de recristalização. Os rendimentos obtidos, assim como as faixas de fusões e os comparativos com a literatura estão descritos na tabela 5. 
Tabela 6. Rendimento e faixa de fusão dos compostos 3-acetil-2-[5-nitrofuran-2-il]-5-[4-substituído-fenil]-2,3-diidro-1,3,4-oxadiazolínico - Série II

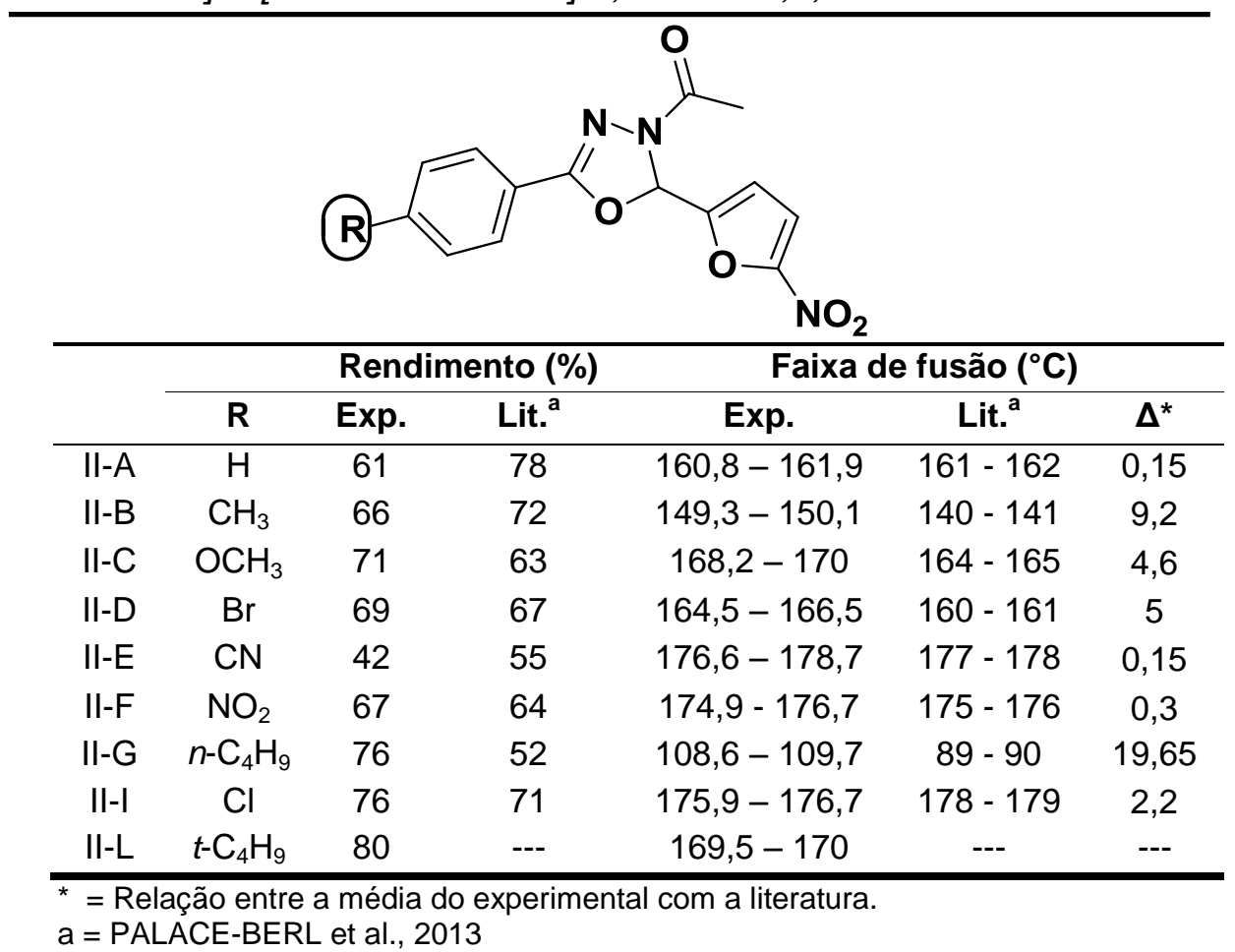

Em relação à pureza e identificação dos compostos, todos se mostraram satisfatórios, uma vez que as suas faixas de fusão se mostraram próximas da literatura, com exceção do compostos II-G que mostrou uma diferença maior que os demais, possivelmente relacionado a aparelho utilizado para análise (PALACEBERL et al., 2013). relacionado a salvo o derivado II-L que até o presente momento não foi encontrado referência na literatura.

$\mathrm{Na}$ análise elementar de $\mathrm{CHN}$, novamente todos os compostos apresentaram boas porcentagens quando comparados aos valores calculados. Portanto, tais compostos podem ser considerados puros. Os valores obtidos para os compostos de série II estão descritos na tabela 6 . 
Tabela 7. Análise elementar de CHN dos compostos 3-acetil-2-[5-nitro-furan-2-il]-5-[4substituído-fenil]-2,3-diidro-1,3,4-oxadiazolínico - Série II

\begin{tabular}{|c|c|c|c|c|c|c|c|c|c|c|c|c|}
\hline & & & & & $\mathbf{N}$ & & $\mathrm{NO}_{2}$ & & & & & \\
\hline & \multirow{2}{*}{$\mathbf{R}$} & \multirow{2}{*}{$\begin{array}{l}\text { Fórmula } \\
\text { molecular }\end{array}$} & \multirow{2}{*}{$\begin{array}{c}\text { Massa } \\
\text { molar }(g)\end{array}$} & \multicolumn{3}{|c|}{ CHN experimental } & \multicolumn{3}{|c|}{ CHN calculado } & \multicolumn{3}{|c|}{$\Delta^{*}$} \\
\hline & & & & $\% \mathrm{C}$ & $\% \mathrm{H}$ & $\% \mathbf{N}$ & $\% \mathrm{C}$ & $\% \mathrm{H}$ & $\% \mathbf{N}$ & $\% \mathrm{C}$ & $\% \mathrm{H}$ & $\% N$ \\
\hline II-A & $\mathrm{H}$ & $\mathrm{C}_{14} \mathrm{H}_{11} \mathrm{~N}_{3} \mathrm{O}_{5}$ & 301,2 & 55,7 & 3,6 & 13,9 & 55,8 & 3,6 & 13,9 & 0,1 & 0 & 0 \\
\hline II-B & $\mathrm{CH}_{3}$ & $\mathrm{C}_{15} \mathrm{H}_{13} \mathrm{~N}_{3} \mathrm{O}_{5}$ & 315,2 & 57,0 & 4,0 & 13,2 & 57,1 & 4,1 & 13,3 & 0,1 & 0,1 & 0,1 \\
\hline II-C & $\mathrm{OCH}_{3}$ & $\mathrm{C}_{15} \mathrm{H}_{13} \mathrm{~N}_{3} \mathrm{O}_{6}$ & 331,2 & 54,3 & 4,0 & 12,6 & 54,3 & 3,9 & 12,6 & 0 & 0,1 & 0 \\
\hline II-D & $\mathrm{Br}$ & $\mathrm{C}_{14} \mathrm{H}_{10} \mathrm{BrN}_{3} \mathrm{O}_{5}$ & 380,1 & 44,2 & 2,6 & 10,9 & 44,2 & 2,6 & 11,0 & 0 & 0 & 0,1 \\
\hline II-E & $\mathrm{CN}$ & $\mathrm{C}_{15} \mathrm{H}_{10} \mathrm{~N}_{4} \mathrm{O}_{5}$ & 326,2 & 55,1 & 3,0 & 17,0 & 55,2 & 3,0 & 17,1 & 0,1 & 0 & 0,1 \\
\hline II-F & $\mathrm{NO}_{2}$ & $\mathrm{C}_{14} \mathrm{H}_{10} \mathrm{~N}_{4} \mathrm{O}_{7}$ & 346,2 & 48,6 & 2,8 & 16,0 & 48,5 & 2,9 & 16,1 & 0,1 & 0,1 & 0,1 \\
\hline II-G & $n-\mathrm{C}_{4} \mathrm{H}_{9}$ & $\mathrm{C}_{18} \mathrm{H}_{19} \mathrm{~N}_{3} \mathrm{O}_{5}$ & 357,3 & 60,4 & 5,5 & 11,7 & 60,5 & 5,3 & 11,7 & 0,1 & 0,2 & 0 \\
\hline II-I & $\mathrm{Cl}$ & $\mathrm{C}_{14} \mathrm{H}_{10} \mathrm{CIN}_{3} \mathrm{O}_{5}$ & 335,7 & 50,0 & 3,0 & 12,5 & 50,0 & 3,0 & 12,5 & 0 & 0 & 0 \\
\hline II-L & $t-\mathrm{C}_{4} \mathrm{H}_{9}$ & $\mathrm{C}_{18} \mathrm{H}_{19} \mathrm{~N}_{3} \mathrm{O}_{5}$ & 357,3 & 60,4 & 5,5 & 11,4 & 60,5 & 5,3 & 11,7 & 0,1 & 0,2 & 0,3 \\
\hline
\end{tabular}

A estrutura química dos compostos da série II também foram confirmadas pelos espectros de $\mathrm{RMN}{ }^{1} \mathrm{H}$ e ${ }^{13} \mathrm{C}$, tabela 7 e 8 , respectivamente. Todos compostos analisados foram comparados com dados da literatura e apresentam os deslocamentos químicos ( $\delta$ ) que representam sua estrutura química (PALACE BERL, 2013; OLIVEIRA, 2011). Os espectros obtidos foram tratados no programa Mestre-C e estão no Anexo 2 deste trabalho. 
Tabela 8. Principais sinais de RMN ${ }^{1} \mathrm{H}$ (ppm) dos compostos 3-acetil-2-[5-nitro-furan-2-il]-5-[4-substituídofenil]-2,3-diidro-1,3,4-oxadiazolínico - Série II

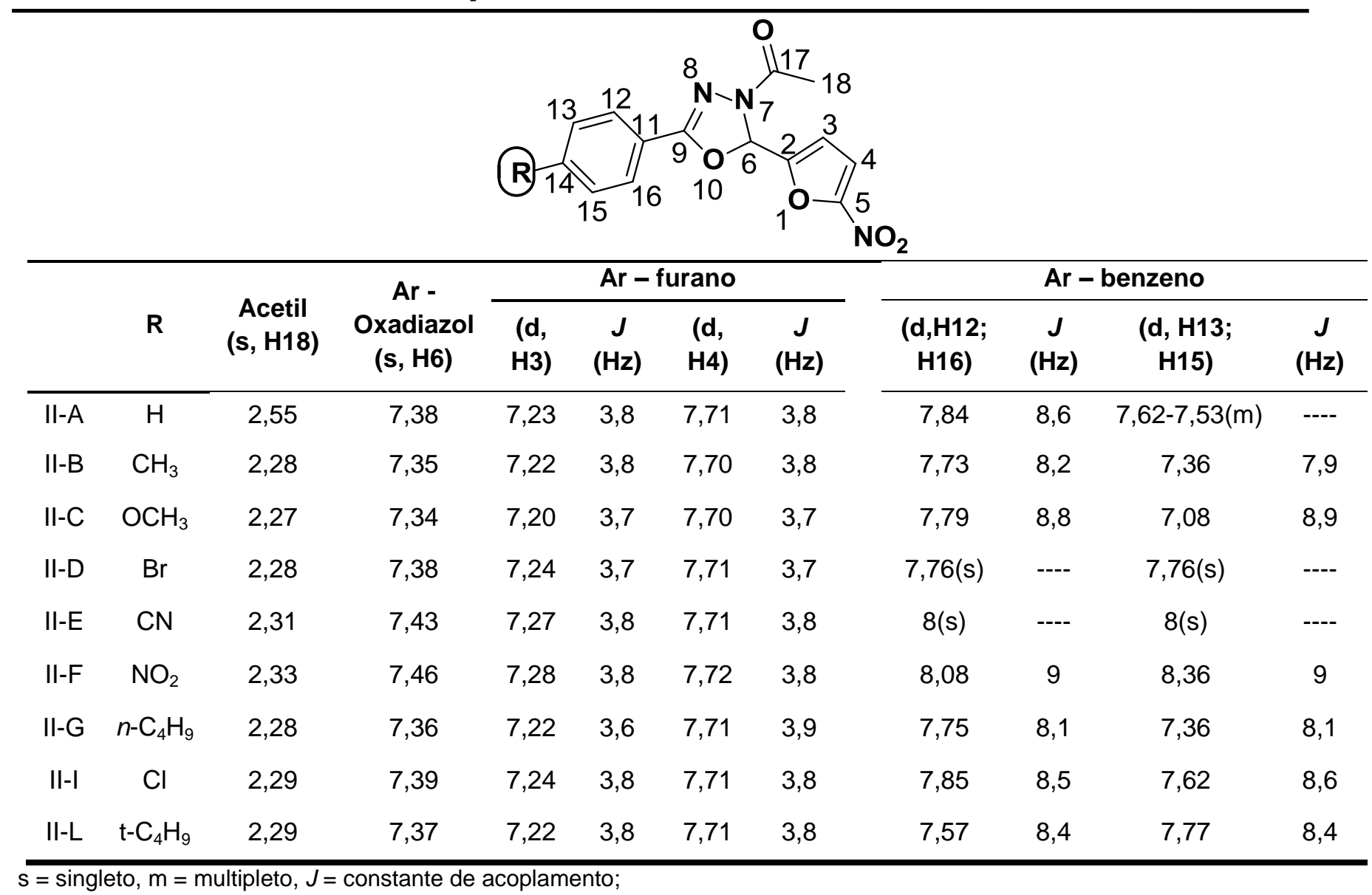


Tabela 9. Principais sinais de RMN ${ }^{13} \mathrm{C}$ dos compostos 3-acetil-2-[5-nitro-furan-2-il]-5-[4-substituído-fenil]-2,3-diidro-1,3,4oxadiazolínico - Série II

\begin{tabular}{|c|c|c|c|c|c|c|c|c|c|c|c|c|c|}
\hline & & & & & & 12 & $\begin{array}{r}\mathbf{O} \\
-\mathbf{N}_{7}\end{array}$ & $>_{\text {NC }}^{4}$ & & & & & \\
\hline & $\mathbf{R}$ & $\mathrm{C} 2$ & C3 & C4 & C5 & C6 & C9 & C11 & C12/16 & C13/15 & C14 & C17 & C18 \\
\hline II-A & $\mathrm{H}$ & 154,5 & 113,1 & 114,4 & 150,5 & 84,4 & 151,7 & 132,1 & 126,6 & 129,1 & 123,3 & 167,1 & 21 \\
\hline II-B & $\mathrm{CH}_{3}$ & 151,7 & 113,1 & 114,3 & 150,6 & 84,2 & 154,6 & 120,5 & 129,6 & 126,5 & 142,3 & 167 & 21 \\
\hline II-C & $\mathrm{OCH}_{3}$ & 151,7 & 113,1 & 114,3 & 154,5 & 84,1 & 150,6 & 115,4 & 114,6 & 128,5 & 162,2 & 166,9 & 21 \\
\hline II-D & $\mathrm{Br}$ & 150,3 & 113,1 & 114,5 & 151,7 & 84,6 & 153,8 & 122,6 & 132,2 & 128,4 & 125,7 & 167,2 & 21 \\
\hline II-E & $\mathrm{CN}$ & 151,7 & 113,1 & 114,7 & 150,1 & 85 & 153,2 & 127,5 & 127,2 & 133 & 114,1 & 167,4 & 21 \\
\hline II-F & $\mathrm{NO}_{2}$ & 151,8 & 113,1 & 114,7 & 150 & 85,1 & 153 & 129,1 & 124,3 & 127,9 & 149,1 & 167,4 & 21 \\
\hline II-G & $n-\mathrm{C}_{4} \mathrm{H}_{9}$ & 154,6 & 113,1 & 113,9 & 150,6 & 84,2 & 151,7 & 120,7 & 129 & 126,6 & 151,7 & 167 & 21 \\
\hline II-I & Cl & 150,3 & 113,1 & 114,5 & 151,7 & 84,6 & 153,7 & 122,2 & 128,3 & 129,3 & 136,8 & 167,2 & 21 \\
\hline II-L & $\mathrm{t}-\mathrm{C}_{4} \mathrm{H}_{9}$ & 154,6 & 113,1 & 114,3 & 151,7 & 84,1 & 155,2 & 120,6 & 126,5 & 125,9 & 150,6 & 167 & 21 \\
\hline
\end{tabular}

= Dados extraídos de PALACE-BERL et al., 2013. 
Nos compostos oxadiazolínicos os sinais são similares às bases de Schiff, devido às subestruturas furânica e benzênica. As diferenças ficam na região central da molécula, o anel 3-acetil-2,3,-diidro-1,3,4-oxadiazolínico. Nesta estrutura, os sinais nais faixas entre 7,46 - 7,34 (6) ppm no espectro de $\mathrm{RMN}{ }^{1} \mathrm{H}$, e 85,1 - 84,1 (6) e 162,2 - 153 (9) ppm no espectro de $\mathrm{RMN}{ }^{13} \mathrm{C}$, são comuns para compostos heterocíclicos que tenham ligações $\mathrm{CH}-\mathrm{O}$, figura 24 (DURGUN et al., 1993; KATRITZKY, POZHARSKII, 2000; ROLLAS, GULERMAN, ERDENIZ, 2002; RAJAK, KHARYA, MISHRA, 2007; BAQUERO et al., 2011).<smiles>[R]C1=NN(C(=O)[18F])C([R])([R])O1</smiles>

Figura 24. Subestrutura oxadiazolínica, com anel heterocíclico e grupo acetila.

Em relação ao grupo acetila, figura 24, os sinais aparecem em torno de 2,55 2,77 ppm (18) na análise de $\mathrm{RMN}{ }^{1} \mathrm{H}$ e 21,00 ppm (18) na análise de $\mathrm{RMN}{ }^{13} \mathrm{C}$, referente a metila do grupo acetil. A porção carbonílica deste radical está situada em 167,4 - 166,9 ppm (17) no espectro de RMN ${ }^{13} \mathrm{C}$ (ROLLAS, GULERMAN, ERDENIZ, 2002; RAJAK, KHARYA, MISHRA, 2007; BAQUERO et al., 2011).

Há também sinais específicos de cada análogo, provenientes do substituinte modificado. Estes são:

RMN ${ }^{1} \mathrm{H}$

- II-A: $7,57(\mathrm{~m}, 1 \mathrm{H}, \mathrm{H})$;

- II-B: 2,38 (s,3H, $\left.\mathrm{CH}_{3}\right)$;

- II-C: $3,84\left(\mathrm{~s}, 3 \mathrm{H}, \mathrm{CH}_{3}\right)$;

- II-G: $1,56\left(\mathrm{~m}, 2 \mathrm{H}, \mathrm{CH}_{2}\right) ; 1,28\left(\mathrm{~m}, 2 \mathrm{H}, \mathrm{CH}_{2}\right) ; 2,64\left(\mathrm{t}, 2 \mathrm{H}, \mathrm{CH}_{2}\right) ; 0,89\left(\mathrm{t}, 3 \mathrm{H}, \mathrm{CH}_{3}\right)$;

- II-L: $1,30\left(\mathrm{~s}, 9 \mathrm{H},\left(\mathrm{CH}_{3}\right)_{3}\right)$. 
$\mathrm{RMN}{ }^{13} \mathrm{C}(\mathrm{ppm})$

- II-B: $21\left(\mathrm{CH}_{3}\right)$;

- II-C: $55,48\left(\mathrm{CH}_{3}\right)$;

- II-E: $117,9(\mathrm{CN})$;

- II-G: $34,7\left(\mathrm{CH}_{2}\right) ; 32,7\left(\mathrm{CH}_{2}\right) ; 21,6\left(\mathrm{CH}_{2}\right) ; 13,6\left(\mathrm{CH}_{3}\right)$;

- II-L: $34,7(\mathrm{C}) ; 30,7\left(\left(\mathrm{CH}_{3}\right)_{3}\right)$.

\subsection{Ensaios de atividade antimicrobiana}

Ensaios de concentração inibitória mínima são medidas quantitativas confiáveis, econômicas e de fácil realização para avaliar a possível atividade antimicrobiana in vitro de fármacos disponíveis no mercado ou investigar a atividade de novas entidades moleculares (TORTORA, 2005). O ensaio consiste em microdiluição seriada dos compostos analisados em caldo nutritivo para serem colocados em contato com os micro-organismos testados e verificar a mais baixa concentração que possa inibir visivelmente o crescimento bacteriano (TORTORA, 2005). Foram testados 23 análogos nesta etapa, além de mais 10 fármaco, entre eles fármacos de referência e composto protótipo. Na tabela 9 e 10 estão descritos os resultados obtidos frente a cepa ATCC 29213 de S. aureus referente aos compostos das séries I e II, respectivamente. 
Tabela 10. Atividade antimicrobiana dos compostos 4-substituído [(5nitrofuran-2il)metileno] benzidrazida - Série I, frente à S. aureus, cepa ATCC 29213.

\begin{tabular}{|c|c|c|c|c|c|c|}
\hline & $\mathbf{R}$ & Fase I $\mu \mathrm{M}$ ** & Fase I $\mu M^{* \star *}$ & Fase II $\mu \mathrm{M}$ & $\mathrm{IC}_{90} \mu \mathrm{M}$ & $D P^{a}$ \\
\hline I-A & $\mathrm{H}$ & $8,0-4,0$ & $8,0-4,0$ & $5,3-4,8$ & 5,27 & 0,04 \\
\hline I-B & $\mathrm{CH}_{3}$ & $16,0-8,0$ & $16,0-8,0$ & $13,1-10,5$ & 10,64 & 0,07 \\
\hline I-C & $\mathrm{OCH}_{3}$ & $8,0-2,0$ & $8,0-4,0$ & $4,0-3,2$ & 4,11 & 0,41 \\
\hline I-D & $\mathrm{Br}$ & $8,0-2,0$ & $8,0-2,0$ & $4,4-3,8$ & 4,5 & 0,09 \\
\hline I-E & $\mathrm{CN}$ & $8,0-4,0$ & $8,0-4,0$ & $5,6-4,9$ & 5,35 & 0,02 \\
\hline I-F & $\mathrm{NO}_{2}$ & $8,0-2,0$ & $8,0-2,0$ & $3,6-2,9$ & 3,31 & 0,1 \\
\hline I-G & $n-\mathrm{C}_{4} \mathrm{H}_{9}$ & $4,0-2,0$ & $4,0-2,0$ & $2,5-1,9$ & 1,8 & 0,04 \\
\hline I-H & $\mathrm{SO}_{2} \mathrm{NH}_{2}$ & $16,0-4,0$ & $16,0-4,0$ & $8,5-6,7$ & 8,34 & 0,06 \\
\hline I-I & $\mathrm{Cl}$ & $4,0-2,0$ & $8,0-4,0$ & $5,2-4,2$ & 5,52 & 0,1 \\
\hline I-J & $\mathrm{N}\left(\mathrm{CH}_{3}\right)_{2}$ & $8,0-4,0$ & $8,0-4,0$ & $9,1-7,2$ & 7,7 & 0,3 \\
\hline I-K & $\mathrm{NH}_{2}$ & $8,0-2,0$ & $8,0-2,0$ & $5,6-5,0$ & 4,77 & 0,15 \\
\hline I-L & $t-\mathrm{C}_{4} \mathrm{H}_{9}$ & $8,0-4,0$ & $8,0-4,0$ & $6,3-4,7$ & 5,28 & 0,11 \\
\hline I-M & I & $4,0-2,0$ & $4,0-2,0$ & $3,0-2,4$ & 2,78 & 0,03 \\
\hline \multicolumn{2}{|c|}{ nifuroxazida } & $16,0-4,0$ & $16,0-4,0$ & $10,0-8,0$ & 8,87 & 0,33 \\
\hline \multirow{2}{*}{\multicolumn{2}{|c|}{$\begin{array}{l}\text { vancomicina } \\
\text { nitrofurantoína }\end{array}$}} & $<2,0$ & \multicolumn{2}{|c|}{$<2,0$} & & \\
\hline & & $32,0-16,0$ & \multicolumn{2}{|c|}{$32,0-16,0$} & & \\
\hline \multicolumn{2}{|c|}{ levofloxacino } & $<2,0$ & \multicolumn{2}{|c|}{$<2,0$} & & \\
\hline \multicolumn{2}{|c|}{ ampicilina } & $<2,0$ & \multicolumn{2}{|c|}{$<2,0$} & & \\
\hline \multicolumn{2}{|c|}{ cloranfenicol } & $16,0-4,0$ & \multicolumn{2}{|c|}{$16,0-4,0$} & & \\
\hline \multicolumn{2}{|c|}{ CS $(\%)^{*}$} & $20,0-10,0$ & $20,0-10,0$ & $13,1-11,8$ & & \\
\hline
\end{tabular}

a = desvio padrão;

* = porcentagem de DMSO como controle de solvente $(\mathrm{v} / \mathrm{v})$;

${ }^{* *}=$ leitura visual;

${ }^{* * *}=$ leitura espectrofotométrica. 
Tabela 11. Atividade antimicrobiana dos compostos 3-acetil-2-[5-nitro-furan2-il]-5-[4-substituído-fenil]-2,3-diidro-1,3,4-oxadiazolínico - Série II, frente à S. aureus, cepa ATCC 29213.

\begin{tabular}{|c|c|c|c|c|c|c|}
\hline & & & & $\mathrm{NO}_{2}$ & & \\
\hline & $\mathbf{R}$ & Fase I $\mu \mathrm{M}$ * & Fase $I \mu M$ ** & Fase II $\mu \mathrm{M}$ & $\mathrm{IC}_{90} \mu \mathrm{M}$ & $\mathrm{DP}^{\mathrm{a}}$ \\
\hline II-A & $\mathrm{H}$ & $16,0-8,0$ & $16,0-4,0$ & $9,2-7,6$ & 8,93 & 0,33 \\
\hline II-B & $\mathrm{CH}_{3}$ & $16,0-8,0$ & $16,0-8,0$ & $11,4-10,2$ & 12,2 & 0,12 \\
\hline II-C & $\mathrm{OCH}_{3}$ & $16,0-8,0$ & $16,0-8,0$ & $12,0-9,6$ & 10,87 & 0,18 \\
\hline II-D & $\mathrm{Br}$ & $8,0-4,0$ & $8,0-4,0$ & $5,5-4,4$ & 5,13 & 0,06 \\
\hline II-E & $\mathrm{CN}$ & $8,0-4,0$ & $8,0-2,0$ & $3,9-3,3$ & 3,89 & 0,07 \\
\hline II-F & $\mathrm{NO}_{2}$ & $8,0-4,0$ & $8,0-4,0$ & $6,1-5,5$ & 7,19 & 0,003 \\
\hline$\|-G$ & $n-\mathrm{C}_{4} \mathrm{H}_{9}$ & $64,0-16,0$ & $32,0-16,0$ & $20,1-18,3$ & 18,47 & 0,56 \\
\hline IIII & $\mathrm{Cl}$ & $16,0-8,0$ & $8,0-4,0$ & $6,2-5,6$ & 5,45 & 0,12 \\
\hline II-L & $t-\mathrm{C}_{4} \mathrm{H}_{9}$ & s.a. & s.a. & s.a. & s.a. & s.a. \\
\hline |I-M & 1 & $8,0-4,0$ & $8,0-4,0$ & $8,0-6,4$ & 7,48 & 0,05 \\
\hline
\end{tabular}

Neste trabalho observou-se que a leitura visual de turvo ou não turvo é equivalente a leitura por espectrofotômetro, principalmente quando é considerada a faixa que inibe $90 \%$ ou mais da população bacteriana. Além disso, a leitura por espectro é muito mais rápida, sensível e permite a utilização de ferramentas estatísticas, portanto uma alternativa bastante adequada. Vale salientar que tais resultados foram similares aos encontrados relativamente a outros microorganismos, com exceção de $C$. albicans, onde ainda há necessidade de mais análises, já que de acordo com a literatura há variação entre os resultados visuais e espectrofométricos (ARTHINGTON-SKAGGS et al., 2002).

Em seguida, a partir dos resultados obtidos na fase I por leitura em espectro, foram realizados os cálculos para obtenção do $I C_{90}$ de todos os compostos, 
descritos nas tabelas 9 e 10 para série I e II, respectivamente. Tal procedimento utilizou o modelo de crescimento exponencial que melhor se adequou aos resultados obtidos. Para construção da curva foram utilizados, no mínimo, 6 pontos, com média geral de 7 pontos. Como forma de exemplo, na tabela 11 mostra-se os dados do composto I-G, mais ativo frente à cepa de ATCC 29213 de S. aureus, e na figura 25 encontra-se a curva de crescimento exponencial, junto com o valor de $\mathrm{IC}_{90}$.

Tabela 12. Inibição de crescimento de S. Aureus, cepa ATCC 29213, nas concentrações testadas do composto I-G.

\begin{tabular}{ccc}
\hline $\begin{array}{c}\text { Concentração } \\
(\mu \mathbf{M})\end{array}$ & $\mathbf{I C}(\%)^{\mathbf{a}}$ & $\mathbf{D P}^{\mathbf{b}}$ \\
\hline 16,0 & 98 & 1 \\
8,0 & 100 & 0 \\
4,0 & 99 & 0 \\
2,0 & 91 & 8 \\
1,0 & 31 & 6 \\
0,5 & 30 & 6 \\
0,25 & 21 & 3 \\
\hline inibição de crescimento da população \\
bacteriana diante de determinada concentração de \\
composto; \\
b = desvio padrão.
\end{tabular}

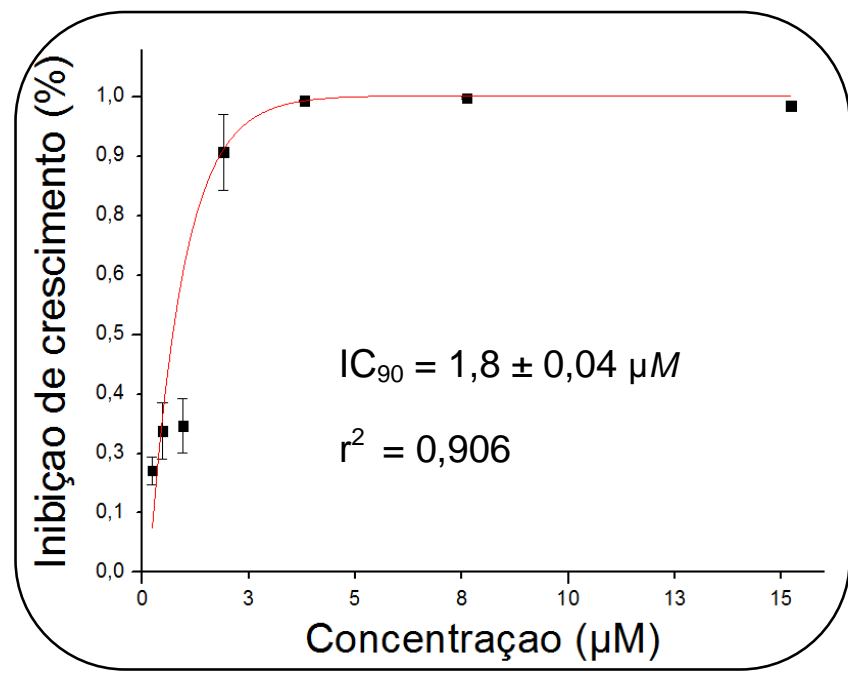

Figura 25. Curva de crescimento microbiano nas concentrações testadas do composto I-G $\left(\mathrm{R}=\mathrm{C}_{4} \mathrm{H}_{9}\right)$ frente a $\mathrm{S}$. Aureus, cepa ATCC 29213. Além, são descritos os respectivos valores de $\mathrm{IC}_{90}(\mu \mathrm{M})$, desvio padrão e o $\mathrm{r}^{2}$.

Para validar os valores de $\mathrm{IC}_{90}$ preditos, realizaram-se as fases II dos compostos de série I e II frente a cepa ATCC de $S$. aureus, que estão descritos, nas tabela 9 e 10. Foram avaliados nesta etapa 24 compostos que foram sintetizados e 0 composto protótipo. A partir dos resultados foi observado a correlação direta entre a média da CIM da fase II, de ambas séries e seus respectivos valores de $\mathrm{IC}_{90}$, calculados pelo coeficiente de correlação de Pearson (programa OriginPro 8), demonstrando alta correlação, sendo esta de 0,98 . Estes resultados estão descritos na tabela 12. 
Tabela 13. Correlação de Pearson entre resultados obtidos na fase II e $\mathrm{IC}_{90}$

\begin{tabular}{cccc}
\hline & $\bar{X}$ da fase II $\mu \mathrm{M}^{\mathrm{a}}$ & $\mathrm{IC}_{90} \mu \mathrm{M}$ & $\mathrm{DP}^{\mathrm{b}}$ \\
\hline NF & 9,00 & 8,87 & 0,33 \\
I-A & 5,05 & 5,27 & 0,04 \\
I-B & 11,80 & 10,64 & 0,08 \\
I-C & 3,60 & 4,11 & 0,41 \\
I-D & 4,10 & 4,50 & 0,09 \\
I-E & 5,25 & 5,35 & 0,02 \\
I-F & 3,25 & 3,31 & 0,10 \\
I-G & 2,20 & 1,80 & 0,04 \\
I-H & 7,60 & 8,34 & 0,06 \\
I-I & 4,70 & 5,52 & 0,10 \\
I-J & 8,15 & 7,70 & 0,29 \\
I-K & 5,30 & 4,77 & 0,15 \\
I-L & 5,50 & 5,28 & 0,11 \\
I-M & 2,70 & 2,78 & 0,03 \\
\hline II-A & 8,40 & 8,93 & 0,05 \\
II-B & 10,84 & 12,20 & 0,12 \\
II-C & 10,80 & 10,87 & 0,18 \\
II-D & 4,95 & 5,13 & 0,06 \\
II-E & 3,60 & 3,89 & 0,07 \\
II-F & 5,20 & 7,19 & 0,00 \\
II-G & 19,14 & 18,47 & 0,56 \\
II-I & 5,90 & 5,45 & 0,12 \\
II-M & 7,20 & 7,48 & 0,05 \\
\hline $\boldsymbol{R}$ & 0,98 & & \\
\hline a = Média entre o ponto máximo e mínimo do CIM de fase II; \\
b = Desvião padrão do ICa0; \\
$R=$ Coeficiente de correlação de Pearson. & \\
& & &
\end{tabular}

Diante disto, os valores de $\mathrm{IC}_{90}$ foram extrapolados para os outros microorganismos, como também foram utilizados como variáveis dependentes na análise exploratória de dados. A análise exploratória de dados foi aplicada porque mesmo o CIM sendo uma técnica altamente utilizada para avaliação da bioatividade de novos compostos e fármacos, a técnica apresenta como peculiaridade não ter valores bem definidos da inibição de crescimento, portanto não são adequados para estudos quantitativos e qualitativos de relação estrutura-atividade. Em contrapartida, o IC go $_{90}$ é um valor fixo que está inserido dentro da faixa de MIC, portanto, mais preciso e apto para estudos desta natureza. 
Ao analisar os resultados obtidos frente à $S$. aureus na tabela 9 , o composto com melhor atividade frente a $S$. aureus foi $\mathrm{I}-\mathrm{G}\left(\mathrm{R}=n-\mathrm{C}_{4} \mathrm{H}_{9} ; \mathrm{IC}_{90}=1,8 \pm 0,04 \mu \mathrm{M}\right)$, que apresentou atividade similar à vancomicina $(\mathrm{CIM}<2, \mu M)$, ampicilina $(\mathrm{CIM}<2,0$ $\mu M$ ) e levofloxacino ( $\mathrm{CIM}<2,0 \mu M$ ), os três fármacos mais ativos frente esta cepa. Outros compostos com atividades interessantes foram I-M $\left(R=I\right.$; $I C_{90}=2,78 \pm 0,03$ $\mu M)$ e I-F $\left(\mathrm{R}=\mathrm{NO}_{2} ; \mathrm{IC}_{90}=3,31 \pm 0,1 \mu \mathrm{M}\right)$.

Do restante da série I (tabela 9), com exceção dos compostos I-B $\left(\mathrm{R}=\mathrm{CH}_{3}\right.$; $\left.I_{90}=10,64 \pm 0,04 \mu M\right), \mathbf{I}-\mathbf{H}\left(\mathrm{R}=\mathrm{SO}_{2} \mathrm{NH}_{2} ; I_{90}=8,34 \pm 0,06 \mu M\right)$ e I-J $\left(\mathrm{R}=\mathrm{N}\left(\mathrm{CH}_{3}\right)_{2}\right.$; $\left.\mathrm{IC}_{90}=7,7 \pm 0,3 \mu M\right)$ que apresentaram as mais baixas atividades de toda a série, todos os compostos apresentaram atividade superior a nitrofurantoína e principalmente ao cloranfenicol $\left(\mathrm{IC}_{90}=7,72 \pm 0,06 \mu \mathrm{M}\right)$, fármaco prescrito na terapêutica e que pode ser utilizado para tratamento de bactérias resistentes à vancomicina (TUON, FILHO, 2009; HARTMANN et al., 2010). Por fim, novamente com exceção destes análogos, todos os compostos tiveram atividade superior ao composto protótipo $\left(\mathrm{R}=\mathrm{OH} ; \mathrm{IC}_{90}=8,87 \pm 0,33 \mu \mathrm{M}\right)$.

Por outro lado, nenhum dos compostos da série II apresentou atividade similar à vancomicina, ampicilina e levofloxacino (tabela 10). $O$ composto que apresentou maior potencial foi o análogo II-E $(R=C N$; IC $90=3,89 \pm 0,07 \mu \mathrm{M})$ que, junto com os compostos II-D $\left(R=B r ; I_{90}=5,13 \pm 0,06 \mu \mathrm{M}\right)$ e II-I $\left(R=C l ; I C_{90}=5,45 \pm 0,12 \mu \mathrm{M}\right)$, II-F $\left(R=\mathrm{NO}_{2} ; I_{90}=7,19 \pm 0,003 \mu \mathrm{M}\right)$, foram os únicos com atividade superior ao composto protótipo e ao cloranfenicol. Ademais, similar ao ocorrido com os compostos da série I, todos da série II apresentaram atividade superior a nitrofurantoína, fármaco muito utilizado na terapêutica para tratamento de infecções do sistema urinário.

O composto II-L $\left(\mathrm{R}=t-\mathrm{C}_{4} \mathrm{H}_{9} ; \mathrm{CIM}>128,0 \mu \mathrm{M}\right)$ não apresentou atividade nas concentrações testadas. Quando optou-se por aumentá-las, o composto precipitou nas faixas de concentração das soluções-mãe preparadas para o ensaio.

Nos testes frente a cepa ATCC 25922 de E. coli, descritos na tabela 13 e 14 para série I e II, respectivamente, a melhor atividade foi do composto I-K $\left(R=\mathrm{NH}_{2}\right.$; $\left.I_{90}=15,89 \pm 0,08 \mu \mathrm{M}\right)$, superior ao fármaco sulfametoxazol $\left(\mathrm{IC}_{90}=24,88 \mu \mathrm{M}\right)$, 
porém com atividade inferior aos outros fármacos de referência utilizados no ensaio. Com exceção deste, nenhum outro composto apresentou atividade significativa frente a este micro-organismo.

Tabela 14. Atividade antimicrobiana dos compostos 4-substituído-[(5nitrofuran-2-il) metileno] benzidrazida - Série I, frente à E. coli, cepa

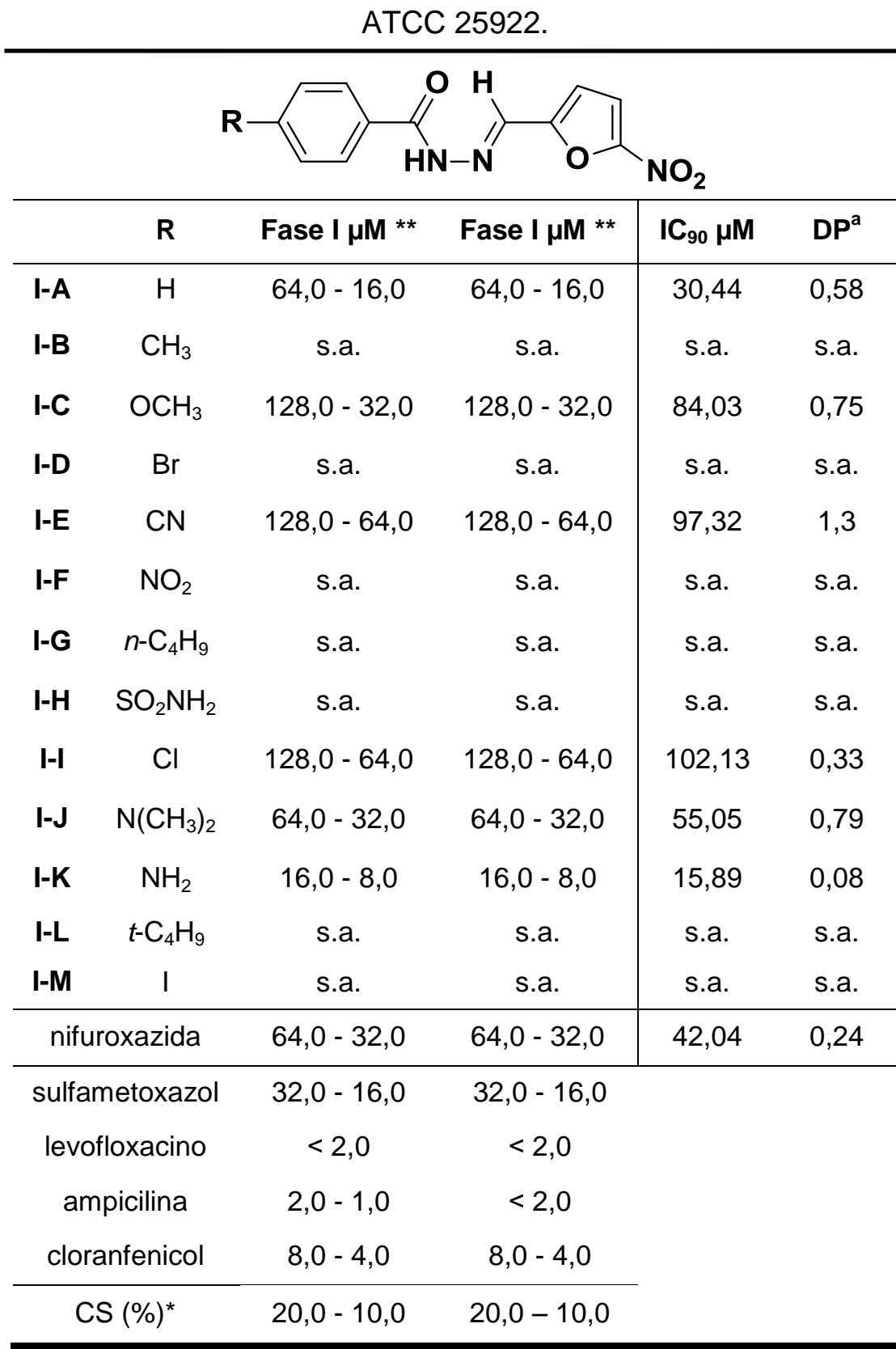

a = desvio padrão;

s.a. = sem atividade na concentração máxima testada;

* = porcentagem de DMSO como controle de solvente $(\mathrm{v} / \mathrm{v})$;

${ }^{* *}=$ leitura visual;

${ }^{\star * *}=$ leitura espectrofotométrica. 
Tabela 15. Atividade antimicrobiana dos compostos 3-acetil-2-[5nitro-furan-2-il]-5-[4-substituído-fenil]-2,3-diidro-1,3,4-oxadiazolínico - Série II, frente à E. coli, cepa ATCC 25922.

\begin{tabular}{|c|c|c|c|c|c|}
\hline & & & $\mathbf{N}^{0}$ & $\begin{array}{c}\mathrm{O}_{2} \\
\mathrm{O}_{2}\end{array}$ & \\
\hline & $\mathbf{R}$ & Fase I $\mu \mathrm{M}$ * & Fase I $\mu \mathrm{M}$ ** & $\mathrm{IC}_{90} \mu \mathrm{M}$ & $\mathrm{DP}^{\mathrm{a}}$ \\
\hline II-A & $\mathrm{H}$ & s.a. & s.a. & s.a. & s.a. \\
\hline II-B & $\mathrm{CH}_{3}$ & s.a. & s.a. & s.a. & s.a. \\
\hline II-C & $\mathrm{OCH}_{3}$ & s.a. & s.a. & s.a. & s.a. \\
\hline II-D & $\mathrm{Br}$ & s.a. & s.a. & s.a. & s.a. \\
\hline II-E & $\mathrm{CN}$ & $64,0-32,0$ & $64,0-32,0$ & 43,13 & 0,04 \\
\hline II-F & $\mathrm{NO}_{2}$ & $64,0-32,0$ & $64,0-32,0$ & 54,65 & 5,56 \\
\hline$\|-G$ & $n-\mathrm{C}_{4} \mathrm{H}_{9}$ & s.a. & s.a. & s.a. & s.a. \\
\hline IIII & $\mathrm{Cl}$ & $128,0-64,0$ & $128,0-64,0$ & 88,71 & 2,63 \\
\hline II-L & $t-\mathrm{C}_{4} \mathrm{H}_{9}$ & s.a. & s.a. & s.a. & s.a. \\
\hline II-M & 1 & s.a. & s.a. & s.a. & s.a. \\
\hline
\end{tabular}

Nos testes realizados com a cepa de E. faecalis, tabelas 15 e 16 para série I e II, respectivamente, diversos compostos apresentaram atividade biológica interessante, em especial o composto I-K $\left(R=\mathrm{NH}_{2}\right.$; IC $\left.\mathrm{C}_{90}=5,63 \pm 0,26 \mu \mathrm{M}\right)$, I-B $(R=$ $\left.\mathrm{CH}_{3} ; \mathrm{IC}_{90}=14,16 \pm 0,9 \mu \mathrm{M}\right)$ e I-C $\left(\mathrm{R}=\mathrm{OCH}_{3} ; \mathrm{IC}_{90}=14,62 \pm 0,71 \mu \mathrm{M}\right)$, porém todos inferiores aos fármacos de referência. Destes, o composto I-K foi o único mais ativo que o composto protótipo $\left(\mathrm{R}=\mathrm{OH} ; \mathrm{IC}_{90}=8,87 \pm 0,33 \mu \mathrm{M}\right)$. 
Tabela 16. Atividade antimicrobiana dos compostos 4-substituído-[(5nitrofuran-2-il) metileno] benzidrazida - Série I, frente à E. faecalis, сера ATCC 29212.

\begin{tabular}{cccc|cc}
\hline & & & & \\
\hline & & & & \\
\hline
\end{tabular}

a = desvio padrão;

s.a. = sem atividade na concentração máxima testada;

* = porcentagem de DMSO como controle de solvente $(\mathrm{v} / \mathrm{v})$;

** $=$ leitura visual;

$* * *$ leitura espectrofotométrica. 
Tabela 17. Atividade antimicrobiana dos compostos 3-acetil-2-[5nitro-furan-2-il]-5-[4-substituído-fenil]-2,3-diidro-1,3,4-oxadiazolínico -

Série II, frente à E. faecalis, cepa 29212.

\begin{tabular}{|c|c|c|c|c|c|}
\hline & & & $\underset{N-N}{\mathbf{N}}$ & & \\
\hline & $\mathbf{R}$ & Fase I $\mu \mathrm{M}$ * & Fase $I \mu M$ ** & $\mathrm{IC}_{90} \mu \mathrm{M}$ & $\mathrm{DP}^{\mathrm{a}}$ \\
\hline II-A & $\mathrm{H}$ & $64,0-32,0$ & $64,0-32,0$ & 52,87 & 2,04 \\
\hline II-B & $\mathrm{CH}_{3}$ & s.a. & s.a. & s.a. & s.a. \\
\hline II-C & $\mathrm{OCH}_{3}$ & s.a. & s.a. & s.a. & s.a. \\
\hline II-D & $\mathrm{Br}$ & s.a. & s.a. & s.a. & s.a. \\
\hline II-E & $\mathrm{CN}$ & $128,0-64,0$ & $128,0-64,0$ & 75,22 & 0,81 \\
\hline II-F & $\mathrm{NO}_{2}$ & $64,0-32,0$ & $64,0-32,0$ & 57,3 & 0,53 \\
\hline$\|-G$ & $\mathrm{C}_{4} \mathrm{H}_{9}$ & s.a. & s.a. & s.a. & s.a. \\
\hline II-I & $\mathrm{Cl}$ & s.a. & s.a. & s.a. & s.a. \\
\hline II-L & $\mathrm{t}-\mathrm{C}_{4} \mathrm{H}_{9}$ & s.a. & s.a. & s.a. & s.a. \\
\hline II-M & I & s.a. & s.a. & s.a. & s.a. \\
\hline
\end{tabular}

Compostos que não apresentaram boa ou nenhuma atividade nas concentrações testadas foram bem frequentes na cepa de $S$. marcescens e $K$. pneumoniae. No primeiro micro-organismo, os compostos com melhor atividade foram II-F $\left(R=\mathrm{NO}_{2} ; \mathrm{IC}_{90}=90,51 \pm 0,17 \mu \mathrm{M}\right)$, II-E $\left(R=C N ; \mathrm{IC}_{90}=96,26 \pm 1,32 \mu \mathrm{M}\right) \mathrm{e}$ I-E $\left(R=C N ; I_{90}=110,75 \pm 1,68 \mu \mathrm{M}\right)$, enquanto que no segundo nenhum composto apresentou atividade biológica. Portanto, os compostos não mostraram potencial para serem considerados promissores para estudos posteriores.

O mesmo foi observado nos testes frente a E. clocae, onde somente dois compostos I-K $\left(\mathrm{IC}_{90}=6,8 \pm 0,9 \mu \mathrm{M}\right)$ e o composto protótipo $\left(\mathrm{R}=\mathrm{OH} ; \mathrm{IC}_{90}=31,2 \pm\right.$ 4,13 $\mu \mathrm{M})$ apresentaram atividade biológica. Porém, diferente dos outros microorganismos com baixa atividade, tais resultados sugerem que compostos com 
substituentes doadores de elétrons e hidrofílicos possam ser de grande importância para a atividade de compostos da série I. Além disso, como nenhum composto da série II apresentou atividade, isto sugere que a ciclização do anel não foi benéfica. Isto pode ter ocorrido devido a diversos fatores, como por exemplo, o impedimento estereoquímico ou restrição de flexibidade que estruturas cíclicas apresentam podem ter diminuido a atividade destes compostos.

Por fim, os compostos com melhor atividade frente $C$. albicans foram componentes da série II, em especial o composto não substituído, II-A $\left(R=H ; I_{90}=\right.$ $15,85 \pm 0,3 \mu \mathrm{M})$. Mesmo que este análogo não tenha demonstrado atividade superior aos fármacos de referência e sua atividade não possa ser explicada por propriedades físico-químicas baseadas no diagrama de Craig, devido ao composto não ser influenciado por nenhuma das duas propriedades utilizadas, tal resultado se mostra similar aos da literatura, que sugerem que estruturas oxadiazolínicas apresentem atividade frente a $C$. albicans, principalmente por interação com a enzima CYP450 presente no fungo (SONEHARA, 2009). Os resultados obtidos para série I e II frente a $C$. albicans estão nas tabelas 17 e 18, respectivamente. 
Tabela 18. Atividade antimicrobiana dos compostos 4-substituído[(5-nitrofuran-2-il) metileno] benzidrazida - Série I, frente à $C$. albicans, cepa ATCC537Y.

\begin{tabular}{cccc|cc}
\hline & & & & \\
& & & & \\
\hline
\end{tabular}

a = desvio padrão;

s.a. = sem atividade na concentração máxima testada;

* = porcentagem de DMSO como controle de solvente $(\mathrm{v} / \mathrm{v})$;

** $=$ leitura visual;

${ }^{* * *}=$ leitura espectrofotométrica. 
Tabela 19. Atividade antimicrobiana dos compostos 3-acetil-2-[5-

nitro-furan-2-il]-5-[4-substituído-fenil]-2,3-diidro-1,3,4-

oxadiazolínico - Série II, frente à C. albicans, cepa ATCC537Y.

\begin{tabular}{lccc|cc}
\hline & & & \\
& & &
\end{tabular}

Nas tabelas 19 a 22 estão apresentados comparativos entre os compostos da série I e os compostos da série II frente aos micro-organismos S. aureus, E. coli, E. faecalis e $C$. albicans, que foram os micro-organismos frente aos quais os compostos se mostraram mais ativos. 
Tabela 20. Valores de $\mathrm{IC}_{90}$ da série I com a série II frente à S. aureus, cepa ATCC 29213

\begin{tabular}{ccc}
\hline \multirow{2}{*}{$\mathbf{R}$} & \multicolumn{2}{c}{ S. aureus - $\mathrm{IC}_{90} \mu \mathrm{M}$} \\
\cline { 2 - 3 } & Série I & Série II \\
\hline $\mathbf{H}$ & 5,27 & 8,93 \\
$\mathbf{C H}_{3}$ & 10,64 & 12,2 \\
$\mathbf{O C H}{ }_{3}$ & 4,11 & 10,87 \\
$\mathbf{B r}$ & 4,5 & 5,13 \\
$\mathbf{C N}$ & 5,35 & 3,89 \\
$\mathbf{N O}_{2}$ & 3,31 & 7,19 \\
$\mathbf{n}-\mathbf{C}_{4} \mathbf{H}_{9}$ & 1,8 & 18,47 \\
$\mathbf{S O}_{2} \mathbf{N H}_{2}$ & 8,34 & $-{ }^{a}$ \\
$\mathbf{C l}$ & 5,52 & 5,45 \\
$\mathbf{N}\left(\mathbf{C H}_{3}\right)_{2}$ & 7,7 & $-{ }^{a}$ \\
$\mathbf{N H}_{2}$ & 4,77 & $--^{a}$ \\
$\boldsymbol{t}-\mathbf{C}_{4} \mathbf{H}_{9}$ & 5,28 & s.a. \\
$\mathbf{~ I}$ & 2,78 & 7,48 \\
\hline
\end{tabular}

$\mathrm{a}=$ Compostos não sintetizados.

Tabela 21. Valores de $I C_{90}$ da série I com a série II frente à E. coli, cepa ATCC 25922

\begin{tabular}{ccc}
\hline \multirow{2}{*}{$\mathbf{R}$} & \multicolumn{2}{c}{ E. coli - $\mathrm{IC}_{90} \mu \mathrm{M}$} \\
\cline { 2 - 3 } & Série I & Série II \\
\hline $\mathbf{H}$ & 30,86 & s.a. \\
$\mathbf{O C H}$ & 84,03 & s.a. \\
$\mathbf{B r}$ & s.a. & 43,13 \\
$\mathbf{C N}$ & 97,32 & s.a. \\
$\mathbf{N O}_{2}$ & s.a. & 54,65 \\
$\mathbf{C l}$ & 102,13 & 88,71 \\
$\mathbf{N}\left(\mathbf{C H}_{3}\right)_{2}$ & 55,05 & - a $^{\mathrm{a}}$ \\
$\mathbf{N H}_{2}$ & 15,89 & $-\mathrm{a}^{\mathrm{a}}$ \\
\hline
\end{tabular}

s.a. = sem atividade na concentração máxima testada; $\mathrm{a}=$ Compostos não sintetizados.

Tabela 22. Valores de $\mathrm{IC}_{90}$ da série I com a série II frente à E. faecalis, cepa ATCC 29212

\begin{tabular}{ccc}
\hline \multirow{2}{*}{$\mathbf{R}$} & \multicolumn{2}{c}{ S. marcescens $-\mathrm{IC}_{90} \mu \mathrm{M}$} \\
\cline { 2 - 3 } & Série I & Série II \\
\hline $\mathbf{H}$ & 58,77 & 52,87 \\
$\mathbf{C H}_{3}$ & 14,16 & s.a. \\
$\mathbf{O C H}_{3}$ & 14,62 & s.a. \\
$\mathbf{C N}$ & 40,38 & 75,22 \\
$\mathbf{N O}$ & s.a. & 57,3 \\
$\mathbf{N} \mathbf{C}_{\mathbf{2}} \mathbf{H}_{9}$ & 55,9 & s.a. \\
$\mathbf{C l}$ & 40,7 & s.a. \\
$\mathbf{N H}_{2}$ & 5,63 & -. \\
$\mathbf{t}-\mathbf{C}_{4} \mathbf{H}_{9}$ & 59,84 & s.a. \\
\hline
\end{tabular}

s.a. = sem atividade na concentração máxima testada; $\mathrm{a}=$ Composto não sintetizado. 
Tabela 23. Valores de $\mathrm{IC}_{90}$ da série I com a série II frente à C. albicans, ATCC 537Y

\begin{tabular}{ccc}
\hline \multirow{2}{*}{$\mathbf{R}$} & \multicolumn{2}{c}{ C. albicans $-\mathrm{IC}_{90} \mu \mathrm{M}$} \\
\cline { 2 - 3 } & Série I & Série II \\
\hline $\mathbf{H}$ & 60,34 & 15,85 \\
$\mathbf{C H}_{3}$ & 58,26 & 49,93 \\
$\mathbf{O C H}_{3}$ & 54,58 & s.a. \\
$\mathbf{B r}$ & s.a. & 47,14 \\
$\mathbf{C N}$ & s.a. & 47,64 \\
$\mathbf{N O}_{2}$ & s.a. & 44,58 \\
$\mathbf{C}_{4} \mathbf{H}_{9}$ & s.a. & s.a. \\
$\mathbf{C l}$ & 52,99 & s.a. \\
\hline
\end{tabular}

s.a. = sem atividade na concentração máxima testada.

Observa-se que as melhores atividades de ambas as séries analisadas foram frente a $S$. aureus. Isso sugere que os nitrocompostos são mais efetivos, principalmente, contra esta bactéria gram-positiva. Além disso, com exceção do substituinte $-\mathrm{CN}$ de série II, todos os compostos oxadiazolínicos apresentaram atividade inferior que seus correspondentes da série I. Isso sugere que a ciclização e adição de um substituinte volumoso, que juntos integram o anel oxadiazolínico, podem não ser representativos para a melhora da atividade.

Diferente das cepas ATCC, O $S$. aureus VISA3 apresenta resistência a dezenove antibióticos, sendo eles: amoxicilina/ácido clavulânico, ampicilina, penicilina, rifampicina, trimetropina/sulfametoxazol, ciprofloxacino, cefotaxima, clindamicina, eritromicina, cefalotina, gentamicina, cefazolina, norfloxacino, imipinem, nitrofurantoína e oxacilina, além de apresentar resistência intermediária a vancomicina (MIC $\geq 4 \mu \mathrm{g} / \mathrm{mL}$ ou 2,76 $\mu \mathrm{M}$ ) (OLIVEIRA et al., 2001a; OLIVEIRA et al., 2011b). Esta é uma cepa de alta periculosidade, com arsenal terapêutico para tratamento é extremamente limitado. Os compostos I-F, I-G, I-L, II-D, II-E, II-I e composto protótipo foram selecionados para testar a atividade antimicrobiana neste micro-organismo porque apresentaram boa e média atividade frente à cepa padrão. Além disso, foi utilizado como fármaco de referência a vancomicina. Na tabela 23 é apresenta-se os resultados obtidos nos ensaios de atividade antimicrobianos. 
Tabela 24. Atividade antimicrobiana frente a $S$. aureus multirresistente, cepa VISA3, dos compostos de série I e II que apresentaram melhor atividade frente a cepa ATCC 29213 de S. aureus.

\begin{tabular}{|c|c|c|c|c|c|}
\hline & $\mathbf{R}$ & Fase I $\mu \mathrm{M}$ *夫 & Fase I $\mu M^{\star \star \star *}$ & $\mathrm{IC}_{90} \mu \mathrm{M}$ & $D^{a}$ \\
\hline I-F & $\mathrm{NO}_{2}$ & $8,0-4,0$ & $8,0-4,0$ & 4,2 & 0.06 \\
\hline I-G & $n-\mathrm{C}_{4} \mathrm{H}_{9}$ & $4,0-2,0$ & $4,0-2,0$ & 2,1 & 0.03 \\
\hline I-L & $t-\mathrm{C}_{4} \mathrm{H}_{9}$ & $8,0-4,0$ & $8,0-4,0$ & 6,2 & 0.06 \\
\hline \multicolumn{2}{|c|}{ nifuroxazida } & $16.0-8.0$ & $16,0-8,0$ & 10,8 & 0,8 \\
\hline II-D & $\mathrm{Br}$ & $16,0-8,0$ & $16,0-8,0$ & 14,6 & 0.73 \\
\hline II-E & $\mathrm{CN}$ & $8,0-4,0$ & $8,0-4,0$ & 4,8 & 0.09 \\
\hline II-I & $\mathrm{Cl}$ & $8,0-4,0$ & $8,0-4,0$ & 8,01 & 0.42 \\
\hline \multicolumn{2}{|c|}{ vancomicina } & $2,0-1,0$ & $2,0-1,0$ & & \\
\hline \multicolumn{2}{|c|}{ CS (\%) $)^{*}$} & $12,5-10,5$ & $12,5-10,5$ & & \\
\hline
\end{tabular}

a = desvio padrão;

* = porcentagem de DMSO como controle de solvente (v/v);

${ }^{* *}=$ leitura visual;

${ }^{\star * *}=$ leitura espectrofotométrica.

Todos os análogos testados apresentaram redução da atividade quando comparados com a cepa ATCC, em especial os compostos de série II. Destes, o composto II-D (IC $90=14,6 \pm 0,73 \mu \mathrm{M})$ foi o que apresentou maior variação, quase três vezes menos ativo que na cepa padrão. $\mathrm{Na}$ tabela 24 é feita a comparação entre os resultados das duas cepas. Esta diminuição na atividade antimicrobiana pode estar correlacionado com o mecanismo de resistência das cepas VISA, que é o espessamento da parede celular e consequente dificuldade na permeação dos compostos pela membrana. Entretanto, o composto mais ativo das duas séries, I-G $\left(\mathrm{IC}_{90}=2,1 \pm 0,03 \mu \mathrm{M}\right)$, foi o que apresentou menor variação de atividade, sugerindo o potencial deste composto para estudos futuros.

Tabela 25. Comparação de $I_{90}$ entre as cepas ATCC 29213 e VISA3 multirresistente de $S$. aureus.

\begin{tabular}{cccc}
\hline R & $\begin{array}{c}\text { S. aureus ATCC 29213 } \\
\mathrm{I}_{90} \mu \mathrm{M}\end{array}$ & $\begin{array}{c}\text { S. aureus VISA3 } \\
\mathrm{IC}_{90} \mu \mathrm{M}\end{array}$ \\
\hline I-F & $\mathrm{NO}_{2}$ & 3,0 & 4,2 \\
I-G & $n-\mathrm{C}_{4} \mathrm{H}_{9}$ & 1,8 & 2,1 \\
I-L & $t-\mathrm{C}_{4} \mathrm{H}_{9}$ & 5,28 & 6,2 \\
\hline \multicolumn{2}{c}{ nifuroxazida } & 52,99 & 10,8 \\
\hline II-D & $\mathrm{Br}$ & 5,13 & 14,6 \\
II-E & $\mathrm{CN}$ & 3,89 & 4,8 \\
II-I & $\mathrm{Cl}$ & 5,45 & 8,01 \\
\hline
\end{tabular}


6.5. Relações entre estrutura química e atividade biológica utilizados na análises quimiométricas

A partir dos resultados de atividade antimicrobiana, observaram-se quais as propriedades físico-químicas que mais influenciariam à atividade dos compostos análogos à nifuroxazida frente aos micro-organismos avaliados, como descrito no item 5.4.4.

Neste trabalho considera-se á atividade em 3 micro-organismos no processo de análise exploratória, a saber: S. aureus, E. coli e E. faecalis. Os outros microorganismos foram excluídos desta etapa porque menos da metade dos compostos apresentaram atividade antimicrobiana. Além disso, nestas três análises realizadas foram excluídos compostos que não apresentaram nenhuma atividade na concentração máxima testada.

\subsubsection{Cálculo das propriedades moleculares}

Para o cálculo das propriedades eletrônicas foi utilizado o método ab initio Hartree-Fock com conjunto de base 3-21G* no programa Gaussian 03W (MORGON, COUTINHO, 2007). O potencial eletrostático de cada análogo foi calculado pelo algoritmo CHELPG (BRENEMAN, WIBERG, 1990), que tem como objetivo avaliar as cargas atômicas pontuais que representam o potencial eletrostático ao redor da molécula a partir de pontos pré-definidos (GUADAGNINI, BRUNS, SOUZA, 1996). Além disso, foi calculado também nesta etapa os mapas de potencial eletrostático (MPEs) nas superfícies moleculares para visualização da distribuição de densidade eletrônica. Estes mapas, calculados em superfície molecular de Connolly, foram gerados para os compostos mais ativos da série I e II frente a $S$. aureus (I-G, $R=n$ $\mathrm{C}_{4} \mathrm{H}_{9} ; \mathrm{II}-\mathrm{E}, \mathrm{R}=\mathrm{CN}$ ) e para o composto com melhor atividade frente $E$. coli, $E$. faecalis e E. clocae (I-K, $\left.\mathrm{R}=\mathrm{NH}_{2}\right)$, figura 26. Além disso, foi gerado o mapa do composto protótipo (NF). Tais dados são interpretados por esquema de cores, vermelho para regiões com mais distribuição de densidade eletrônica $(-0,05)$ e azul para regiões com menor distrubuição de densidade eletrônica $(0,05)$. 


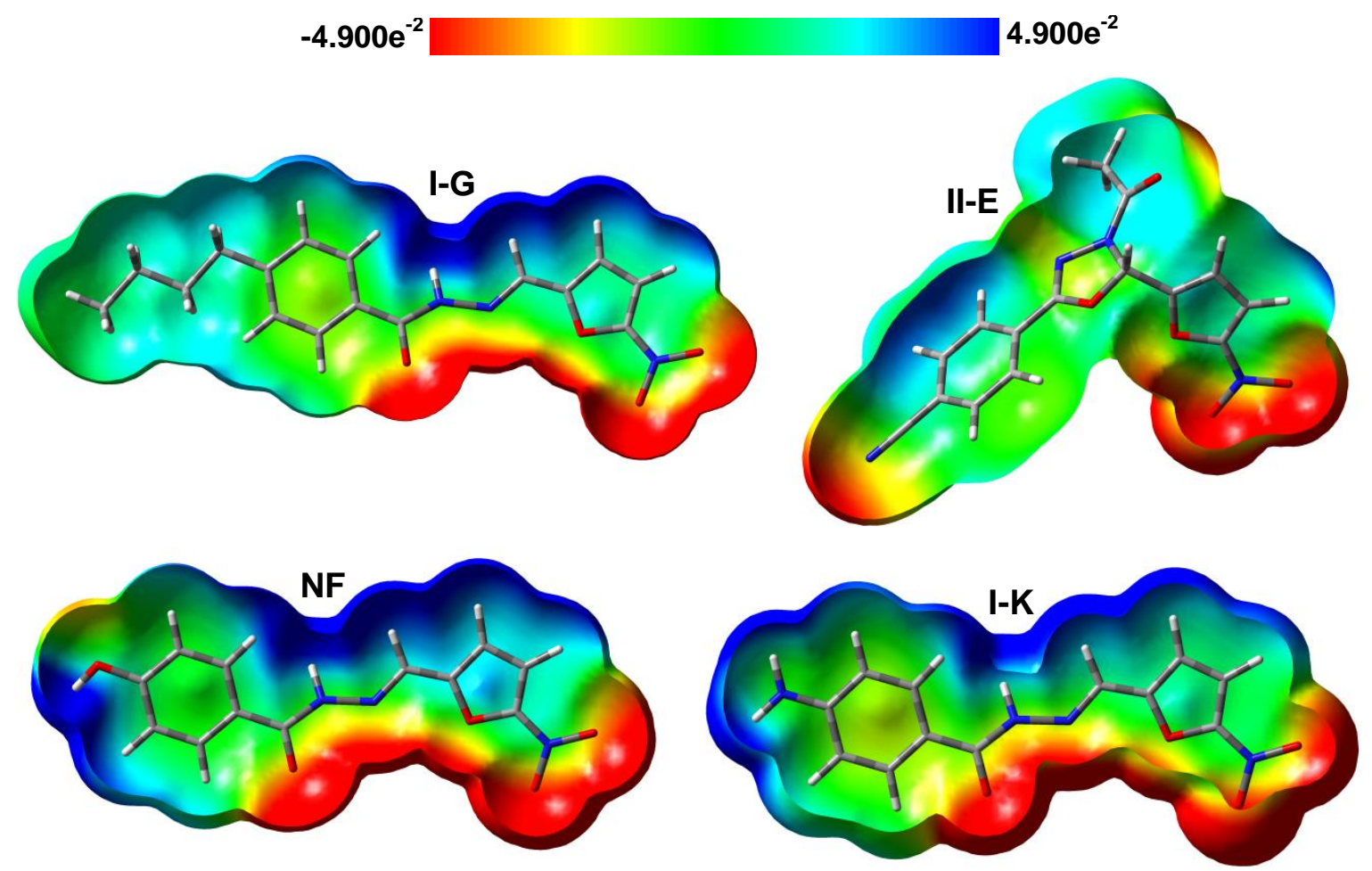

Figura 26. Mapas de potencial eletrostático (MPEs) dos compostos I-G, II-E, NF, I-K e o composto protótipo, gerados no programa Gaussian 03W e visualizados no GaussView. [Vermelho indica regiões com alta densidade eletrônica $(-0,05)$ e azul indica regiões com baixa densidade eletrônica $(0,05)$. Estruturas 3D exibidas por modelo de tudo (átomos de carbono em cinza, oxigênio em vermelho, nitrogênio em azul, hidrogênio em branco)].

O composto II-E apresenta distribuição de densidade eletrônica diferente da encontrada nos compostos I-G, I-K e NF, principalmente na posição para do anel benzênico. Enquanto o primeiro apresenta alta distrubuição de densidade eletrônica (coloração amarelo a vermelho), os compostos I-G, I-K e NF apresentam distribuição de baixa densidade eletrônica (verde a azul). Além disso, os compostos de série I apresentam alta densidade eletrônica próxima ao grupo farmacofórico, propagandose para o centro da molécula. Na série II, a região furânica também apresenta alta distrubuição de densidade eletrônica, porém a mesma diminui próximo à região do anel oxadiazolínico.

Outro descritor eletrônico é o momento de dipolo, que demonstra as diferenças de eletronegatividade entre átomos estão conectados. Portanto, grupos substituintes com diferentes eletronegatividades mudam as propriedades moleculares de uma estrutura e, consequentemente, podem influenciar na bioatividade (ARROIO, 
HONÓRIO, SILVA, 2010). Na figura 27 apresentam-se o vetor dos momento de dipolo totais $(\mu)$ dos compostos I-G, II-E, I-K e NF, todos calculados no programa Gaussian 03W.
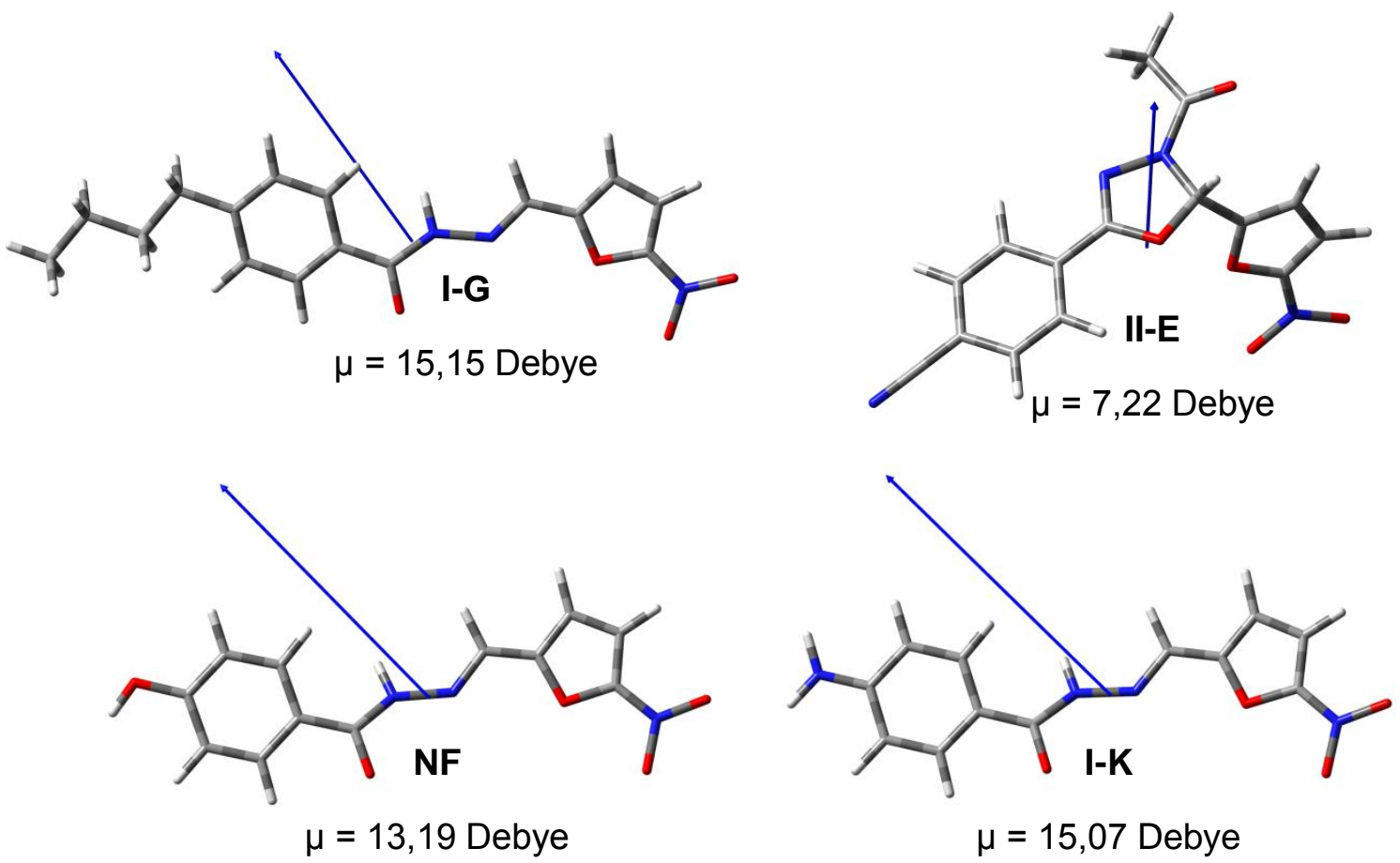

Figura 27. Vetores do momento de dipolo dos compostos I-G, II-E, NF, I-K e o composto protótipo, gerados pelo método de HF/3-21G* com cálculo de cargas CHELPG, no programa Gaussian 03W e visualizados no programa GaussView. As moléculas são exibidas em modelo tubo (átomos de carbono em cinza, oxigênio em vermelho, nitrogênio em azul e hidrogênio em branco).

Em geral, compostos de série I apresentaram valores de momento de dipolo superiores aos encontrados na série II. Isto sugere maior polaridade da molécula e, consequentemente, influência na bioatividade, como no caso dos compostos I-G, ativo frente à $S$. aureus, e I-K, ativo frente à E. coli, E. faecalis e E. clocae, pois estes compostos apresentaram os maiores valores de $\mu$ dentre as séries (ARROIO, HONÓRIO, SILVA, 2010). Similarmente, o composto oxadiazolínico II-E apresenta um dos maiores valores de $\mu$ da série II. Tais evidências sugerem que esta propriedade físico-química possa ser importante para atividade de compostos nitrofurânicos (JORDÃO et al., 2011; MONASTERIOS et al., 2006; PALACE-BERL et al., 2013). Adicionalmente, os vetores de $\mu$ (setas azuis) apontam dos locais de maior para menor densidade eletrônica. Os compostos da série I possuem $\mu$ 
similares, pois indicam que as regiões mais eletronegativas estão à direita da molécula (grupo nitrofurânico), enquanto que as menos eletronegativas estão à esquerda (anel benzênico p-substituído). Em contrapartida, o composto II-E apresenta $\mu$ menor, resultando em vetor pequeno do centro da molécula em direção ao grupo acetila.

Por fim, realizaram-se também cálculo de propriedades hidrofóbicas os estudos de modelagem molecular também foram aplicados para cálculo das propriedades hidrofóbicas como o coeficiente de partição n-octanol/água (ClogP) e mapas de potencial lipofílico (MLP). Foi utilizado nesta etapa o programa Sybyl 8.0 e os seguintes métodos para o cálculo de coeficiente de partição: Ghose e colaboradores (GHOSE, VISWANADHAN, WENDOLOSKY,, 1998) e Viswanadhan e colaboradores (VISWANADHAN et al., 1989). A figura 28 ilustra os mapas calculados em superfície de Connolly para os compostos I-G, I-K, II-E e NF, assim como seus respectivos valores de ClogP. Tais mapas são interpretados por esquema de cores, marrom para regiões hidrofóbicas $(0,1)$ e azul para regiões hidrofílicas $(-0,1)$.

O compostos I-G, um dos compostos mais lipofílicos das séries analisadas, apresenta grande parte de sua estrutura com coloração marrom, principalmente na posição para do anel benzênico, alta o suficiente para influenciar a hidrofilicidade da região farmacofórica, diferente dos outros compostos analisados que apresentam coloração azul nesta região da molécula. Com excessão deste análogo, as demais moléculas apresentam coloração verde em grande parte das suas estruturas, indicando caráter hidro-lipofílico.

Os valores obtidos de cada descritor das diferentes propriedades fisicoquímicas coletadas estão agrupados no anexo 3 deste trabalho. 


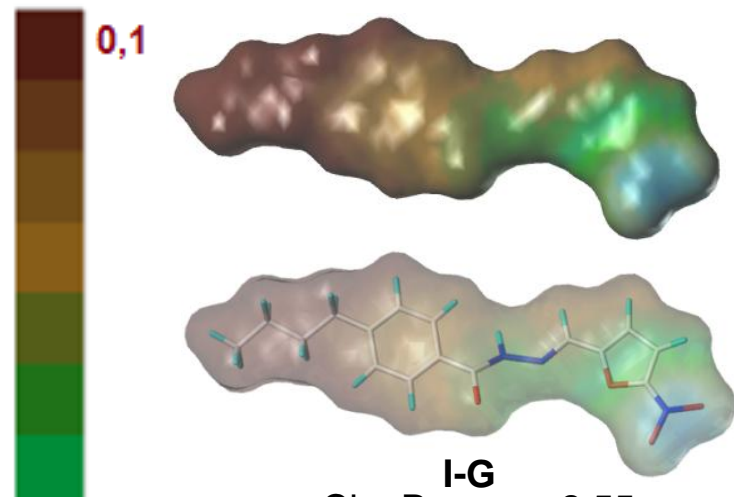

ClogP $P_{\text {SG-SLN }}=2,55$

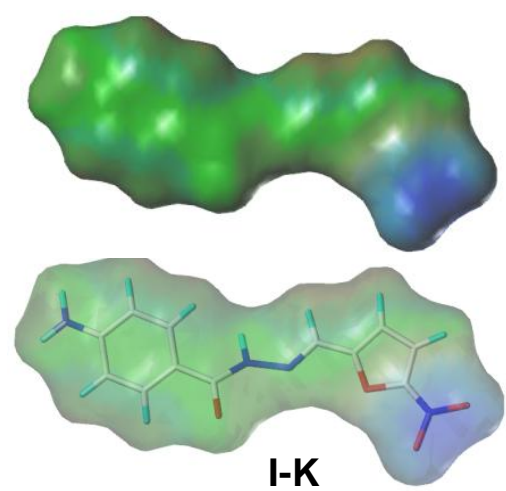

Clog $P_{\text {SG-SLN }}=-0,05$

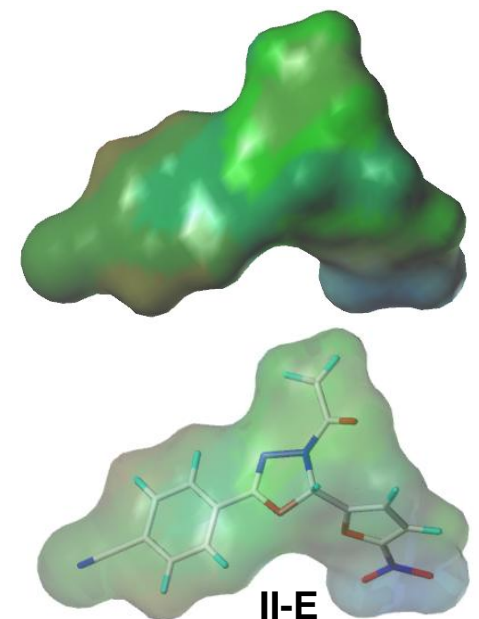

ClogP $P_{\text {SG-SLN }}=0,26$

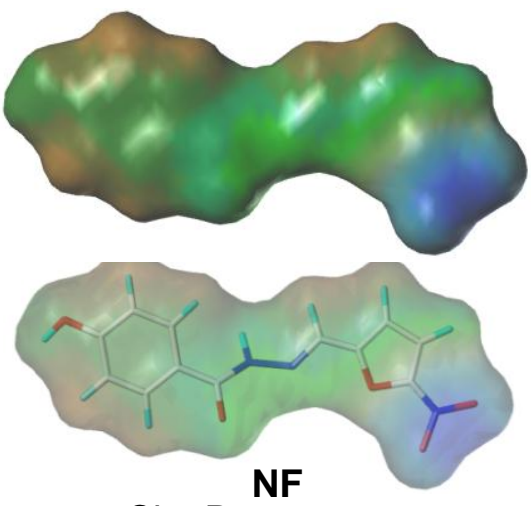

ClogP $P_{\text {SG-SLN }}=0,43$

Figura 28. Mapas de potencial lipofílico (MPLs) dos compostos I-G, II-E, I-K e NF, o composto protótipo, gerados no programa Sybyl 8.0 pelo método de Ghose (GHOSE, VISWANADHAN, WENDOLOSKY,, 1998).

[Marrom indica regiões hidrofóbicas $(0,1)$ e azul indica regiões hidrofílicas $(-0,1)$. Estruturas 3D exibidas por modelo de tudo (átomos de carbono em branco, oxigênio em vermelho, nitrogênio em azul, hidrogênio em ciano)].

A partir destes dados foi construída uma tabela de dados com 23 linhas (compostos sintetizados e composto prótotipo) e 38 colunas (descritores de diferentes naturezas e a variável dependente). Como já citado anteriormente, a variável dependente utilizada foi o $\mathrm{IC}_{90}$ que foi transformada em potência log $1 / \mathrm{IC}_{90}$, ilustrados na tabela 26. Além disso, os compostos foram classificados quanto a atividade biológica: $R=$ compostos com baixa atividade, $M=$ atividade moderada e $B$ = compostos ativos. Cada micro-organismo apresenta uma classificação diferente, 
devido aos resultados variados entre si. Tais valores estão detalhados nas seções seguintes deste trabalho.

Tabela 26. Atividade antimicrobiana, representado por $\mathrm{IC}_{90}$, dos compostos de série I e II

\begin{tabular}{|c|c|c|c|c|c|c|c|c|c|c|c|}
\hline & \multirow{2}{*}{$\mathbf{R}$} & \multirow{2}{*}{$\begin{array}{l}\text { Massa } \\
\text { Molar }\end{array}$} & \multicolumn{3}{|c|}{$\begin{array}{c}\text { S. aureus ATCC } \\
29213 \\
\end{array}$} & \multicolumn{3}{|c|}{ E. coli ATCC 25922} & \multicolumn{3}{|c|}{$\begin{array}{c}\text { E. faecalis ATCC } \\
29212 \\
\end{array}$} \\
\hline & & & $\begin{array}{l}I C_{90} \\
\mu M^{\mathrm{a}}\end{array}$ & DP & $\begin{array}{l}\log \\
1 / C^{b}\end{array}$ & $\begin{array}{l}I C_{90} \\
\mu M^{\mathrm{a}}\end{array}$ & DP & $\begin{array}{l}\log \\
1 / C^{6}\end{array}$ & $\begin{array}{l}I_{90} C_{90} \\
\mu M^{\mathrm{a}}\end{array}$ & DP & $\begin{array}{l}\log \\
1 / C^{6}\end{array}$ \\
\hline I-A & $\mathrm{H}$ & 259,22 & 5,27 & 0,04 & 5,28 & 30,44 & 0,58 & 4,52 & 58,77 & 1,15 & 4,23 \\
\hline$I-B$ & $\mathrm{CH}_{3}$ & 273,24 & 10,6 & 0,07 & 4,97 & --- & --- & --- & 14,16 & 0,9 & 4,85 \\
\hline$I-C$ & $\mathrm{OCH}_{3}$ & 289,24 & 4,11 & 0,41 & 5,39 & 84,03 & 0,75 & 4,08 & 14,62 & 0,71 & 4,84 \\
\hline$I-D$ & $\mathrm{Br}$ & 338,11 & 4,5 & 0,09 & 5,35 & --- & --- & --- & --- & --- & --- \\
\hline$I-E$ & $\mathrm{CN}$ & 284,23 & 5,35 & 0,02 & 5,27 & 97,32 & 1,3 & 4,01 & 40,38 & 0,58 & 4,39 \\
\hline$I-F$ & $\mathrm{NO}_{2}$ & 304,22 & 3,31 & 0,62 & 5,48 & --- & --- & -- & --- & --- & --- \\
\hline$I-G$ & $n-\mathrm{C}_{4} \mathrm{H}_{9}$ & 315,32 & 1,8 & 0,04 & 5,74 & --- & --- & --- & 55,9 & 1,13 & 4,25 \\
\hline$I-H$ & $\mathrm{SO}_{2} \mathrm{NH}_{2}$ & 338,30 & 8,34 & 0,06 & 5,08 & --- & --- & --- & --- & --- & --- \\
\hline$I-I$ & $\mathrm{Cl}$ & 293,66 & 5,52 & 0,1 & 5,26 & 102,1 & 0,33 & 3,99 & 40,7 & 3,18 & 4,39 \\
\hline$I-J$ & $\mathrm{~N}\left(\mathrm{CH}_{3}\right)_{2}$ & 302,29 & 7,7 & 0,29 & 5,11 & 55,05 & 0,79 & 4,26 & --- & --- & \\
\hline$I-K$ & $\mathrm{NH}_{2}$ & 274,23 & 4,77 & 0,15 & 5,32 & 15,89 & 0,08 & 4,80 & 5,63 & 0,26 & 5,25 \\
\hline$I-L$ & $t-\mathrm{C}_{4} \mathrm{H}_{9}$ & 315,32 & 5,28 & 0,11 & 5,28 & --- & --- & --- & 59,84 & 0,09 & 4,22 \\
\hline$I-M$ & I & 385,11 & 2,78 & 0,03 & 5,56 & --- & --- & --- & --- & --- & --- \\
\hline II-A & $\mathrm{H}$ & 301,25 & 8,93 & 0,05 & 5,05 & --- & --- & --- & 52,87 & 2,04 & 4,28 \\
\hline II-B & $\mathrm{CH}_{3}$ & 315,28 & 12,2 & 0,12 & 4,91 & --- & --- & --- & --- & --- & --- \\
\hline$I I-C$ & $\mathrm{OCH}_{3}$ & 331,28 & 10,8 & 0,18 & 4,96 & --- & --- & --- & --- & --- & --- \\
\hline$I I-D$ & $\mathrm{Br}$ & 380,15 & 5,13 & 0,06 & 5,29 & --- & --- & --- & --- & --- & --- \\
\hline II-E & $\mathrm{CN}$ & 326,26 & 3,89 & 0,07 & 5,41 & 43,13 & 0,04 & 4,37 & 75,22 & 0,81 & 4,12 \\
\hline$I I-F$ & $\mathrm{NO}_{2}$ & 346,25 & 7,19 & 0,00 & 5,14 & 54,65 & 5,56 & 4,26 & 57,3 & 0,53 & 4,24 \\
\hline$I I-G$ & $n-\mathrm{C}_{4} \mathrm{H}_{9}$ & 357,36 & 18,4 & 0,56 & 4,73 & --- & --- & --- & --- & --- & --- \\
\hline II-I & $\mathrm{Cl}$ & 335,70 & 8,93 & 0,05 & 5,26 & 88,71 & 2,63 & 4,05 & --- & --- & --- \\
\hline$I I-L$ & $t-\mathrm{C}_{4} \mathrm{H}_{9}$ & 357,36 & --- & --- & --- & --- & --- & --- & --- & --- & --- \\
\hline II-M & I & 427,15 & 7,48 & 0,05 & 5,13 & --- & --- & --- & --- & --- & --- \\
\hline nif & xazida & 275,22 & 8,87 & 0,33 & 5,05 & 42,04 & 0,24 & 4,38 & 31,2 & 4,13 & 4,97 \\
\hline
\end{tabular}

a: Referente a triplicata do ensaio;

b: Valor de $\mathrm{IC}_{90}$ em potência (concentração $\mathrm{C}$ em M);

--- = Compostos que não apresentaram atividade;

$\mathrm{DP}=$ Desvio Padrão.

Os descritores obtidos foram pré-selecionados por dois filtros: (i) Dispersão gráfica entre atividade biológica e descritores (scatter plot) (FERREIRA, KUNDALJ, 2011); (ii) Coeficiente de correlação linear de Pearson entre atividade biológica e descritores, com valor de corte de 0,2 . Na figura 29 estão ilustrados dois exemplos frente a $S$. aureus: Um descritor incluído na análise com boa dispersão e coeficiente de Pearson $(\mathrm{R})$ alto (ASA- $=\mathrm{x} 14$ ); e outro com pouca dispersão, coeficiente de Pearson baixo e, consequentemente, descartado dos estudos $\left(\right.$ Chelpg_NO $\left.\mathrm{NO}_{2}=x 35\right)$. 
Os descritores analisados neste trabalho, considerando os critérios de seleção citados neste trabalho estão listados no anexo 4.

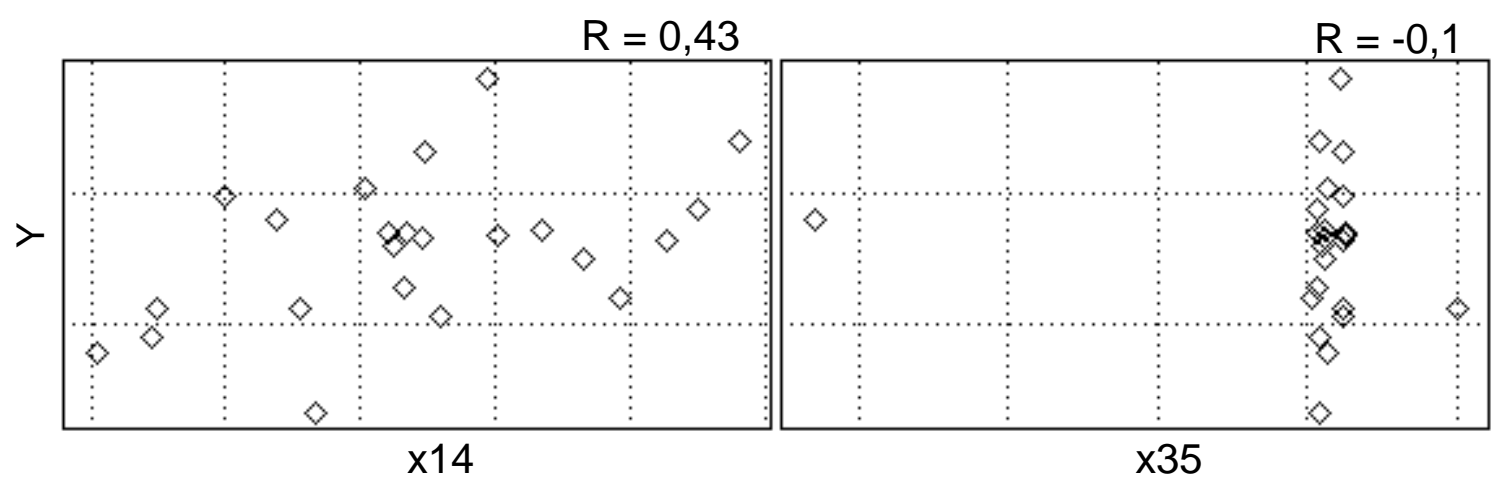

Figura 29. Dispersão da atividade biológica dos compostos de série I e II frente à $S$. aureus com os descritores x14 (ASA-) e x35 (Chelpg_NO $\mathrm{NO}_{2}$ e coeficiente de correlação de Pearson, $\mathbf{R}$.

\subsubsection{Análise exploratória de dados}

Após cálculo dos descritores, a relação estrutura-atividade for realizada pela análise exploratória dos dados, que compreende-se pela análise de agrupamentos hierárquico (HCA, Hierarchical Clusters) e análise de componentes principais (PCA, Principal Component Analysis) no programa Pirouette, versão 3.11. A análise exploratória de dados como em método quimiométrico não-supervisionado tem como objetivo a identificação de padrões em um conjunto de dados a partir da informação contida nas variáveis independentes sem a necessidade de se descobrir relações entre causa e efeito da atividade (FERREIRA, KIRALJ, 2011).

Primeiramente, para esta análise foi realizado pré-tratamento de dados considerado importante, chamado de autoescalamento (FERREIRA, KIRALJ, 2012). É comum que descritores apresentem variações de dados muito grandes durante a análise, portanto com este procedimento a influência de uma variável dominante em cálculos posteriores diminui, subtraindo de cada elemento de uma coluna da tabela o valor médio da respectiva coluna para dividir o resultado pelo desvio padrão da mesma, explicado na equação 6 . 
$X i j=\frac{(X i j-\bar{X} j)}{s j}$

Equação 6

Em que: $X i j$ é descritor j para o composto i; $\bar{X} j$ é a média dos valores para o descritor $j$ e sjé o desvio padrão dos valores do descritor $j$.

A análise de PCA é definida por Ferreira e Kiralj como "método usado para transformar dados complexos em uma nova perspectiva, onde se espera que as informações mais importantes e relevantes se tornem mais visíveis e de fácil interpretação" (FERREIRA, KIRALJ, 2011). Isso se dá pela decomposição dos dados originais em duas matrizes, uma de escores $\mathbf{T}$, referente a relações entre as amostras, e outra de pesos (loadings) L, relacionada com a informação que cada descritor contribuiu para a formação de uma PC (Principal Component Componente Principal) (FERREIRA, KIRALJ, 2011). Além disso, nestas duas matrizes também se obtêm a porcentagem de variância, relacionado à quantidade de informação contida nas PCs (FERREIRA, KIRALJ, 2011). A expressão geral 7 representa a obtenção de PCs.

$X=T L^{T}=T_{A} L_{A}{ }^{T}+E$

Equação 7

Em que:

$\mathrm{X}=$ Matriz de dados originais;

$\mathrm{T}=$ Matriz de escores;

$L=$ Matriz de pesos;

$\mathrm{E}=$ Resíduos;

$A=$ Componentes principais significativas.

O método HCA agrupa conjuntos de dados com atributos semelhantes na forma de dendrograma. Neste, a distância entre amostras $a$ e $b$ é modificado em uma matriz de similaridade, equação 8 , cujos elementos são os índices de similaridade (FERREIRA, 2002). Tal abordagem é interessante porque o índice de similaridade varia de 0 a 1 , sendo 1 a máxima similaridade entre amostras (FERREIRA, KIRALJ, 2011). Coletaram-se dois tipos de dendrograma neste trabalho, um dendrograma de amostras, onde foi analisado a similaridade entre amostras, e outro dendrograma de variáveis, que considerou a atividade biológica 
como variável independente para visualizar com quais descritores a mesma apresenta maior similaridade. (FERREIRA, KIRALJ, 2011; TURRA, PASQUALATO, BARROS, 2012).

$$
S_{a b}=1-\left(d_{a b} / d_{\max }\right)
$$

Equação 8

Em que:

$S_{a b}=$ Índice de similaridade entre as amostras a e $b$

$d_{a b}=$ Distância entre duas amostras;

$d_{\text {max }}=$ Maior distância do conjunto de dados.

O $\mathrm{d}_{\mathrm{ab}}$ na equação 8 é derivado de um modelo matemático de distância euclidiana, equação 9, que calculas a distância entre as amostras a e $b$ (FERREIRA, 2002).

$$
d a b=\sqrt{(X a 1-X b 1)^{2}+(X a 2-X b 2)^{2}+\ldots+(X a n-X b n)^{2}} \quad \text { Equação } 9
$$

Em que:

$d_{a b}=$ Distância entre dois vetores de amostras;

$X a$ e $\mathrm{X} b=$ Amostras;

Por fim, a distância de Mahalanobis foi utilizada para a identificação de possíveis amostras atípicas, comumente chamadas de outliers. Esta validação estatística se baseia na correlação e distância entre amostras (Pirouette, 2003). Caso a amostra esteja normalmente distribuída, o valor crítico ( $\mathrm{MD}_{\text {crit }}$ ) pode ser determinado pela distruibuição qui-quadrado com $\mathrm{k}$ graus de liberdade. Caso a amostra exceda o $\mathrm{MD}_{\text {crit, }}$ que compreende ao limite de confiança de $95 \%$, é sugerido que a amostra possa ser uma possível amostra atípica ou outlier. Na equação 10 está representada a distância de Mahalanobis.

$$
M D_{i}=(t i-\bar{t})^{\top} S_{k}^{-1}\left(t_{i}-\bar{t}\right) \quad \text { Equação } 10
$$

Em que:

$S$ = Matriz de pontuações de covariância;

$t=$ Vetor de escores médios. 


\subsubsection{Análise Exploratória frente à Staphylococcus aureus}

$\mathrm{Na}$ análise exploratória dos dados para $S$. aureus, a tabela final foi composta por 23 linhas (compostos) e 9 colunas (descritores e atividade antimicrobiana). $O$ gradiente de atividade foi: $R\left(\log 1 / I C_{90}=4,73-5,08\right), M\left(\log 1 / I C_{90}=5,11-5,41\right)$, $B\left(\log 1 / / C_{90}=5,48-5,74\right)$.

$\mathrm{Na}$ análise de componentes principais (PCA), a primeira componente (PC1) apresenta $61,29 \%$ da informação do conjunto de dados originais, enquanto que a segunda (PC2) apresenta 20,65\%. Tais dados estão presentes na figura 30A. Na tabela de pesos (loadings) é demonstrado que a PC1 é influenciada por descritores topológicos como Índice de Platt e Randic (calculados no programa Marvin Beans), enquanto que na PC2 descritores como $\sigma$ de Hammett se mostraram importantes (figura 30B) (HAMMETT, 1937). Na análise do gráfico de escores (figura 30C) as duas principais PCs discriminaram o conjunto de dados em dois grupos: A (Compostos da série I) e B (Compostos de série II ou série I com maior volume na posição para), que pode ser dividido em B' (Substituintes retiradores de elétrons) e B" (Substituintes com impedimento estérico). 


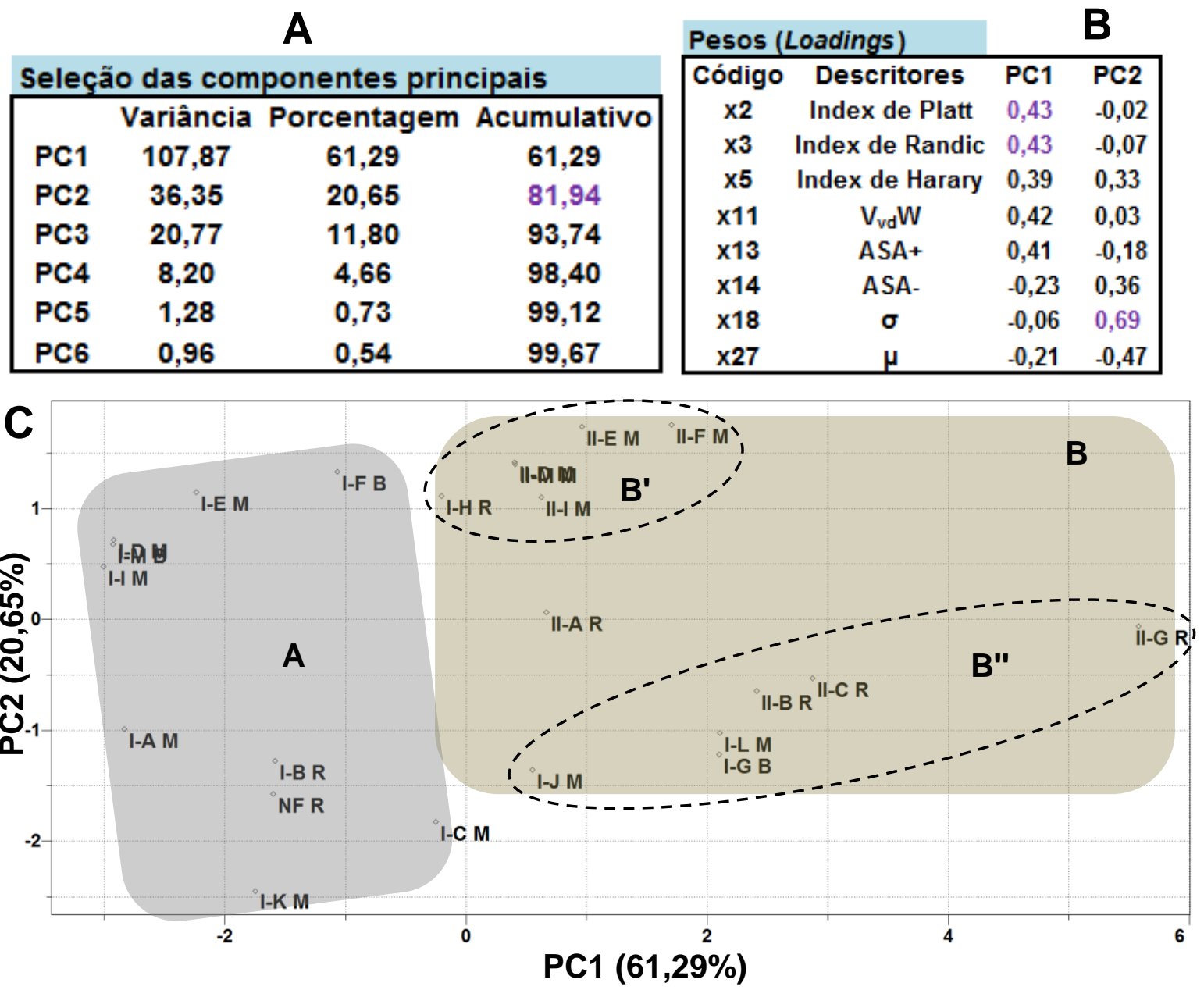

Figura 30. Análise de PCA dos compostos de série I e II frente à S. aureus: Seleção de componentes principais (A) e tabe.a de pesos de descritores nas duas PCs (B); gRáfico de escores entre PC1 e PC2, separando o conjunto de dados em A e B (B' e B') (C).

O HCA de amostras, figura 31, com a atividade biológica como variável dependente e com o cursor de similaridade em 0,3 (linha pontilhada) foi separado em dois grupos: Vermelho (A) com 31\% de similaridade (Em geral, compostos de série I com substituintes volumosos e todos análogos da série II; molécula mais ativa da série se inseriu neste agrupamento [cluster]); Marrom (B) com 51\% de similaridade (Compostos de série I). 


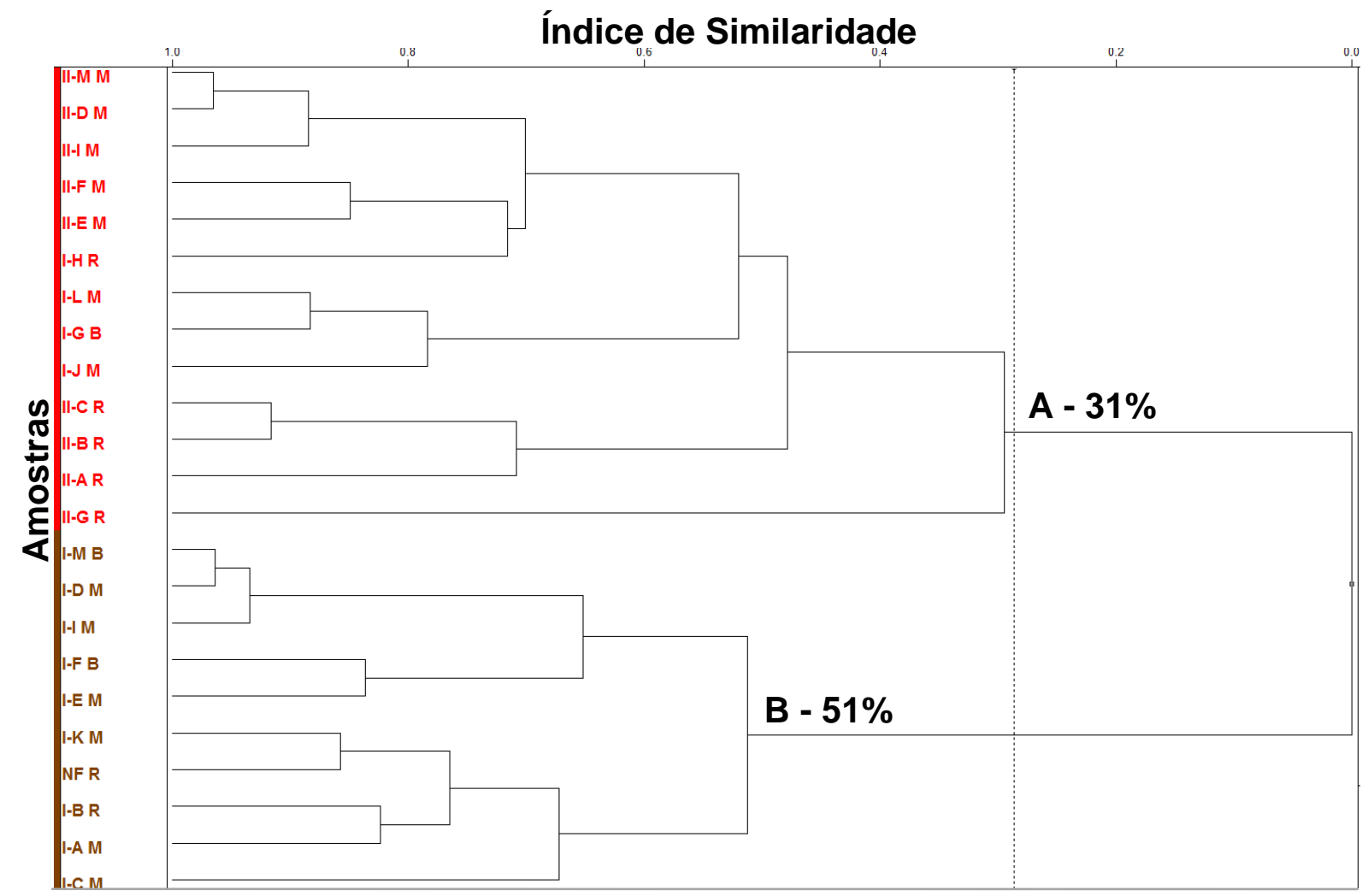

Figura 31. Dendrograma dos compostos estudados das séries I e II frente à $S$. aureus. Conjunto de dados separado nos agrupamentos A e B. Letras R, M, B foram utilizadas para demonstrar o gradiente de atividade biológica em ruim, moderado e bom, respectivamente.

No dendrograma de variáveis, utilizado para verificar com quais descritores se agrupa a atividade biológica (y), é observado que propriedades eletrônicas ( $\mu$ e $\sigma$ ) e topológicas (ASA-) apresentaram maior semelhança com y, figura 32. O descritor $\mu$, que foi o mais próximo a atividade biológica e extraído do programa Gaussian, representa qualitativamente a diferença de eletronegatividade entre átomos conectados na molécula. Outros descritores que demonstraram alta semelhança com y foram os descritores $\sigma$, referente à eletronegatividade de um determinado substituinte, e ASA-, variável de natureza geométrica referente a área acessível ao solvente de átomos com carga parcial negativa. $\mathrm{Na}$ literatura são encontrados indícios que tais propriedades eletrostáticas são realmente influentes na atividade de nitrofuranos, principalmente $\mu$, onde estudos indicam que compostos com baixo valor neste descritor não apresentaram nenhuma atividade frente a $S$. aureus (MONASTEIROS et al., 2006). Além disso, os outros descritores topológicos selecionados para a análise se agruparam em um terceiro agrupamento, onde apresentaram menor relação com a atividade biológica. 


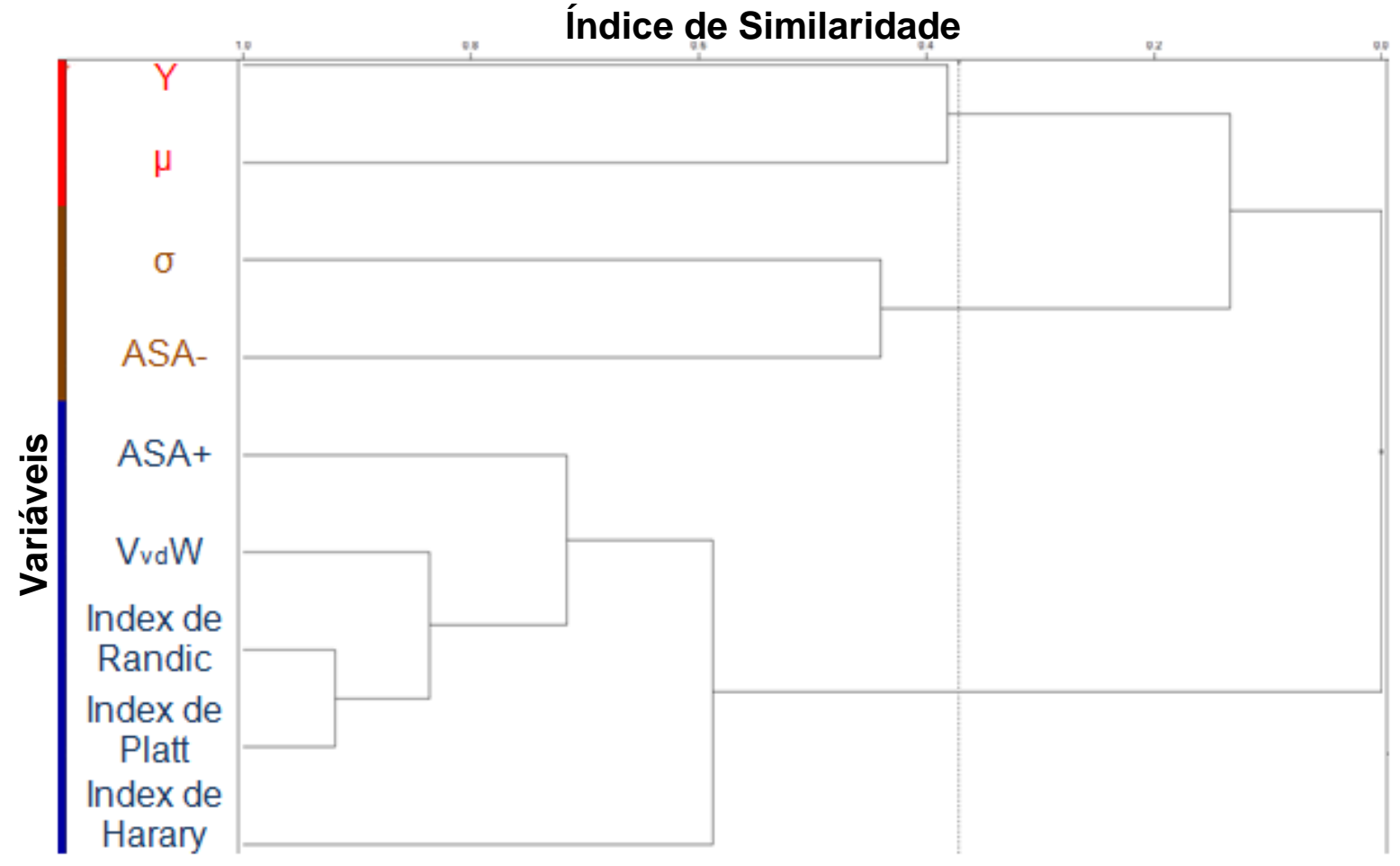

Figura 32. Dendrograma de variáveis para o conjunto de análise frente à $S$. aureus.

Atividade antimicrobiana como variável independente; descritores agrupados nas cores vermelha, marrom, roxo, laranja.

$\mathrm{Na}$ análise da distância de Mahalanobis, figura 33, nenhum composto excedeu o valor de MDcrit (95\% de confiança), o que demonstra a ausência de amostras atípicas (outliers) nos dados analisados (MAHALANOBIS, 1936).

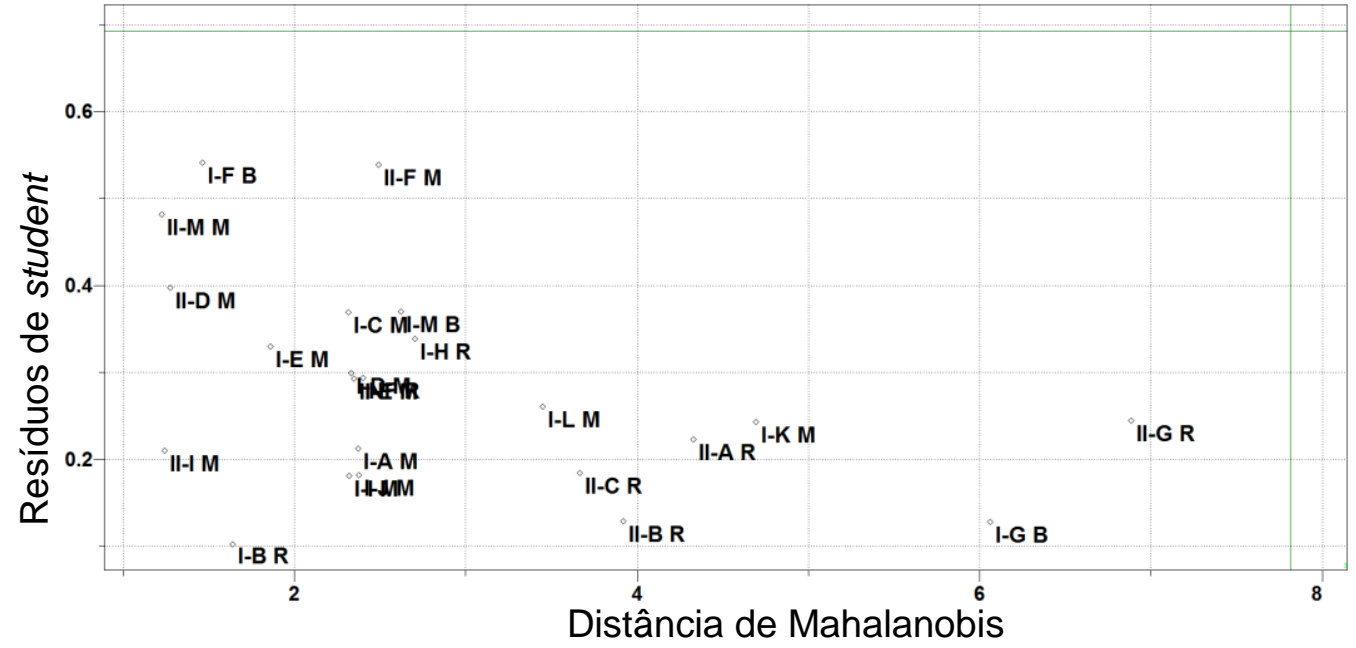

Figura 33. Resíduos de student versus distância de Mahalanobis para compostos analisados frente à $S$. aureus. As linhas verdes correspondem ao intervalo de confiança de $95 \%$. 


\subsubsection{Análise Exploratória para atividade frente à Escherichia coli}

$\mathrm{Na}$ análise exploratória de dados E. coli, a tabela final foi composta por 10 linhas (compostos) e 10 colunas (descritores e atividade biológica). A classificação quanto a atividade foi: $R\left(\log 1 / \operatorname{IC} C_{90}=3,99-4,26\right), M\left(\log 1 / I C_{90}=4,26-4,52\right)$, $B$ $\left(\log 1 / / C_{90}=4,8\right)$.

$\mathrm{Na}$ análise de PCA, as duas principais PCs (PC1 e PC2) apresentam $67,3 \%$ da informação do conjunto de dados originais. Tais dados estão presentes na figura 34A. A tabela de pesos (figura 34B), mostra que os descritores que foram mais influentes em PC1 apresentam características eletrônicas, por exemplo $F$, a constante de efeito indutivo de Swain-Lupton (SWAIN, LUPTON, 1968), enquanto que os descritores que mais influenciaram a PC2 foram descritores topológicos como ASA_P e ASA_H (área acessível a solventes de átomos hidrofílicos e hidrofóbicos, respectivamente), ASA_P com influência favorável (ASA_P $=0,56$ ) e ASA_H com influência desfavorável (ASA_H $=-0,48)$. Na análise do gráfico de escores, figura $34 \mathrm{C}$, as duas primeiras PCs discriminaram o conjunto em três grupos: A (Compostos da série I com substituintes hidrofílicos e doadores de elétrons com média a alta atividade); $\mathbf{B}$ (Compostos com substituintes retiradores de elétrons com média a baixa atividade); $\mathbf{C}$ (Compostos com baixa atividade). Os compostos mais ativos da série frente a este micro-organismo, marcados com um $B$, situam-se no grupo $\mathbf{A}$. 


\begin{tabular}{|c|c|c|c|c|c|c|c|}
\hline \multirow[b]{2}{*}{$\mathbf{A}$} & & & & \multicolumn{2}{|c|}{ Pesos (Loadings) } & \multicolumn{2}{|l|}{$\mathbf{B}$} \\
\hline & & & & \multirow{3}{*}{\begin{tabular}{|c|} 
Código \\
x12 \\
x15 \\
x16
\end{tabular}} & \multirow{3}{*}{$\begin{array}{c}\text { Descritores } \\
\text { ASA } \\
\text { ASA_H }\end{array}$} & \multirow{2}{*}{$\begin{array}{l}\text { PC1 } \\
0,33 \\
0,31\end{array}$} & \multirow{3}{*}{$\begin{array}{l}\text { PC2 } \\
-0,14 \\
-0,48\end{array}$} \\
\hline \multicolumn{4}{|c|}{ Seleção das componentes principais } & & & & \\
\hline & Variânci & centac & Acumulativo & & & $\begin{array}{r}0,31 \\
-0,09\end{array}$ & \\
\hline PC1 & 32,32 & 39,90 & 39,91 & x17 & $\pi$ & 0,28 & $-0,47$ \\
\hline PC2 & 22,19 & 27,40 & 67,31 & $\mathrm{x} 18$ & $\sigma$ & 0,42 & 0,23 \\
\hline PC3 & 12,94 & 15,98 & 83,29 & x19 & $\mathbf{F}$ & 0,43 & 0,33 \\
\hline PC4 & 5,40 & 6,66 & 89,96 & $x 21$ & $\mathbf{L}$ & 0,39 & 0,13 \\
\hline PC5 & 4,08 & 5,03 & 95,00 & $x 27$ & $\mu$ & $-0,41$ & $-0,17$ \\
\hline PC6 & 2,55 & 3,15 & 98,15 & $\times 34$ & Chelpg_N-H & 0,17 & 0,05 \\
\hline
\end{tabular}

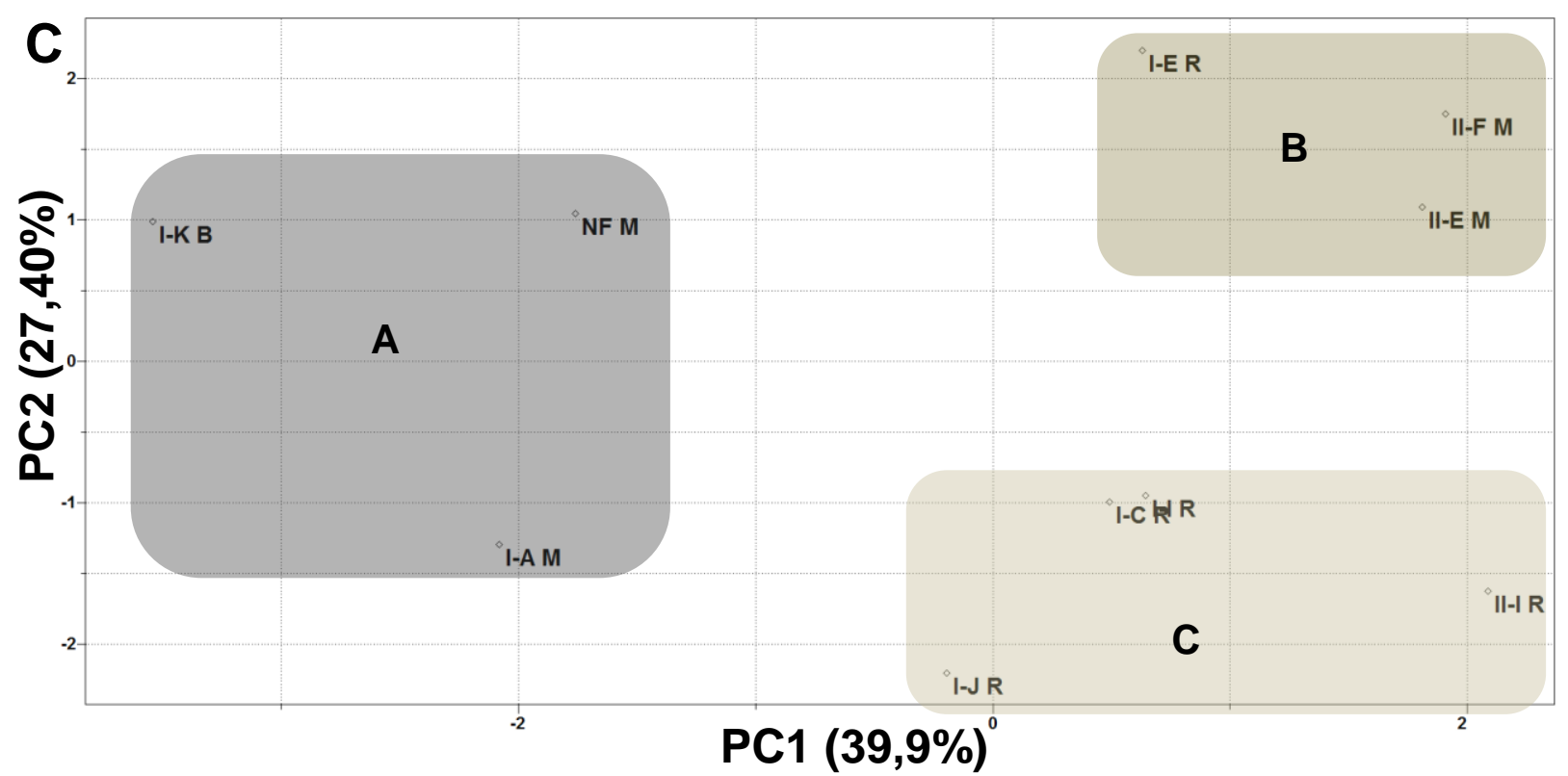

Figura 34. Análise de PCA dos compostos de série I e II frente à E. coli: Seleção de componentes principais $(A)$ e tabela de pesos de descritores nas duas primeiras PCs (B); Gráfico de escores entre PC1 e PC2, separando o conjunto de dados em A, B, C (C).

O dendrograma de amostras, figura 35, com o cursor de similaridade em 0,35 (linha pontilhada), foi separado em 3 grupos distintos: Vermelho (A) com similaridade de 38,3\% (compostos com baixa atividade biológica); Marrom (B) com similaridade de $53,2 \%$ (compostos com substituentes retiradores de elétrons com média atividade); Roxo (C) com 35,5\% de similaridade (compostos com alta ou média atividade e substituentes com características hidrofílicas e doadoras de elétrons). 


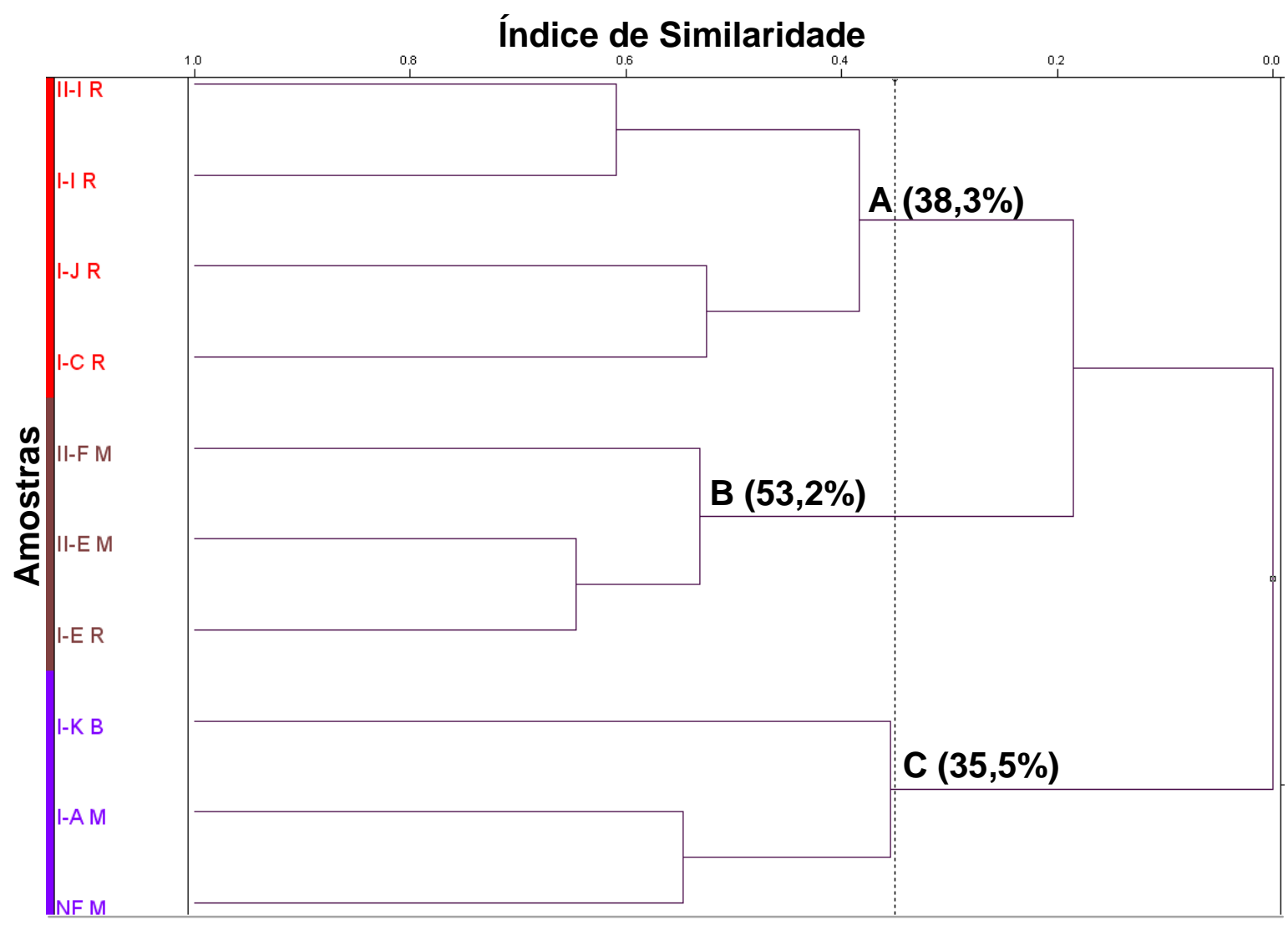

Figura 35. Dendrograma dos compostos estudados das séries I e II frente à $E$. coli. Conjunto de dados foi separado em quatro agrupamentos distintos: A, B, C. Letras $\mathrm{R}, \mathrm{M}, \mathrm{B}$ foram utilizados na classificação da atividade biológica em ruim, moderado e bom, respectivamente.

Os descritores mais próximos à atividade (mesmo grupo que y), figura 36, foram $\mu$ e ASA_P, onde o primeiro apresenta natureza eletrônica e o segundo geométrica. ASA_P é referente a área de superfície de átomos hidrofílicos, enquanto que $o \mu$, como explicado para $S$. aureus, representa a diferença de eletronegatividade entre ligações atômicas. Em seguida, o segundo agrupamento também apresenta descritores com características eletrônicas (Chelpg_N-H, F e $\sigma$ ) e topológicas, como o parâmetro de STERIMOL (L) (HANSCH, LEO, HOEKMAN, 1995). Por fim, o último grupo apresenta descritores com características lipofílicas e estéricas, como m (HANSCH, LEO, HOEKMAN, 1995), ASA_H e ASA. 


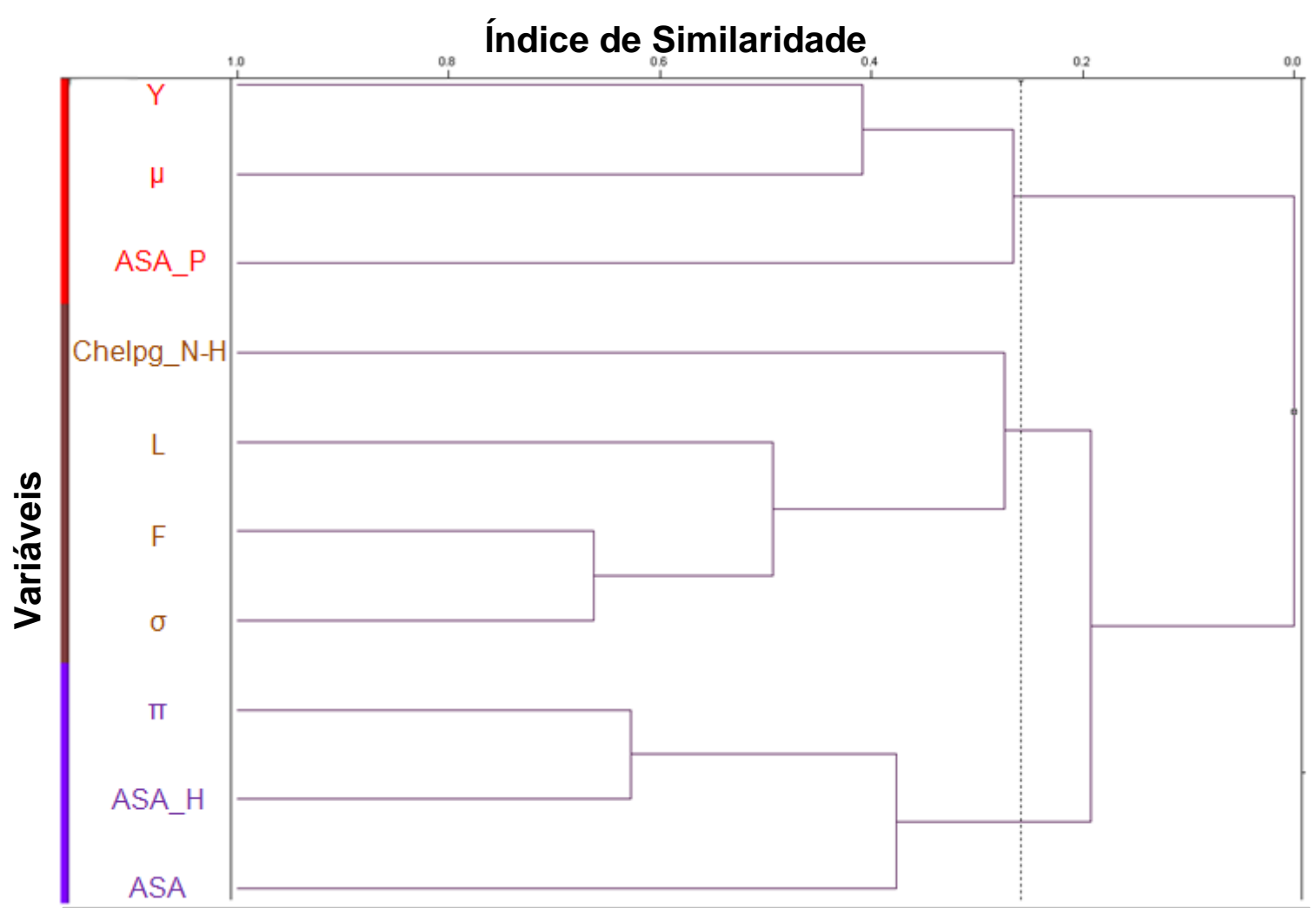

Figura 36. Dendrograma de variáveis para os compostos anaisados frente à $E$. coli. Atividade biológica como variável independente; descritores agrupados nas cores vermelha, marrom, roxo.

$\mathrm{Na}$ análise da distância de Mahalanobis, figura 37, nenhum composto ultrapassou o valor de MDcrit (limite de confiança de 95\%) (MAHALANOBIS, 1936). Portanto, não há presença de amostras atípicas.

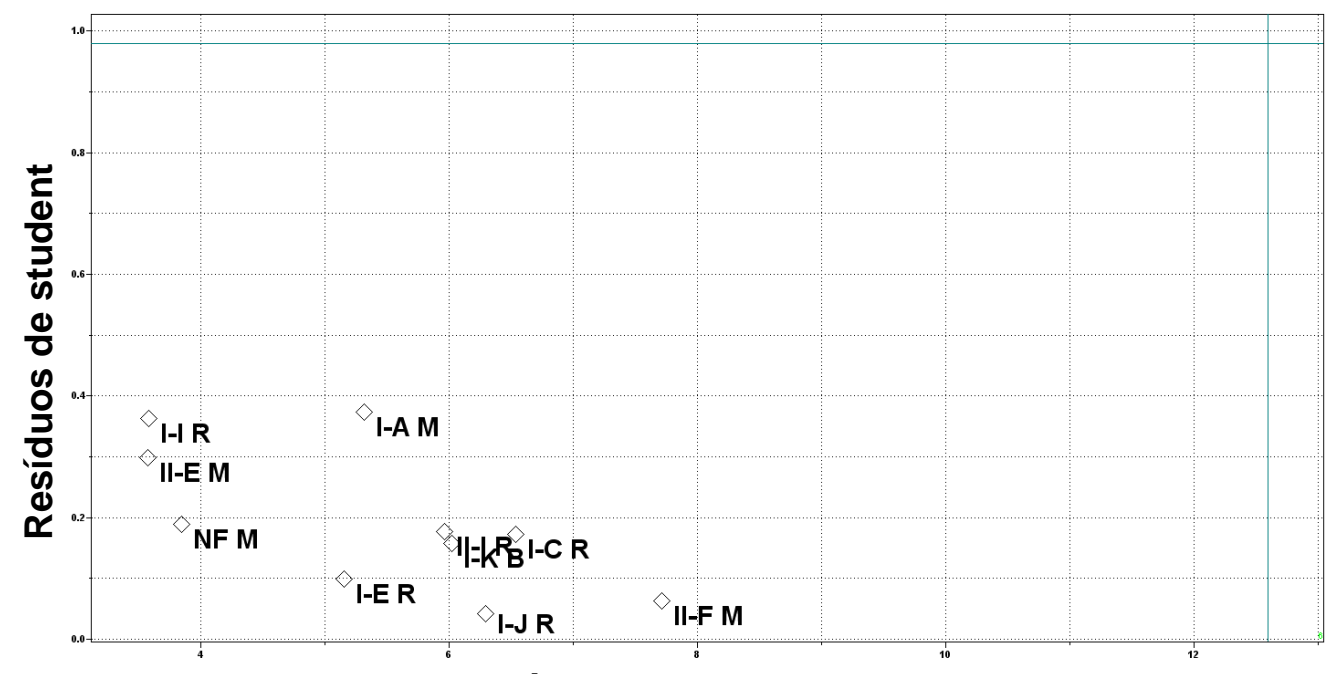

Distância de Mahalanobis

Figura 37. Resíduos de student versus distância de Mahalanobis para compostos analisados frente à $E$. coli. As linhas verdes são correspondentes ao intervalo de confiança de $95 \%$. 
6.5.2.3. Análise Exploratória para os dados obtidos com Enterococcus faecalis

$\mathrm{Na}$ análise exploratória de $E$. faecalis, a tabela final foi composta por 12 linhas (compostos) e 10 colunas (descritores e atividade biológica). O gradiente de atividade biológica foi: $\mathrm{R}\left(\log 1 / \mathrm{IC} \mathrm{C}_{90}=4,12-4,39\right), \mathrm{M}\left(\log 1 / \mathrm{IC} \mathrm{C}_{90}=4,84-4,85\right)$, $\mathrm{B}$ $\left(\log 1 / / C_{90}=4,97-5,25\right)$.

No método PCA, as duas primeiras PC (PC1 e PC2) apresentaram um total de $68,3 \%$ de variância da informação do conjunto original de dados, figura 38A. Na análise da tabela de pesos (figura 38B) é observado que a PC1 foi mais influenciada por descritores com características hidrofóbicas e topológicas como $\operatorname{Clog}_{\mathrm{MB}}$, ASA_H e $\pi$. A PC2 é mais influenciada por descritores de efeito eletrônico como $\sigma, \mu$ e Chelpg_C. $\mathrm{Na}$ análise do gráfico de escores, figura 38C, as duas primeiras PCs discriminaram o conjunto de dados em quatro grupos: $\mathbf{A}$ (compostos de ambas séries com substituentes retiradores de elétrons e baixa atividade); B (compostos com alta atividade e substituentes hidrofílicos e doadores de elétrons); C (compostos volumosos com baixa atividade). Os compostos mais ativos da série frente a este micro-organismo, marcados com um B no gráfico de escores, estão situados em local com valor positivo na PC2 e negativos na PC1. 
A

Seleção das componentes principais

\begin{tabular}{|lccc|}
\hline & Variância & Porcentagem & Acumulativo \\
PC1 & 39,94 & 40,34 & 40,34 \\
PC2 & 27,67 & 27,95 & 68,30 \\
PC3 & 19,40 & 19,59 & 87,89 \\
PC4 & 6,83 & 6,90 & 94,80 \\
PC5 & 3,45 & 3,49 & 98,29 \\
PC6 & 1,17 & 1,19 & 99,48 \\
\hline
\end{tabular}

\begin{tabular}{|c|c|c|c|}
\hline \multicolumn{2}{|c|}{ Pesos (Loadings) } & \multicolumn{2}{|l|}{ B } \\
\hline Código & Descritores & PC1 & $\overline{\mathrm{PC2}}$ \\
\hline $\mathrm{x} 1$ & CLog $\mathrm{P}_{\mathrm{MB}}$ & 0.51 & -0.02 \\
\hline $\mathrm{x} 2$ & Index de Platt & 0.44 & -0.12 \\
\hline $\mathrm{x} 4$ & Index de Balaban & 0.17 & 0.28 \\
\hline x15 & ASA_H & 0.50 & 0.02 \\
\hline $\mathrm{x} 17$ & $\pi$ & 0.50 & 0.10 \\
\hline x18 & $\sigma$ & -0.04 & -0.56 \\
\hline$x 27$ & $\mu$ & 0.03 & 0.54 \\
\hline x29 & Lumo & 0.09 & -0.16 \\
\hline$x 36$ & Chelpg_C & -0.12 & 0.52 \\
\hline
\end{tabular}

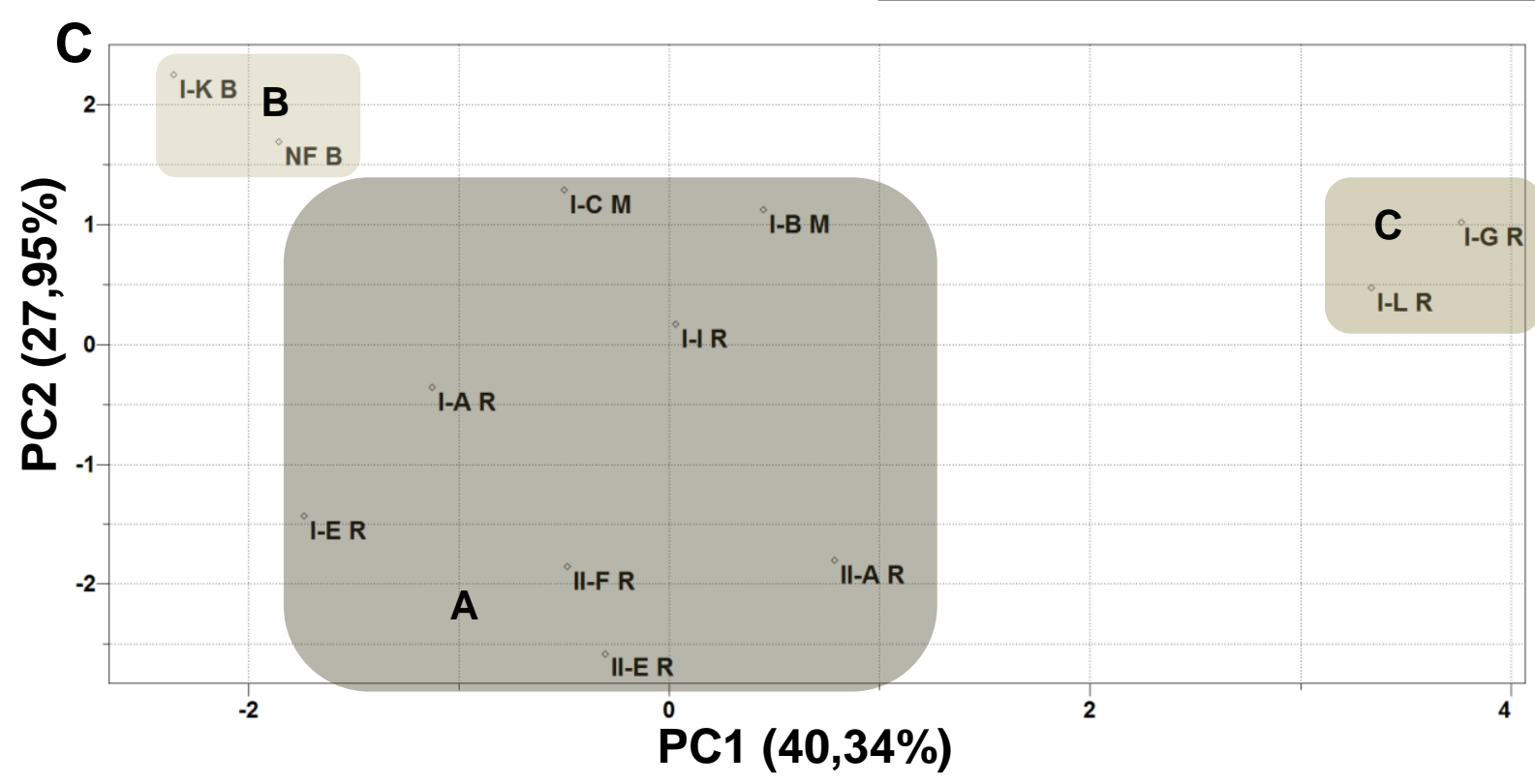

Figura 38. Análise de PCA dos compostos de série I e II frente à E. faecalis: Seleção de componentes principais $(A)$ e tabela de pesos de descritores (B); Gráfico de escores entre PC1 e PC2, separando o conjunto de dados em A, B e C (C).

O dendrograma de amostras, figura 39, com o cursor de similaridade em 0,45 (linha pontilhada), foi separado em 3 grupos distintos: Vermelho (A) (compostos com média a baixa atividade), dividido em $\mathbf{A}^{\prime}$ com similaridade de 47,5\% (compostos com substituintes retiradores de elétrons e baixa atividade), A" com similaridade 59,4\% (compostos com média e baixa atividade); Marrom (B) com 74,2\% de similaridade (compostos hidrofílicos e com boa atividade); Roxo (C) com 72,7\% de similaridade (compostos volumosos com baixa atividade). 


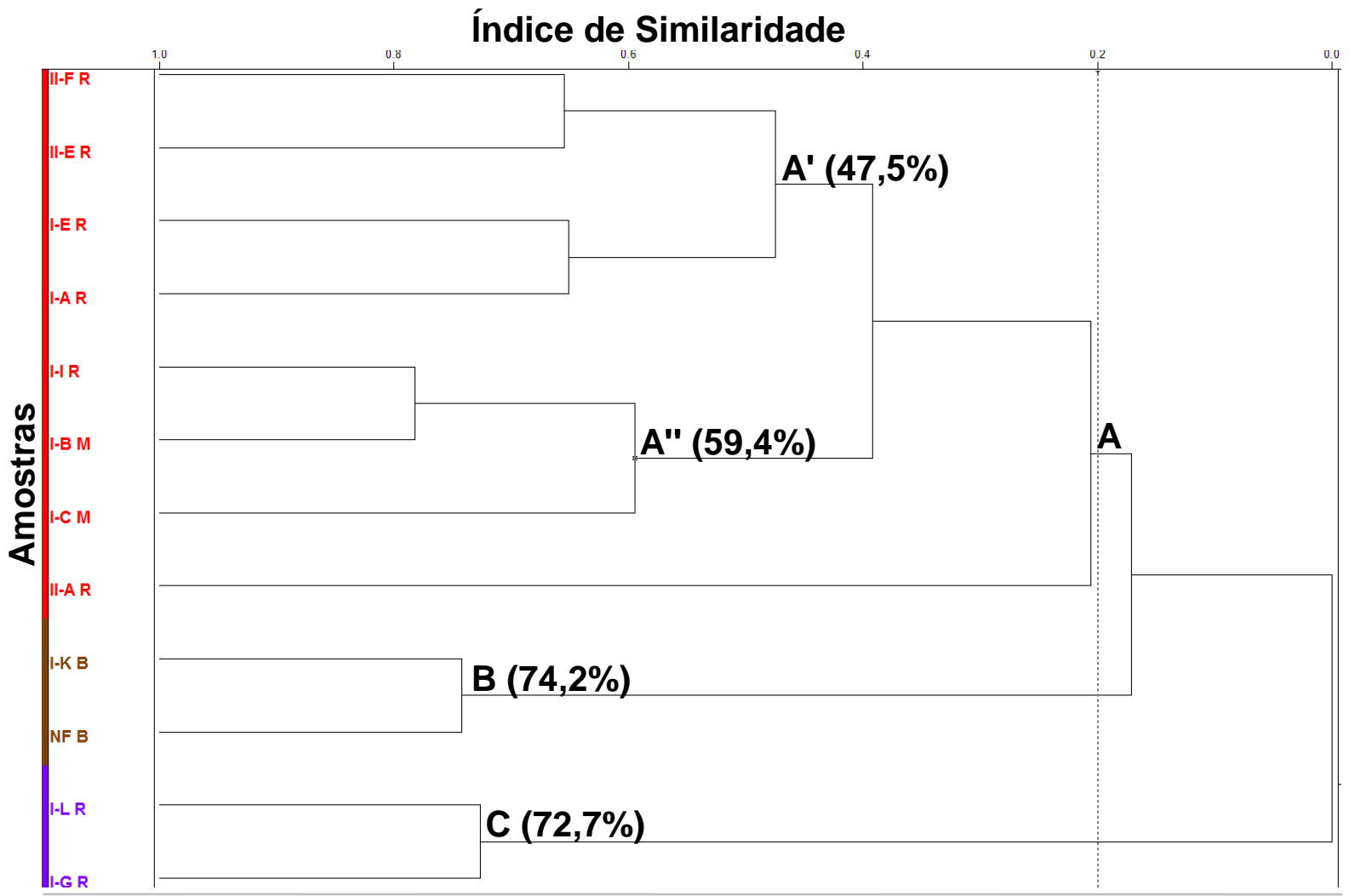

Figura 39. Dendrograma dos compostos estudados das séries I e II frente à $E$. faecalis. Conjunto de dados foi separado em quatro agrupamentos distintos: $A, B, C$. Letras $R, M$, $B$ foram utilizados no gradiente de atividade biológica em ruim, moderado e bom, respectivamente.

Os descritores mais próximos à y, figura 40, foram os descritores eletrônicos Chelpg_C e $\mu$. O primeiro representa a carga atômica parcial do carbono ligado ao substituinte da molécula modificada, que é influenciado pela eletronegatividade do substituinte. Isto está relacionado com o segundo descritor $(\mu)$, porque tal diferença de eletronegatividade aumenta o momento dipolo do análogo, o que pode alterar as propriedades moleculares e, consequentemente, influenciar na atividade. Ademais, nos agrupamentos marrom, roxo e laranja existem outros descritores eletrônicos como também de outras naturezas, como variáveis hidrofóbicas e estereoquímicas. 


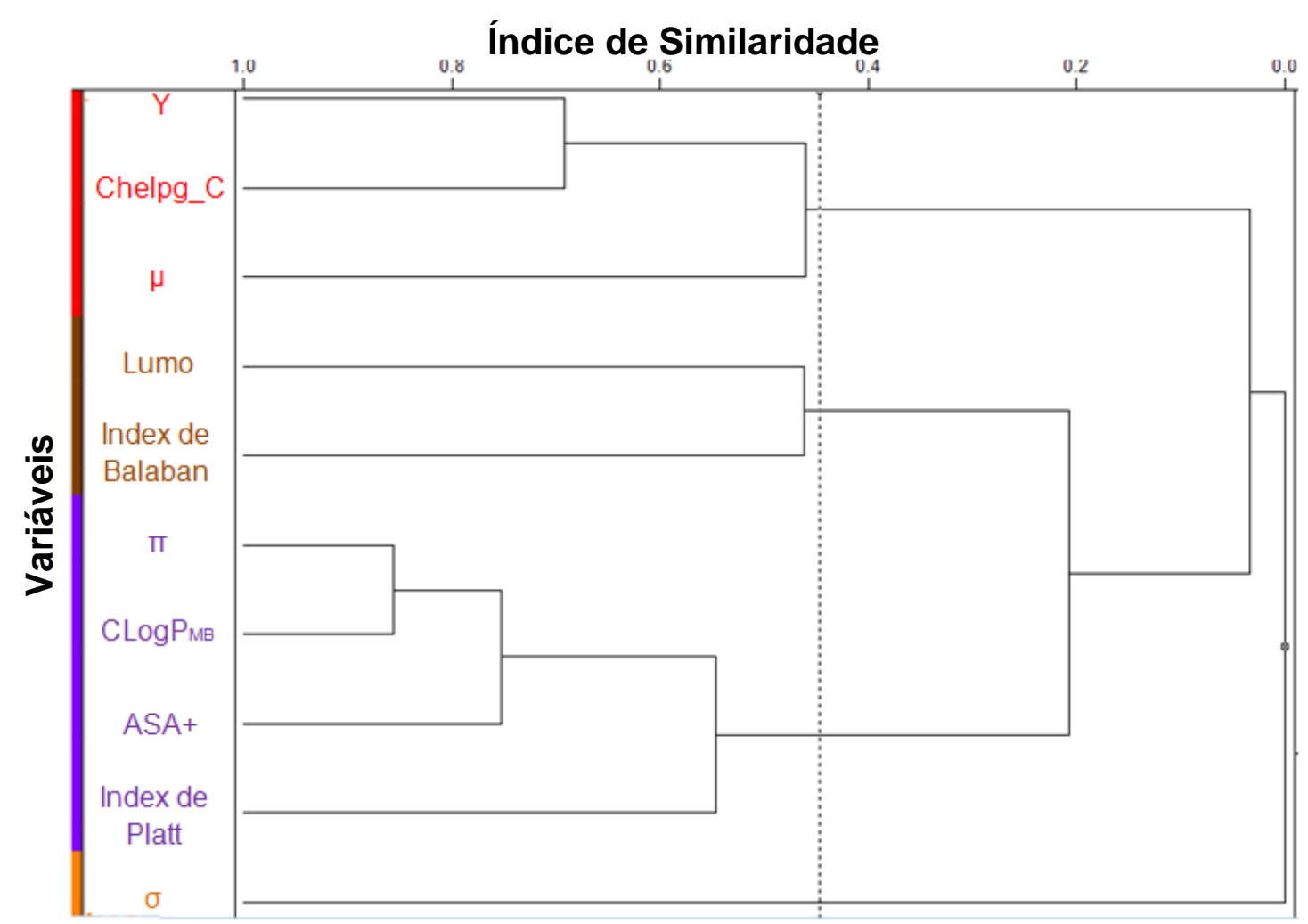

Figura 40. Dendrograma de variáveis para o conjunto de análise frente à E. faecalis.

Atividade biológica como variável independente; descritores agrupados nas cores vermelha, marrom, roxo e laranja.

Por fim, na análise da distância de Mahalanobis, figura 41, novamente nenhum composto ultrapassou o valor de MDcrit (limite de confiança de 95\%), não indicando presença de outliers.

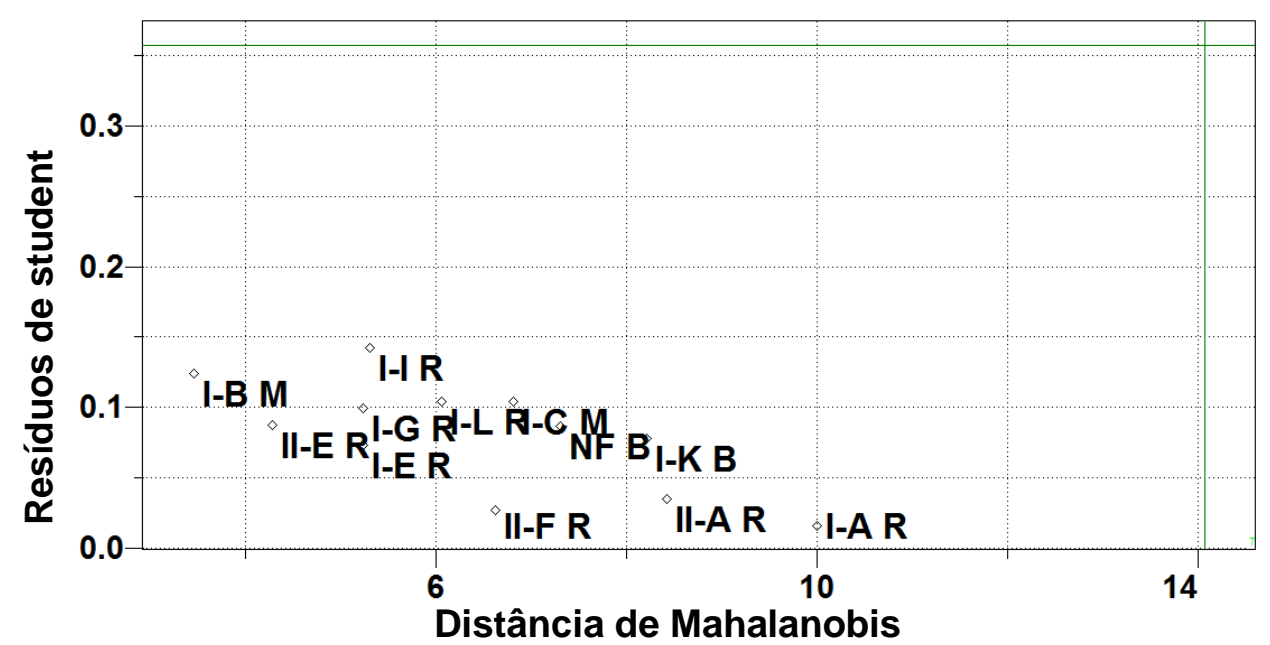

Figura 41. Resíduos de student versus distância de Mahalanobis para compostos analisados frente à $E$. faecalis. As linhas verdes são correspondentes ao limite de confiança de $95 \%$. 
De uma maneira geral, os estudos quimiométricos indicam que descritores com características eletrônicas e topológicas são importantes na definição das bioatividades. Estes descritores podem estar relacionados com o mecanismo de ação dos compostos nitrofurânicos, os quais podem favorecer a bioredução do grupo nitro e aumentar seus efeitos deletérios. Em especial, a propriedade $\mu$, que expressa diferenças de eletronegatividade em partes distintas da molécula, o que pode influenciar na instabilidade do grupo farmacofórico e, consequentemente, potencializar a liberação de radicais livres. Estudos na literatura indicam que, além de $S$. aureus, este descritor apresenta importância para a atividade de nitrofuranos frente a Mycobacterium tuberculosis, agente patológico da tuberculose, onde compostos com alto valor de $\mu$ apresentaram melhor atividade (JORDÃO et al., 2011).

Por fim, os resultados obtidos aqui demonstraram que estes compostos apresentam grande potencial para estudos posteriores, em especial pela boa atividade dos compostos de série I, em especial I-G, I-M e I-K, que foram mais ativos que o compostos protótipo e diversos outros fármacos utilizados como referência frente aos diversos micro-organismos analisados. Tais dados se juntam com os resultados obtidos nos estudos de análise exploratória, que demonstraram que as propriedades eletrônicas e topológicas influenciaram fortemente a atividade analisada. Diante disso, aproveitando o fato que tais moléculas são de fácil síntese, obtenção e purificação, a busca por novos derivados furfurilidênicos com estrutura azometínica ou oxadiazolínica com boa atividade, seletividade e baixa toxicidade pode ser otimizada para obtenção de um composto protótipo ou até mesmo um fármaco de grande importância no âmbito de infecções hospitalares.

\section{CONCLUSÕES}

Neste trabalho foram planejados e sintetizados 23 compostos estruturalmente semelhantes à nifuroxazida. Todos estes foram planejados de acordo com suas propriedades eletrônicas e hidrofóbicas, e apresentaram rendimento, pureza e compatibilidade estrutural similares à literatura. Além disso, foram obtidos análogos não descritos anteriormente, onde seus dados fisico-químicos como faixa de fusão, análise elementar e RMN de ${ }^{1} \mathrm{C}$ e ${ }^{13} \mathrm{C}$ foram obtidos com sucesso. 
Os resultados da leitura nas análises de atividade antimicrobiana realizada com espectrofotômetro foram similares aos resultados obtidos visualmente. A utilização de modelos estatísticos para obtenção do $I_{90}$ dos compostos se mostrou viável, pois não houve variação entre o resultado destes com os resultados obtidos na fase II. Portanto, o IC $\mathrm{IC}_{90}$ mostrou-se uma boa ferramenta na padronização de um endpoint biológico para estudos que requerem valores precisos de variáveis depedentes, como no caso de abordagens quimiométricas.

Nos ensaios de atividade antimicrobiana houve grandes variações de resultados entre os micro-organismos testados. Apesar das cepas de $S$. marcescens, $K$. pneumoniae e $E$. clocae não terem apresentado grande suscetibilidade aos compostos, a atividade antimicrobiana frente à $E$. coli, $C$. albicans e, principalmente, de $S$. aureus se mostrou satisfatória, já que alguns análogos apresentaram atividade significativa. Além disso, diversos compostos apresentaram atividade superior ao composto protótipo, cerca de 15 frente a $S$. aureus, dois frente a $E$. coli, três frente a $S$. marcescens, um frente a $E$. clocae e $E$. faecalis, e oito frente a $C$. albicans. Os ensaios frente a VISA3, cepa de $S$. aureus multirresistente, e demonstrou que os compostos também apresentam boa atividade frente a esta cepa, porém com redução na atividade de todos os compostos testados, quando comparados aos resultados obtidos frente à cepa ATCC.

Quando comparadas, as duas séries apresentaram boa atividade frente aos micro-organismos analisados. Apesar disso, as melhores atividades foram da série I, em especial contra $S$. aureus. Portanto, futuramente, esta série pode ser mais vantajosa para a identificação de compostos com atividade potencialmente aproveitável frente a bactérias Gram-positivas.

Nos três micro-organismos avaliados por análises exploratória de dados (HCA e PCA), os dados obtidos foram similares quanto à importância das propriedades eletrônicas e estereoquímicas. Descritores como momento de dipolo $(\mu)$, CHELPG_C, ASA-, ASA_P e $\sigma$ são os que mais influenciaram a atividade antimicrobiana. Ademais, na análise da relação estrutura-atividade de C. albicans, os compostos de série II se mostraram mais ativos que os de série I. Entretanto, não 
houve possibilidade de discernir às propriedades físico-químicas que mais influenciaram os mesmos, devido ao composto mais ativo ser o não-substituído.

Os resultados obtidos neste trabalho foram considerados muito promissores, em especial frente $S$. aureus, dos quais alguns compostos mostraram grande potencial para estudos futuros, como os compostos I-G, I-M e I-K. Além disso, a partir dos resultados obtidos nos estudos de relação estrutura-atividade, o no entedimento de quais propriedades físico-químicas seriam importante para a atividade destes compostos, possibilitando assim, futuramente, se obter um novo composto com caracteristicas favoráveis para a atividade antimicrobiana frente a micro-organismos causadores de infecções hospitalares.

Como perspectivas futuras deste trabalho, citam-se algumas abordagens, a saber:

- Planejar novas séries de compostos com características eletrônicas diferenciadas para otimizar a atividade antimicrobiana destes compostos para, por fim, obter-se um novo composto com capacidade de ser líder para novos estudos;

- Avaliação dos compostos frente a outros micro-organismos Gram-positivos, Gramnegativos e fungos, a fim de obter-se maior espectro de ação;

- Buscar maior informação acerca do mecanismo de ação de compostos nitrofurânicos para auxiliar em estudos de vertentes LBDD ou SBDD, otimizando assim o estudo e/ou busca por novos fármacos;

- Realizar citotoxidade dos compostos mais ativos. 


\section{Referências}

ALBRECHT, S. J., FISHMAN, N. O., KITCHEN, J.,NACHAMKIN, I., BILKER, W. B., HOEGG, C., SAMEL, C., BARBAGALLO, S., ARENTZEN, J., LAUTEBANCH, E., Reemergence of Gram-negative Health Care-Associated Bloodstream Infections. Arch. Intern. Med., v. 166, p. 1289-1294, 2006.

ALLINGER, N. L., Conformational analysis. 130. MM2. A hydrocarbon force field utilizing V1 and V2 torsional terms. J. Am. Chem. Soc., v. 99, p. 8127-8134, 1977.

ANDERSSON, M. I., MACGOWAN, A. P., Development of the quinolones. J. Antimicrob. Chemoth., v. 51, suppl. S1, p. 1 - 11, 2003.

ANSEL, H. C., NORRED, W. P., ROTH, I. L., Antimicrobial activity of dimethyl sulfoxide against Escherichia coli, Pseudomonas aeruginosa, and Bacillus megaterium. J. Pharm. Sci., v. 58, i. 7, p. 836-839, 1969.

ANTONIADOU, A., KONTOPIDOU, F., POULAKOU, G., KORATZANES, E., GALANIL, I., PAPADOMICHELAKIS, E., KOPTERIDES, P., SOULI, M., ARMAGANIDIS, A., GIAMARELLOU, H., Colistin-resistant isolates of Klebsiella pneumoniae emerging in intensive care unit patients: first report of a multiclonal cluster. J. Antimicrob. Chemoth., v. 59, p. 786-790, 2007.

ANVISA, Agência Nacional de Vigilância Sanitária. Farmacovigilância. <http://portal.anvisa.gov.br/wps/portal/anvisa/posuso/farmacovigilancia>. Acesso em: 14 de maio de 2011.

ARROIO, A., HONÓRIO, K. M., SILVA, A. B. F. d., Quantum chemical properties used in structure-activity relationship studies. Quím. Nova, v. 33, p. 694-699, 2010.

ARTHINGTON-SKAGGS, B. A., LEE-YANG, W., CIBLAK, M. A., FRADE, J. P., BRANDT, M. E., HAJJEH, R. A., HARRISON, L. H., SOFAIR, A. N., WARNOCK, D. W. and for the Candidemia Active Surveillance Group, Comparison of visual and Spectrophotometric Methods of Broth Microdilution MIC End Point Determination and Evaluation of a Sterol Quantitation Method for In Vitro Susceptibility Testing of Fluconazole and Itraconazole against Trailing and Nontrailing Candida Isolates. Antimicrob. Agents Chemother., v. 46, n. 8, p. 2477-2481, 2002. 
AVRIL, J. L., BRIFFORD, J., BEINIS, J. P., DUBRISAY, J., Etude de l'influence de l'antibiothérapie sur les résistances des entérobactéries de l'íntestin. Ann. Microbiol., v. 131B, p. 21-29, 1980.

BAQUERO, E., QUIÑONES, W., RIBON, W., CALDAS, M. L., SARMIENTO, L., ECHEVERRI, F., Effect of an Oxadiazoline and a Lignan on Mycolic Acid Biosynthesis and Ultrastructural Changes of Mycobacterium tuberculosis. Tuberculosis Research and Treatment, v. 2011, p. 6, 2011.

BARAN JUNIOR, J., KLAUBER, E., BARCZAK, J., RIEDERER, K., KHATIB, R., Trends in antifungal susceptibility among Candida sp. urinary isolates from 1994 and 1998. J. Clin. Microbiol., v. 38, p. 870-871, 2000.

BARREIRO, E. J., Strategy of molecular simplification in rational drug design: the discovery of a new cardioactive agent. Quim. Nova, v. 25, n. 6B, p. 1172-1180, 2002.

BCG, Boston Consulting Group. A revolution in R\&D: How genomics and genetics are transforming the biopharmaceutical industry. (Boston Consulting Group, Boston, Massachusetts, 2001).

BENNETT, J. W., HERRERA, M. L., LEWIS, J. S., WICKES, B. H., JORGENSEN, J. H., KPC-2 Producing Enterobacter cloacae and Pseudomonas putida Coinfection in a Liver Transplant Recipient. Antimicrob. Agents Chemother., v. 53, n. 1, p. 292294, 2009.

BLUMENSTIEL, K.., SCHONECK, R., YARDLEY, V., CROFT, S. L., KRAUTH-SIEGEL, R. L., Nitrofuran drugs as common subversive substrates of Trypanosoma cruzi lipoamide dehydrogenase and trypanothione reductase. Biochem. Pharm., v. 58, p. 1791-1799, 1999.

BRENEMAN, C. M., WIBERG, K. B., Determining atom-centered monopoles from molecular electrostatic potentials. The need for high sampling density in formamide conformational analysis. J. Comp. Chem., v. 11, i. 3, p. 361-373, 1990.

BRYSKIER, A., Antimicrobial Agents, 1.ed., Washington: ASM Press, 2005. 
CAGLIERO, G., Method of and fodder for rearing white-meat calves for slaughter. U.S. Patents 4.093.746, arquivada em 7 de abril de 1977, emitida em 6 de junho de 1978.

CAI, J. C., ZHOU, H. W., ZHANG, R., CHEN, GONG-XIANG, Emergence of Serratia marcescens, Klebsiella pneumoniae, and Escherichia coli isolates possessing the plasmid-mediated carbapenem-hydrolyzing $\beta$-lactamase KPC-2 in intensive care units of a chinese hospital. Antimicrob. Agents Ch., v. 52, n. 6, p. 2014-2018, 2008.

CAREY F. A., Organic Chemistry, 7.ed. Nova lorque: McGraw-Hill, p. 439, 2008.

CARRON, M., JULLIEN, M. A., JULIA, M. T., GARCZYNSKA, M., Propriétés antiseptiques de quelques nitro - 5 furfurilydène benzhydrazides. Etude du (nitro5'furfurilydène-2) hydroxy-4-benzhydrazide. Ann. Pharm. Fr., v. 21, n. 4, p. 287-297, 1962.

CARVALHO, M., GUIMARÃES, C. M., MAYER JUNIOR, J. R., BORDIGNON, G. P. F., QUEIROZ-TELLES, F., Hospital-associated funguria: Analysis of risk factors, clinical presentation and outcome. Braz. J. Infect. Dis., v. 5, p. 313-318, 2001.

CDC, Center for Disease Control, Investigation and Control of Vancomycin Intermediate and Resistant Staphylococcus aureus (VISA/VRSA).Disponível em $<$ <ttp://www.cdc.gov/ncidod/dhqp/pdf/ar/visa_vrsa_guide.pdf>. Acesso em: 15 de abril de 2011.

CDC, Centers for Disease Control and Prevention. Staphylococcus aureus resistant to vancomycin-United States, 2002. MMWR. Morb. Mortal Wkly. Rep., v. 51, n. 26, p. 565-567, 2002.

CDC, Centers of disease control and prevention, Healthcare-associated infection working group of the joint public policy committe, essentials of public reporting of healthcare-assosciated infections: A tool kit. <http://www.cdc.gov/ncidod/dhqp/pdf/ar/06_107498_Essentials_Tool_Kit.pdf>. Acessado em 2 de novembro de 2012.

CERECETTO, H., DI MAIO, R., GONZÁleZ, M., RISSO, M., SAGRERA, G., Denicola, A., PEluffo, G., QUIJANO, C., STOPPANI, A. O., PAUlinO, M., OLEA-AZAR, C., BASOMBRíO, M. A., Synthesis and anti-trypanosomal activity of 
novel 5-nitro-2-furaldehyde and 5-nitrothiophene-2-carboxaldehyde semicarbazone derivatives. II Farmaco, v. 53, p. 89-94, 1998.

CHANG, S., SIEVERT, D. M., HAGERMAN, J. C., BOULTON, M. L., TENOVER, F. C., DOWNES, F. P., SHAH, S., RUDRIK, J. T., PUPP, G. R., BROWN, W. J., CARDO, D., FRIDKIN, S. K., Infection with vancomycin-resistant Staphylococcus aureus containing the vanA resistance gene. N. Engl. J. Med., v. 348, n. 14, p. 13421347, 2003.

CHEN, S. C-A., SLAVIN, M. A., SORRELL, T. C., Echinocandin Antifungal Drugs in Fungal Infections: A Comparison. Drugs, v. 71, i. 31, n. 1, p. 11-41, 2011.

CLSI, Clinical and Laboratorial Standards Institute. Metodologia dos testes de sensibilidade a agentes antimicrobianos por diluição para bactéria de crescimento aeróbico. 6. ed. M7A6, v. 23, n. 2, 2003.

CLSI, Clinical and Laboratory Standards Institute. Método de referência para testes de diluição em caldo para determinação da sensibilidade de leveduras. 2. ed. M27A2, v. 22, n. 15, 2002.

COATES, A., HU, Y., BAX, R., PAGE, C., The future challenges facing the development of new antimicrobial drugs. Nat. Rev. Drug Discov., v. 1, i. 11, p. 895910, 2002.

COREY, G. R., STRYJEWSKI, M. E., WEYENBERG, W., YASOTHAN, U., KIRKPATRICK, P., Telavancin. Nat. Rev. Drug Discov., v. 8, p. 929-930, 2009.

COWEN, L. E., The evolution of fungal drug resistance: modulating the trajectory from genotype to phenotype. Nat. Rev. Microbiol., v. 6, i. 3, p. 187-198, 2008.

CRAIG, P. N., Interdependence between physical parameters and selection of substituent groups for correlation studies. J. Med. Chem., v. 14, n. 8, 1971.

CREWS, P., RODRIGUEZ, J., JASPARS, M., Organic structure analysis, 1 ed., Oxford: Oxford university press, cap. 3, p. 62-63, 1998.

DANCER, S. J., The problem with cephalosporins. J. Antimicrob. Chemother., v. 48, i. 4, p. 463-478, 2001. 
DE OLIVEIRA, R. D. R., MAFFEI, C. M. I., MARTINEZ, R., Infecção urinária hospitalar por leveduras do gênero Candida. Rev. Ass. Med. Brasil, v. 47, p. 231 235, 2001.

DESHPANDE, L. M., JONES, R. N., FRITSCHE, T. R., SADER, H. S., Occurrence and characterization of carbapenemase-producing Enterobacteriaceae: report from the SENTRY Antimicrobial Surveillance Program (2000-2004). Micro. Drug. Resis., v. 12 , n. 4 , p. 223-230, 2006.

DEWAR, M. J. S., ZOEBISCH, E. G., HEALY, E. F., STEWART, J. J. P., Development and use of quantum mechanical molecular models. 76. AM1: a new general purpose quantum mechanical molecular model. J. Am. Chem. Soc., v. 107, i. 13, p. 3902 - 3909, 1985.

DIEDEREN, B. M. W., DUIJIN, I. V., WILLEMSE, P., KLUYTMANS, J. A. J. W., In vitro activity of daptomycin against Methicillin-Resistant Staphylococcus aureus, including heterogeneously Glycopeptide-Resistant Strains. Antimicrob. Agents Chemother., v. 50, n. 9, p. 3189-3191, 2006.

DIENSTMANN, R., PICOLI, S. U., MEYER, G., SCHENKEL, T., STEYER, J., Phenotypic research on Klebsiella pneumoniae carbapenemase (KPC) enzyme in Enterobacteriaceae from hospitals. J. Bras. Patol. Med. Lab., v. 46, n. 1, p. 23-27, 2010.

DIMASI, J. A., HANSEN, R. W., GRABOWSKI, H. G., The price of innovation: new estimates of drug development costs. J. Health Econ., v. 22, p. 151-185, 2003.

DOCAMPO, R., Sensitivity of parasites to free radical damage by antiparasitic drugs. Chem. Biol. Interact., v. 73, i. 1, p. 1-27, 1990.

DODD, M. C., STILLMAN, W. B., The in vivo bacteriostatic action of some simple furan derivatives. J. Pharmacol. Exp. Ther., v. 82, p. 11-18, 1944.

DOĞAN, H. N., ROLLAS, S., ERDENIZ, H., Farmaco, v. 53, p. 462-467, 1998.

DOGGRELL, S. A., Comparison of clinical trials with sildenafil, vardenafil and tadalafil in erectile dysfunction. Expert. Opin. Pharmacother., v. 6, i. 1, p. 75-84, 2005. 
DURGUN, B., ÇAPAN, G., ERGENÇ, N., ROLLAS, S., Synthesis, characterization and biological evaluation of new benzylidenebenzohydrazides and 2,5-disubstituted 2, 3-dihydro-1, 3, 4-oxadiazoles. Pharmazie, n. 48, v. 12, p. 942-943, 1993.

ECDC, European Centre for Disease Prevention and Control. Healthcare-associated

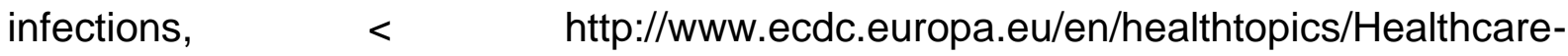
associated_infections/Pages/index.aspx>. Acessado em 4 de janeiro de 2012.

EICHER, T., HAUPTMANN, S., The chemistry of heterocycles: Structure, reactions, syntheses and applications, 2 ed., Weinheim: Wiley-Vch GmbH \& Co. KGaA, cap. 5, p. 52-62, 2003.

ELSAHN, A. F., YILDIZ, E. H., JUNGKIND, D. L., ABDALLA, Y. F., ERDURMUS, M., CREMONA, F. A., RAPUANO, C. J., HAMMERSMITH, K. M., COHEN, E. J., In vitro susceptibility patterns of methicillin-resistant Staphylococcus aureus and coagulasenegative Staphylococcus corneal isolates to antibiotics. Cornea, v. 29, i. 10, p. 1131 1135, 2010.

FEIZ, V., REDLINE, D. E., Infectious scleritis after pars plana vitrectomy because of methicilin-resistant Staphylococcus aureus resistant to fourth-generation fluoroquinolones. Cornea, v. 26, i. 2, p. 238-240, 2007.

FERREIRA, M. M. C, Multivariate QSAR. J. Braz. Chem. Soc., v. 13, n. 6, p. 742 753, 2002.

FERREIRA, M. M. C., KIRALJ, R., Métodos quimiométricos em relações quantitativas estrutura-atividade (QSAR) In: MONTANARI, A., Química medicinal: Métodos e fundamentos em planejamento de fármacos. 1 ed., São Paulo: Editora da Universidade de São Paulo, 2011.

FILLIPPIN, F. B., SOUZA, L. C., Eficiência terapêutica das formulações lipídicas de anfotericina B. Rev. Bras. Cienc. Farm., v. 42, n. 2, p. 167-194, 2006.

FRAGA, C. A. M., LIMA, L. M., BARREIRO, E. J., O paradigma atual da química medicinal: Descoberta racional do composto-protótipo. In: MONTANARI, A., Química medicinal: Métodos e fundamentos em planejamento de fármacos. 1 ed., São Paulo: Editora da Universidade de São Paulo, 2011. 
FRANCE PRESSE, Infecções hospitalares mais frequentes têm forte baixa nos EUA. 19 de outubro de 2011.

GALDINO, S. L., PITTA, I. R., Descoberta de fármacos. In: MONTANARI, A., Química medicinal: Métodos e fundamentos em planejamento de fármacos. 1 ed., São Paulo: Editora da Universidade de São Paulo, 2011.

GAO, United States Government Accountability Office. New Drug Development. Science, business, regulatory, and intellectual property issue cited as hampering drug development efforts, 2006.

GHOSE, A. K., VISWANADHAN, V. N., WENDOLOSKI, J. J., Prediction of Hydrophobic (Liphofilic) properties of small organic molecules using fragmental methods: An analysis of ALOGP and CLOGP methods. J. Phys. Chem. A., v. 102, p. 3752-3772, 1998.

GIES, J. P., LANDRY, Y., Drug targets: Molecular mechanisms of drug action. In: WERMUTH, C. G., The Practice of Medicinal Chemistry, 2. ed., Londres: Elsevier Academic Press, 2003.

GOLDSTEIN, F. W., ACAR, J. F., Epidemiology of quinolone resistance: Europe and North and South America. Drugs, v. 49, suppl. 2, p. 36-42, 1995.

GUADAGNINI, P. H., BRUNS, R. E., SOUZA, A. A., Cargas atômicas em moléculas. Quim. Nova, v. 19, p. 148-155, 1996.

HAMMETT, L. P., The Effect of Structure upon the Reactions of Organic Compounds. Benzene Derivatives. J. Am. Chem. Soc., v. 59, i. 1, p. 96, 1937.

HANSCH, C., FUJITA, T., p- $\sigma-\pi$ Analysis. A Method for the Correlation of Biological Activity and Chemical Structure. J. Am. Chem. Soc., v. 86, p. 1616, 1964.

HANSCH, C., LEO, A., HOEKMAN, D., Exploring QSAR: Hydrophobic, Eletronic and Steric Constants, 1. ed., Washington, DC: American Chemical Society, 2005.

haRTMANN, C., PETER, C., HERMANN, E., URE, B., SEDLACEK, L., HANSEN, G., BOHNHORST, B., Successful treatment of vancomycin-resistant Enterococcus faecium ventriculitis with combined intravenous and intraventricular chloramphenicol in a newborn. J. Med. Microbiol., v. 59, n. 11, p. 1371-1374, 2010. 
HAYDEN, M. K., REZAI, K., HAYES, R. A., LOLANS, K., QUINN, J. P., WEINSTEIN, R. A., Development of daptomycin resistance in vivo in methicillin-resistant Staphylococcus aureus. J. clin. microbiol., v. 43, i. 10, p. 5285-5287, 2005.

HEARN, M. J., CHANYAPUTHIPONG, P. H., Preparation and spectroscopic properties of 3-acyl-1,3,4-oxadiazolines. J. Heterocycl. Chem., v. 32, p. 1647-1649, 1995.

HIRAMATSU, K., HANAKI, H., ITO, J., YABATA, K., OGURI, T., TENOVER, F. C., Methicilin-resistant $S$. aureus clinical strain with reduced vancomycin susceptibility. J. Antimicrob. Chemother., v. 40, p. 135-136, 1997.

HORIYAMA, T., NIKAIDO, E., YAMAGUCHI, A., NISHINO, K., Roles of Salmonella multidrug efflux pumps in tigecycline resistance. J. Antimicrob. Chemother., v. 66, i. 1, p. 105-110, 2011.

HOWDEN, B. P., DAVIES, J. K., JOHNSON, P. D. R., STINEAR, T. P., GRAYSON, M. L., Reduced vancomycin susceptibility in Staphylococcus aureus, including vancomycin-Intermediate and heterogeneous vancomycin-intermediate strains: Resistance mechanisms, laboratory detection, and clinical implications. Clin. Microbiol. Rev., v. 23, n. 1, p. 99-139, 2010.

INWEREGBU, K., DAVE, J., PITTARD, A., Nosocomial infections. Contin. Educ. Anaesth. Crit. Care Pain., v. 5, n. 1, p. 14-17, 2005.

ISHII, M., JORGE, S. D., OLIVEIRA, A. A., PALACE-BERL, F., SONEHARA, I. Y., PASQUALOTO, K. F. M., TAVARES, L. C., Synthesis, molecular modeling and preliminar biological evaluation of a set of 3-acetyl-2,5-disubstituted-2,3-dihydro1,3,4-oxadiazole as potential antibacterial, anti-Trypanosoma cruzi and antifungal agents. Bioorgan. Med. Chem., v. 19, p. 6292-6301, 2011.

JARVIS, W. R., Epidemiology of Nosocomial Fungal Infections, with Emphasis on Candida Species. Clin. Infect. Dis., v. 20, p. 1526-1630, 1995.

JONES, R. N., PFALLER, M. A., Diagn. Microbiol. Infect. Dis., v. 31, p. 379-388, 1998. 
JONES, R. N., Resistance Patterns among nosocomial pathogens: Trends over the past few years. Chest, v. 119, p. 397S-404S, 2001.

JORDÃO, A. K., SATHLER, P. C., FERREIRA, V. F., CAMPOS, V. R., DE SOUZA, M. C. B. V., CASTRO, H. C., LANNES, A., LOURENCO, A., RODRIGUES, C. R., BELLO, M. L., LOURENCO, M. C. S., CARVALHO, G. S. L., ALMEIDA, M. C. B., CUNHA, A. C., Synthesis, antitubercular activity, and SAR study of $\mathrm{N}$-substitutedphenylamino-5-methyl-1H-1,2,3-triazole-4-carbohydrazides. Bioorgan. Med. Chem., v. 18 , i. 18, p. $5605-5611,2011$.

JORGE, S. D., MASUNARI, A., RANGEL-YAQUI, C. O., PASQUALOTO, K. F., TAVARES, L. C., Design, synthesis, antimicrobial activity and molecular modeling studies of novel benzofuroxan derivatives against Staphylococcus aureus. Bioorgan. Med. Chem., v. 17, i. 8, p. 3028-3036, 2009.

JORGE, S. D., PALACE-BERL, F., MASUNARI, A., CECHINEL, C. A., ISHII, M., PASQUALOTO, K. F. M., TAVARES, L. C., Novel benzofuroxan derivatives against multidrug-resistant Staphylococcus aureus strains: Design using Topliss' decision tree, synthesis and biological assay. Bioorgan. Med. Chem., v. 19, i. 16, n. 19, p. 5031-5038, 2011.

JOULE, J. A., MILLS, K., Heterocycles Chemistry. 4 ed. Berlin: Blackwell Science, 2007.

KANJ, S. S., KANAFANI, Z. A., Current concepts in antimicrobial therapy against resistant Gram-negative organisms: Extended-Spectrum $\beta$-Lactamase-Producing Enterobacteriaceae, Carpapenem-Resistant Enterobacteriaceae, and MultidrugResistant Pseudomonas aeruginosa. Mayo Clin. Proc., v. 86, n. 3, p. 250-259, 2011.

KATRITZKY, A. R., POZHARSKII, A. F., Handbook of Heterocyclic Chemistry, 2 ed., Oxford: Elsevier Science Ltd., 2000.

KIM, Y. A., QURESHI, Z. A., ADAMS-HADUCH, J. M., PARK, Y. S., SHUTT, K. A., $\mathrm{DOI}, \mathrm{Y}$., Features of infections due to Klebsiella pneumoniae carbapenemase (KPC)Producing Escherichia coli: Emergence of sequence type (ST) 131. Clin. Infect. Dis., 2012. 
KLEVENS, R. M., EDWARDS, J. R., RICHARDS, C . L. Jr., HORAN, T. C., GAYNES, R. P., POLLOCK, D. A., CARDO, D. M., Estimating health care-associated infections and deaths in U.S. hospitals, 2002. Public Health Rep., v. 122, n. 2, p. 160-166, 2007.

KLOPMAN, G., LI. J. Y., WANG, S., DIMAYUGAT, M., Computer automated log P calculations based on an extended group contribuition approach. J. Chem. Inf. Comput. Sci., v. 34, p. 752-781, 1994.

KOÇYIĞIT-KAYMAKÇIOĞLU, B., ORUÇ-EMRE, E. E., ÜNSALAN, S., TABANCA, N., KHAN, S. I., WEDGE, D. E., IŞCAN, G., DEMIRCI, F., ROLLAS, S., Med. Chem. Res., v. 21, i. 11, p. 3499-3508, 2012.

KOETH, L. M., KING, A., KNIGHT, H., MAY, J., MILLER, L. A., PHILLIPS, I., POUPARD, J. A., Comparison of cation-adjusted Mueller-Hinton broth with IsoSensitest broth for the NCCLS broth microdiluition method. J. Antimicrob. Chemoth., v. 46, p. 369-376, 2000.

KOLLEF, M. H., Inadequate Antimicrobial Treatment: An Important Determinant of Outcome for Hospitalized Patients. Clin. Infect. Dis., v. 31, s. 4, p. S131-S138, 2000. KRESSE, H., BELSEY, M. J., ROVINI, H., The antibacterial drugs market. Nat. Rev. Drug Discov., v. 6, p. 19-20, 2007.

KUBINYI, H., QSAR: Hansch analysis and related approaches, Nova lorque: VCR, 1993.

LAUDANO, J. B., Ceftaroline fosamil: a new broad-spectrum cephalosporin. J. Antimicrob. Chemother., V. 66, i. suppl. 3, iii11-iii18, 2011.

LEMKE, T. L., WILLIAWS, D. A., Foye's Principals of medicinal chemistry. Baltimore: Williaws \& Wilkins, p. 1377, 2008.

LESKO, L. J., ROWLAND, M., PECK, C. C., BLASCHKE, T. F., Optimizing the science of drug development: opportunities for better candidate selection and accelerated evaluation in humans. J. Clin. Pharmacol., v. 40, p. 803-814, 2000. 
LI, C. K., MA, Y. J., CAO, L. H., Synthesis of Novel 3-Acetyl-2-aryl-5-(3-aryl-1-phenylpyrazol-4-yl)-2,3- dihydro-1,3,4-oxadiazoles. J. Chin. Chem. Soc.-Taip., v. 56, p. 182185, 2009.

LONGZHU, C., IWAMOTO, A., LIAN, JIAN-Q., NEOH, HUI-M., MARUYAMA, T., HORIKAWA, Y., HIRAMATSU, K., Novel mechanism of antibiotic resistance originating in Vancomycin-Intermediate Staphylococcus aureus. Antimicrob. Agents. Chemother., v. 50, n. 2, p. 428-438, 2006.

LUPETTI, A., DANESI, R., CAMPA, M., TACCA, M. D., KELLY, S., Molecular basis of resistance to azole antifungals. Trends Mol. Med., v. 8, n. 2, p. 76-81, 2002.

MACCIONI, E., ALCARO, S., CIRILLI, R., VIGO, S., CARDIA, M. C., SANNA, M. L., MELEDDU, R., YANEZ, M., COSTA, G., CASU, L., MATYUS, P., DISTINTO, S., J. Med. Chem., v. 54, p. 6394-6398, 2011.

MAHALANOBIS, P. C., On the generalized distance in statistics, in: Proceedings of the National Institute of Sciences of India. vol 2. Nova Delhi, 1936.

MANGILI, A., BICA, I., SNYDMAN, D. R., HAMER, D. H., Daptomycin-Resistant, Methicillin-Resistant Staphylococcus aureus bacteremia. Clin. Infect. Dis., v. 40, i. 7 , p. 1058-1060, 2005.

MARTIN, G. S., MANNINO, D. M., EATON, S., MOSS, M., The epidemiology of sepsis in the United States from 1979 through 2000. N. Engl. J. Med., v. 348, p. 1546-1554, 2003.

MASUNARI, A., Planejamento, desenvolvimento e estudos de QSAR-2D e QSAR-3D de derivados 5-nitro-2-tiofilidênicos com atividade frente a Staphylococcus aureus multiresistentes. São Paulo, 2005. (Tese de Doutorado - Faculdade de Ciências Farmacêuticas - Universidade de São Paulo).

MASUNARI, A., TAVARES, L. C., Aplicação de estudos de QSAR-2D em derivados 5-nitro-2-tiofilidênicos com atividade antimicrobiana frente a Staphylococcus aureus multi-resistente (MRSA). Braz. J. Pharm. Sci., v. 42, n. 2, p. 203 - 214, 2006.

MAYA, J. D., BOLLO, S., NUÑES-VERGARA, L. J., SQUELLA, J. A., REPETTO, S., MORELLO, A., PÉRIÉ, J., CHAUVIÈRE, G., Trypanosoma cruzi: effect and mode of 
action of nitroimidazole and nitrofuran derivatives. Biochem. Pharmacol., v. 65, i. 6, p. 999-1006, 2003.

MOLINDER, H. K., The development of cimetidine: 1964-1976: A human story. J. Clin. Gastroenterol., v. 19, i. 3, p. 248-254, 1994.

MONASTERIOS, M., AVENDAÑO, M., AMARO, M. I., INFANTE, W., CHARRIS, J., Relation between molecular electrostatic potential, several electronic properties and antibacterial activity of some synthetic furane derivatives. J. Mol. Struct., v. 798, i. 13, p. 102-108, 2006.

MORAles, G., PICAZO, J. J., BAOS, E., CANDEL, F. J., ARRIBI, A., PELÁEZ, B., ANDRADE, R., DE LA TORRE, M. Á., FERERES, J., SÁNCHEZ-GARCÍA, M., Resistance to Linezolid Is Mediated by the cfr Gene in the First Report of an Outbreak of Linezolid-Resistant Staphylococcus aureus. Clin. Infect. Dis., v. 50, i. 6, p. 821-825, 2010.

MORGON, N. H., COUTINHO, K., Métodos de Química Teórica e Modelagem Molecular. 1 ed. São Paulo: Editora Livraria da Física, 2007.

MORRISON, R., BOYD, R., Química Orgânica, 7.ed., Lisboa: Fundação Calouste Gulbenkian, p. 761-822, 1981.

MOSER, C. L., MEYER, B. K., Comparison of compendial antimicrobial effectiveness testes: A review. AAPS Pharmscitech, v. 12, n. 1, 2011.

MUÑIZ, C. C., ZELAYA, T. E. C., ESQUIVEL, G. R., FERNÁNDEZ, F. J., Penicilin and cephalosporin production: A historical perspective. Revista Latinoamericana De Microbiologia, v. 49, ns. 3-4, p. 88-98, 2007.

MURTHY, M. H.; OLSON, M. E.; WICKERT, R. W.; FEY, P. D.; JALALI, Z., Daptomycin non-susceptible meticillin-resistant Staphylococcus aureus USA 300 isolate. J. Med. Microbiol., v. 57, i. 8, p. 1036-1038, 2008.

NAVON-VENEZIA, S., LEAVITT, A., CARMELI, Y., High tigecycline resistance in multidrug-resistant Acinobacter baumannii. J. Antimicrob. Chemother., v. 59, i. 4, p. 772-774, 2007. 
NORDMANN, P., CUZON, G., NAAS, T., The real threat of Klebsiella pneumoniae carbapenemase-producing bacteria. Lancet Infect. Dis., v. 9, p. 228-236, 2009.

NORMARK, B. H., NORMARK, S., Evolution and spread of antibiotic resistance. J. Int. Med., v. 252, i. 2, p. 91-106, 2002.

OKAMOTO, M. P., NAKAHIRO, R. K., CHIN, A., BEDIKIAN, A., GILL, M. A., Cefepime: a new fourth-generation cephalosporin. Am. J. Health-Syst. Ph., v. 51, n. 4, p. 463-477, 1994.

OlIVEIRA, A. A., Planejamento, síntese e avaliação da atividade anti-T.cruzi de derivados 1,3,4-oxadiazolínicos. São Paulo, 2011. (Dissertação de Mestrado Faculdade de Ciências Farmacêuticas - Universidade de São Paulo).

OLIVEIRA, G. A., DELL'AQUILA, A. M., MASIERO, R. L., LEVY, C. E., GOMES, M. S., CUI, L., HIRAMATSU, K., MAMIZUKA, E. M., Isolation in Brazil of Nosocomial Staphylococcus aureus with Reduced Susceptibility to Vancomycin. Infect. Cont. Hosp. Ep., v. 22, i. 7, p. 443-448, 2001 a.

OLIVEIRA, G. A., FARIA, J. B., LEVYAND, C. E., MAMIZUKA, E. M., Characterization of the Brazilian endemic clone of methicillin-resistant Staphylococcus aureus (MRSA) from hospitals throughout Brazil. Braz. J. Infect. Dis., v. 5, p. 163-170, 2001 b.

OSÓRIO, T. M., MONACHE, F. D., CHIARADIA, L. D., MASCARELLO, A., STUMPF, T. R., ZANETTI, C. R., SILVEIRA, D. B., BARARDI, C. R. M., SMÂNIA E. F. A., VIANCELLI, A., GARCIA, L. A. T., YUNES, R. A., NUNES, R. J., SMÂNIA JR., A., Bioorgan. Med. Chem. Lett., v. 22, p. 225-230, 2012.

OTERO, L., M., VIEITES, M., BOIANI, L., DENICOLA, A., RIGOL, C., OPAZO, L., OLEAAZAR, C., MAYA, J. D., MORELLO, A., KRAUTH-SIEGEL, R. L., PIRO, O. E., CASTELlANO, E., GONZÁlEZ, M., GAMBINO, D., CERECETTO, H., Novel Antitrypanosomal Agents Based on Palladium Nitrofurylthiosemicarbazone Complexes: DNA and Redox Metabolism as Potential Therapeutic Targets. J. Med. Chem., v. 49, i. 11, n. 11, p. 3322-3331, 2006.

PALACE-BERL, F., JORGE, S. D., PASQUALOTO, K. F. M., FERREIRA, A. K., MARIA, D. A., ZORZI, R. R., BORTOLOZZO, L. D. S., LINDOSO, J. Â. L., 
TAVARES, L. C., 5-Nitro-2-Furfuriliden Derivatives as Potential Anti-Trypanosoma cruzi Agents: Design, Synthesis, Bioactivity Evaluation, Cytotoxicity and Exploratory Data Analysis. Bioorgan. Med. Chem., v. 21, i. 17, p. 5395-5406, 2013.

PATRICK, G. L., An Introduction to Medicinal Chemistry, 4. ed. Nova lorque: Oxford University Press, 2009.

PAULA, F. R., JORGE, S.D., DE ALMEIDA, V. L., PASQUALOTO, K. F., TAVARES, L. C., Molecular modeling studies and in vitro bioactivity evaluation of a set of novel 5-nitro-heterocyclic derivatives as anti-T. cruzi agents Bioorg. \& Med. Chem., v. 17, i. 7, p. 2673-2679, 2009.

PAULA, F. R., QSPR / QSAR em derivados 5-nitro-heterocíclicos: correlação entre o potencial redox e a atividade antichagássica. São Paulo, 2007 (Tese de Doutorado Faculdade de Ciências Farmacêuticas - Universidade de São Paulo).

PAULA, F. R., SERRANO, S. H. P., TAVARES, L. C., Aspectos mecanísticos da bioatividade e toxicidade de nitrocompostos. Quim. Nova, v. 32, n. 4, p. 1013-1020, 2009.

PAVIA, D. L., LAMPMAN, G. M., KRIZ, G. S., VYVYAN, J. R., Introdução à espectroscopia, 4 ed., São Paulo: Cengage Learning, p. 633 - 635, 2010.

PELEG, A. Y., HOOPER, D. C., Hospital-acquired infections due to gram-negative bacteria. N. Engl. J. Med., v. 362, n. 19, p. 1804-1813, 2010.

PELOSO, P. F. D., BARROS, M. F. L., SANTOS, F. A., Sepse por Serratia marcescens KPC. J. Bras. Patol. Med. Lab., v. 46, n. 5, p. 365-367, 2010.

PEREIRA, D. G., Importância do metabolismo no planejamento de fármacos. Quim. Nova, v. 30, n. 1, p. 171-177, 2007.

PERLIN, D. S., Resistance to echinocandin-class antifungal drugs. Drug resist. update, v. 10, i. 3, p. 121-130, 2007.

PFALLER, M. A., MESSER, S. A., MILLS, K., BOLMSTRÖM. In vitro susceptibility testing of filamentous fungi: Comparison of etest and reference microdilution methods for determining itraconazole MICs. J. Clin. Microbiol., v. 38, n. 9, p. 3359$3361,2000$. 
PhRMA, Pharmaceutical Research and Manufactures of America. Pharmaceutical Industry Profile, Washington, DC: PhRMA, 2012.

PHYSPROPC database. Disponível em: <http://www.syrres.com/whatwedo/databaseforms.aspx?id=386>. Acessado em 2013.

PINHO, A.,24 pessoas já morreram no Estado de São Paulo com superbactéria KPC. Folha de São Paulo, 23 de outubro, 2010.

POLAK, E., RIBIERE, G., Note sur la convergence de méthodes de directions conjugées. Revue française d'informatique et de recherché opérationnelle, v. 3, n. 1, p. 35-43, 1969.

POUND, M. W., REEL, J. E., Daptomycin-Nonsusceptible Vancomycin-Resistant Enterococcal Bacteremia: A Case Report and Review of the Literature. Infect. Dis. Clin. Prac., v. 21, i. 2, p. 79-84, 2013.

RAJAK, H., KHARYA, M. D., MISHRA, P., Synthesis of some novel oxadiazole and oxadiazoline analogues for their antiinflammatory activity. Yakugaku Zasshi, n. 127, v. 10, p. $1757-1764,2007$.

RAMMELKAMP, M., Resistance of Staphylococcus aureus to the action of penicillin. Proc. R. Soc. Exp. Biol. Med., v. 51, p. 386 - 389, 1942.

RANDO, D. G., AVERY, M. A., TEKWANI, B. L., KHAN, S. I., FERREIRA, E. I., Antileishmanial activity screening of 5-nitro-2-heterocyclic benzylidene hydrazides. Bioorgan. Med. Chem., v. 16, p. 6724-6731, 2008.

RANDO, D. G., SATO D. N., SIQUEIRA L., MALVEZZI, A., LEITE, C. Q. F., DO_AMARAL, A. T., FERREIRA, E. I., TAVARES L. C., Potential tuberculostatic agents. Topliss application on benzoic acid [(5-Nitro-thiophen-2-yl)-methylene]hydrazide series. Bioorgan. Med. Chem., v. 10, i. 3, p. 557-560, 2002.

RAWLINS, M. D., Cutting the cost of drug development?. Nature Rev. Drug Discov., v. 3, i. 4, n. 4, p. 360-364, 2004.

REED, D., KEMMERLY, S. A., Infection control and prevention: A review of hospitalacquired infections and the economic implications. The Ochsner Journal, v. 9, p. 27-31, 2009. 
REZENDE, P., Relações quantitativas estrutura-atividade de derivados 5-nitro2tiofilidenicos: Planejamento, síntese e determinação da atividade antimicrobiana nfrente a cepas de Staphylococcus aureus. São Paulo, 2002. (Dissertação de Mestrado - Faculdade de Ciências Farmacêuticas - Univerisdade de São Paulo).

ROBlEDO, I. E., AQUINO, E. E., VÁZQUEZ, G. J., Detection of the KPC Gene in Escherichia coli, Klebsiella pneumoniae, Pseudomonas aeruginosa, and Acinetobacter baumannii during a PCR-Based Nosocomial Surveillance Study in Puerto Rico. Antimicrob Agents Chemother., v. 55, n. 6, p. 2968-2970, 2011.

RODRIGUEZ, A. M., Síntese e determinação da concentração inibitória mínima frente a Staphylococcus aureus de 5-nitro-2-furfurilideno benzidrazidas substituídas. São Paulo, 2000 (Dissertação de Mestrado - Faculdade de Ciências Farmacêuticas - Universidade de São Paulo).

RODRIGUEZ-BAÑO, J., NAVARRO, M. D., ROMERO, L., MUNIAIN, M. A., PEREA, E. J., PÉREZ-CANO, R., HERNÁNDEZ, J. R., PASCUAL, A., Clinical and molecular epidemiology of extended-spectrum $\beta$-Lactamase-Producing Escherichia coli as a cause of nosocomial infection or colonization: Implications for control. Clin. Infect. Dis., v. 42, p. 37-45, 2006.

ROLLAS, S., GULERMAN, N., ERDENIZ, H., Synthesis and antimicrobial activity of some new hydrazones of 4-flurobenzoic acid hydrazide and 3-acetyl-2,5-disubstituted-1,3,4oxadiazolines. Farmaco, v. 57, p. 171-174, 2002.

ROLLAS, S., KARAKUŞ, S., Marmara Pharmaceutical Journal, v. 16, n. 2, p. 120133, 2012.

ROSS, E. L., Mecanismos de ação de fármacos e a relação entre sua concentração e seu efeito. In: HARDMAN, J. G., LIMBIRD, L. E., GILMAN, A. G., Goodman \& Gilman As Bases farmacológicas da terapêutica. 8. ed., Nova lorque: McGraw Hill, 1996.

SADER, H. S., JONES, R. N., GALES, A. C., WINOKUR, P., KUGLER, K. C., PFALLER, M. A., DOERN, G. V., and the SENTRY Latin America Study Group, Antimicrobial susceptibility patterns for pathogens isolated from patients in Latin American medical centers with a diagnosis of pneumonia: analysis of results from the 
SENTRY Antimicrobial Surveillance Program (1997). Diagn. Microbial. Infect. Dis., v. 32, i. 4 , p. 289-301, 1998.

SCHMITZ, F. J., KREY, A., SADURSKI, R., VERHOEF, J., MILATOVIC, D., FLUIT, A. C. and the European SENTRY participants, Resistance to tetracycline and distribution of tetracycline resistance genes in European Staphylococcus aureus isolates. J. Antimicrob. Chemother., v. 47, i. 2., p. 239-240, 2001.

SHERMAN, W. R., 5-nitro-2-furyl-substituited 1,3,4-oxadiazoles, 1,3,4-thiadiazoles, and 1,3,5-triazines. J. Org. Chem., v. 26, i. 1, p. 88-95, 1961.

SINGER, S. J., NICOLSON, G. L., The fluid mosaic of the structure of cell membranes. Science, v. 175, i. 4023, p. 720-731, 1972.

SONEHARA, I. Y., Estudos de identificação de possiveis alvos para nitro-compostos azometínicos ou oxadiazolínicos com atividade antifúngica e anti-T. cruzi. São Paulo, 2009 (Tese de Doutorado - Faculdade de Ciências Farmacêuticas - Universidade de São Paulo).

SOULI, M., GALANI, I., GIAMARELLOU, H., Emergence of extensively drug-resistant and pandrug-resistant Gram-negative bacilli in Europe. Euro. Surveill., v. 13, i. 47, 2008.

SQUELLA, J. A., LETELIER, M. E., LINDERMEYER, L., NUNEZ-VERGARA, L. J., Redox behaviour of nifuroxazide: generation of the one-electron product. J. Chem. Biol. Interact., v. 99, p. 227-238, 1996.

STEIN, G. E., CRAIG, W. A., Tigecycline: A Critical Analysis. Clin. Infect. Dis., v. 43, i. 4, p. 518-524, 2006.

SUH, J-Y., SON, J. S., CHUNG, D. R., PECK, K. R., KO, K. S. K., SONG, J-K., Nonclonal Emergence of Colistin-Resistant Klebsiella pneumoniae Isolates from Blood Samples in South Korea. Antimicrob. Agents. Ch., v. 54, n. 1, p. 560-562, 2010.

SWAIN, C. G., LUPTON, E. C. Jr., Field and resonance components of substituent effects. J. Am. Chem. Soc., v. 90, i. 16, p. 4328-4337, 1968. 
tavares, L. C., CHISTÉ, J. J., SANTOS, M. G. B., PENNA, T. C. V., Synthesis and biological activity of nifuroxazide and analogs. Boll. Chim. Farma., v. 139, n. 8, 1999.

TAVARES, L. C., PENNA, T. C. V., AMARAL, A. T., Synthesis and biological activity of nifuroxazide and analogs. Boll. Chim. Farma., v. 136, n. 3, p. 224-229, 1997.

TAVARES, L. C., QSAR: A abordagem de Hansch. Quim. Nova, v. 27, n. 4, p. 631639, 2004.

TAVARES, L. C., Relações quantitativas entre a estrutura química e a atividade antimicrobiana de análogos à nifuroxazida. São Paulo, 1993. (Tese de Doutorado Faculdade de Ciências Farmacêuticas - Universidade de São Paulo).

THOMAS, G., Química Medicinal, uma introdução. 1.ed. Rio de Janeiro: Guanabara koogan, cap. 2, p. 28, 2003.

TIEMERSMA, E. W., BRONZWIER, S., LYYTIKÄINEN O., DEGENER, J. E., SCHIJNEMAKERS, P., BRUISMA, N., MONEN, J., WITTE., W., GRUNDMANN, H., Methicilin-resistant Staphylococcus aureus in Europe: 1999-2002. Emerg. Infect. Dis., v. 10, p. 1627-1634, 2004.

TMM, The Merck Manual for Health Care Professionals. Drug Excretion. $<$ http://www.merckmanuals.com/professional/clinical_pharmacology/pharmacokinetic s/drug_excretion.html>. Acesso em: 1 de maio de 2012.

TORTORA, G. J., FUNKE, B. R., CASE, C. L., Microbiologia, 8. ed., São Paulo: Artmed, 2005.

TUON, F. F., FILHO, S. R. P., Controle e tratamento de enterococcus resistente a vancomicina (VRE). Prat. Hosp., n. 62, p. 75-80, 2009.

TURNER, M. S., DREW, R. H., PERFECT, J. R., Emerging echinocandins for treatment of invasive fungal infections. Expert Opin. Emerg. Drugs, v. 11, n. 2, p. 231-250, 2006.

TURRA, K. M., PASQUALOTO, K. F. M., BARROS, S. B. M., A novel set of b-Nbiaryl ether sulfonamide hydroxamates as potential MMPs inhibitors: Molecular 
dynamics simulations and molecular properties evaluation. Int. J. Quantum Chem., v. 112, p. 3374-3389, 2012.

VARGAS, R., UTI de dois hospitais de Mato Grosso estão isoladas por superbactéria. Folha de São Paulo, 14 de janeiro 2011.

VEBER, D. F., JOHNSON, S. R., CHENG, H. Y., SMITH, B. R., WARD, K. W., KOOPLE, K. D., Molecular properties that influence the oral bioavailability of drug candidates. J. Med. Chem., v. 45, n. 12, p. 2615-2623, 2002.

VEIGA, L.,Registrado mais um caso de infecção pela superbactéria KPC. Bom dia DF, 14 de março 2011.

VERLOOP, A., The STERIMOL Approach to Drug Design. Marcel Dekker: New York, 1987.

VIANA, L. A., Síntese e determinação da atividade antimicrobiana de 2-[ 5-nitrotiofen-2-il]-3-acetil-5-[4-fenil-substituído]-2,3-diidro-1,3,4-oxadiazolinas frente à cepa ATCC 25923 de Staphtlococcus aureus. São Paulo, 2009 (Tese de Mestrado Faculdade de Ciências Farmacêuticas - Universidade de São Paulo).

VILLEGAS, M. V., LOLANS, K., CORREA, A., KATTAN J. N., QUINN, J. P., and the Colombian Nosocomial Resistance Study Group, First identification of Pseudomonas aeruginosa isolates producing a KPC-type carbapenem-hydrolyzing $\beta$-lactamase. Antimicrob. Agents Ch., v. 51, n. 4, p. 1553-1555, 2007.

VILleGAS, M. V., LOLANS, K., CORREA, A., SUAREZ, C. J., LOPEZ, J. A., VALLEJO, M., QUINN, J. P., and the Colombian Nosocomial Resistance Study Group, First detection of the plasmid-mediated class A carbapenemase KPC-2 in clinical isolates of Klebsiella pneumoniae from South America. Antimicrob. Agents Ch., v. 50, n. 8, p. 2880-2882, 2006.

VIODÉ, C., BETTACHE, N., CENAS, N., KRAUTH-SIEGEL, R. L., CHAVIÉRE, G., BALAKARA, N., PÉRIE, Enzymatic reduction studies of nitroheterocycles. J. Biochem. Pharmacol., Oxford, v. 57, n. 5, p. 549-557, 1999.

VISWANADHAN, V. N., GHOSE, A. K., REYANKAR, G. R., ROBINS, R. K., Atomic physicochemical parameters for three dimensional structure directed Quantitative 
Structure-Activity Relationships. 4. Additional parameters for hydrophobic and dispersive interactions and their application for an automated superposition of certain naturally occurring nucleoside antibiotics. J. Chem. Inf. Comput. Sci., v. 29, p. 163$172,1989$.

WALKER, L. A.; GOW, N. A. R.; MUNRO, C. A., Fungal echinocandin resistance. Fungal Genet. Biol., v. 47, i. 2, p. 117-126, 2010.

WERMUTH, C. G., Medicinal chemistry: Definition and objectives, the three main phases of drug activity, drug activity, drug and disease classifications. In: WERMUTH, C. G., The Practice of Medicinal Chemistry, 2. ed., Londres: Elsevier Academic Press, 2003. $b$

WERMUTH, C. G., The Practice of Medicinal Chemistry, 2.ed., Londres: Elsevier Academic Press, 2003.

WHO a, World Health Organization, Prevention of hospital-acquired infections.<http://www.who.int/csr/resources/publications/drugresist/WHO_CDS_CSR _EPH_2002_12/en/>. Acesso em: 11 de março de 2011.

WHO $b$, World Health Organization, Antimicrobial Resistance < http://www.who.int/mediacentre/factsheets/fs194/en/>. Acesso em: 13 de março de 2011.

WHO $c$, World Health Organization. Antimicrobial discovery and development, <http://www.who.int/drugresistance/Microbes_and_Antimicrobials/en/>. Acesso em: 18 de março de 2011.

WISPLINGHOFF, H., BISCHOFF, T., TALLENT, S. M., SEIFERT, H., WENZEL, R. P., EDMOND, M. B., Nosocomial Bloodstream Infections in US Hospitals: Analysis of 24,179 cases from a prospective nationwide surveillance study. Clin. Infect. Dis., v. 39, i. 3, p. 309-317, 2004.

WITTE, W., GRIMM, H., Occurrence of quinolone resistance in Staphylococcus aureus from nosocomial infection. Epidemiol. Infect., v. 109, i. 3, p. 413-421, 1992. 
ZORZI, R. R., Planejamento, síntese e avaliação da atividade anti-T.cruzi de derivados azometínicos. São Paulo, 2011. (Monografia de conclusão de curso Faculdade Presbiteriana Mackenzie). 
ANEXO 1

Espectros de RMN ${ }^{1} \mathrm{H}$ e RMN ${ }^{13} \mathrm{C}$ dos compostos de série I 
Espectro de RMN ${ }^{1} \mathrm{H}$ do composto $N^{\prime}$-(5-nitrofuran-2-il)metileno)benzidrazida, I-A
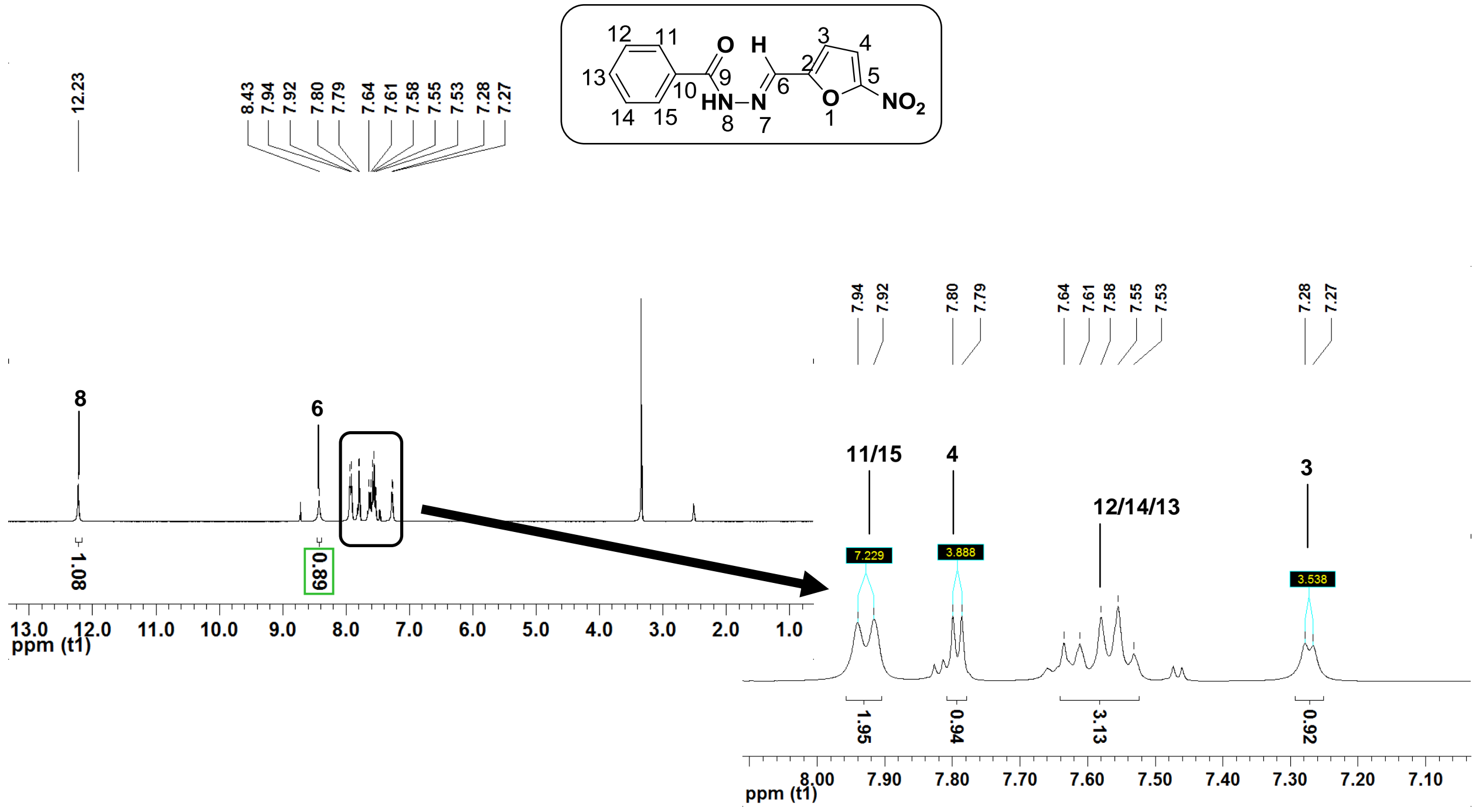
Espectro de RMN ${ }^{13} \mathrm{C}$ do composto $N^{\prime}$-(5-nitrofuran-2-il)metileno)benzidrazida, I-A

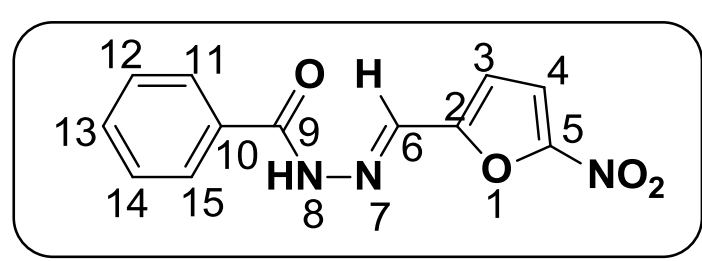

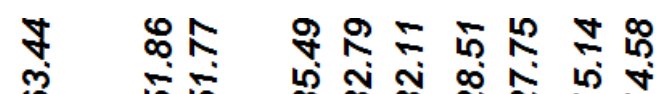

ญ

$111 j\rfloor$
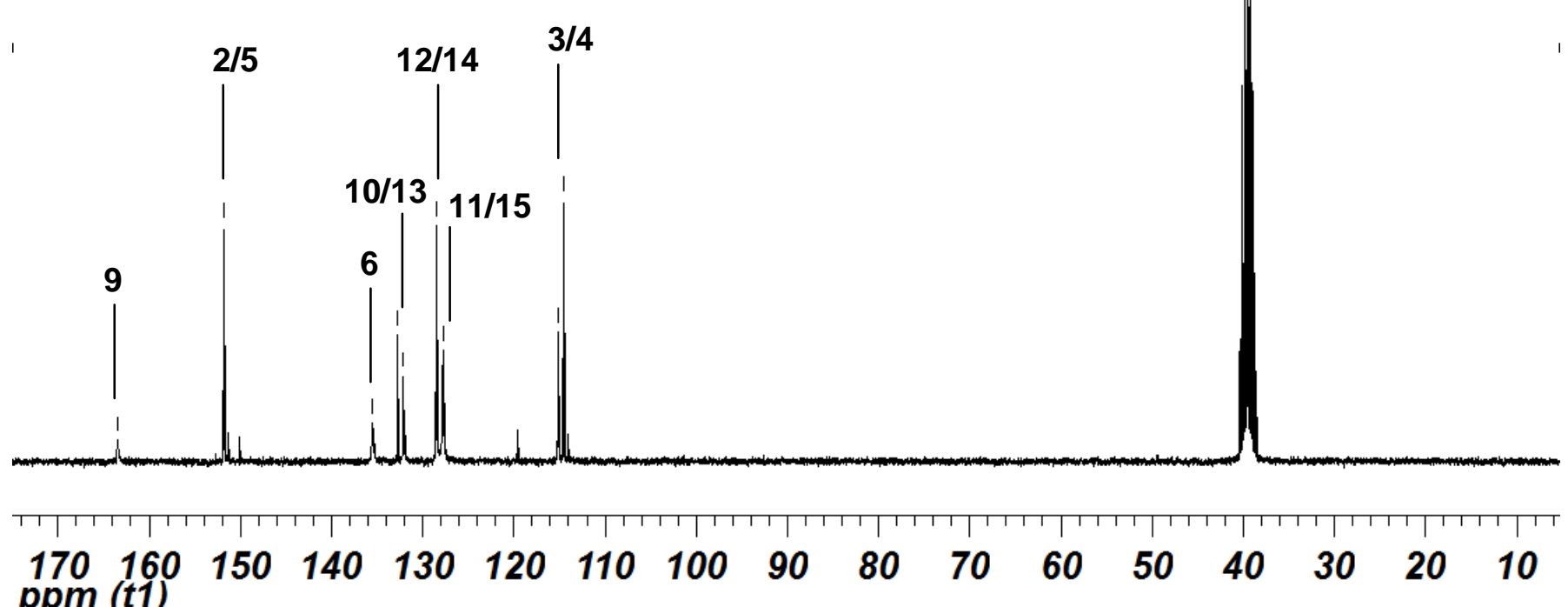
Espectro de RMN ${ }^{1} \mathrm{H}$ do composto 4-metil-(5-nitrofuran-2-il)metileno)benzidrazida, I-B
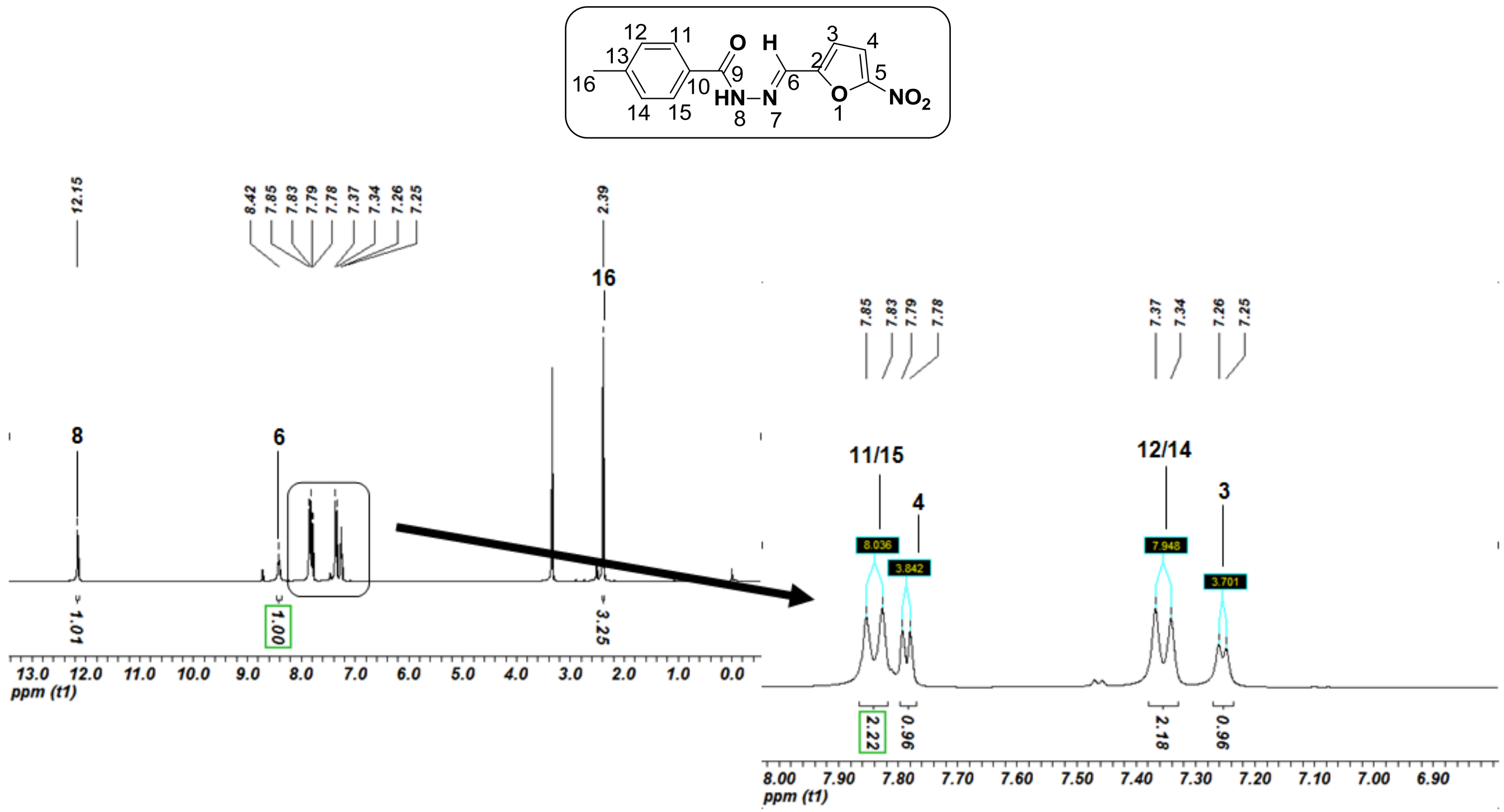
Espectro de RMN ${ }^{13} \mathrm{C}$ do composto 4-metil-(5-nitrofuran-2-il)metileno)benzidrazida, I-B

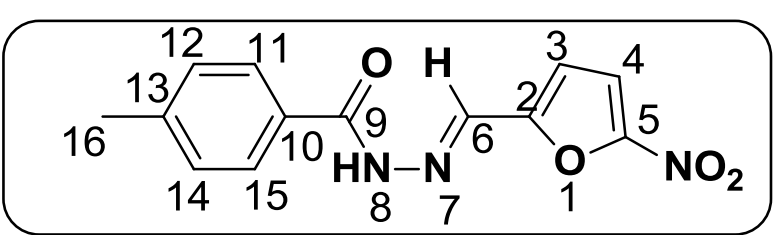

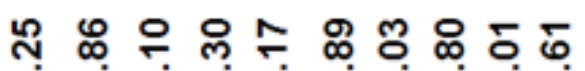

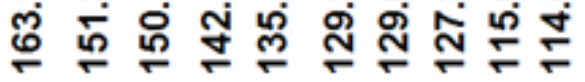

(र)

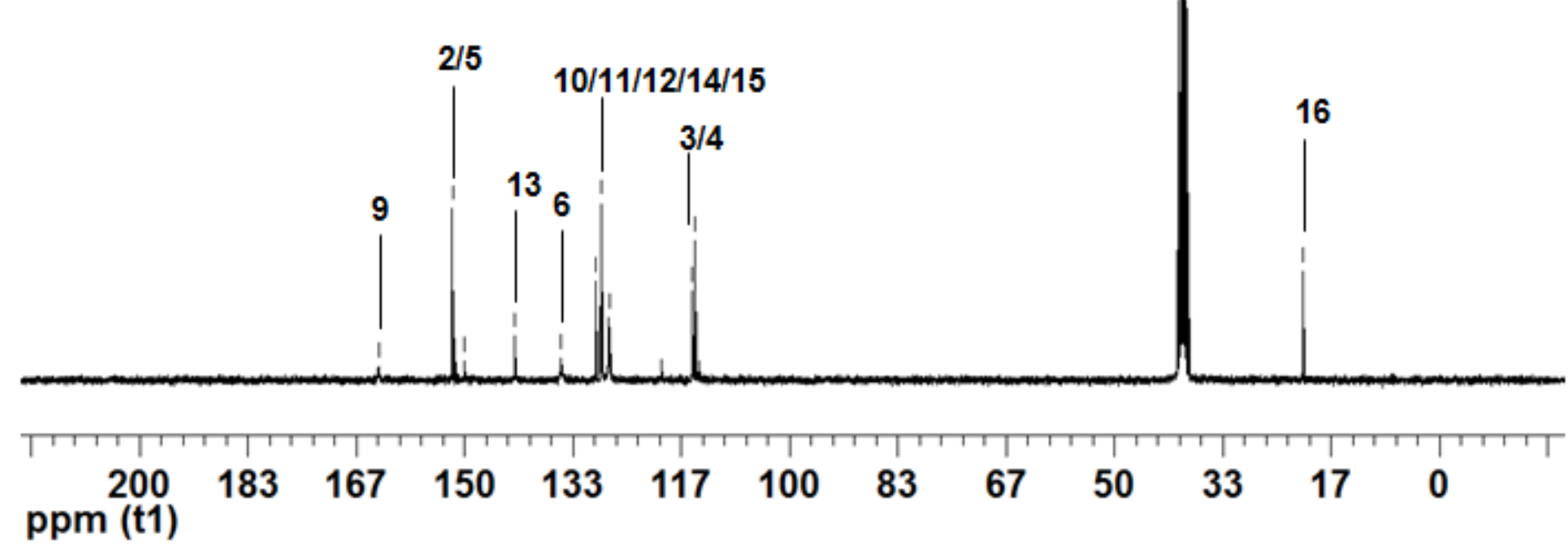


Espectro de RMN ${ }^{13} \mathrm{C}$ do composto 4-metóxi-(5-nitrofuran-2-il)metileno)benzidrazida, I-C

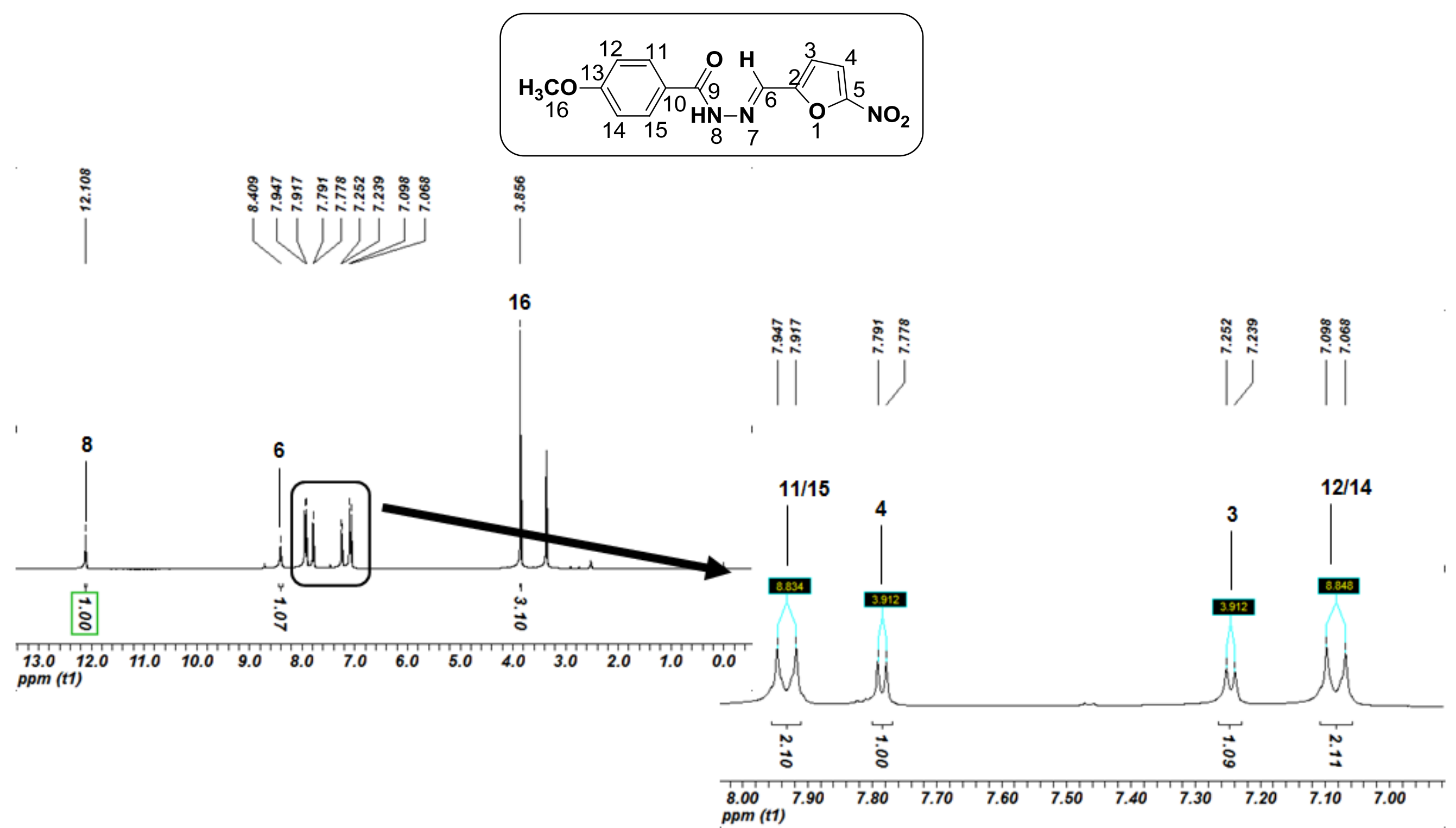


Espectro de RMN ${ }^{13} \mathrm{C}$ do composto 4-metóxi-(5-nitrofuran-2-il)metileno)benzidrazida, I-C

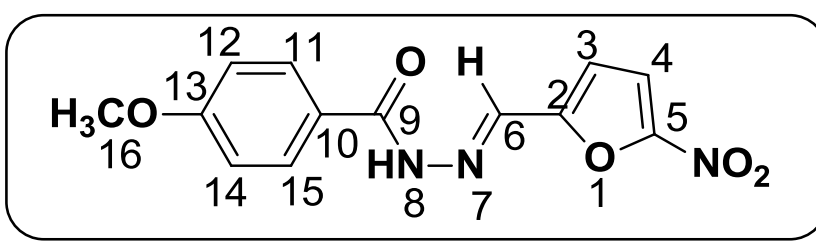

8 ำ

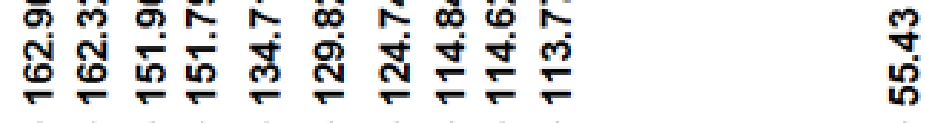

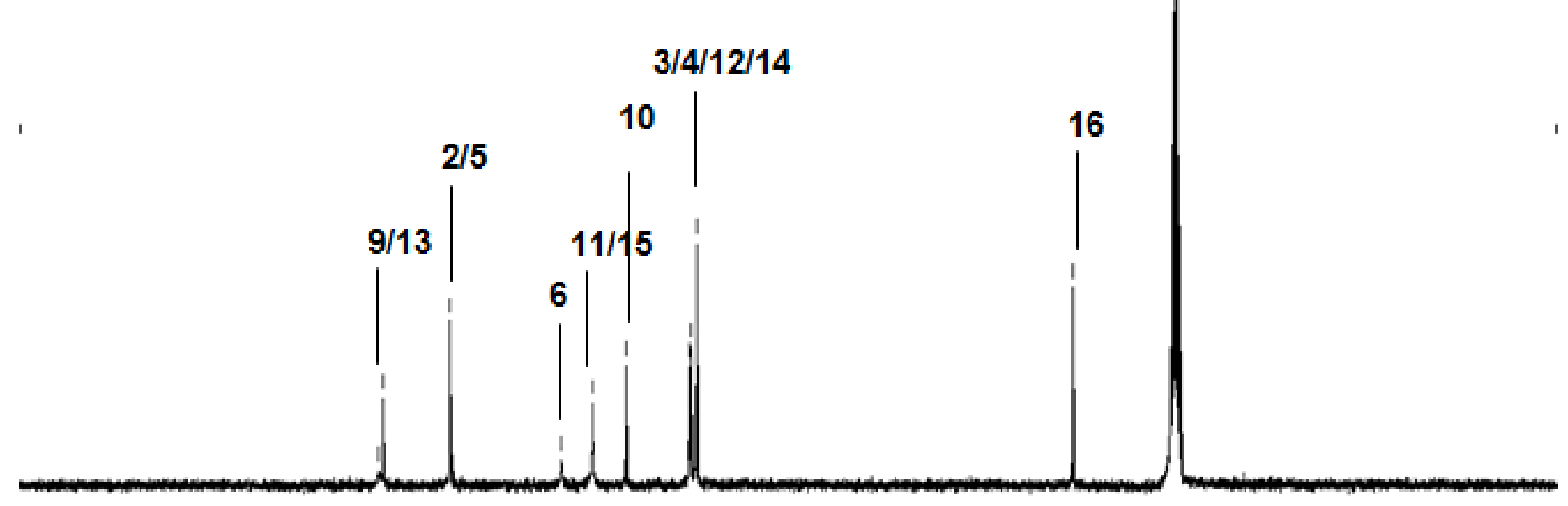

200 ppm (t1)

$\begin{array}{llllllllllll}183 & 167 & 150 & 133 & 117 & 100 & 83 & 67 & 50 & 33 & 17 & 0\end{array}$


Espectro de RMN ${ }^{13} \mathrm{C}$ do composto 4-bromo-(5-nitrofuran-2-il)metileno)benzidrazida, I-D
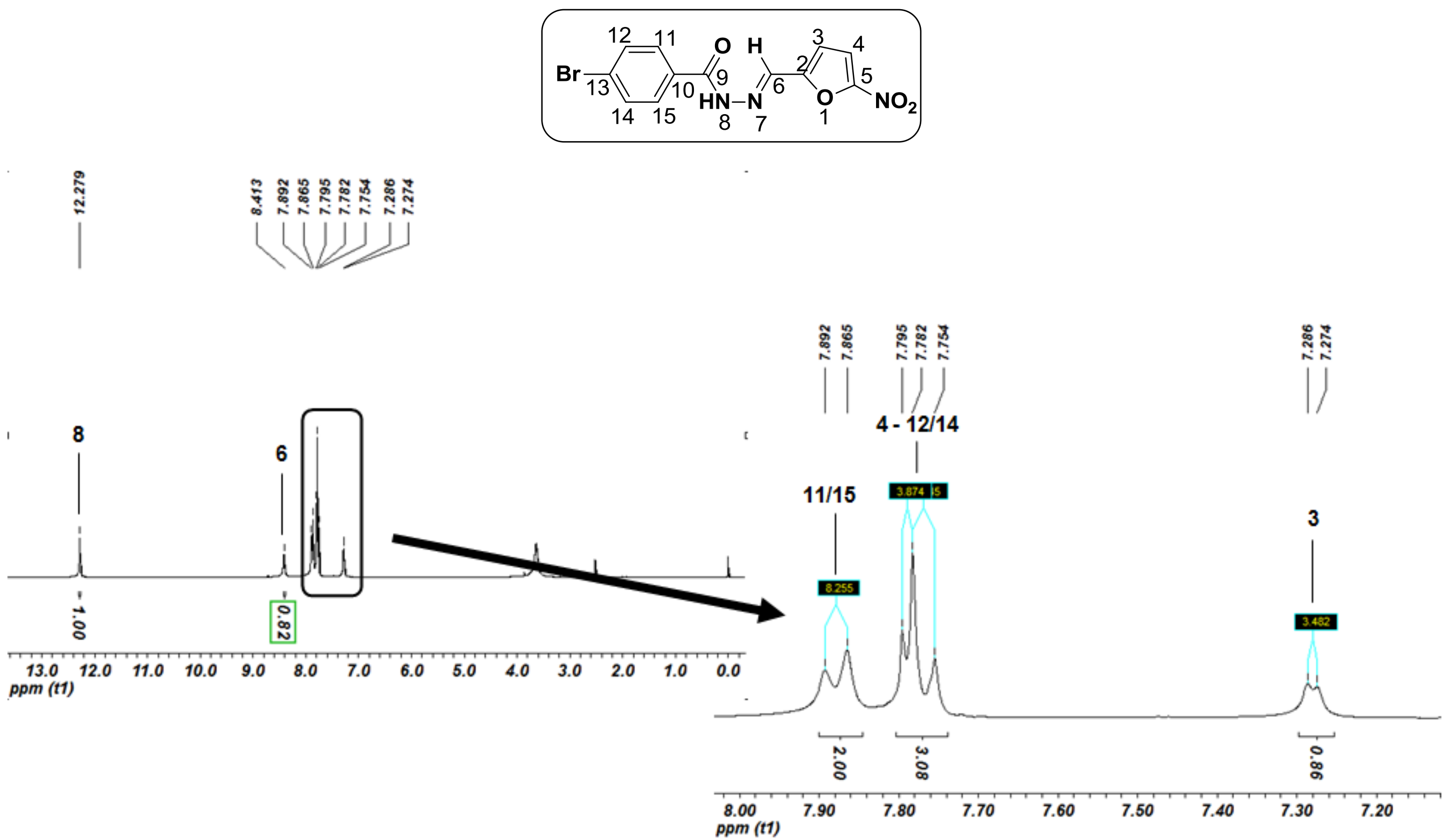
Espectro de RMN ${ }^{13} \mathrm{C}$ do composto 4-bromo-(5-nitrofuran-2-il)metileno)benzidrazida, I-D
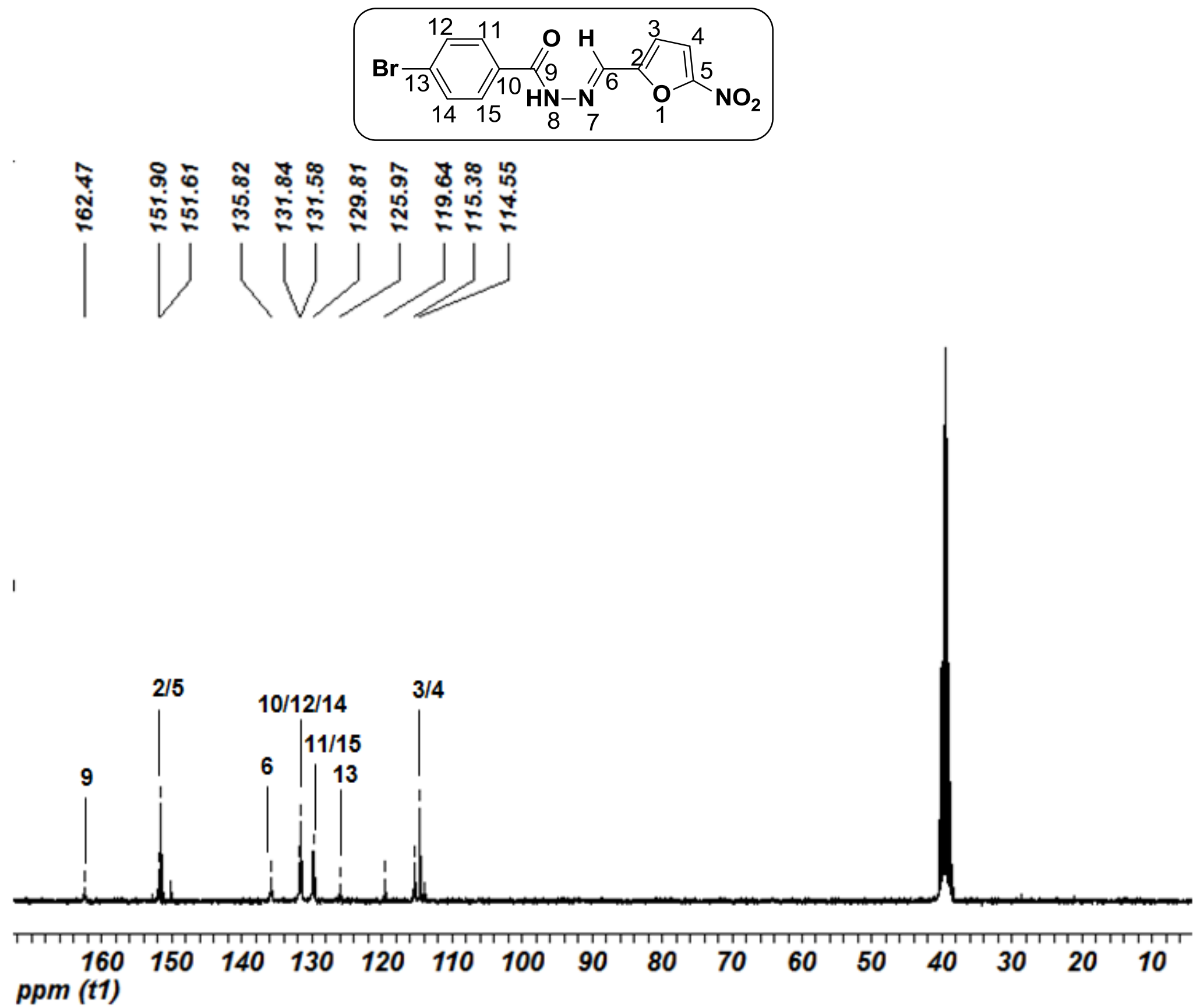
Espectro de RMN ${ }^{1} \mathrm{H}$ do composto 4-butil-(5-nitrofuran-2-il)metileno)benzidrazida, I-G

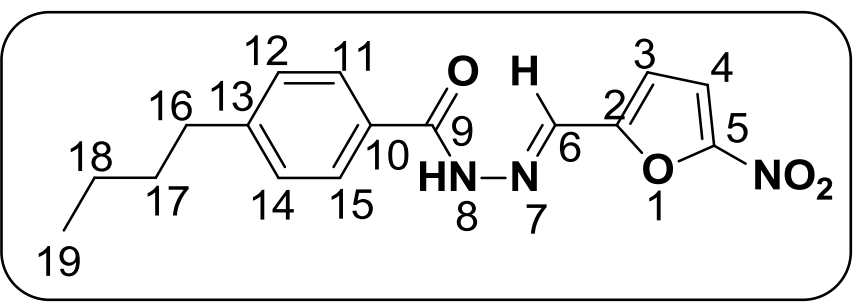

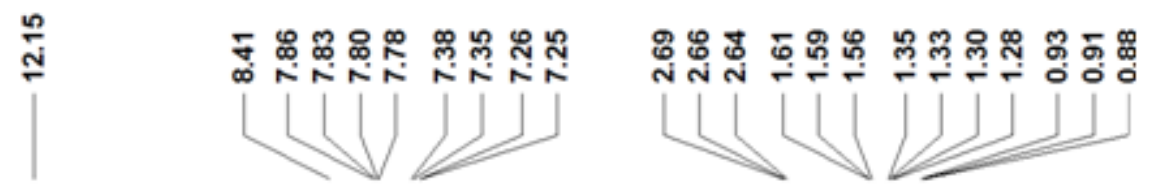

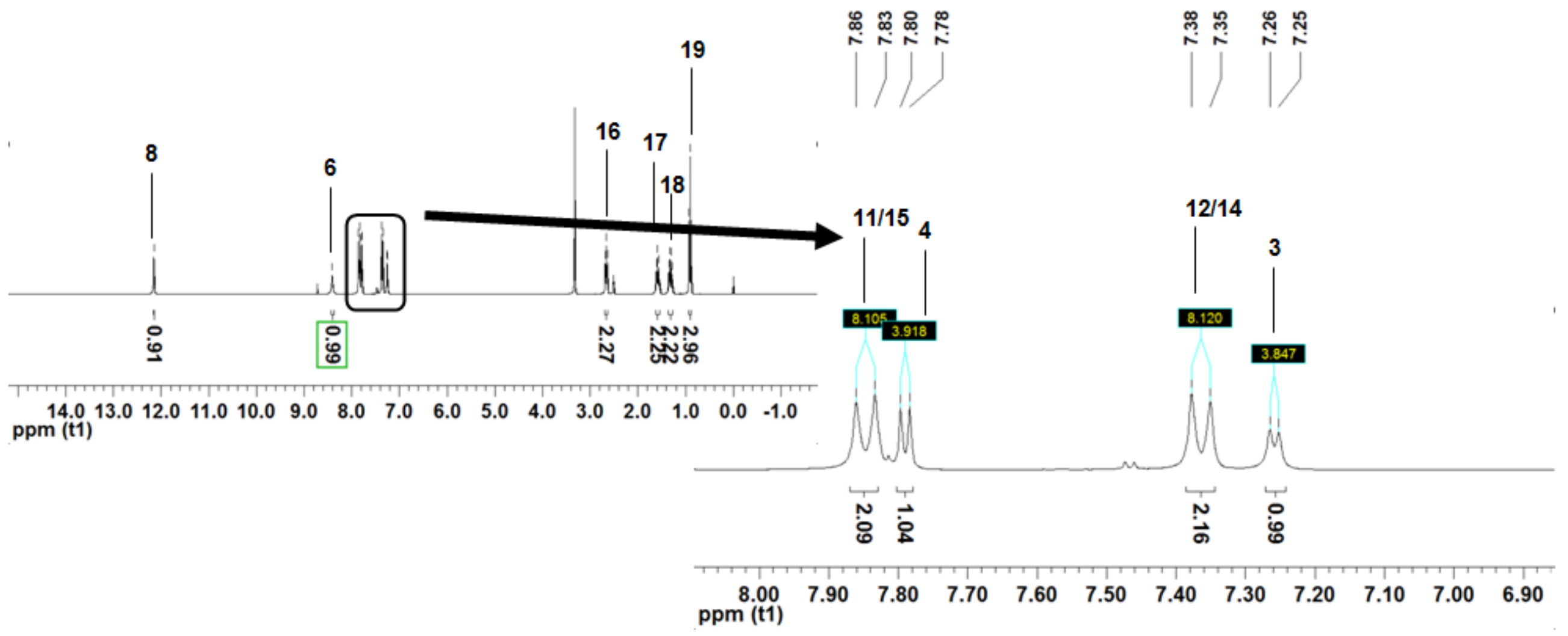


Espectro de RMN ${ }^{13} \mathrm{C}$ do composto 4-butil-(5-nitrofuran-2-il)metileno)benzidrazida, I-G

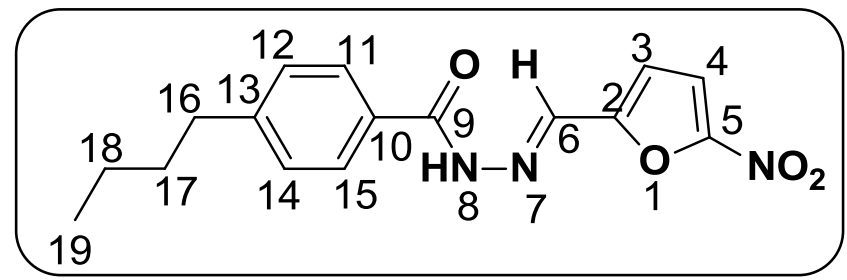

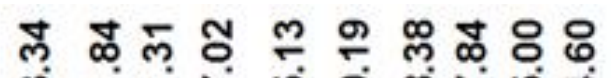

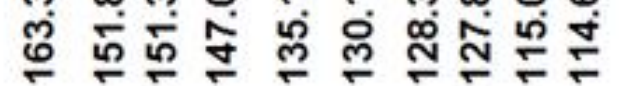

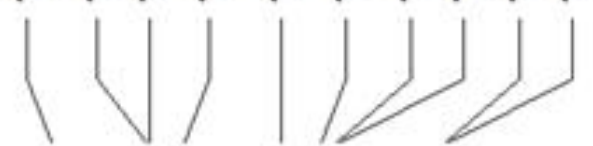

ㄷํㅇํㅇ

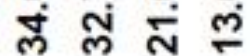
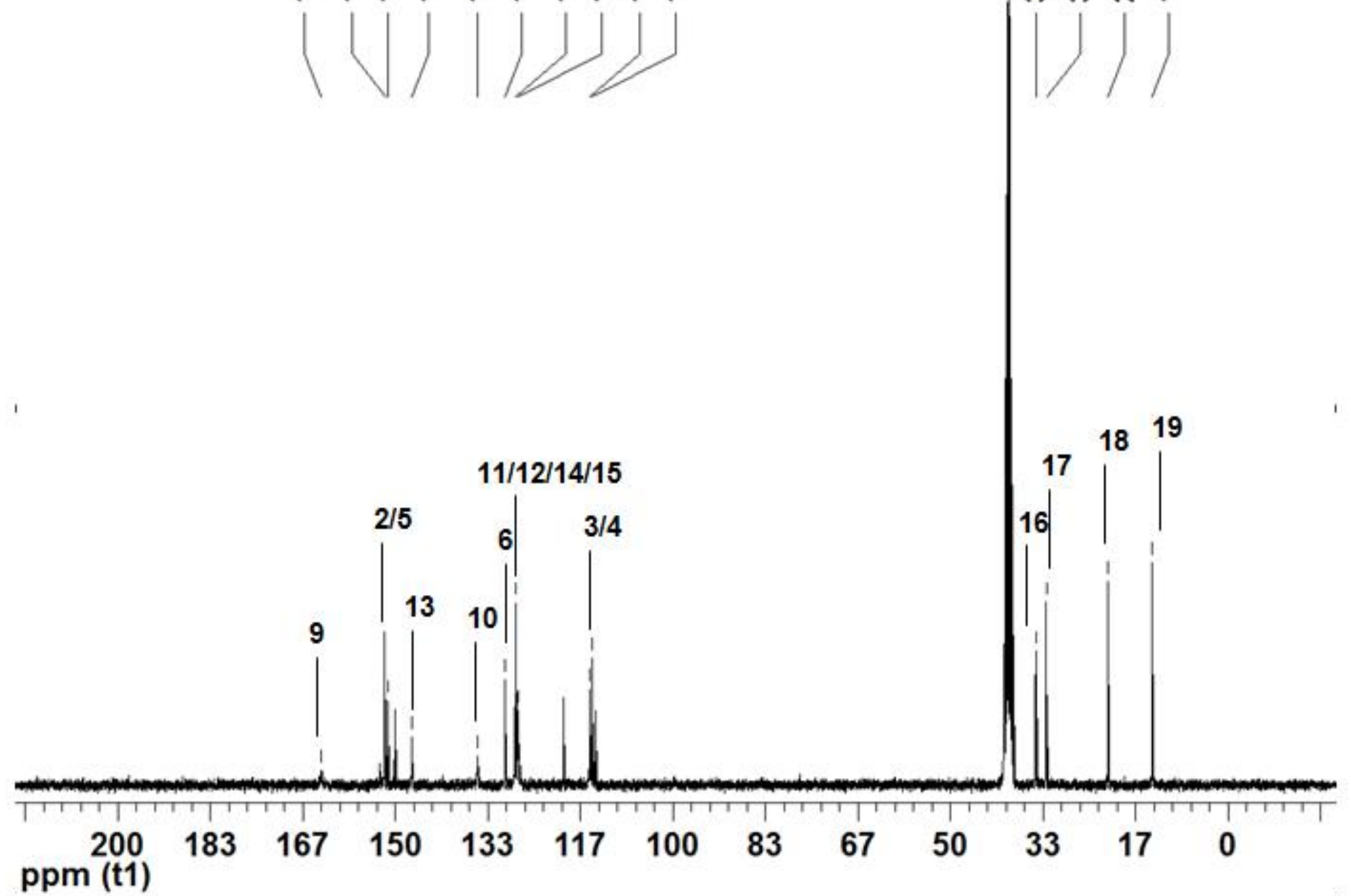
Espectro de RMN ${ }^{1} \mathrm{H}$ do composto 4-sulfamoil-(5-nitrofuran-2-il)metileno)benzidrazida, I-H
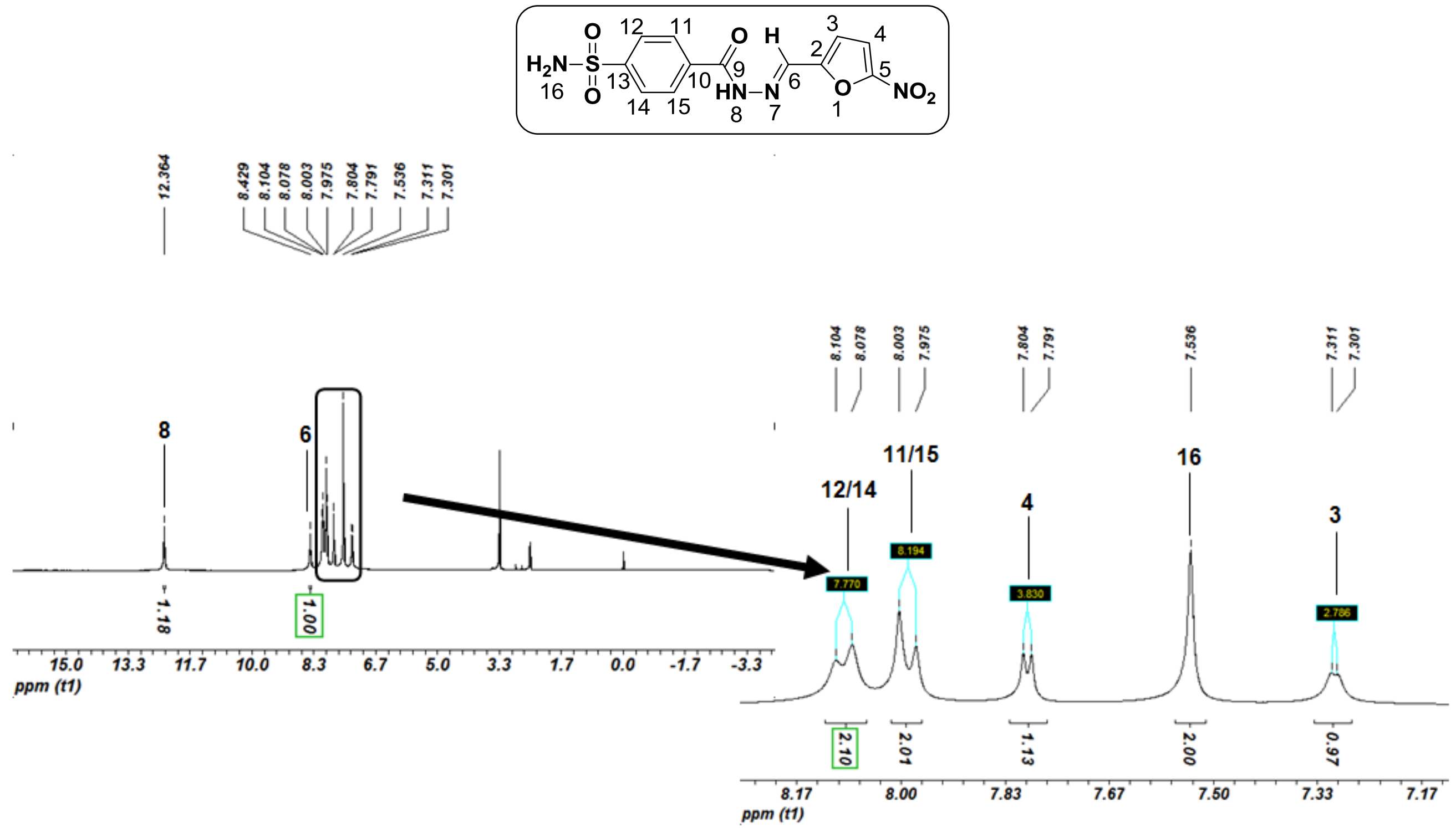
Espectro de RMN ${ }^{13} \mathrm{C}$ do composto 4-sulfamoil-(5-nitrofuran-2-il)metileno)benzidrazida, I-H

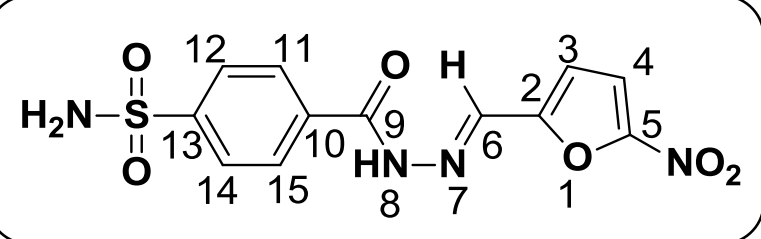

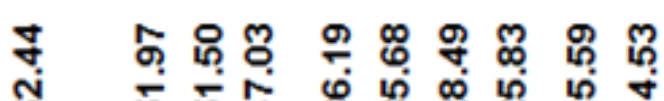

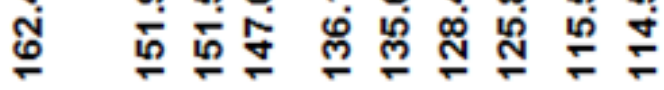
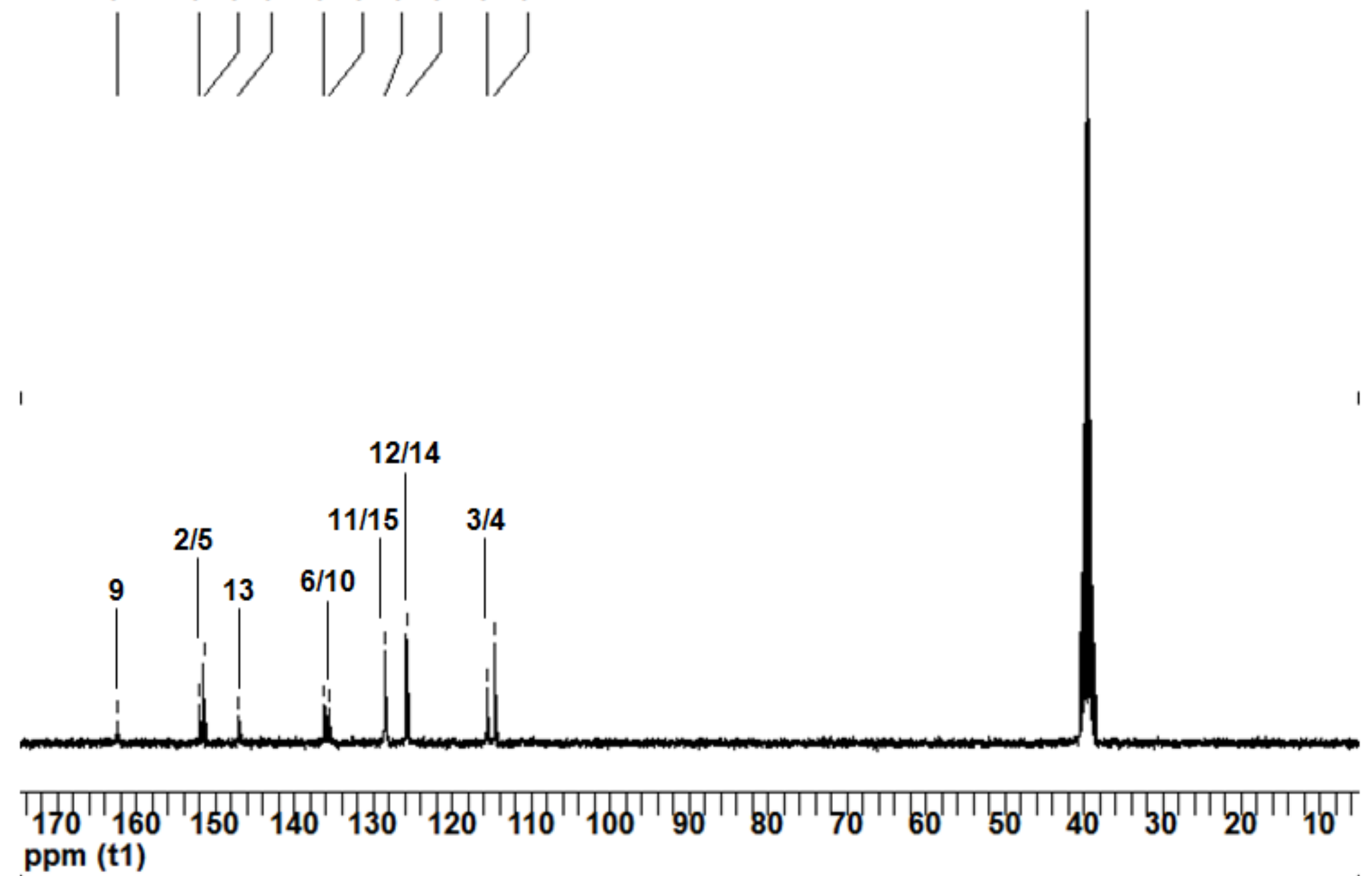
Espectro de RMN ${ }^{1} \mathrm{H}$ do composto 4-cloro-(5-nitrofuran-2-il)metileno)benzidrazida, I-I
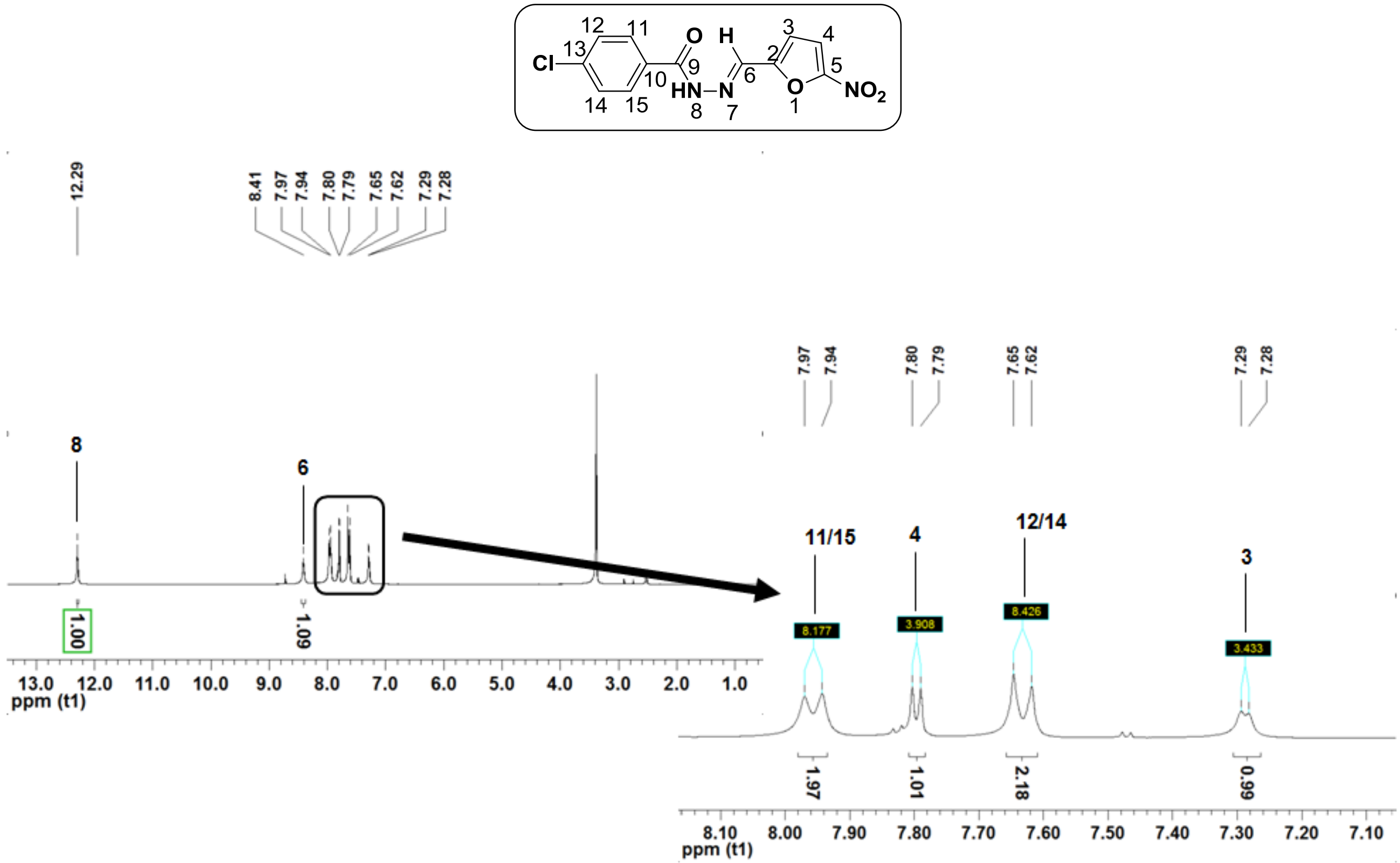
Espectro de RMN ${ }^{1} \mathrm{H}$ do composto 4-dimetil-(5-nitrofuran-2-il)metileno)benzidrazida, I-J

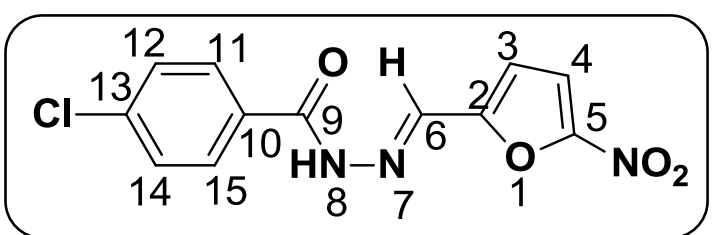

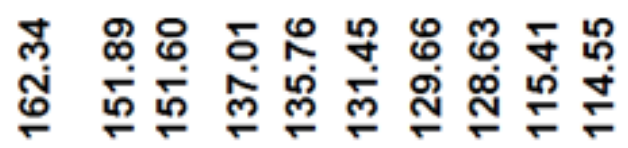

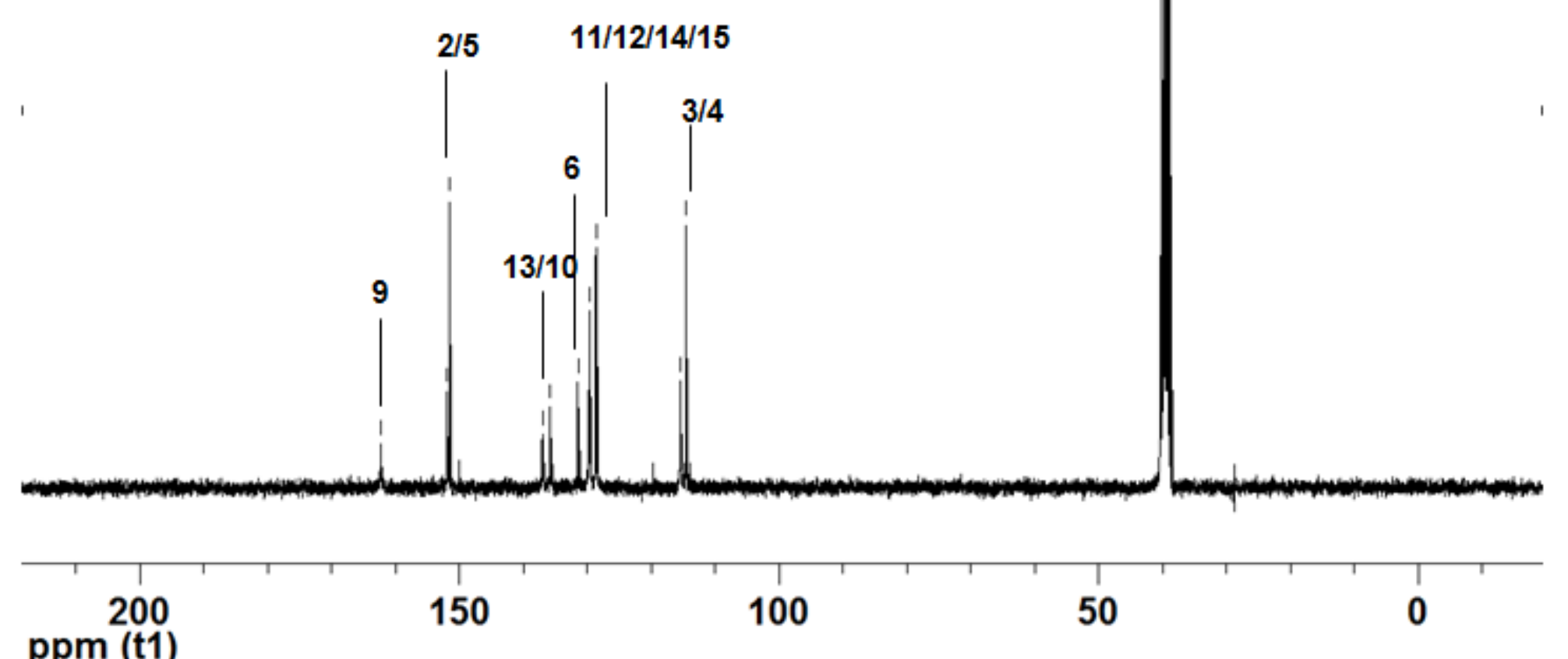

ppm (t1) 
Espectro de RMN ${ }^{1} \mathrm{H}$ do composto 4-dimetil-(5-nitrofuran-2-il)metileno)benzidrazida, I-J
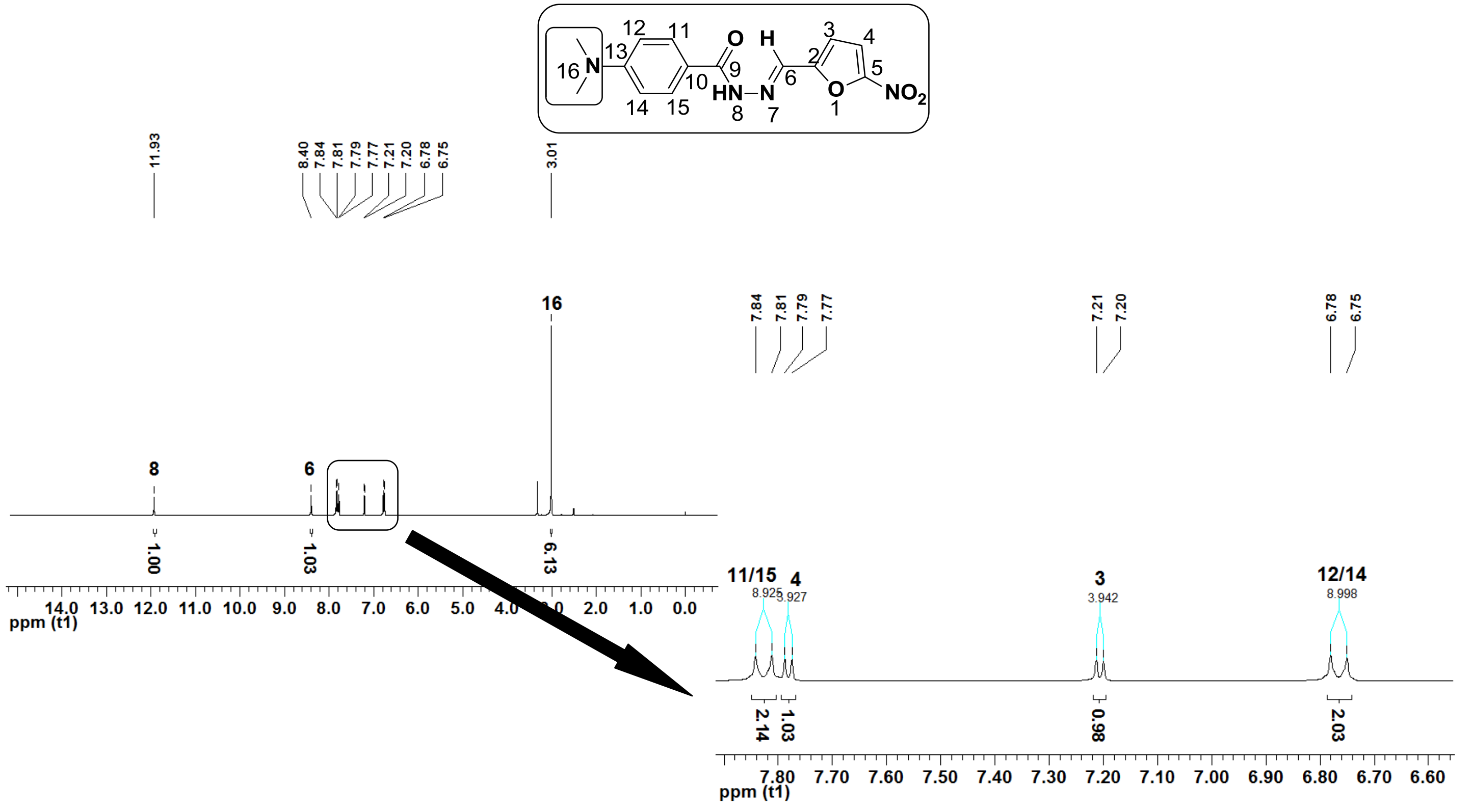
Espectro de RMN ${ }^{13} \mathrm{C}$ do composto 4-dimetil-(5-nitrofuran-2-il)metileno)benzidrazida, I-J

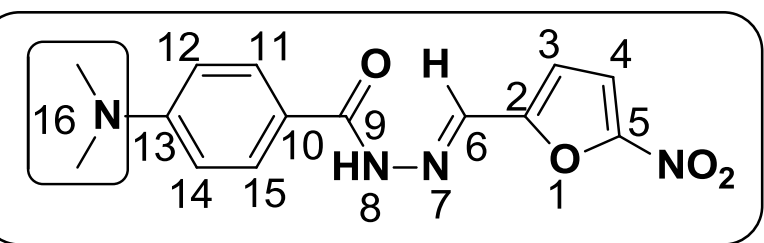

సั่

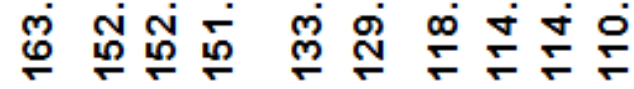
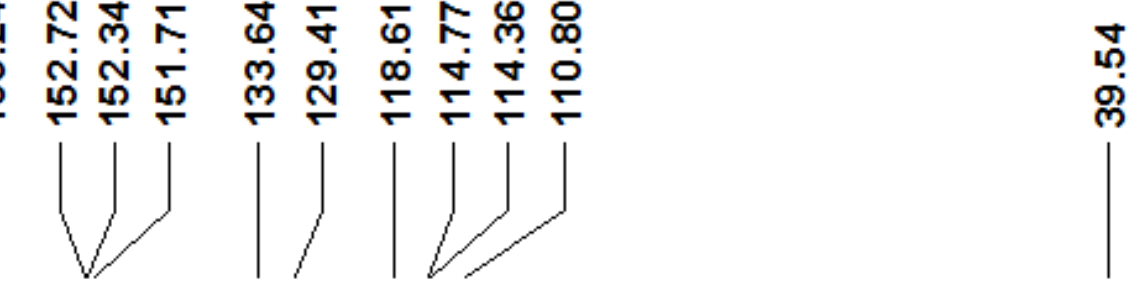

16

$12 / 14$

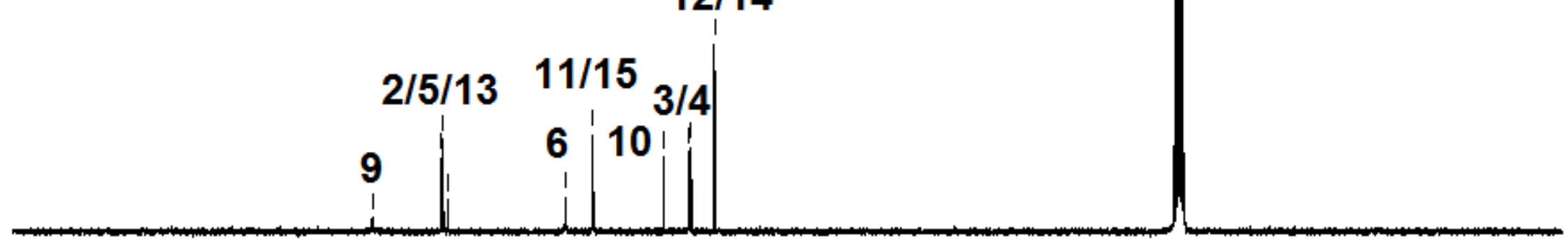

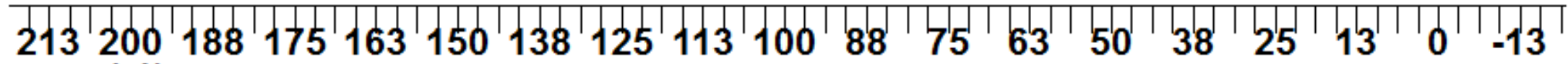
ppm (t1) 
Espectro de RMN ${ }^{13} \mathrm{C}$ do composto 4-amino-(5-nitrofuran-2-il)metileno)benzidrazida, I-K
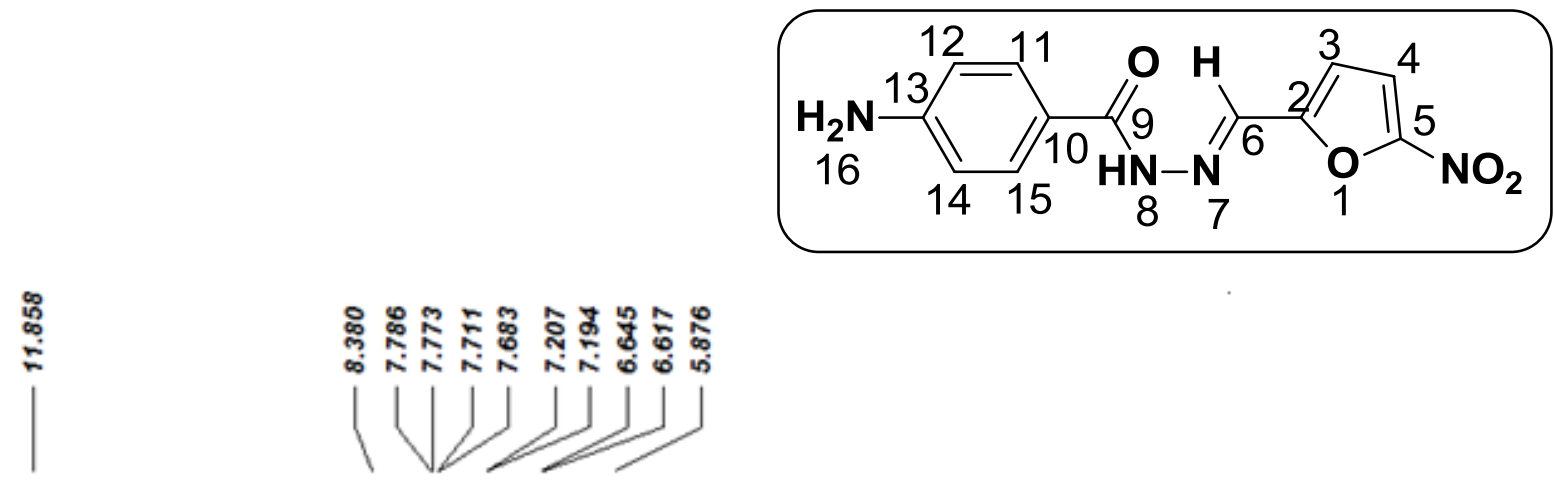

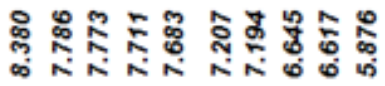
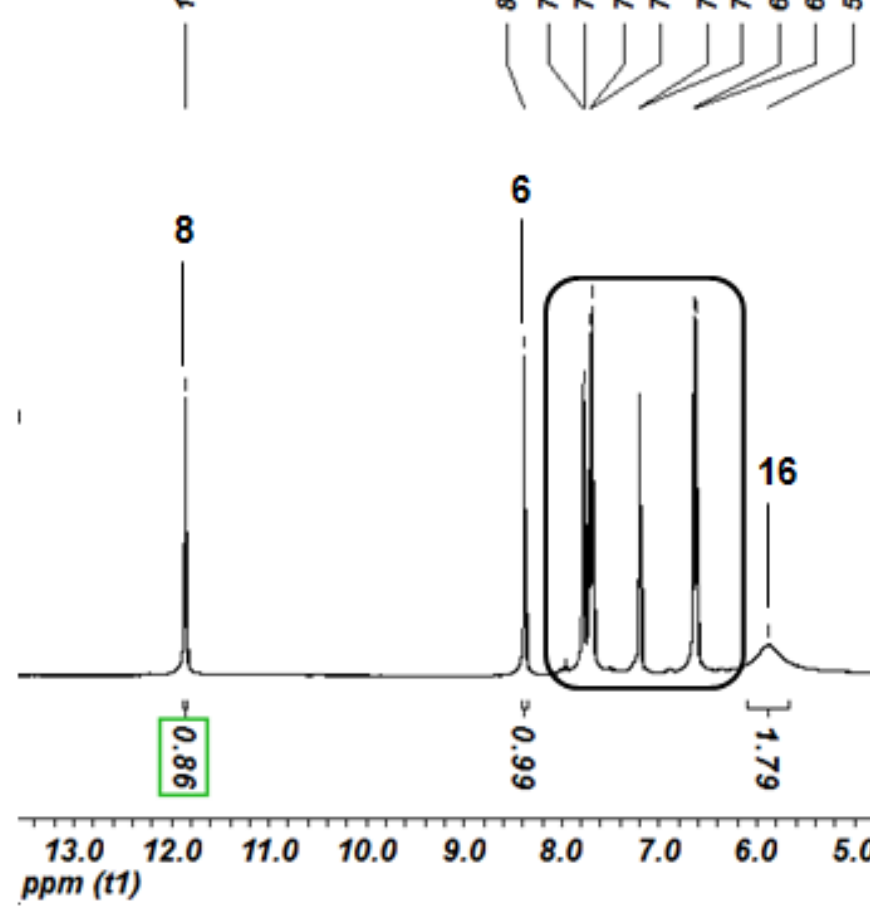

6
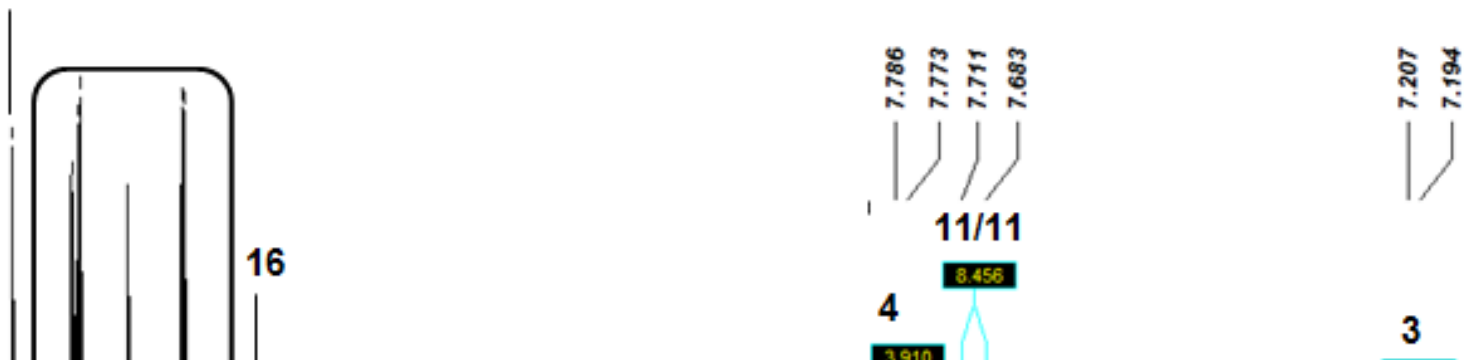

3

B..42 ppm (t1)
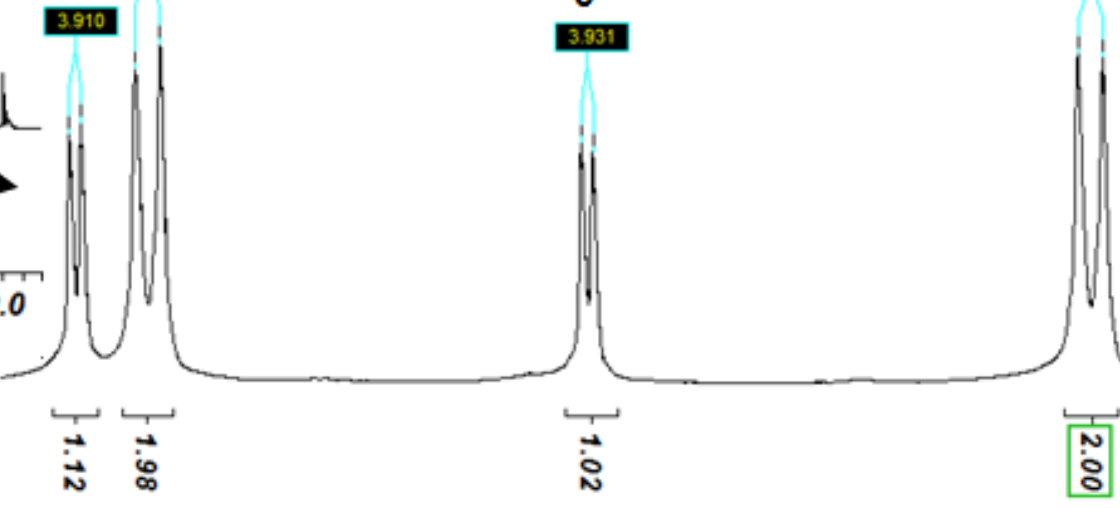

$\begin{array}{lllllllllllllllll}7.80 & 7.70 & 7.60 & 7.50 & 7.40 & 7.30 & 7.20 & 7.10 & 7.00 & 6.90 & 6.80 & 6.70 & 6.60 & 6.50\end{array}$ ppm (t1) 
Espectro de RMN ${ }^{13} \mathrm{C}$ do composto 4-amino-(5-nitrofuran-2-il)metileno)benzidrazida, I-K

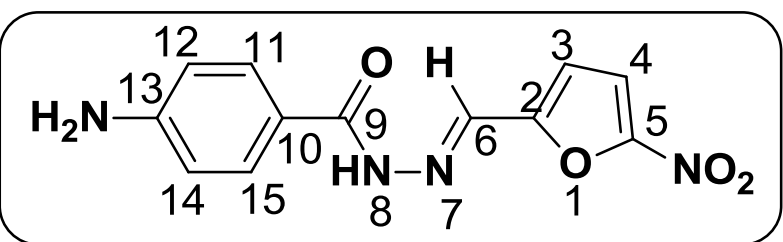

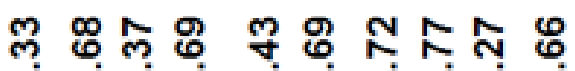

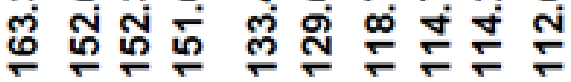
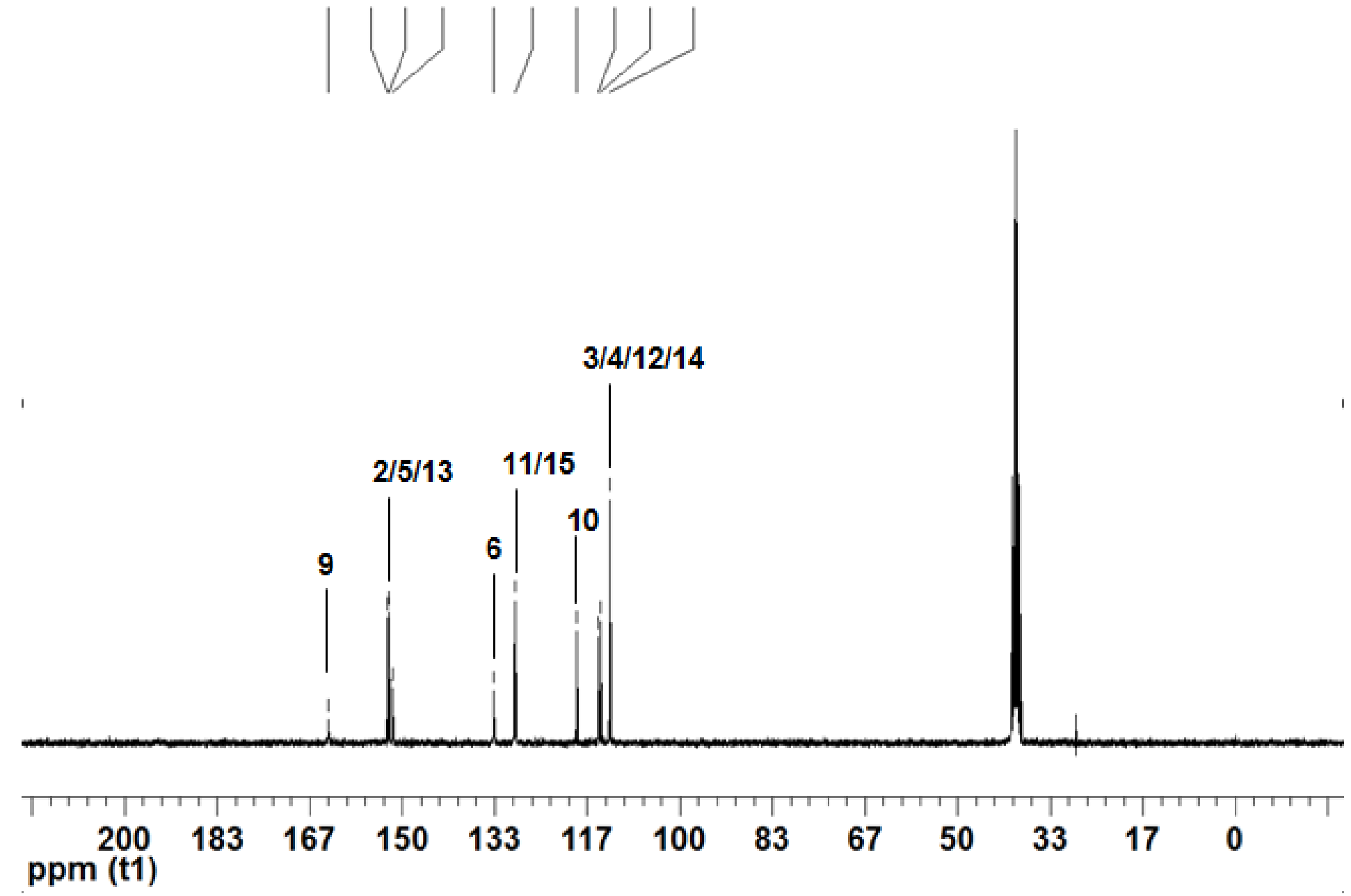
Espectro de RMN ${ }^{1} \mathrm{H}$ do composto 4-(tert-butil)-(5-nitrofuran-2-il)metileno)benzidrazida, I-L
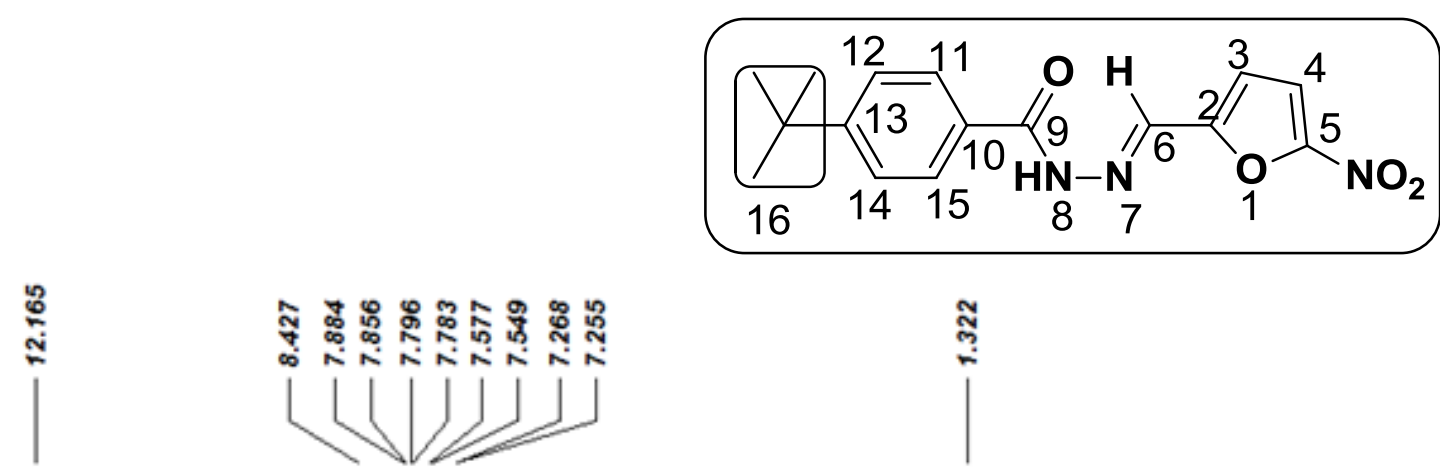

స్

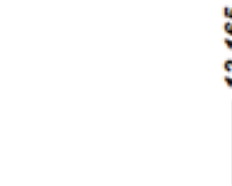

萬

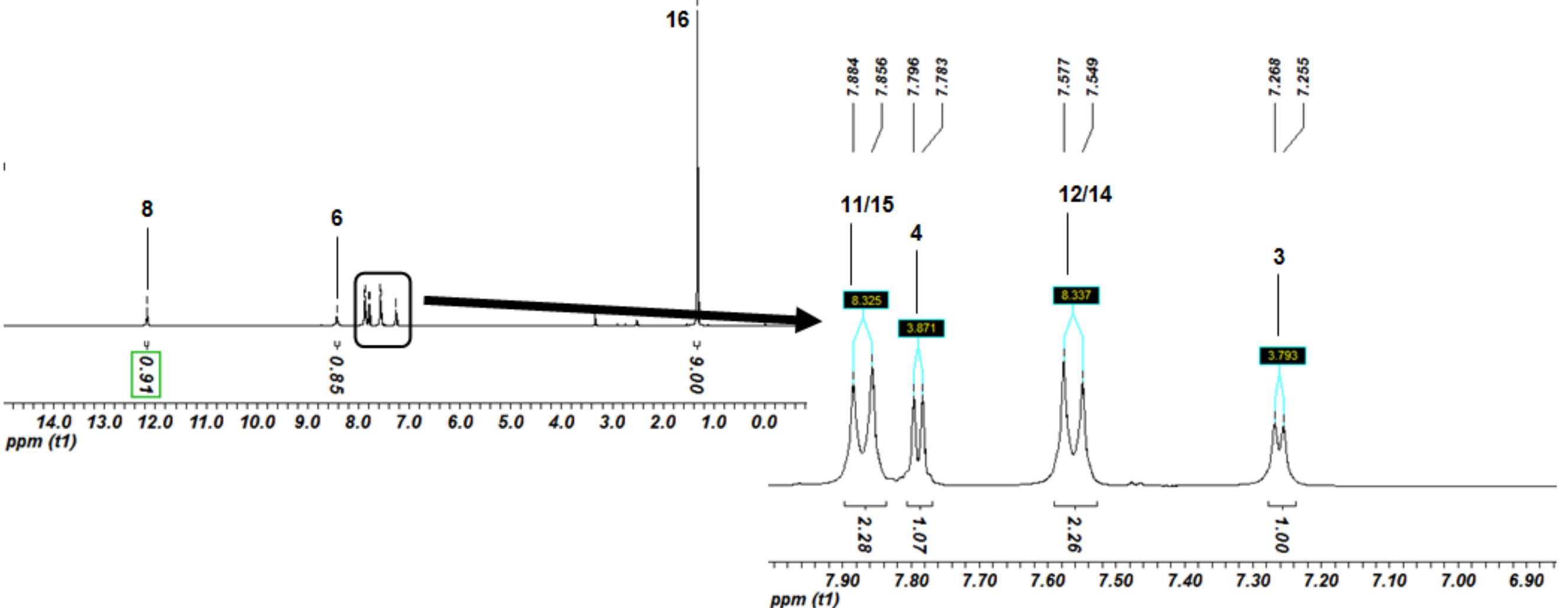


Espectro de RMN ${ }^{13} \mathrm{C}$ do composto 4-(tert-butil)-(5-nitrofuran-2-il)metileno)benzidrazida, I-L
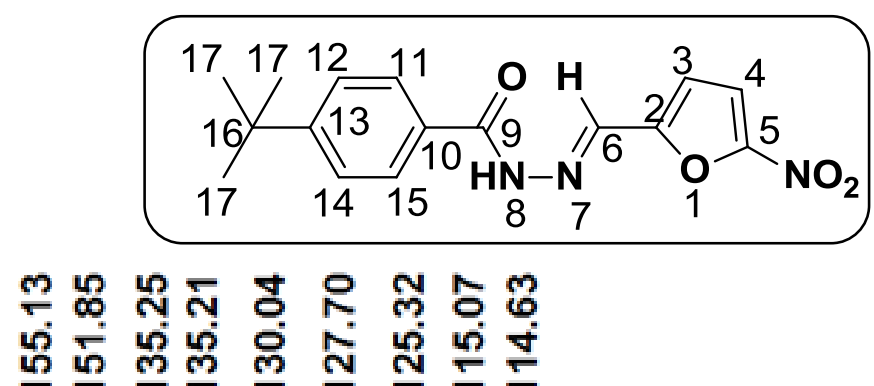

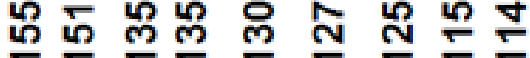
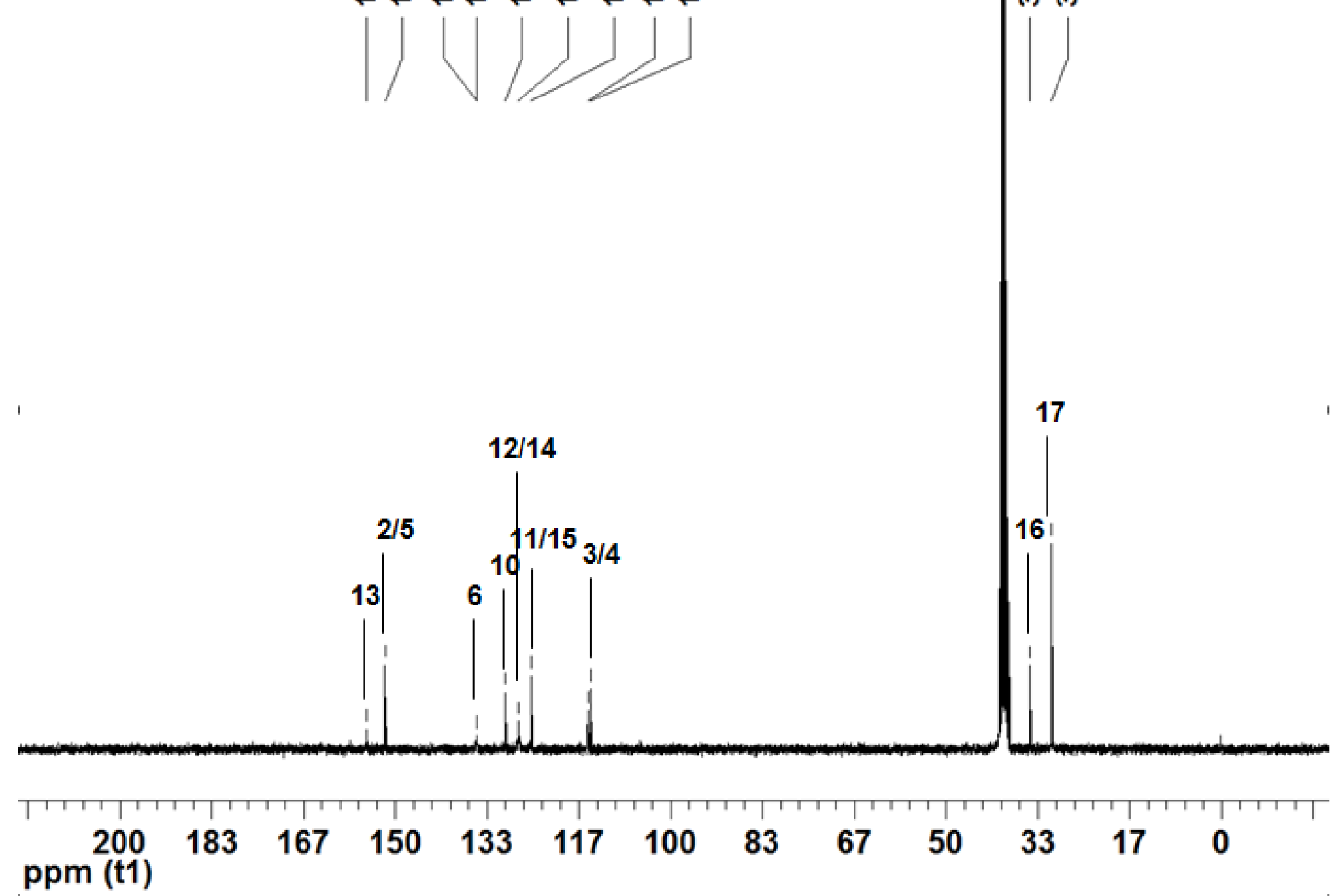

ANEXO 2

Espectros de RMN ${ }^{1} \mathrm{H}$ e RMN ${ }^{13} \mathrm{C}$ dos compostos de série II 
Espectro de RMN ${ }^{1} \mathrm{H}$ do composto 3-acetil-2-[5-nitro-furan-2-il]-5-fenil-2,3-diidro-1,3,4-oxadiazolínico, II-A

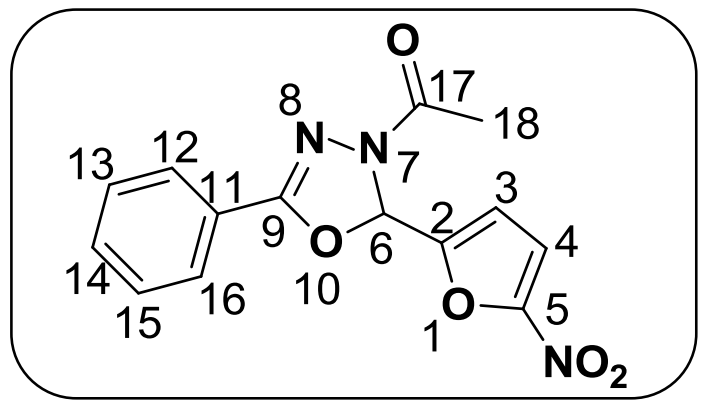

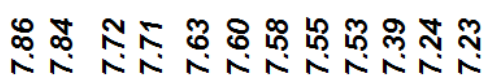

[L L

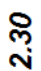

18
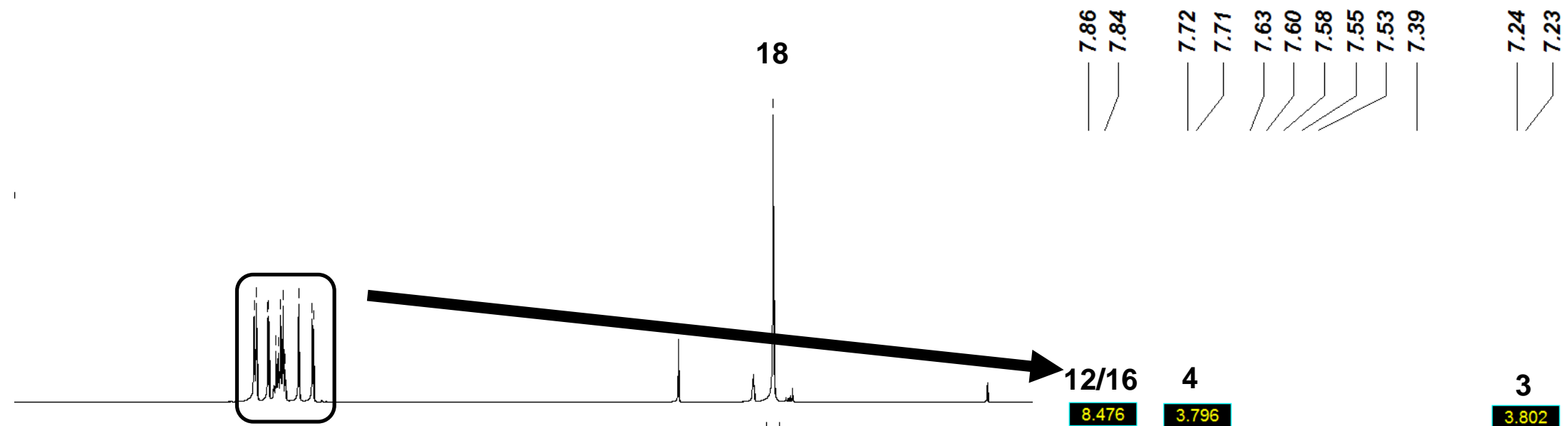

$12 / 16$

4
3.796

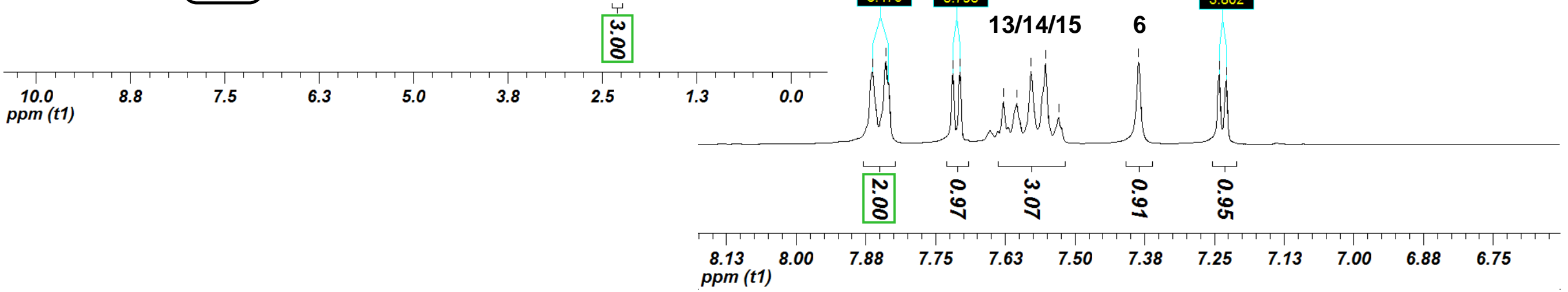


Espectro de RMN ${ }^{13} \mathrm{C}$ do composto 3-acetil-2-[5-nitro-furan-2-il]-5-fenil-2,3-diidro-1,3,4-oxadiazolínico, II-A

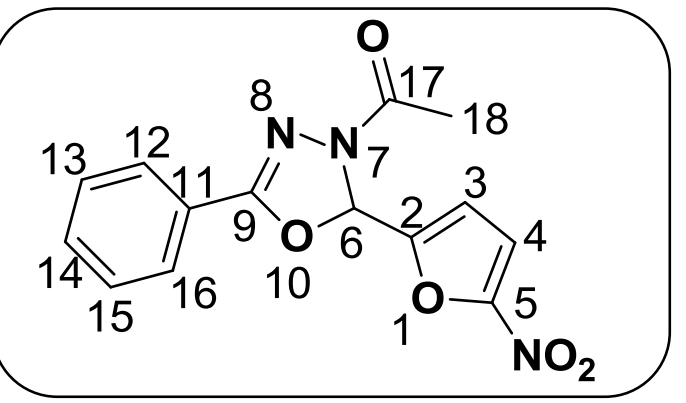

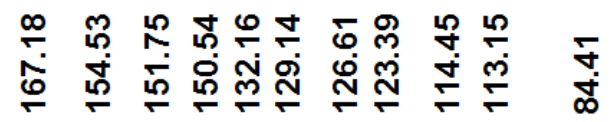

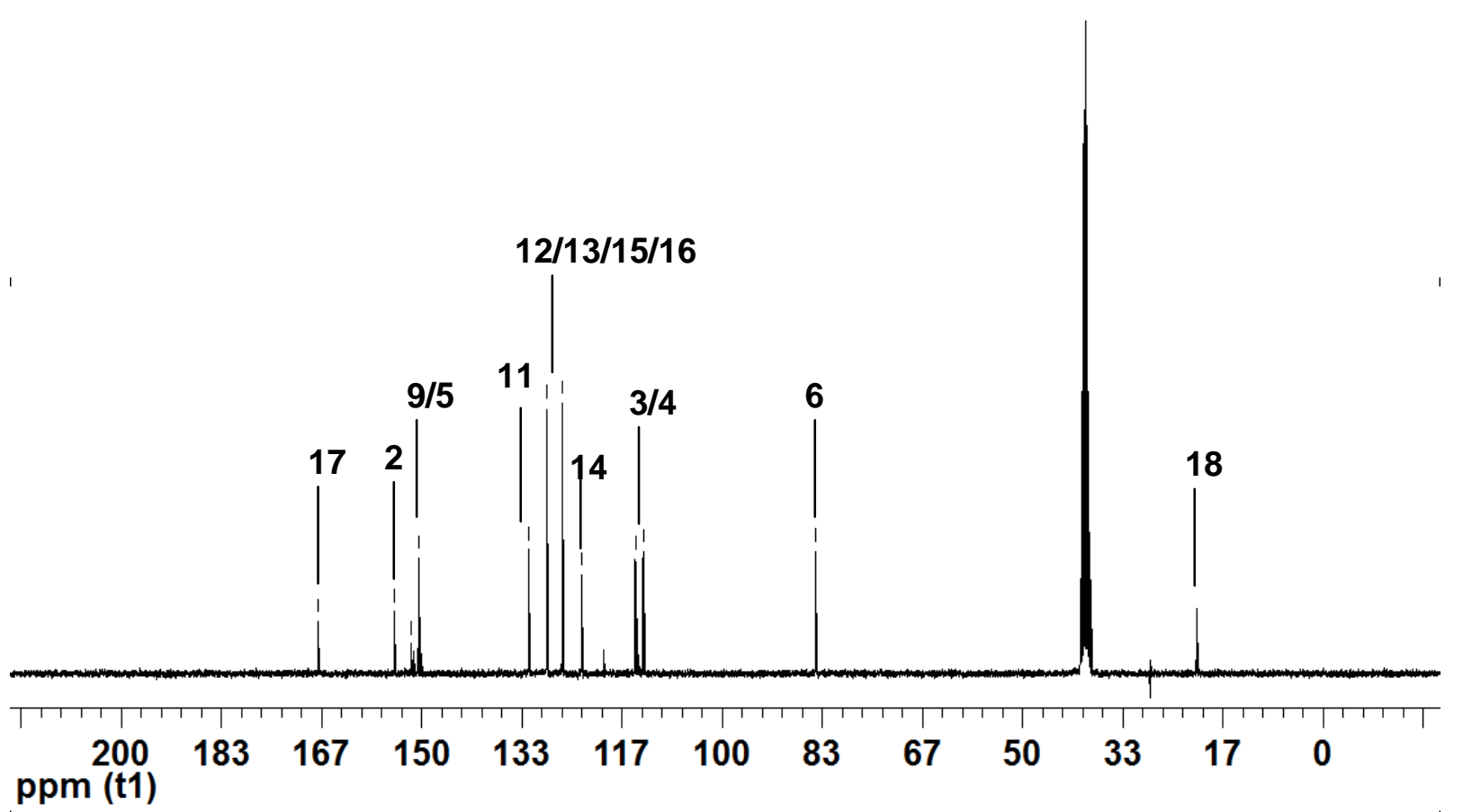


Espectro de RMN ${ }^{1} \mathrm{H}$ do composto 3-acetil-2-[5-nitro-furan-2-il]-5-[4-metil-fenil]-2,3-diidro-1,3,4-oxadiazolínico, II-B
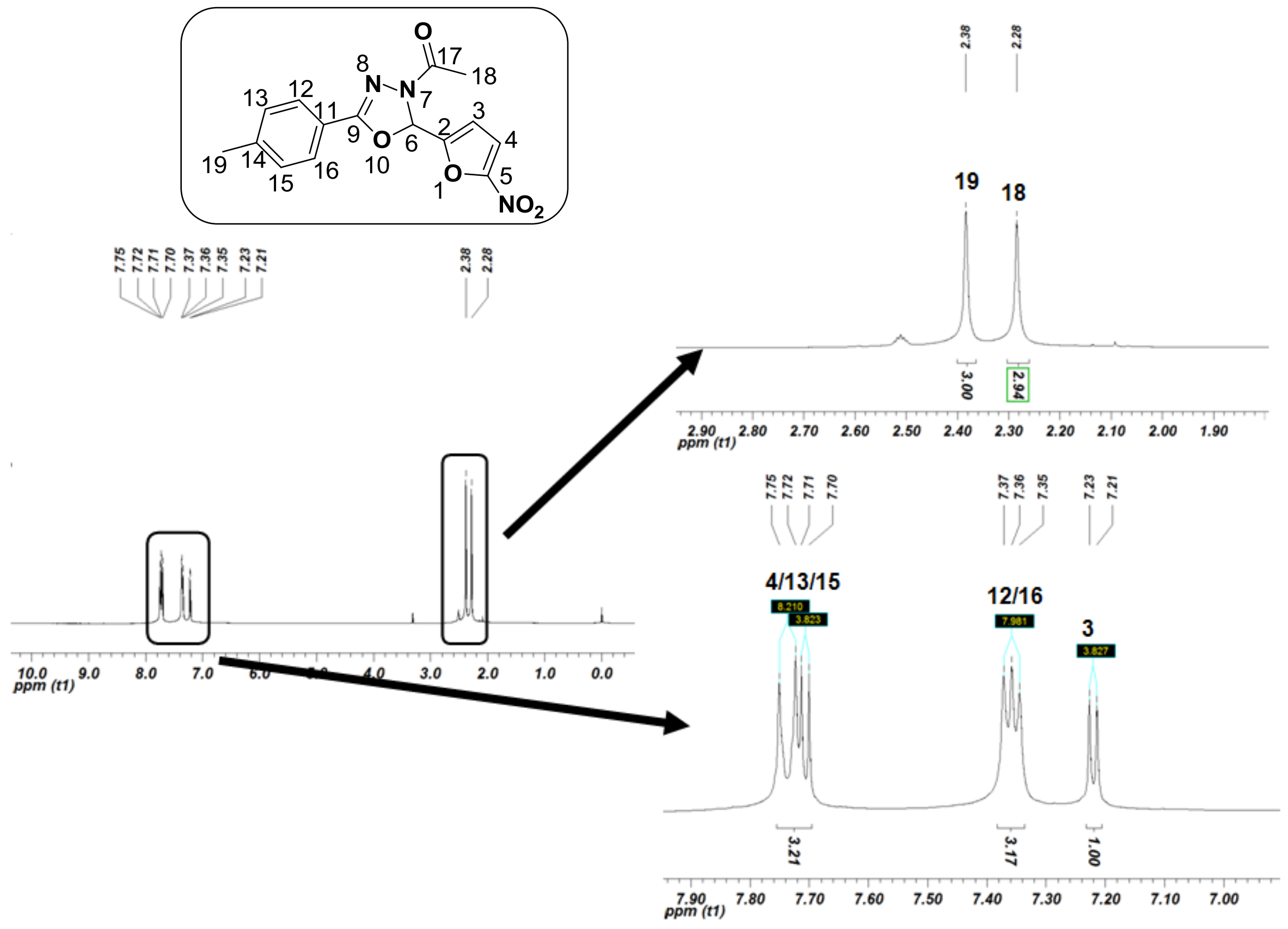
Espectro de RMN ${ }^{13} \mathrm{C}$ do composto 3-acetil-2-[5-nitro-furan-2-il]-5-[4-metil-fenil]-2,3-diidro-1,3,4-oxadiazolínico, II-B
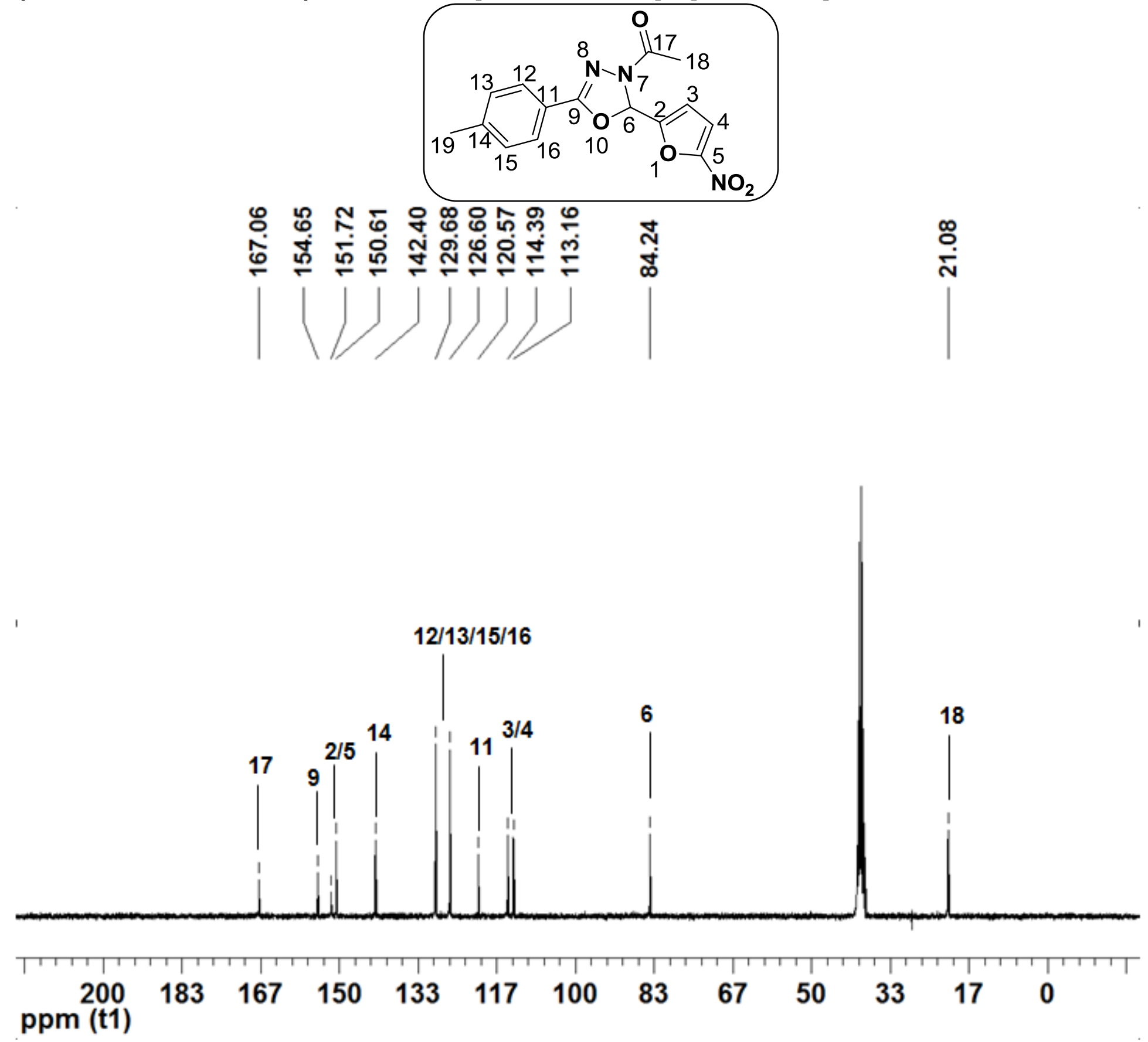
Espectro de RMN ${ }^{1} \mathrm{H}$ do composto 3-acetil-2-[5-nitro-furan-2-il]-5-[4-metóxi-fenil]-2,3-diidro-1,3,4-oxadiazolínico, II-C
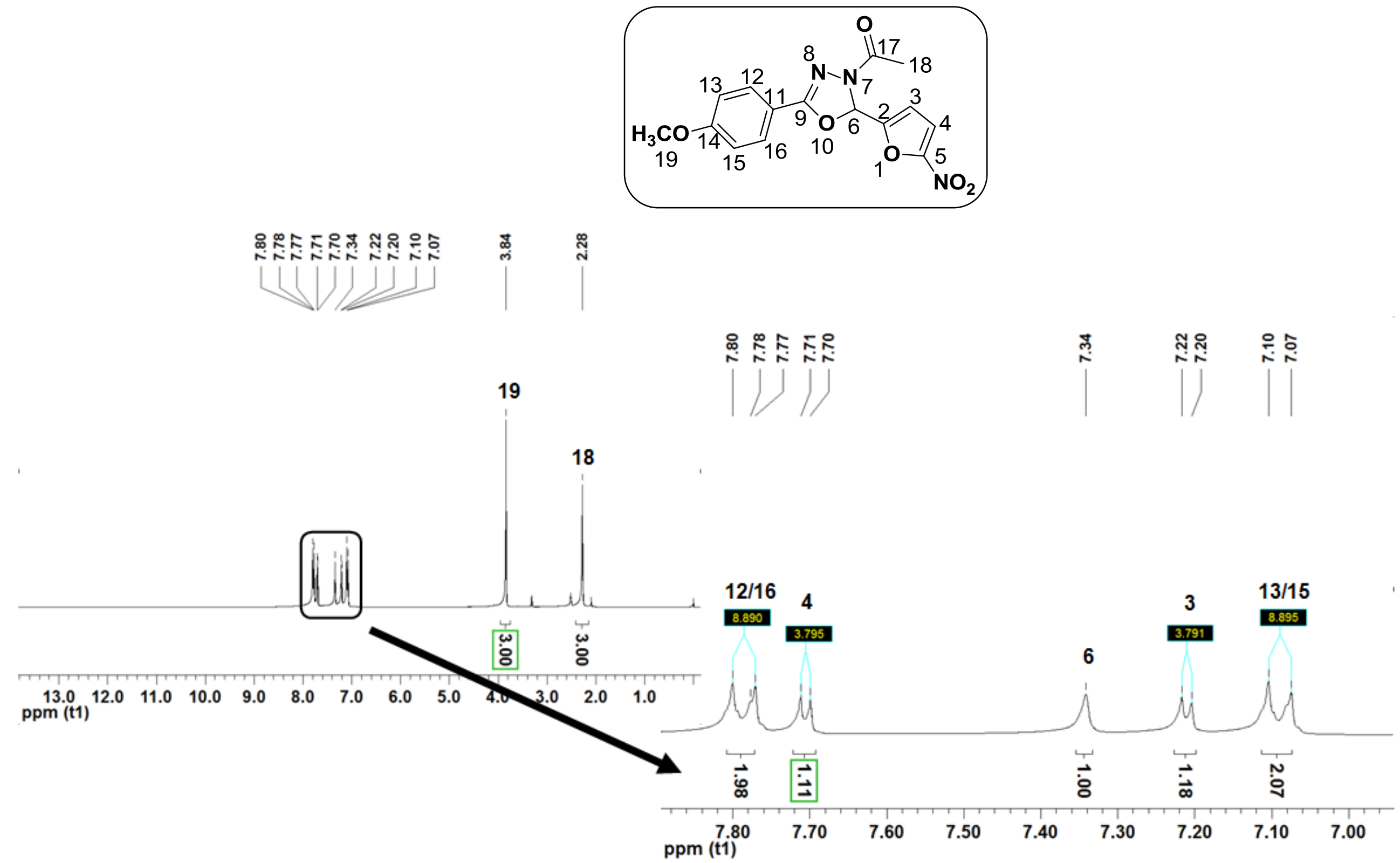
Espectro de RMN ${ }^{13} \mathrm{C}$ do composto 3-acetil-2-[5-nitro-furan-2-il]-5-[4-metóxi-fenil]-2,3-diidro-1,3,4-oxadiazolínico, II-C
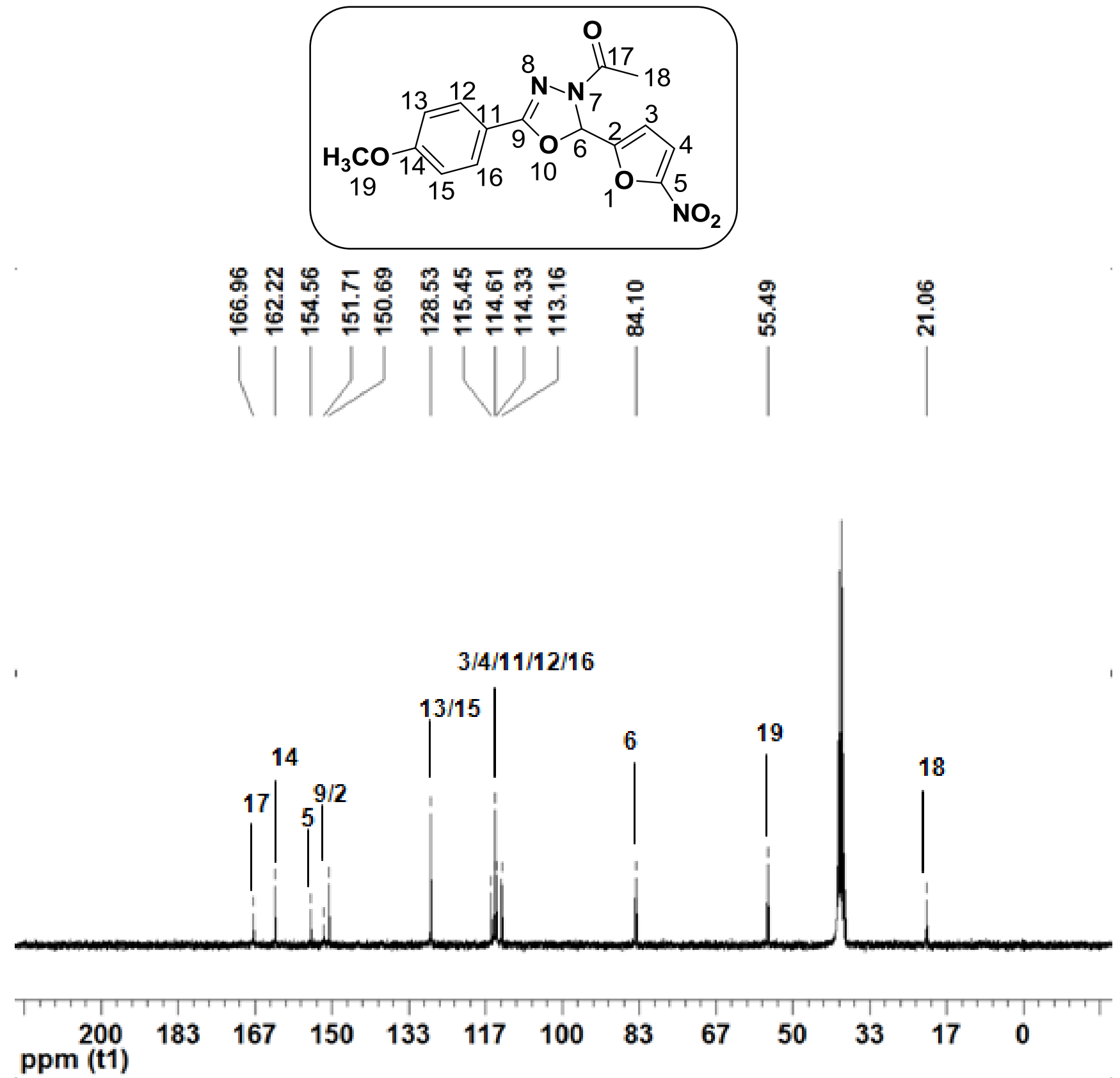
Espectro de RMN ${ }^{1} \mathrm{H}$ do composto 3-acetil-2-[5-nitro-furan-2-il]-5-[4-bromo-fenil]-2,3-diidro-1,3,4-oxadiazolínico, II-D

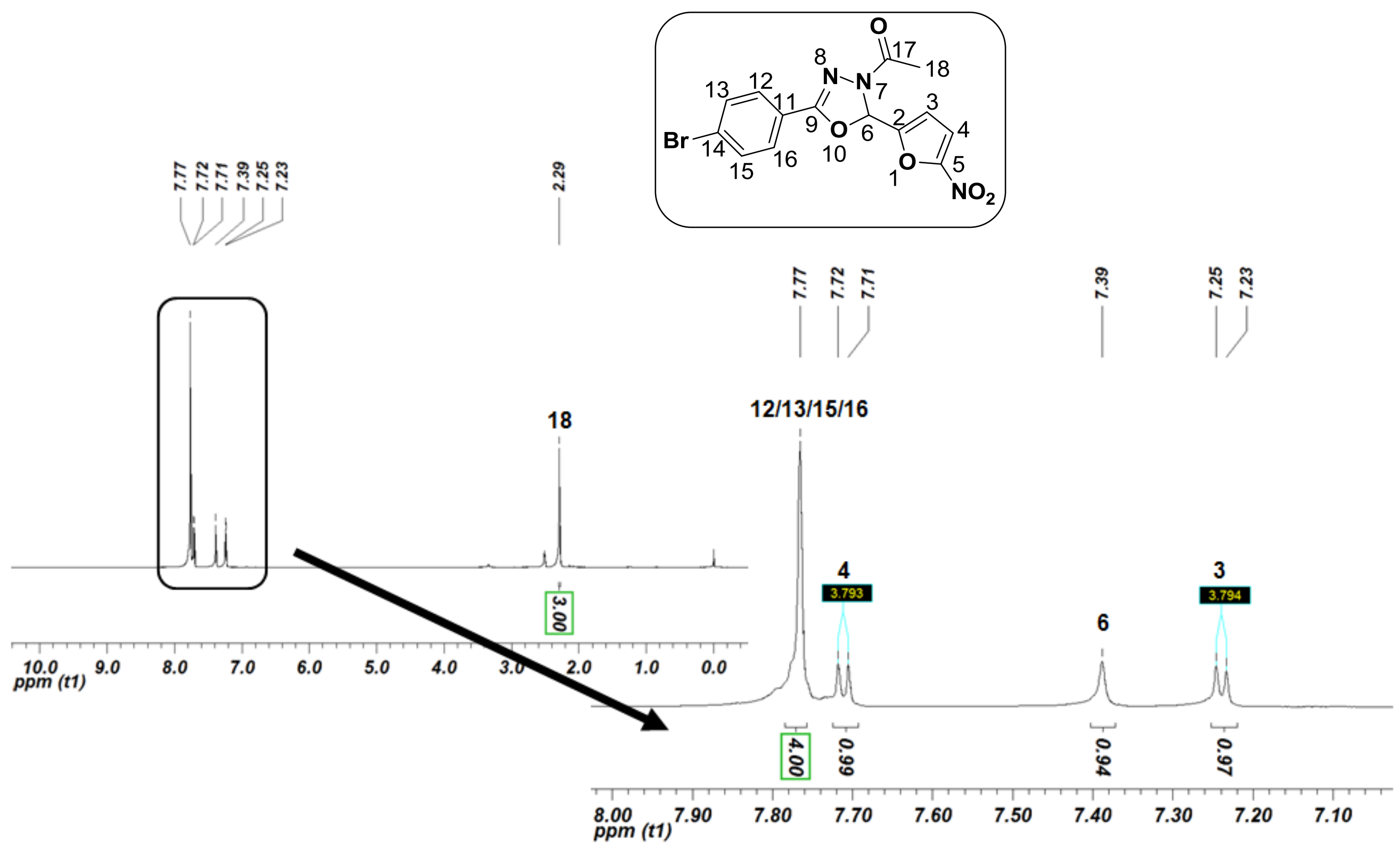


Espectro de RMN ${ }^{13} \mathrm{C}$ do composto 3-acetil-2-[5-nitro-furan-2-il]-5-[4-bromo-fenil]-2,3-diidro-1,3,4-oxadiazolínico, II-D
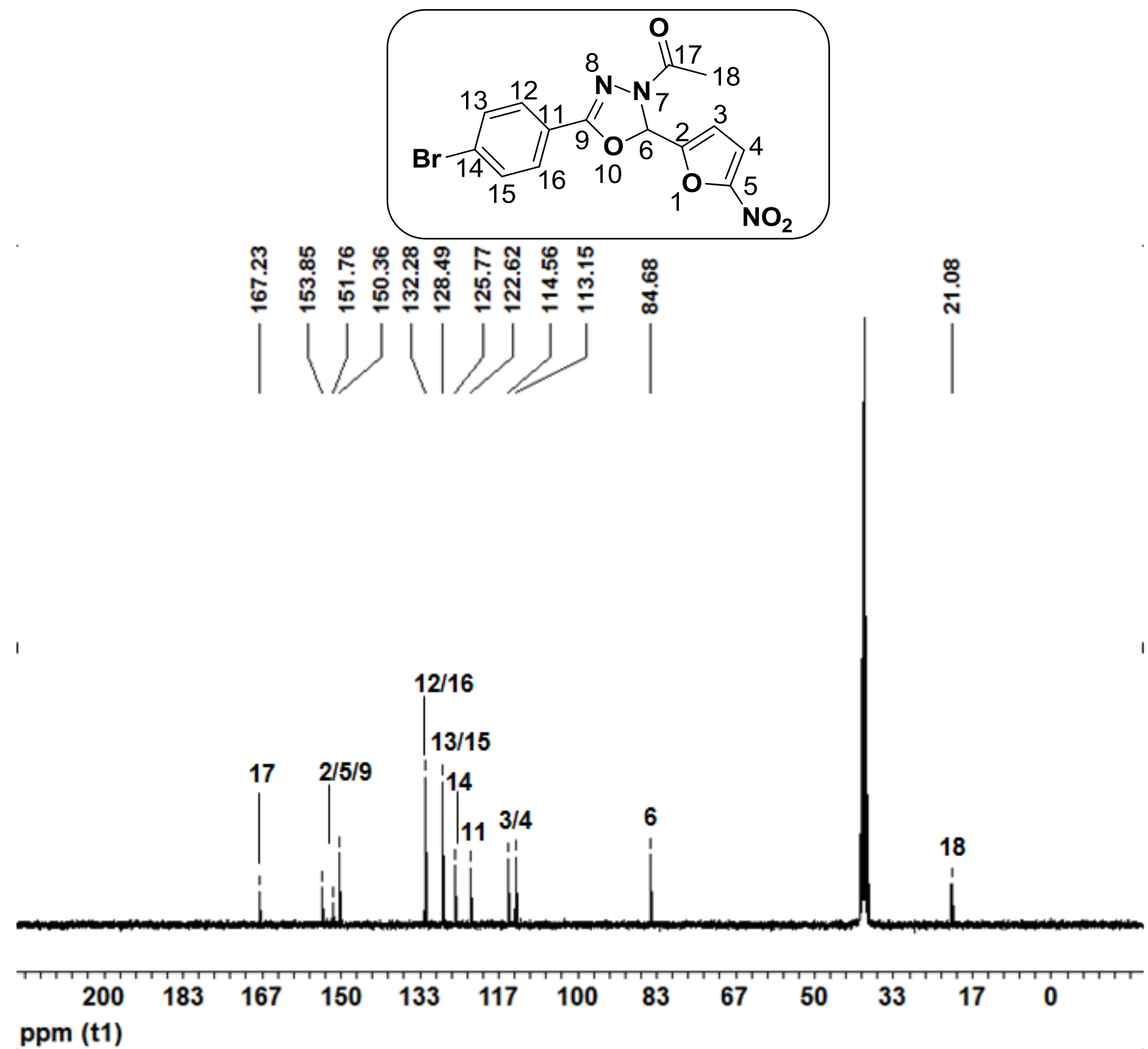
Espectro de RMN ${ }^{1} \mathrm{H}$ do composto 3-acetil-2-[5-nitro-furan-2-il]-5-[4-ciano-fenil]-2,3-diidro-1,3,4-oxadiazolínico, II-E
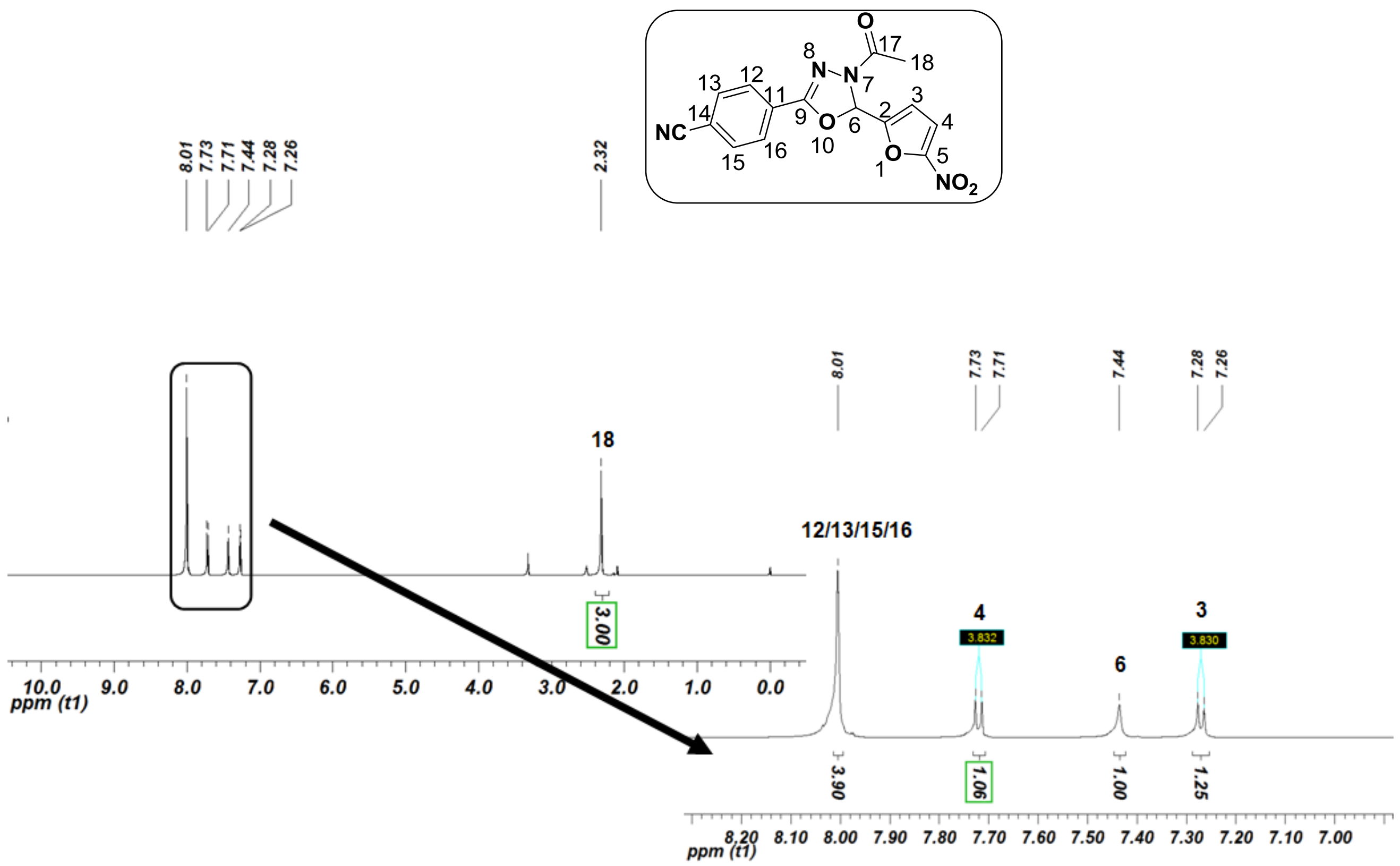
Espectro de RMN ${ }^{13} \mathrm{C}$ do composto 3-acetil-2-[5-nitro-furan-2-il]-5-[4-ciano-fenil]-2,3-diidro-1,3,4-oxadiazolínico, II-E
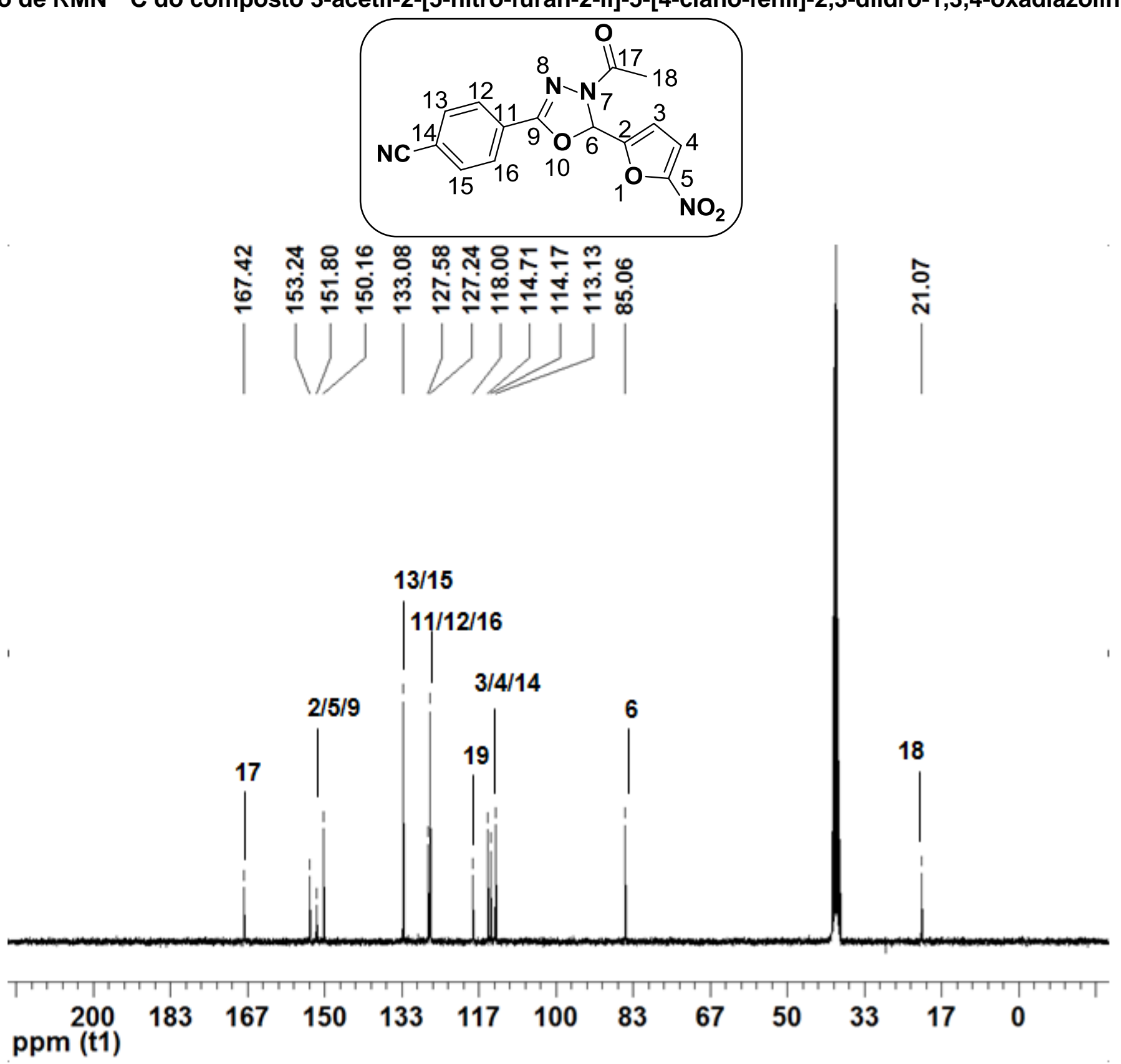
Espectro de RMN ${ }^{1} \mathrm{H}$ do composto 3-acetil-2-[5-nitro-furan-2-il]-5-[4-nitro-fenil]-2,3-diidro-1,3,4-oxadiazolínico, II-F

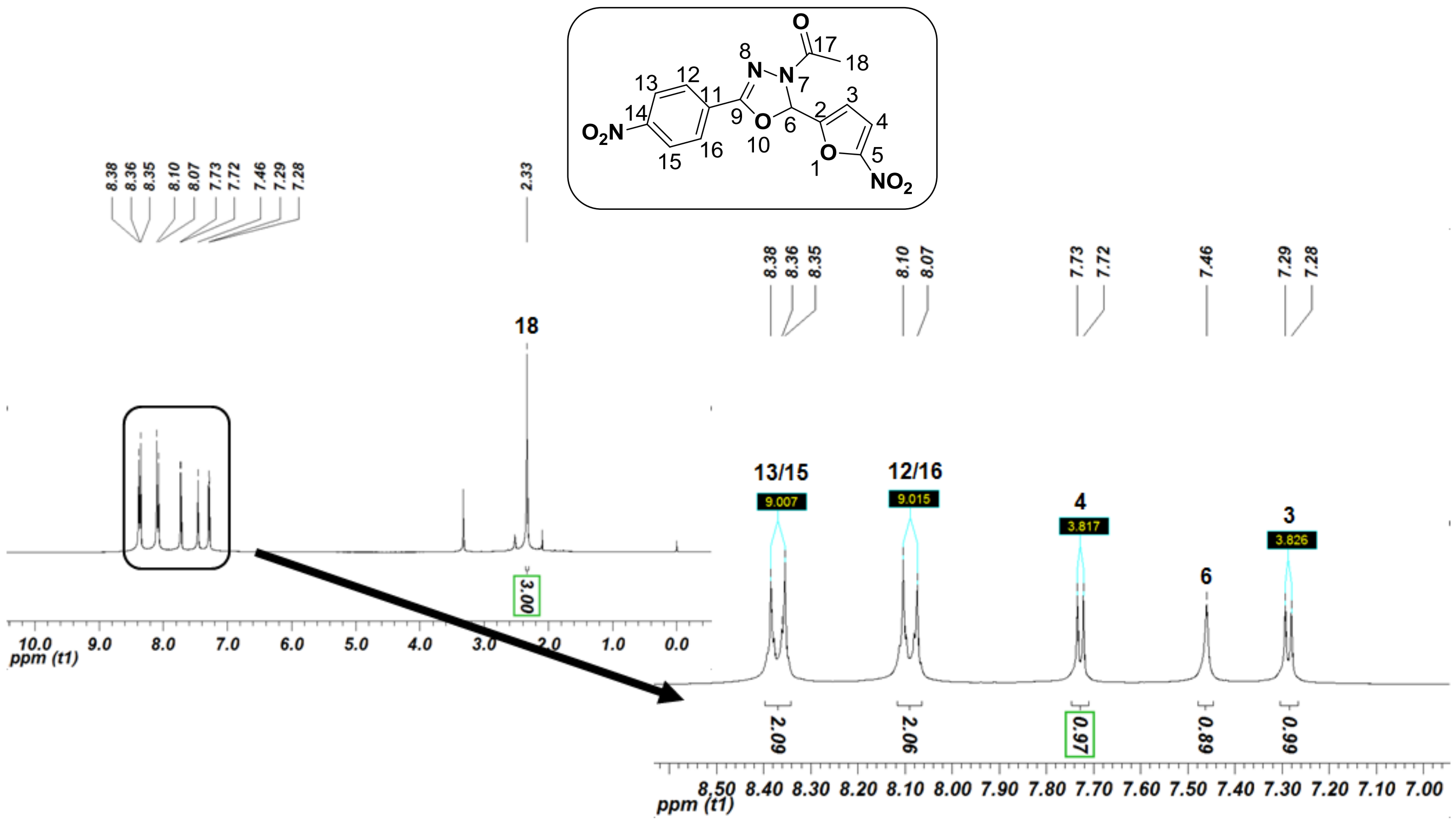


Espectro de RMN ${ }^{13} \mathrm{C}$ do composto 3-acetil-2-[5-nitro-furan-2-il]-5-[4-nitro-fenil]-2,3-diidro-1,3,4-oxadiazolínico, II-F
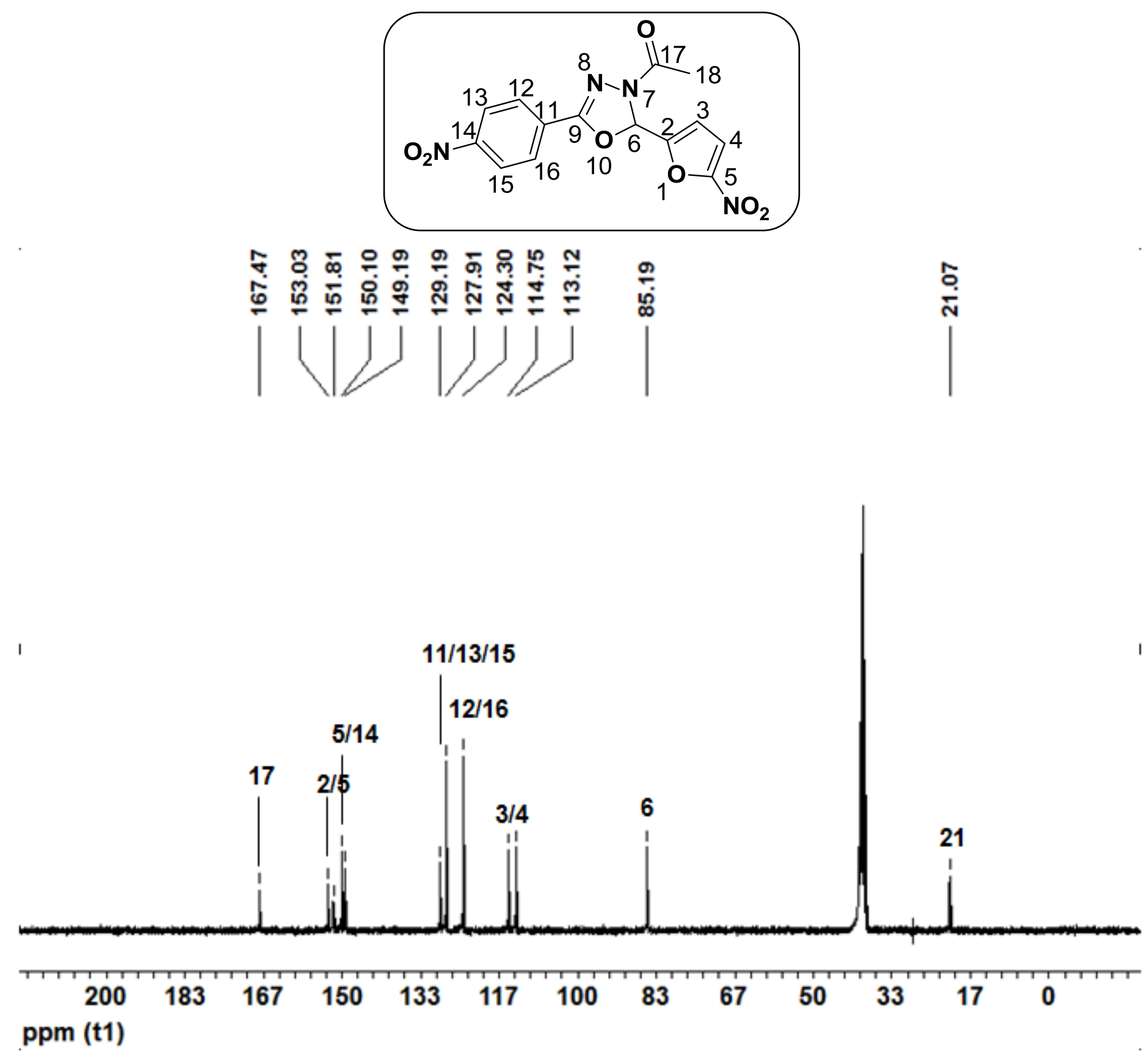
Espectro de RMN ${ }^{1} \mathrm{H}$ do composto 3-acetil-2-[5-nitro-furan-2-il]-5-[4-butil-fenil]-2,3-diidro-1,3,4-oxadiazolínico, II-G

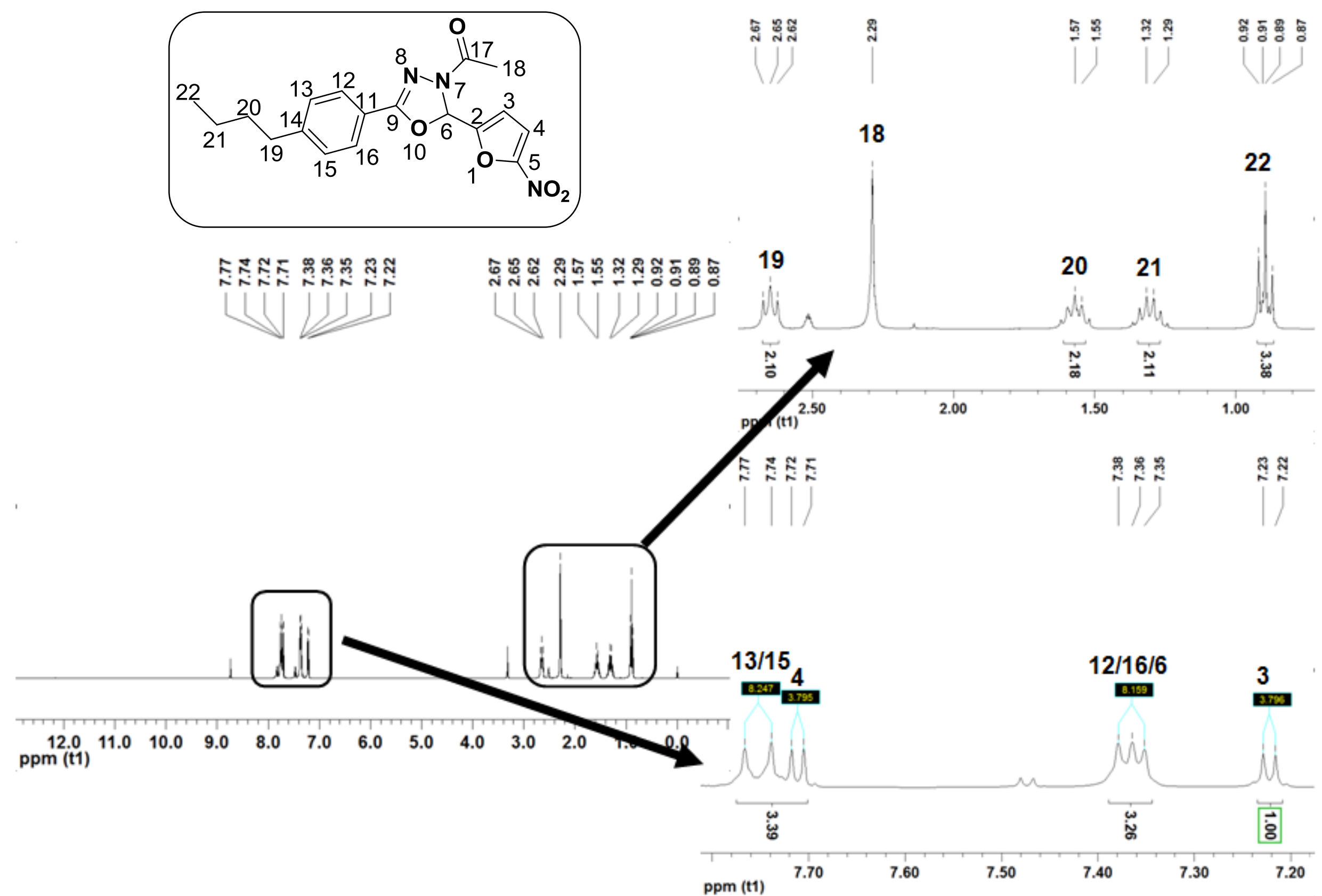


Espectro de RMN ${ }^{13} \mathrm{C}$ do composto 3-acetil-2-[5-nitro-furan-2-il]-5-[4-butil-fenil]-2,3-diidro-1,3,4-oxadiazolínico, II-G

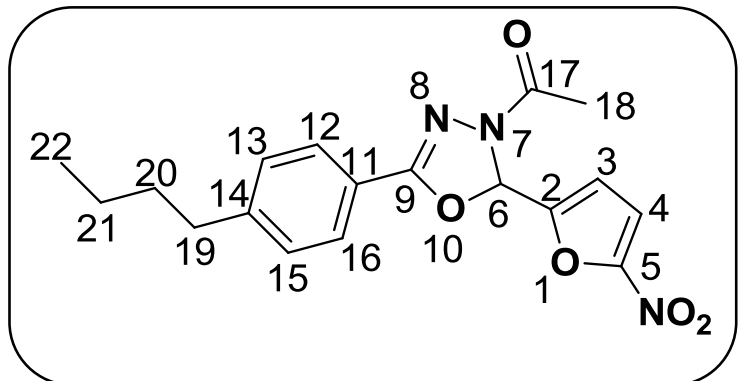

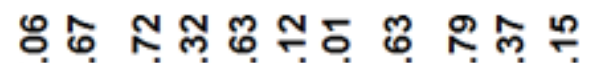

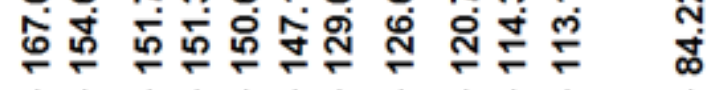

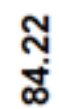

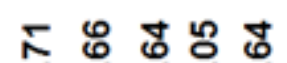

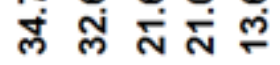
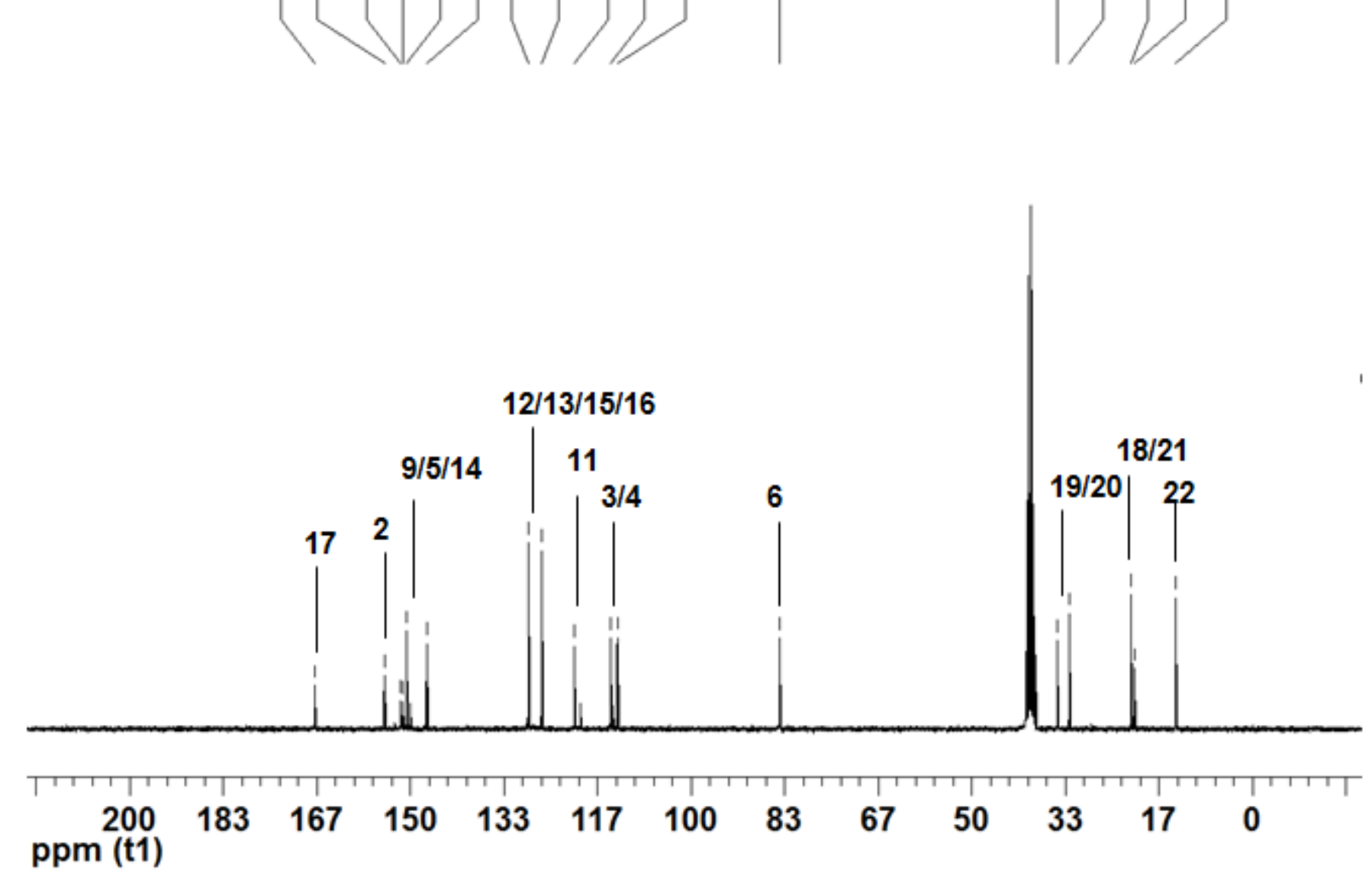
Espectro de RMN ${ }^{1} \mathrm{H}$ do composto 3-acetil-2-[5-nitro-furan-2-il]-5-[4-cloro-fenil]-2,3-diidro-1,3,4-oxadiazolínico, II-I

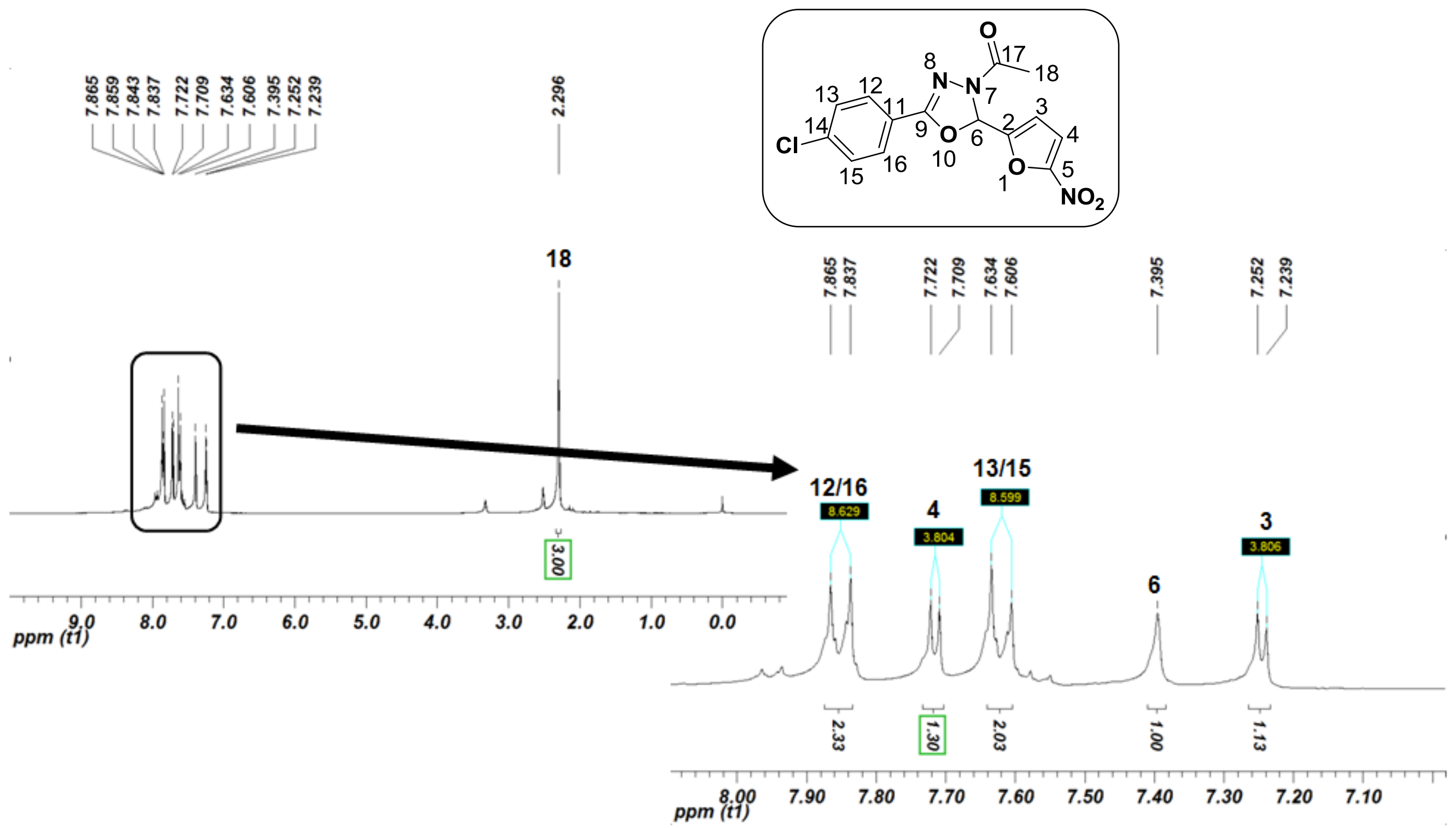


Espectro de RMN ${ }^{13} \mathrm{C}$ do composto 3-acetil-2-[5-nitro-furan-2-il]-5-[4-cloro-fenil]-2,3-diidro-1,3,4-oxadiazolínico, II-I

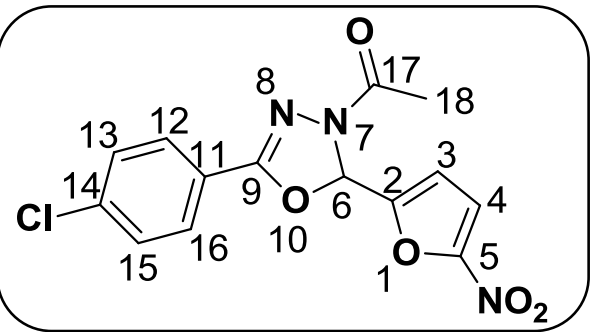

సָำ

ஸิ

$\stackrel{\text { ஸे }}{\text { ஸे }}$
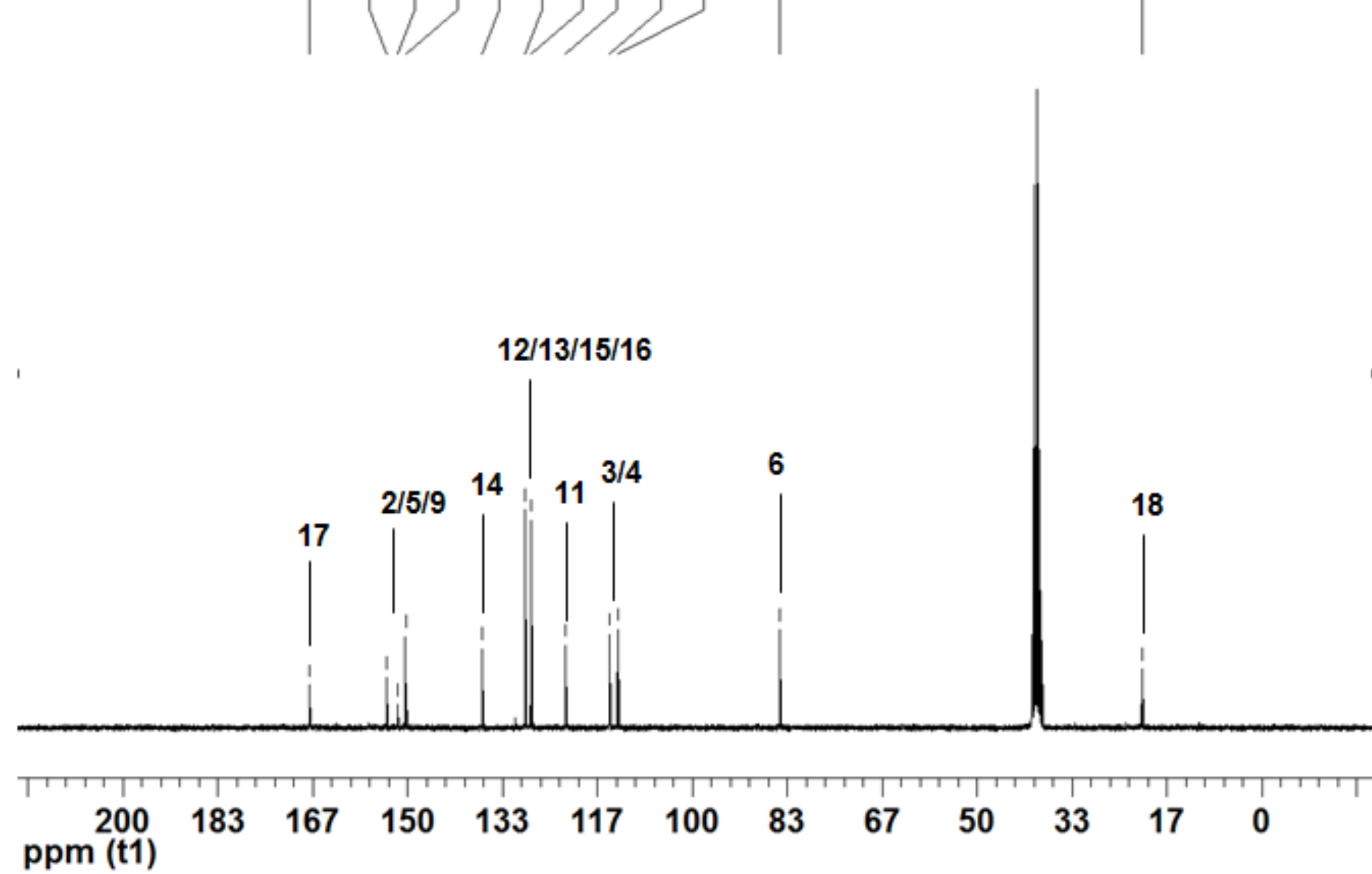
Espectro de RMN ${ }^{1} \mathrm{H}$ do composto 3-acetil-2-[5-nitro-furan-2-il]-5-[4-(tert-butil)-fenil]-2,3-diidro-1,3,4-oxadiazolínico, II-L

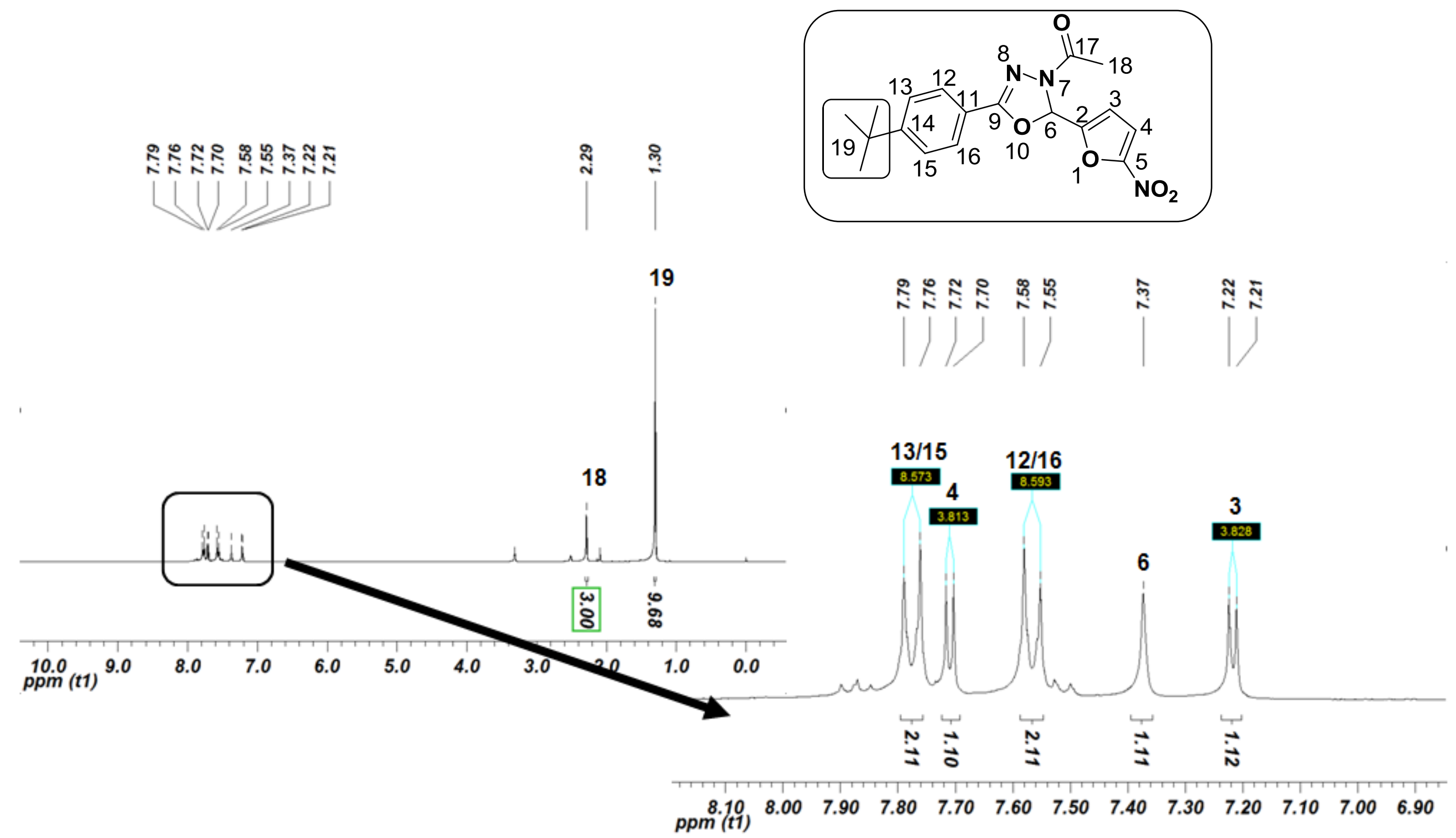


Espectro de RMN ${ }^{13} \mathrm{C}$ do composto 3-acetil-2-[5-nitro-furan-2-il]-5-[4-(tert-butil)-fenil]-2,3-diidro-1,3,4-oxadiazolínico, II-L
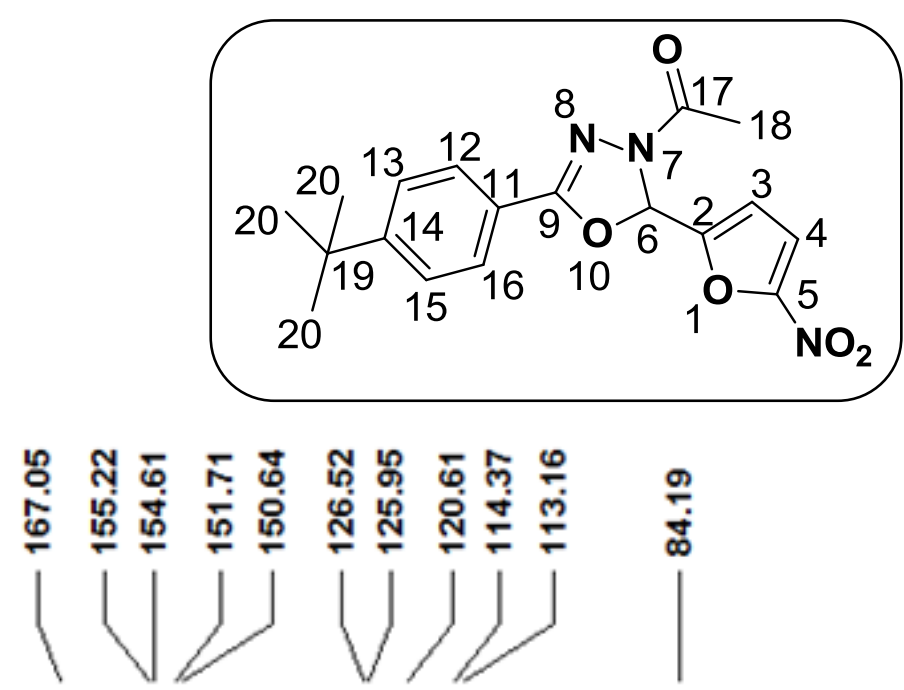

R.

से

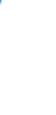

।

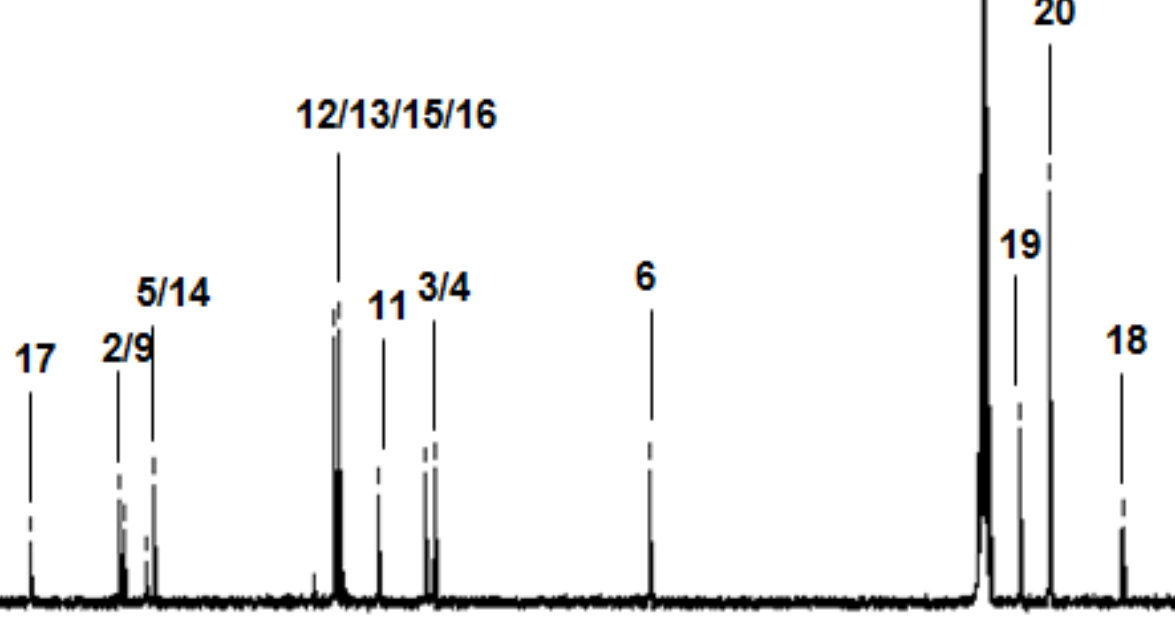

200
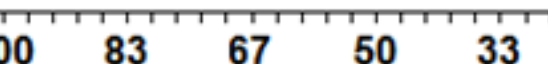

ppm (t1) 



\section{ANEXO 3}

Tabela de descritores calculados para os compostos de série I e II 


\begin{tabular}{|c|c|c|c|c|c|c|c|c|c|c|c|c|c|c|}
\hline & $\mathbf{R}_{1}$ & $\mathbf{R}_{\mathbf{2}}$ & $\mathbf{R}_{3}$ & $C \operatorname{Cog} \mathrm{P}_{\mathrm{MB}}$ & IPLATT & $I_{\text {RANDIC }}$ & I BALABAN & I IARARY & $I_{\text {HWIENER }}$ & $I_{\text {SZEGED }}$ & I WIENER & Dreiding & PSA & $\mathbf{V}_{\mathrm{WD}} \mathbf{W}$ \\
\hline$N F$ & $\mathrm{OH}$ & $\mathrm{H}$ & $\mathrm{H}$ & 1,75 & 90,0 & 13,43 & 1,59 & 61,58 & 3968,00 & 1244,0 & 981,0 & 146,20 & 120,65 & 384,04 \\
\hline $2 a$ & $\mathrm{H}$ & $\mathrm{H}$ & $\mathrm{H}$ & 2,05 & 88,0 & 12,89 & 1,43 & 57,13 & 3271,00 & 1055,0 & 845,0 & 144,89 & 100,42 & 336,99 \\
\hline $2 b$ & $\mathrm{CH}_{3}$ & $\mathrm{H}$ & $\mathrm{H}$ & 2,57 & 100,0 & 14,11 & 1,59 & 61,58 & 3968,00 & 1244,0 & 981,0 & 146,77 & 100,42 & 369,24 \\
\hline $2 c$ & $\mathrm{OCH}_{3}$ & $\mathrm{H}$ & $\mathrm{H}$ & 1,89 & 102,0 & 14,58 & 1,51 & 65,80 & 4821,00 & 1453,0 & 1137,0 & 152,62 & 109,65 & 385,04 \\
\hline $2 d$ & $\mathrm{Br}$ & $\mathrm{H}$ & $\mathrm{H}$ & 2,82 & 88,0 & 12,89 & 1,59 & 61,58 & 3968,00 & 1244,0 & 981,0 & 143,44 & 100,42 & 357,58 \\
\hline $2 e$ & $\mathrm{CN}$ & $\mathrm{H}$ & $\mathrm{H}$ & 1,91 & 90,0 & 13,43 & 1,51 & 65,80 & 4821,00 & 1453,0 & 1137,0 & 147,22 & 124,21 & 354,98 \\
\hline $2 f$ & $\mathrm{NO}_{2}$ & $\mathrm{H}$ & $\mathrm{H}$ & 1,99 & 94,0 & 13,81 & 1,46 & 70,52 & 5677,00 & 1664,0 & 1295,0 & 189,29 & 146,24 & 379,90 \\
\hline $2 g$ & $n-\mathrm{C}_{4} \mathrm{H}_{9}$ & $\mathrm{H}$ & $\mathrm{H}$ & 3,90 & 136,0 & 17,86 & 1,56 & 73,99 & 7080,00 & 1935,0 & 1513,0 & 155,81 & 100,42 & 460,97 \\
\hline $2 h$ & $\mathrm{SO}_{2} \mathrm{NH}_{2}$ & $\mathrm{H}$ & $\mathrm{H}$ & 0,66 & 106,0 & 15,05 & 1,62 & 75,75 & 6536,00 & 1877,0 & 1455,0 & 214,76 & 160,58 & 421,83 \\
\hline $2 i$ & $\mathrm{Cl}$ & $\mathrm{H}$ & $\mathrm{H}$ & 2,66 & 88,0 & 12,89 & 1,59 & 61,58 & 3968,00 & 1244,0 & 981,0 & 143,92 & 100,42 & 353,58 \\
\hline $2 j$ & $\mathrm{~N}\left(\mathrm{CH}_{3}\right)_{2}$ & $\mathrm{H}$ & $\mathrm{H}$ & 2,15 & 118,0 & 16,23 & 1,46 & 70,52 & 5677,00 & 1664,0 & 1295,0 & 172,38 & 103,66 & 420,61 \\
\hline $2 k$ & $\mathrm{NH}_{2}$ & $\mathrm{H}$ & $\mathrm{H}$ & 1,22 & 94,0 & 13,81 & 1,59 & 61,58 & 3968,00 & 1244,0 & 981,0 & 145,50 & 126,44 & 351,80 \\
\hline $2 I$ & $t-\mathrm{C}_{4} \mathrm{H}_{9}$ & $\mathrm{H}$ & $\mathrm{H}$ & 3,60 & 136,0 & 17,86 & 1,62 & 75,75 & 6536,00 & 1877,0 & 1455,0 & 168,35 & 100,42 & 461,19 \\
\hline $2 m$ & I & $\mathrm{H}$ & $\mathrm{H}$ & 2,98 & 88,0 & 12,89 & 1,59 & 61,58 & 3968,00 & 1244,0 & 981,0 & 143,27 & 100,42 & 363,10 \\
\hline $3 a$ & $\mathrm{H}$ & $\mathrm{H}$ & $\mathrm{H}$ & 2,36 & 114,0 & 15,03 & 1,64 & 76,62 & 3612,00 & 1408,0 & 1051,0 & 110,76 & 100,86 & 382,66 \\
\hline $3 b$ & $\mathrm{CH}_{3}$ & $\mathrm{H}$ & $\mathrm{H}$ & 2,87 & 126,0 & 16,25 & 1,56 & 81,51 & 4338,00 & 1636,0 & 1204,0 & 158,19 & 100,86 & 422,47 \\
\hline $3 c$ & $\mathrm{OCH}_{3}$ & $\mathrm{H}$ & $\mathrm{H}$ & 2,20 & 128,0 & 16,72 & 1,48 & 86,12 & 5240,00 & 1887,0 & 1380,0 & 199,02 & 110,09 & 433,60 \\
\hline $3 d$ & $\mathrm{Br}$ & $\mathrm{H}$ & $\mathrm{H}$ & 3,13 & 114,0 & 15,03 & 1,56 & 81,51 & 4338,00 & 1636,0 & 1204,0 & 155,56 & 100,86 & 410,84 \\
\hline $3 e$ & $\mathrm{CN}$ & $\mathrm{H}$ & $\mathrm{H}$ & 2,21 & 116,0 & 15,57 & 1,48 & 86,12 & 5240,00 & 1887,0 & 1380,0 & 164,19 & 124,65 & 408,63 \\
\hline $3 f$ & $\mathrm{NO}_{2}$ & $\mathrm{H}$ & $\mathrm{H}$ & 2,30 & 120,0 & 15,95 & 1,42 & 91,23 & 6145,00 & 2140,0 & 1558,0 & 298,99 & 146,68 & 434,84 \\
\hline $3 g$ & $n-\mathrm{C}_{4} \mathrm{H}_{9}$ & $\mathrm{H}$ & $\mathrm{H}$ & 4,21 & 162,0 & 20,00 & 1,55 & 94,97 & 7669,00 & 2462,0 & 1805,0 & 177,63 & 100,86 & 511,20 \\
\hline $3 i$ & $\mathrm{Cl}$ & $\mathrm{H}$ & $\mathrm{H}$ & 2,96 & 114,0 & 15,03 & 1,56 & 81,51 & 4338,00 & 1636,0 & 1204,0 & 156,77 & 100,86 & 406,85 \\
\hline $3 I$ & $t-\mathrm{C}_{4} \mathrm{H}_{9}$ & $\mathrm{H}$ & $\mathrm{H}$ & 3,90 & 162,0 & 20,00 & 1,60 & 96,84 & 7053,00 & 2395,0 & 1738,0 & 182,67 & 100,86 & 513,61 \\
\hline $3 m$ & 1 & $\mathrm{H}$ & $\mathrm{H}$ & 3,29 & 114,0 & 15,03 & 1,56 & 81,51 & 4338,00 & 1636,0 & 1204,0 & 155,31 & 100,86 & 416,29 \\
\hline
\end{tabular}

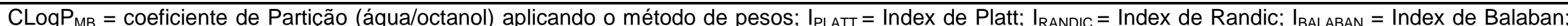

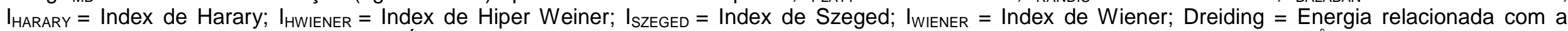
estabilidade molecular (kcal/mol); PSA = Área de Superfície Polar; $V_{W D} W=$ Superfície de van der Waals calculada para uma molécula (Å2 ). 


\begin{tabular}{|c|c|c|c|c|c|c|c|c|c|c|c|c|c|c|c|}
\hline & ASA & ASA+ & ASA- & ASA_H & ASA_P & $\pi$ & $\boldsymbol{\sigma}$ & $\mathbf{F}$ & $\mathbf{R}$ & $\mathbf{L}$ & B1 & B5 & MR & CLogP $_{\text {SG-SLN }}$ & CLogP $_{\text {sv }}$ \\
\hline NF & 515,39 & 284,22 & 231,18 & 291,86 & 223,54 & $-0,67$ & $-0,37$ & 0,33 & $-0,70$ & 2,74 & 1,35 & 1,93 & 0,29 & 0,43 & 2,92 \\
\hline $2 a$ & 508,26 & 264,04 & 244,22 & 329,27 & 178,99 & 0,00 & 0,00 & 0,00 & 0,00 & 2,06 & 1,00 & 1,00 & 0,10 & 0,70 & 3,21 \\
\hline $2 b$ & 549,36 & 297,55 & 251,81 & 370,38 & 178,98 & 0,56 & $-0,17$ & 0,01 & $-0,18$ & 2,87 & 1,52 & 2,04 & 0,57 & 1,18 & 3,67 \\
\hline $2 c$ & 575,11 & 355,43 & 219,68 & 377,92 & 197,19 & $-0,02$ & $-0,27$ & 0,29 & $-0,56$ & 3,98 & 1,35 & 3,07 & 0,79 & 0,68 & 5,66 \\
\hline $2 d$ & 530,28 & 240,29 & 289,99 & 351,29 & 178,99 & 0,86 & 0,23 & 0,45 & $-0,22$ & 3,82 & 1,95 & 1,95 & 0,89 & 1,44 & 4,00 \\
\hline $2 e$ & 520,63 & 260,37 & 260,26 & 292,15 & 228,48 & $-0,57$ & 0,66 & 0,51 & 0,15 & 4,23 & 1,60 & 1,60 & 0,63 & 0,57 & 3,24 \\
\hline $2 f$ & 559,63 & 310,30 & 249,34 & 296,99 & 262,64 & $-0,28$ & 0,78 & 0,65 & 0,13 & 3,44 & 1,70 & 2,44 & 0,74 & $-1,56$ & 3,16 \\
\hline $2 g$ & 640,11 & 381,34 & 258,76 & 461,59 & 178,52 & 2,13 & $-0,16$ & $-0,01$ & $-0,15$ & 6,17 & 1,52 & 4,54 & 1,96 & 2,55 & 4,86 \\
\hline $2 h$ & 602,05 & 323,63 & 278,42 & 296,38 & 305,67 & $-1,82$ & 0,60 & 0,49 & 0,10 & 4,02 & 2,04 & 3,05 & 1,23 & $-0,10$ & 1,73 \\
\hline $2 i$ & 525,51 & 240,06 & 285,46 & 346,52 & 178,99 & 0,71 & 0,23 & 0,42 & $-0,19$ & 3,52 & 1,80 & 1,80 & 0,60 & 1,36 & 3,72 \\
\hline $2 j$ & 589,38 & 343,06 & 246,31 & 403,79 & 185,59 & 0,18 & $-0,16$ & 0,15 & $-0,98$ & 3,53 & 2,56 & 1,35 & 1,55 & 0,86 & 3,47 \\
\hline $2 k$ & 514,65 & 287,27 & 227,39 & 282,74 & 231,91 & $-1,23$ & $-0,66$ & 0,08 & $-0,74$ & 2,78 & 1,35 & 1,97 & 0,54 & $-0,05$ & 2,42 \\
\hline $2 I$ & 593,48 & 346,53 & 246,96 & 414,97 & 178,52 & 1,98 & $-0,20$ & $-0,02$ & $-0,18$ & 4,11 & 2,60 & 3,17 & 1,96 & 2,10 & 4,83 \\
\hline $2 m$ & 536,71 & 240,61 & 296,10 & 357,72 & 178,98 & 1,12 & 0,18 & 0,42 & $-0,24$ & 4,23 & 2,15 & 2,15 & 1,39 & 1,27 & 4,46 \\
\hline $3 a$ & 520,43 & 310,47 & 209,97 & 364,99 & 155,44 & 0,00 & 0,00 & 0,00 & 0,00 & 2,06 & 1,00 & 1,00 & 0,10 & 0,38 & 3,43 \\
\hline $3 b$ & 580,61 & 379,58 & 201,03 & 417,48 & 163,13 & 0,56 & $-0,17$ & 0,01 & $-0,18$ & 2,87 & 1,52 & 2,04 & 0,57 & 0,87 & 3,90 \\
\hline $3 c$ & 594,82 & 385,85 & 208,97 & 413,11 & 181,71 & $-0,02$ & $-0,27$ & 0,29 & $-0,56$ & 3,98 & 1,35 & 3,07 & 0,79 & 0,36 & 3,18 \\
\hline $3 d$ & 561,88 & 294,91 & 266,97 & 398,75 & 163,13 & 0,86 & 0,23 & 0,45 & $-0,22$ & 3,82 & 1,95 & 1,95 & 0,89 & 1,13 & 4,22 \\
\hline $3 e$ & 552,80 & 311,96 & 240,84 & 349,50 & 203,30 & $-0,57$ & 0,66 & 0,51 & 0,15 & 4,23 & 1,60 & 1,60 & 0,63 & 0,26 & 3,47 \\
\hline $3 f$ & 593,39 & 348,40 & 244,99 & 342,36 & 251,04 & $-0,28$ & 0,78 & 0,65 & 0,13 & 3,44 & 1,70 & 2,44 & 0,74 & $-1,88$ & 3,39 \\
\hline $3 g$ & 659,79 & 426,59 & 233,20 & 496,66 & 163,13 & 2,13 & $-0,16$ & $-0,01$ & $-0,15$ & 6,17 & 1,52 & 4,54 & 1,96 & 2,23 & 5,09 \\
\hline $3 i$ & 557,18 & 308,08 & 249,10 & 394,05 & 163,13 & 0,71 & 0,23 & 0,42 & $-0,19$ & 3,52 & 1,80 & 1,80 & 0,60 & 1,04 & 3,95 \\
\hline $3 I$ & 623,03 & 399,90 & 223,13 & 459,90 & 163,13 & 1,98 & $-0,20$ & $-0,02$ & $-0,18$ & 4,11 & 2,60 & 3,17 & 1,96 & 1,78 & 5,06 \\
\hline $3 m$ & 568,15 & 295,20 & 272,94 & 405,01 & 163,13 & 1,12 & 0,18 & 0,42 & $-0,24$ & 4,23 & 2,15 & 2,15 & 1,39 & 0,96 & 4,69 \\
\hline
\end{tabular}

ASA = Área de acessibilidade de solvente calculado utilizando raio do solvente (1.4 Å para molécula de água) (Å2 ); ASA+ = Área de acessiblidade de solvente para todos os átomos com carga parcial positiva (Å2); ASA- = Área de acessiblidade de solvente para todos os átomos com carga parcial negativa (Å2); ASA_H = Área de acessiblidade de solvente para todos os átomos hidrofóbicos (Å2); ASAP_P = Area de acessiblidade de solvente para todos os átomos polares $(\AA 2) ; \pi=$ Constante de hidrofobicidade de Hansch-Fujita; $\sigma=$ Constante de Hammet; $F=$ Constante de efeito indutivo de Swain-Lupton; $R=$ Constante de efeito de ressonância de Swain-Lupton; L, B1 and B5 = Parâmetros de STERIMOL; MR = Refratividade Molar; CLogP SG-SLN = Coeficiente de Partição (água/octanol) aplicando método Sybyl; CLogP $\mathrm{Sv}_{\mathrm{Sv}}=$ Coeficiente de Partição (água/octanol) aplicando método de Viswanadhan. 


\begin{tabular}{|c|c|c|c|c|c|c|c|c|c|c|}
\hline & $\mu$ & $\mathbf{E}_{\text {номо }}$ & $E_{\text {LUMO }}$ & GAP & CHELPG_01 & CHELPG_02 & CHELPG_N1 & CHELPG_N2 & CHELPG_N3 & CHELPG_C \\
\hline$N F$ & 13,19 & $-220,92$ & $-24,27$ & $-196,65$ & $-0,67$ & $-0,44$ & $-0,36$ & $-0,23$ & 0,62 & 0,71 \\
\hline $2 a$ & 14,52 & $-220,83$ & $-24,30$ & $-196,53$ & $-0,65$ & $-0,43$ & $-0,33$ & $-0,24$ & 0,63 & $-0,05$ \\
\hline $2 b$ & 15,06 & $-219,81$ & $-23,49$ & $-196,32$ & $-0,65$ & $-0,44$ & $-0,33$ & $-0,24$ & 0,62 & 0,31 \\
\hline $2 c$ & 13,77 & $-219,81$ & $-23,27$ & $-196,54$ & $-0,68$ & $-0,44$ & $-0,39$ & $-0,22$ & 0,62 & 0,67 \\
\hline $2 d$ & 11,46 & $-211,51$ & $-6,92$ & $-204,59$ & $-0,56$ & $-0,37$ & $-0,35$ & $-0,21$ & 0,53 & 0,00 \\
\hline $2 e$ & 10,99 & $-225,94$ & $-28,51$ & $-197,43$ & $-0,63$ & $-0,43$ & $-0,33$ & $-0,25$ & 0,63 & $-0,01$ \\
\hline $2 f$ & 9,80 & $-229,53$ & $-43,67$ & $-185,86$ & $-0,62$ & $-0,43$ & $-0,35$ & $-0,25$ & 0,62 & 0,12 \\
\hline $2 g$ & 15,15 & $-219,42$ & $-22,78$ & $-196,64$ & $-0,67$ & $-0,44$ & $-0,37$ & $-0,22$ & 0,61 & 0,38 \\
\hline $2 h$ & 12,76 & $-216,75$ & $-10,74$ & $-206,01$ & $-0,55$ & $-0,37$ & $-0,21$ & $-0,36$ & 0,51 & 0,01 \\
\hline $2 i$ & 12,76 & $-223,13$ & $-26,17$ & $-196,96$ & $-0,65$ & $-0,44$ & $-0,34$ & $-0,24$ & 0,62 & 0,20 \\
\hline $2 j$ & 15,52 & $-186,23$ & $-1,60$ & $-184,63$ & $-0,59$ & $-0,37$ & $-0,20$ & $-0,35$ & 0,54 & 0,56 \\
\hline $2 k$ & 15,07 & $-193,28$ & $-2,09$ & $-191,19$ & $-0,59$ & $-0,37$ & $-0,20$ & $-0,35$ & $-1,14$ & 0,79 \\
\hline 21 & 13,23 & $-208,68$ & $-3,80$ & $-204,88$ & $-0,58$ & $-0,36$ & $-0,19$ & $-0,40$ & 0,53 & 0,19 \\
\hline $2 m$ & 11,74 & $-211,46$ & $-6,97$ & $-204,49$ & $-0,56$ & $-0,36$ & $-0,33$ & $-0,21$ & 0,54 & $-0,03$ \\
\hline $3 a$ & 5,57 & $-191,36$ & 36,05 & $-227,41$ & $-0,50$ & $-0,17$ & $-0,60$ & 0,00 & 1,00 & $-0,09$ \\
\hline $3 b$ & 6,72 & $-206,24$ & 5,57 & $-211,81$ & $-0,56$ & $-0,25$ & $-0,55$ & $-0,27$ & 0,57 & 0,27 \\
\hline $3 c$ & 6,20 & $-202,72$ & 5,11 & $-207,83$ & $-0,56$ & $-0,27$ & $-0,56$ & $-0,26$ & 0,54 & 0,62 \\
\hline $3 d$ & 6,30 & $-210,94$ & 2,72 & $-213,66$ & $-0,57$ & $-0,25$ & $-0,54$ & $-0,27$ & 0,56 & $-0,03$ \\
\hline $3 e$ & 7,22 & $-221,04$ & 1,00 & $-222,04$ & $-0,56$ & $-0,26$ & $-0,52$ & $-0,28$ & 0,57 & $-0,01$ \\
\hline $3 f$ & 9,34 & $-231,63$ & $-33,80$ & $-197,83$ & $-0,56$ & $-0,25$ & $-0,51$ & $-0,26$ & 0,55 & 0,27 \\
\hline $3 g$ & 6,75 & $-205,32$ & 5,81 & $-211,13$ & $-0,57$ & $-0,27$ & $-0,56$ & $-0,26$ & 0,54 & 0,30 \\
\hline $3 i$ & 6,40 & $-214,17$ & 3,04 & $-217,21$ & $-0,55$ & $-0,26$ & $-0,54$ & $-0,26$ & 0,56 & 0,07 \\
\hline $3 I$ & 6,73 & $-204,99$ & 5,73 & $-210,72$ & $-0,56$ & $-0,26$ & $-0,55$ & $-0,27$ & 0,56 & 0,23 \\
\hline $3 m$ & 6,41 & $-207,07$ & 3,32 & $-210,39$ & $-0,58$ & $-0,25$ & $-0,54$ & $-0,29$ & 0,56 & $-0,05$ \\
\hline
\end{tabular}

$\mu=$ Momento Dipolo; $E_{\text {HOMO }}=$ Energia de fronteira de HOMO $(\mathrm{kcal} / \mathrm{mol}) ; E_{\mathrm{LUMO}}=$ Energia de fronteira de LUMO $(\mathrm{kcal} / \mathrm{mol}) ; \mathrm{GAP}=\mathrm{Diferença} \mathrm{entre}$ $E_{\text {HOMo e }} E_{\text {LUMo; }}$ CHELPG_O1= Potencial eletrostático do oxigênio carbonílico da série I e do oxigênio do anel oxadiazolínico para série II; CHELPG O2 = Potencial eletrostático do oxigênio do anel furfurilidênico para série I e II; CHELPG N1 = Potencial eletrostático na ligação N=C para série I e o nitrogênio do anel oxadiazolínico para série II; CHELPG_N2 = Potencial eletrostático do átomo de nitrogênio para série I e nitrogênio no anel oxadiazolínico para série II; CHELPG_N3 = Potencial eletrostático do nitrogênio do grupo nitro para série I e II; CHELPG_C = Potencial eletrostático do átomo de carbono na posição para do anel benzênico para série I e II. 


\section{ANEXO 4}

Critério para seleção de variáveis

- Inspeção visual (gráfico de $A B \times$ descritor)

- Valores de coeficiente de correlação de Pearson (R) 
$>$
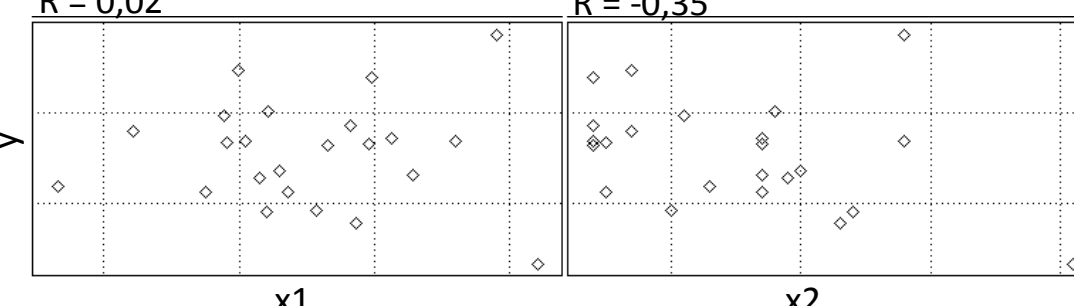

$\triangle$

$\stackrel{\Delta}{\otimes} \diamond \otimes$

$$
\text { x1 }
$$

$$
\mathrm{x} 2
$$

x3

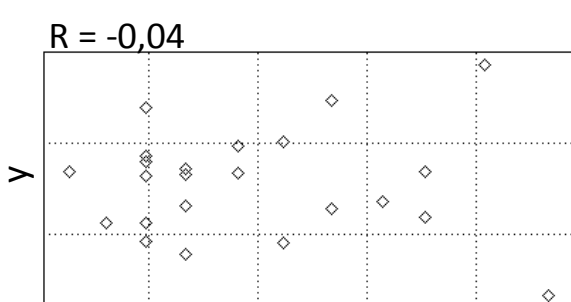

$R=-0,23$

x6

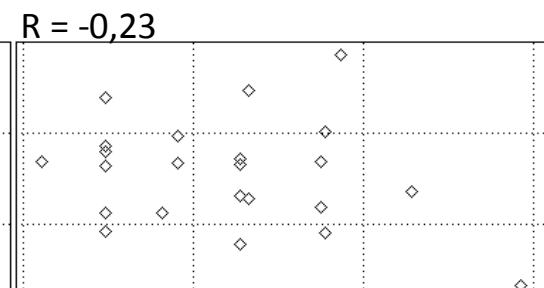

$R=-0,19$

$$
x 7
$$

\begin{tabular}{|c|c|c|c|}
\hline \multicolumn{3}{|c|}{$R=-0,36$} & \multirow{2}{*}{$\diamond$} \\
\hline$\diamond$ & & $\diamond$ & \\
\hline$\diamond$ & $\begin{array}{c}\diamond \diamond \\
\diamond \diamond\end{array}$ & $\diamond$ & \\
\hline & & & $\diamond$ \\
\hline
\end{tabular}

$x 8$

$R=0,42$

$x 9$

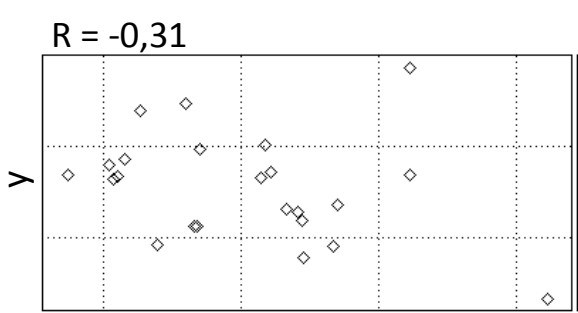

$R=-0,18$

$x 11$

$$
x 12
$$

$x 13$

$R=0,22$

$R=0,07$

$R=0,22$

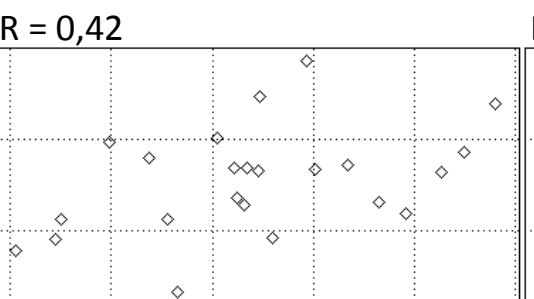

$R=-0,20$

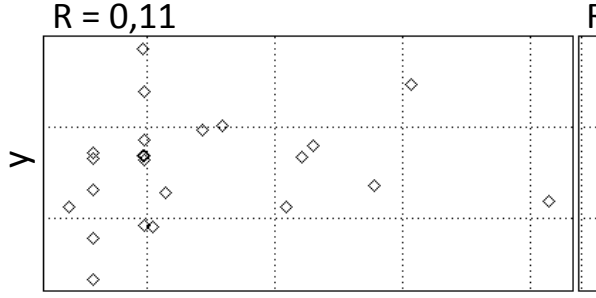

x16

$\times 17$

$\mathrm{x} 18$

$R=0,26$

x14

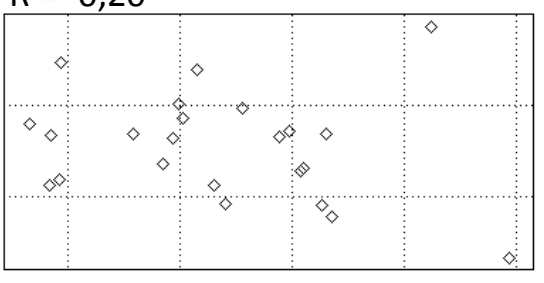

$R=0,13$

$\mathrm{x} 15$

x5

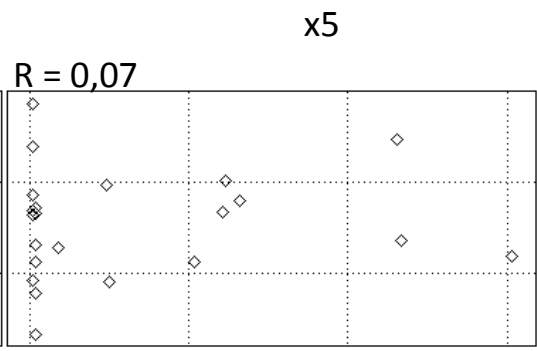

$x 10$

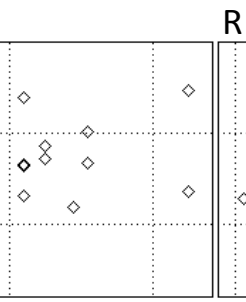

$\times 19$ 


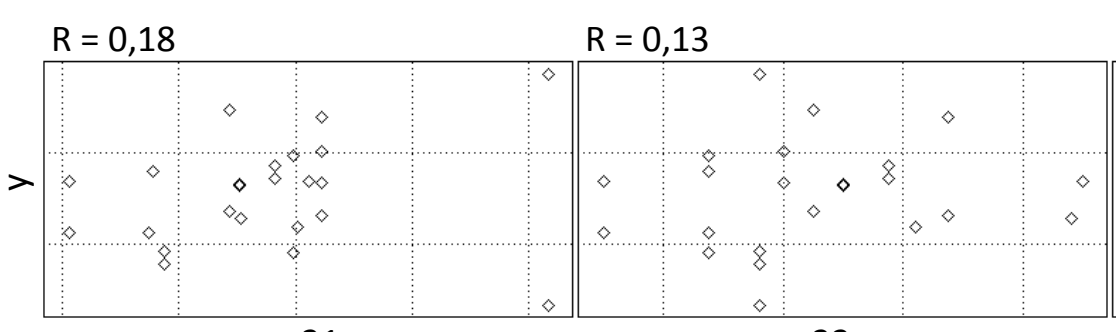

\begin{tabular}{|l}
$\mathrm{R}=0,02$ \\
\hline \\
\hdashline
\end{tabular}

$R=0,11$

$R=0,01$

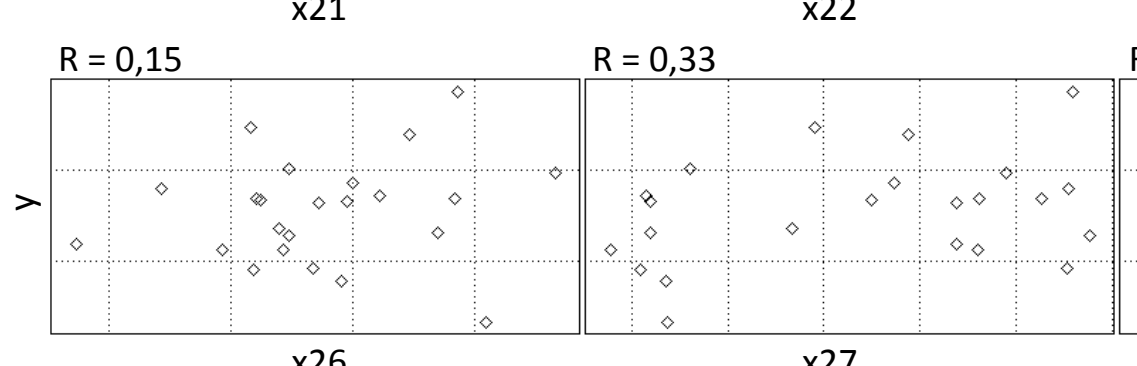

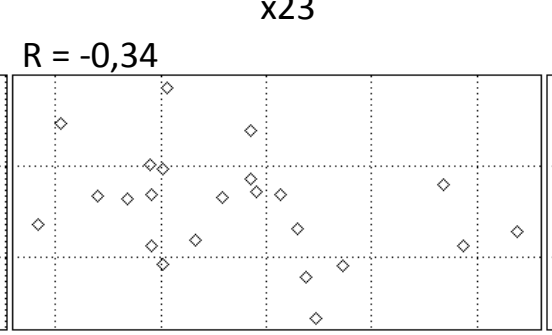

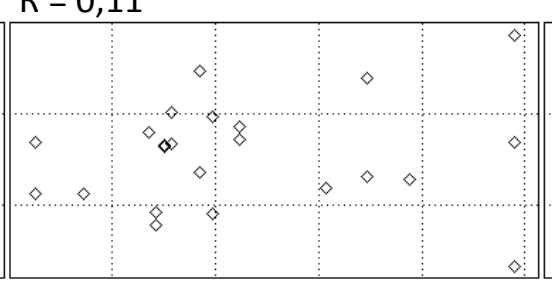
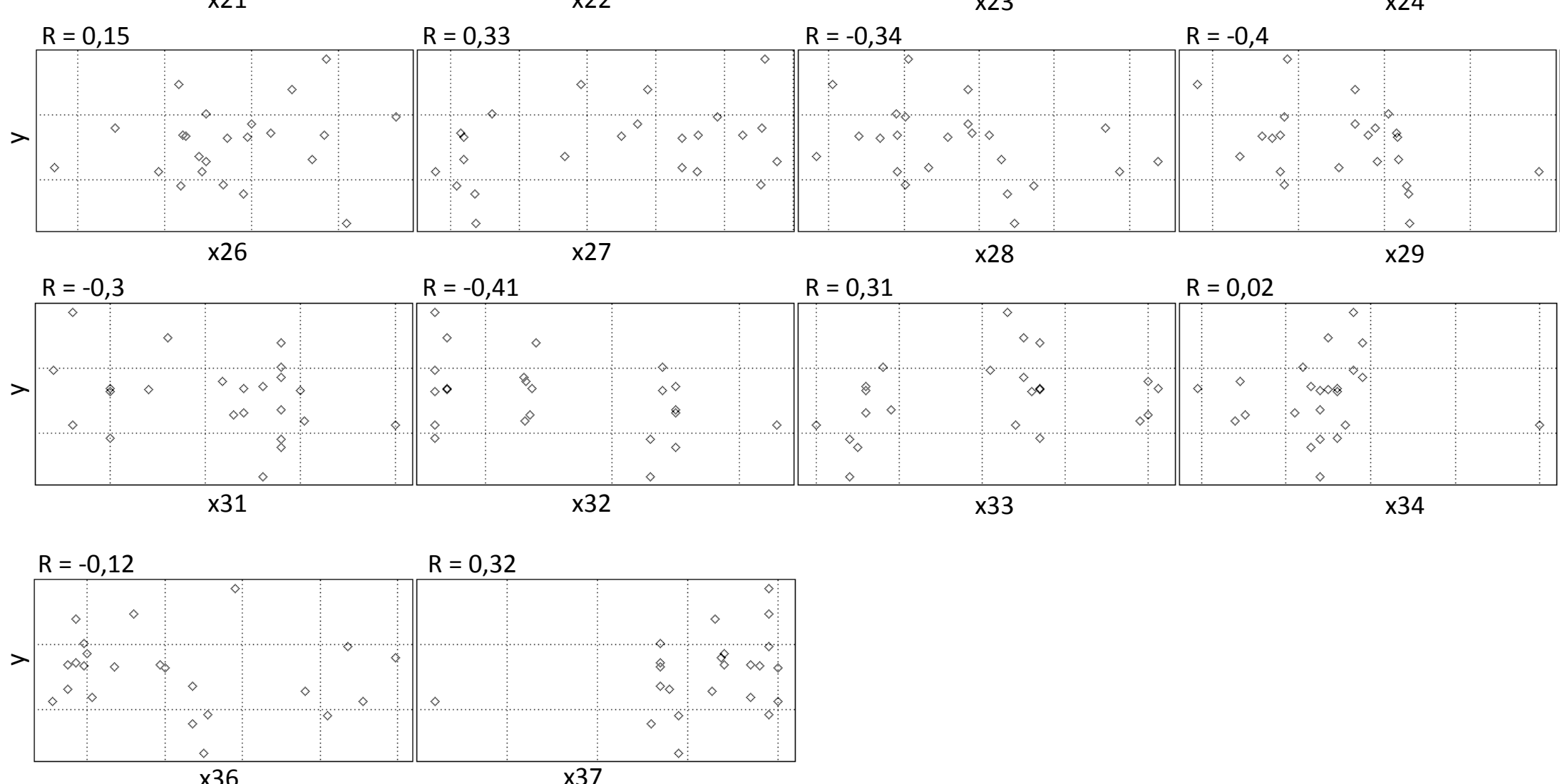

\section{$R=0,24$}

$\times 25$

\begin{aligned} \multicolumn{1}{c}{ X28 } \\ $\mathrm{R}=0,31 \\$\hline\end{aligned}




\section{E. coli}

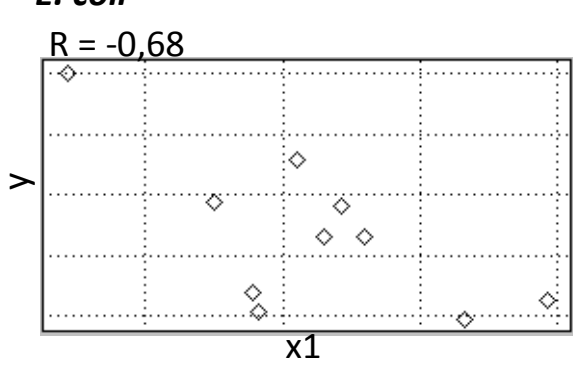

$R=-0,11$

$R=-0,07$

$R=-0,02$

$R=-0,20$
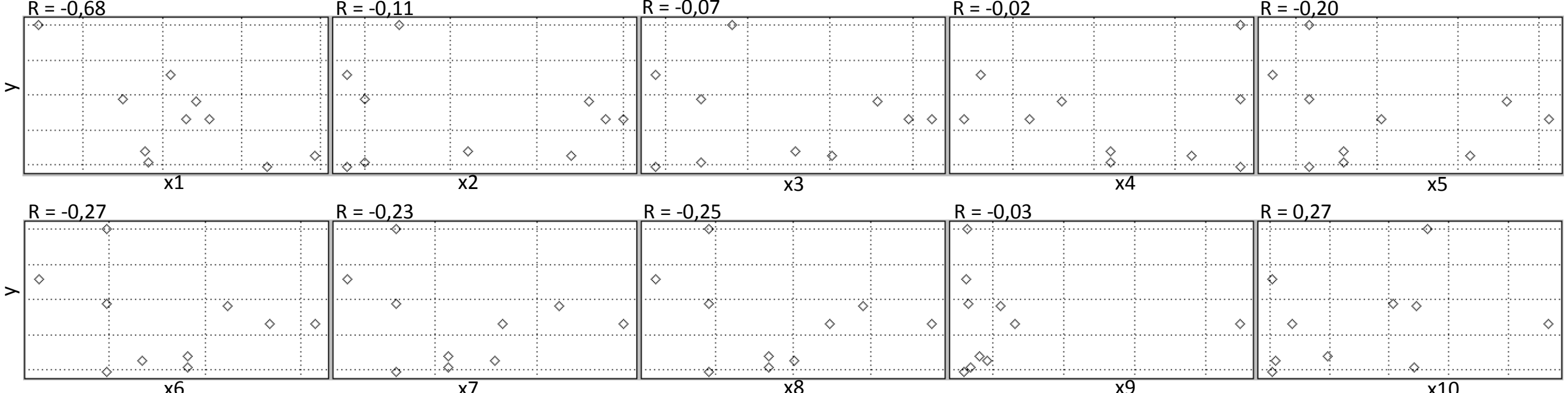

$R=-0,23$

$R=-0,25$

$R=-0,03$

$\mathrm{x} 4$

x5

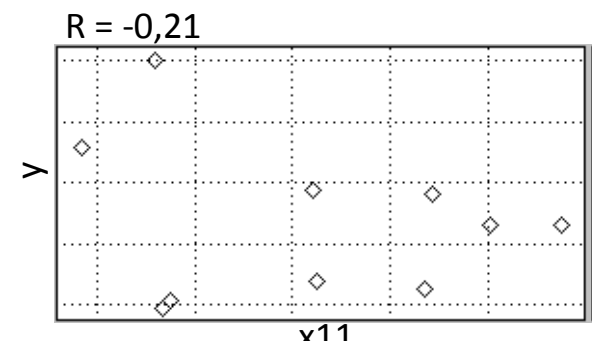

$R=-0,33$

x7 $R=-0,03$

$\times 8$

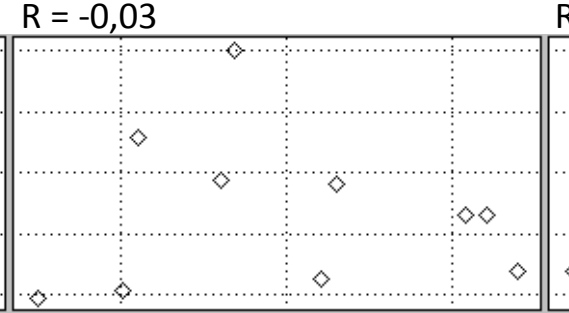

$R=-0,53$

$\times 9$

$R=0,27$
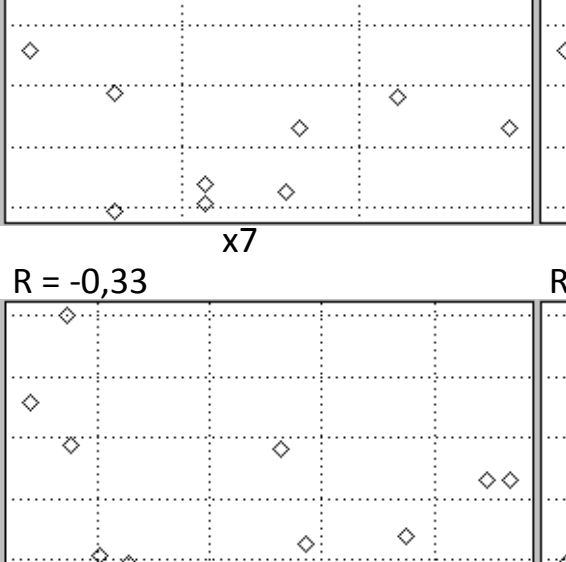

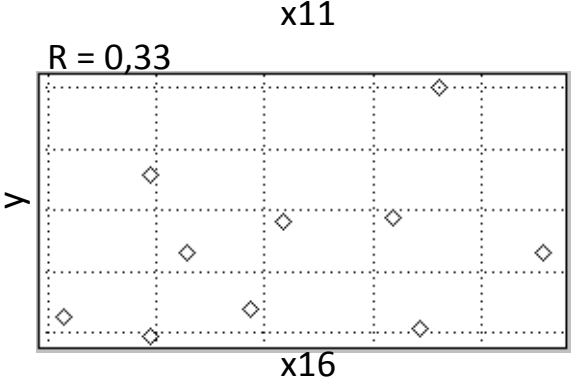

$R=-0,69$
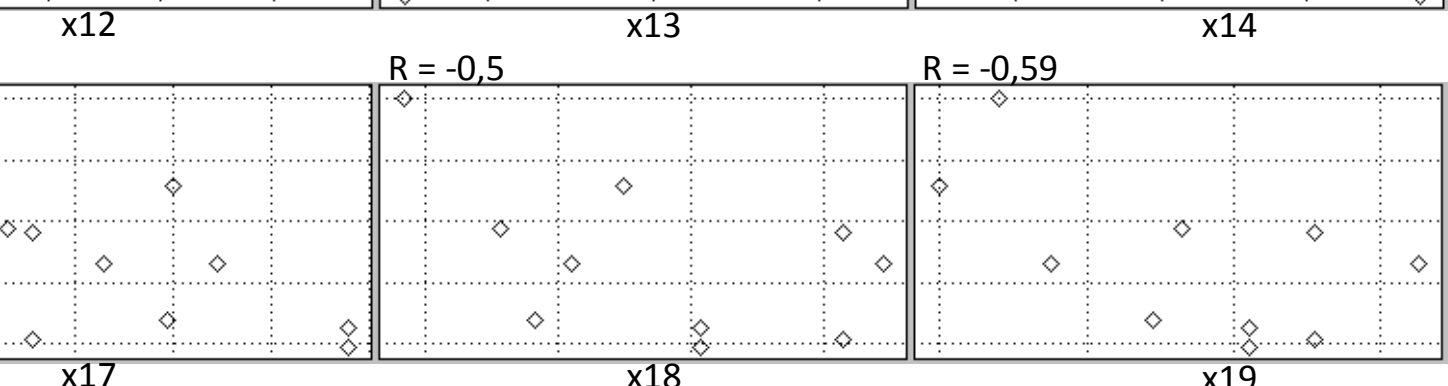

$R=-0,28$

x15 

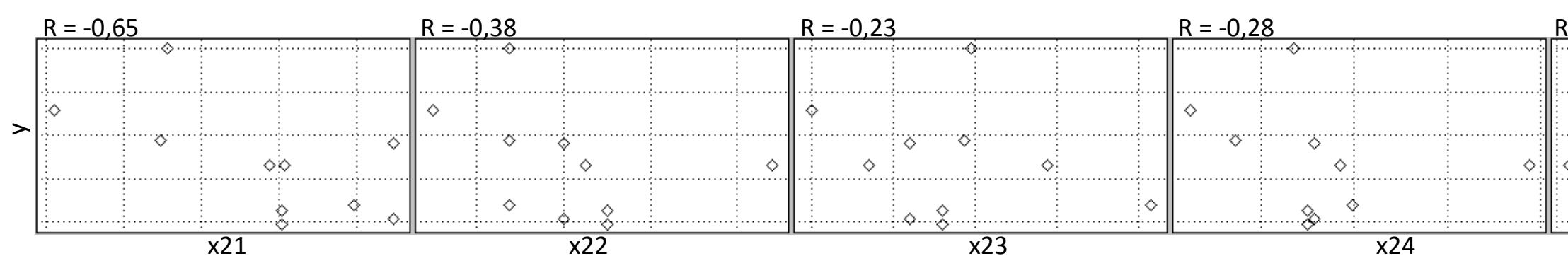

$R=-0,33$
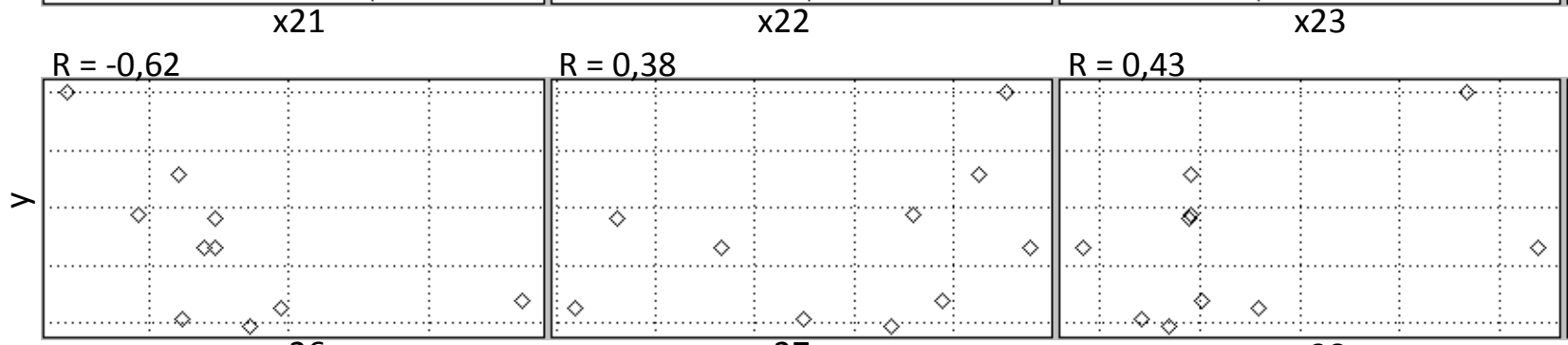

\section{$R=0,29$}

$\times 24$
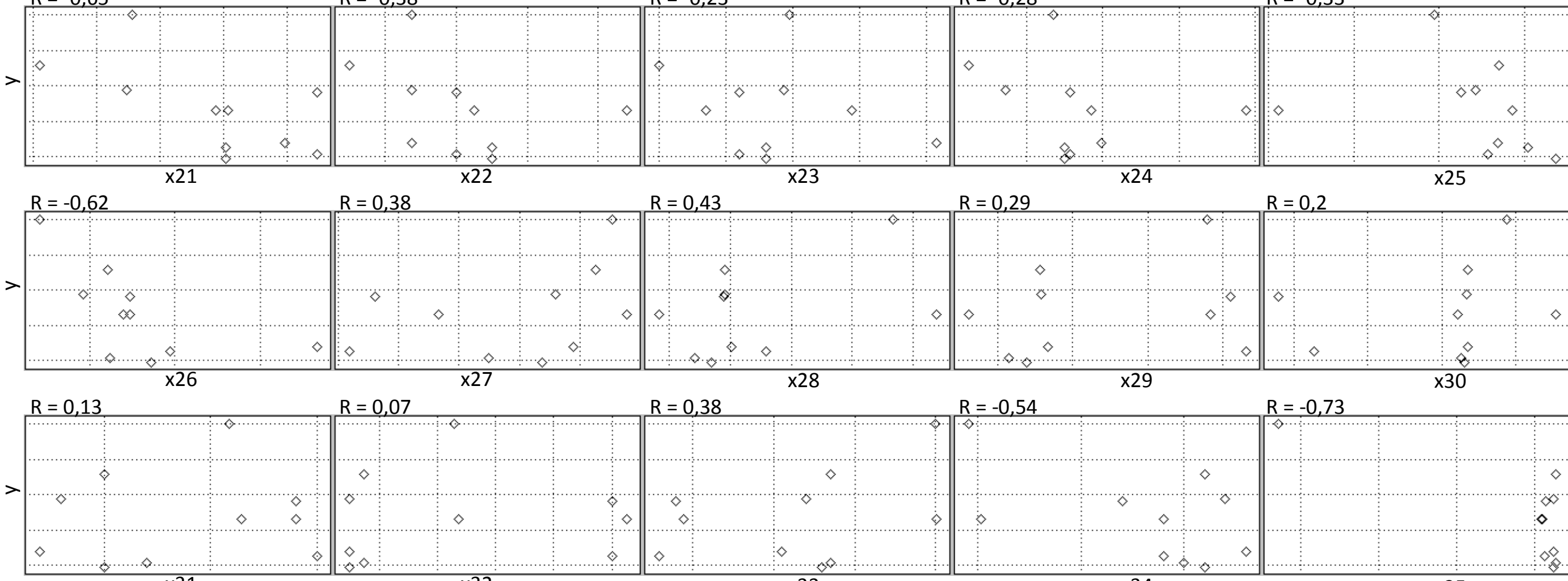

$R=0,2$

$\times 33$

x34

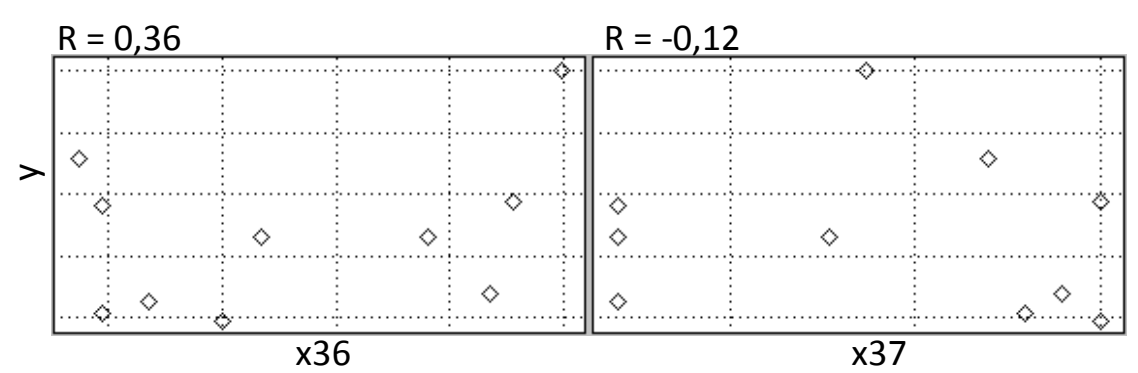




\section{E. faecalis}
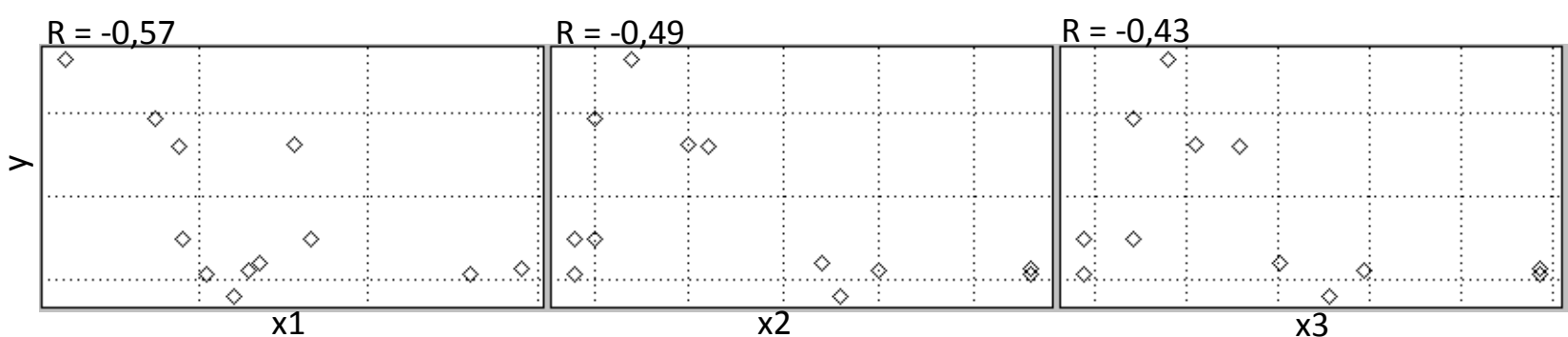

$R=-0,33$
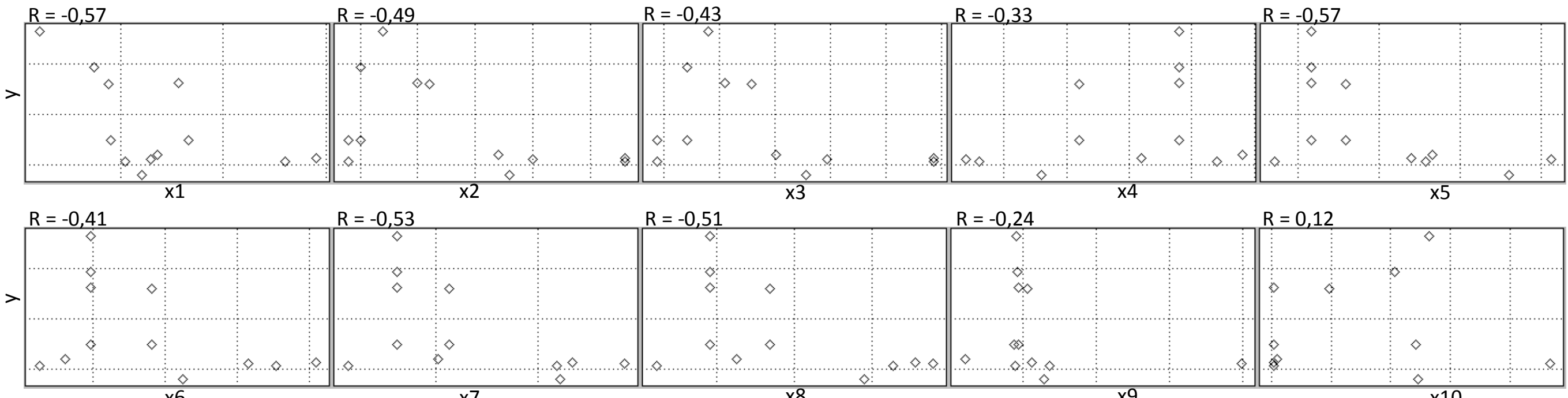

$R=-0,53$ $R=-0,51$
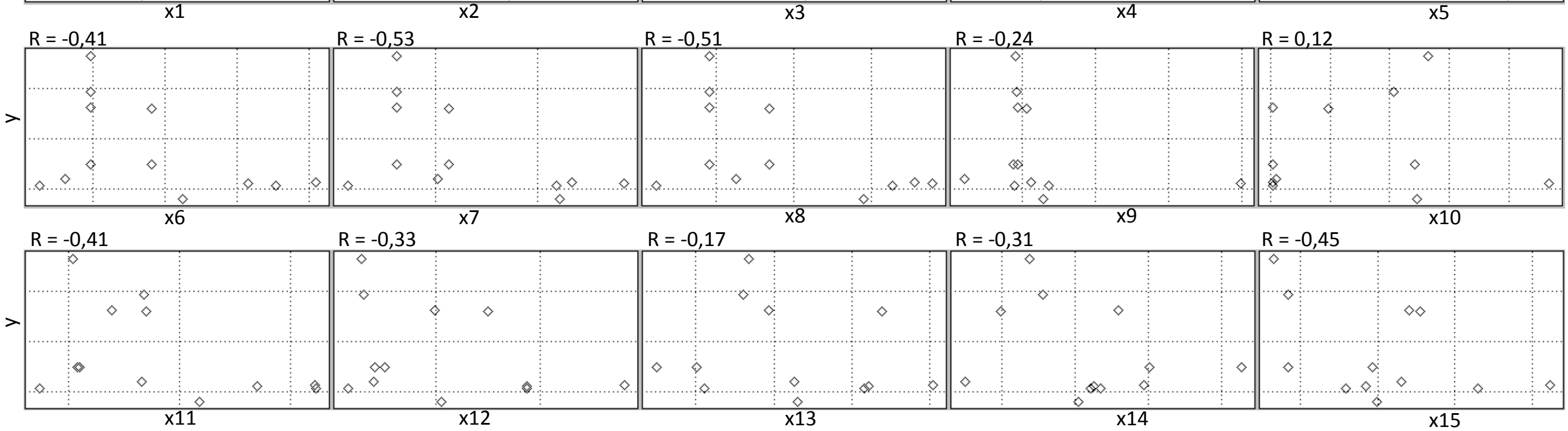

$R=-0,45$

x10
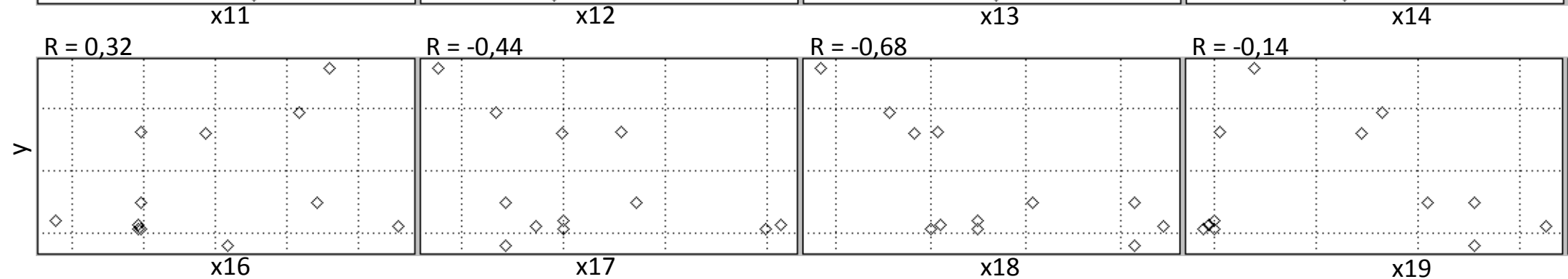

x15 

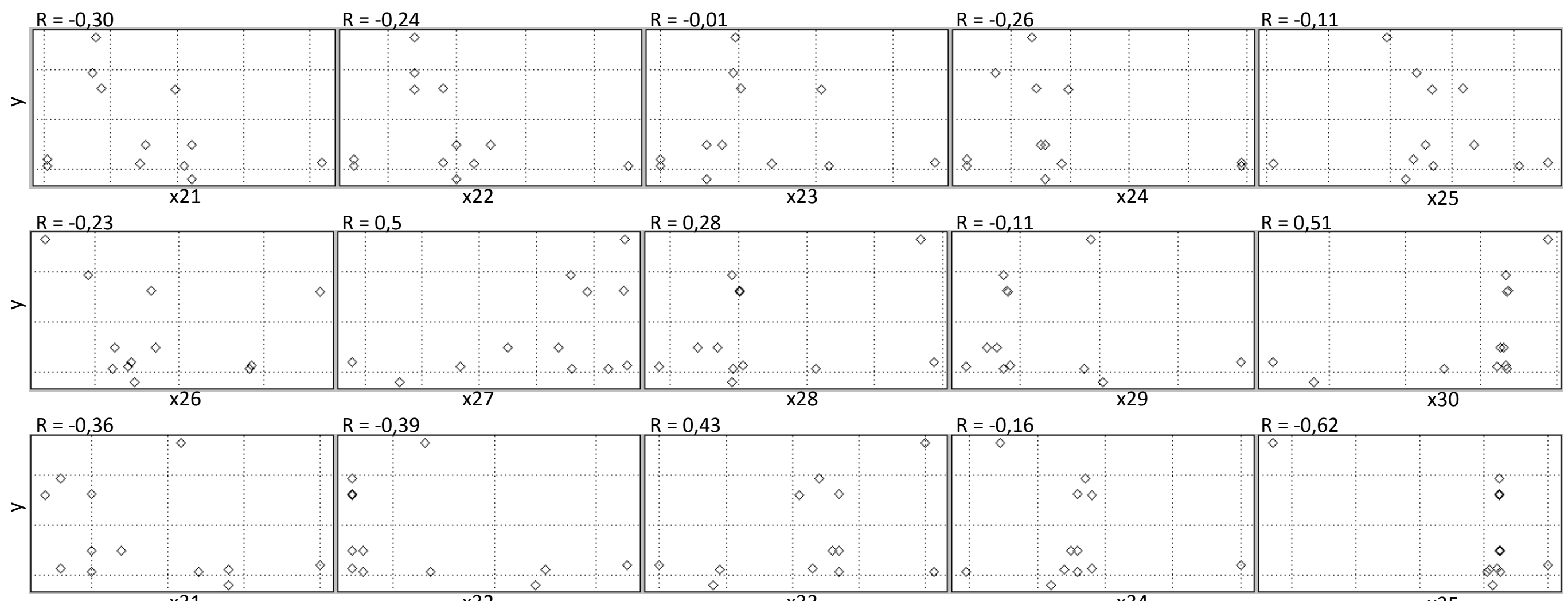

$\times 30$

x31

$\times 32$

x33

x34

x35

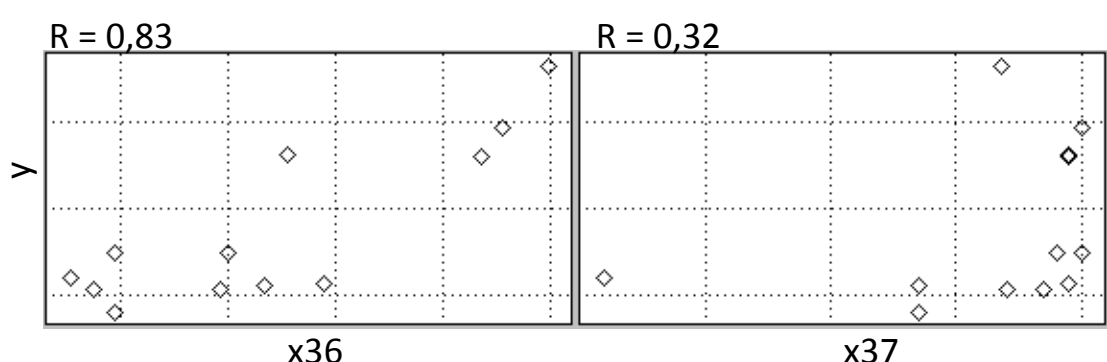

x36 